\title{
Characterisation of killer immunoglobulin- like receptors in rhesus macaques (Macaca mulatta)
}

\author{
Dissertation \\ for the award of the degree \\ „Doctor rerum naturalium“ \\ of the Georg-August-Universität Göttingen
}

submitted by

Meike Hermes

from Hannover

Göttingen 2012 
Professor Dr. Lutz Walter (Reviewer of thesis)

Department of Primate Genetics, German Primate Center

Professor Dr. Torben Lübke (Reviewer of thesis)

Biochemical Institute, University of Bielefeld

Professor Holger Reichardt

Department of Cellular and Molecular Immunology, Göttingen University Medical School

Date of the oral examination: 13.07 .2012 


\section{Declaration}

I hereby declare that this submission is my own work and that, to the best of my knowledge and belief, it contains no materials previously published or written by another person nor material which to a substantial extent has been accepted for the award of any other degree of the university or other institute of higher education, except where due acknowledgment has been made in the text.

Signature

Name

Date and Place 
Parts of this dissertation are already published:

Hermes M, Weil S, Groth A, Dressel R, Koch J, Walter L (2012). Characterisation of mouse monoclonal antibodies against rhesus macaque killer immunoglobulin-like receptors KIR3D. Immunogenetics. 64:845-848. 


\section{Table of Contents}

$\begin{array}{lll}\text { LIST OF FIGURES } & \text { VIII }\end{array}$

$\begin{array}{ll}\text { LIST OF TABLES } & \text { IX }\end{array}$

LIST OF ABBREVIATIONS $\quad$ X

1 INTRODUCTION 1

$\begin{array}{llr}1.1 & \text { Natural Killer Cells } & 1\end{array}$

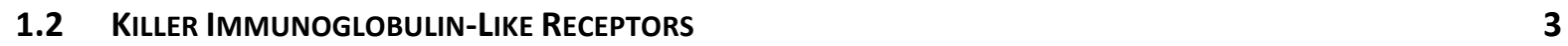

$\begin{array}{lll}1.2 .1 & \text { STRUCTURE OF KIR MOLECULES } & 4\end{array}$

$\begin{array}{lll}1.2 .2 & \text { KIR EXPRESSION BY NK CELLS } & 6\end{array}$

$\begin{array}{lll}1.2 .3 & \text { KIR EXPRESSION BY T CELL SUBSETS } & 7\end{array}$

$\begin{array}{llr}1.3 & \text { KIR AND DISEASE } & \mathbf{8}\end{array}$

$\begin{array}{lll}\text { 1.3.1 DISEASE ASSOCIATION STUDIES } & 8\end{array}$

$\begin{array}{ll}\text { 1.3.2 KIR AND HIV } & 9\end{array}$

$\begin{array}{llr}1.4 & \text { RHESUS MACAQUE } & \mathbf{9}\end{array}$

1.4.1 RHESUS MACAQUE NK CELLS AND KIR 9

$\begin{array}{ll}\text { 1.4.2 RHESUS MACAQUES AND SIV INFECTION } & 10\end{array}$

$\begin{array}{llr}1.5 & \text { AIM OF THE STUDY } & 12\end{array}$

2 MATERIAL AND METHODS $\quad 13$

$\begin{array}{llr}2.1 & \text { MATERIAL } & 13\end{array}$

$\begin{array}{ll}2.1 .1 & 13\end{array}$

$\begin{array}{ll}2.1 .2 & 14\end{array}$

\begin{tabular}{ll}
2.1 .3 & CONSUMABLES AND CHEMICALS \\
\hline
\end{tabular}

$\begin{array}{ll}2.1 .4 & 19\end{array}$

$\begin{array}{ll}2.1 .5 & 19\end{array}$

\begin{tabular}{lr}
2.1 .6 & 20 \\
\hline
\end{tabular}

$\begin{array}{ll}2.1 .7 & \text { SIZE STANDARDS } \\ 2.1 .8 & \text { BUFFERSANDSOLUTIONS }\end{array}$

\begin{tabular}{ll}
2.1 .8 & BUFFERS AND SOLUTIONS \\
\hline
\end{tabular}

$\begin{array}{ll}2.1 .9 \text { MEDIA } & 25\end{array}$

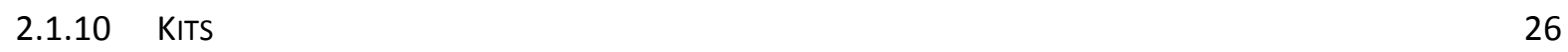

\begin{tabular}{lr}
2.1 .11 & ANTIBODIES \\
\hline
\end{tabular}

\begin{tabular}{lr}
2.1 .12 & OLIGONUCLEOTIDES \\
\hline
\end{tabular}

\begin{tabular}{ll}
2.1 .13 & SOFTWARE AND DATABASES \\
\hline
\end{tabular}

$\begin{array}{llr}2.2 & 29\end{array}$

$\begin{array}{lr}2.2 .1 & 29\end{array}$

\begin{tabular}{ll}
2.2 .1 .1 & Polymerase chain reaction \\
\hline
\end{tabular}

$\begin{array}{ll}2.2 .1 .2 & \text { Sequencing analysis } \\ 2.2 .1 .3 & \text { Separation of DNA fragments }\end{array}$

$\begin{array}{lll}2.2 .1 .3 & \text { Separation of DNA fragments } & 30\end{array}$

$\begin{array}{lll}2.2 .1 .4 & \text { DNA Extraction from agarose gels } & 30\end{array}$

$\begin{array}{lll}2.2 .1 .5 & \text { Quantification of DNA concentrations } & 30\end{array}$

$\begin{array}{ll}\text { 2.2.1.6 Cloning of PCR products } & 30\end{array}$

$\begin{array}{ll}\text { 2.2.1.7 DNA restriction by endonucleases } & 31\end{array}$

$\begin{array}{lll}\text { 2.2.1.8 Ligation of restricted DNA fragments } & 31\end{array}$

$\begin{array}{ll}\text { 2.2.1.9 Transformation of prokaryotic cells } & 31\end{array}$

$\begin{array}{lll}\text { 2.2.1.10 Mini preparation of plasmid DNA } & 31\end{array}$ 
2.2.1.11 Midi preparation of plasmid DNA 32

2.2.1.12 DNA extraction from blood $\quad 32$

2.2.1.13 RNA extraction from blood $\quad 32$

2.2.1.14 Reverse transcription of RNA $\quad 32$

$\begin{array}{lll}2.2 .2 & \text { TISSUE CULTURE TECHNIQUES } & 33\end{array}$

2.2.2.1 Transfection of eukaryotic cells $\quad 33$

2.2.2.2 PBMC isolation from whole blood 33

2.2.2.3 Quantification of viable cells 33

2.2.2.4 Cryopreservation $\quad 33$

2.2.2.5 Antibody staining of HEK293 cells for flow cytometry 33

2.2.2.6 Antibody staining of PBMC for flow cytometry 34

$\begin{array}{lll}2.2 .3 & \text { BIOCHEMICAL TECHNIQUES } & 34\end{array}$

$\begin{array}{lll}2.2 .3 .1 & \text { SDS-PAGE } & 34\end{array}$

$\begin{array}{lll}2.2 .3 .2 & 35\end{array}$

$\begin{array}{lll}2.2 .3 .3 & \text { Protein purification } & 35\end{array}$

2.2.3.4 Quantification of protein concentrations $\quad 35$

2.2.3.5 Enzyme-linked immunosorbent assay (ELISA) 35

2.2.3.6 Immunisation of mice with antigen 36

$\begin{array}{lll}\text { 2.2.3.7 Fusion of cells } & 36\end{array}$

2.2.3.8 Antibody labelling $\quad 36$

\section{\begin{tabular}{llr}
3 & RESULTS & 38 \\
\hline
\end{tabular}}

3.1 CHARACTERISATION OF MONOCLONAL ANTI-RHESUS MACAQUE KIR ANTIBODIES 38

$\begin{array}{lll}3.1 .1 & \text { ESTABLISHMENT OF ANTI-RHESUS MACAQUE KIR ANTIBODIES } & 38\end{array}$

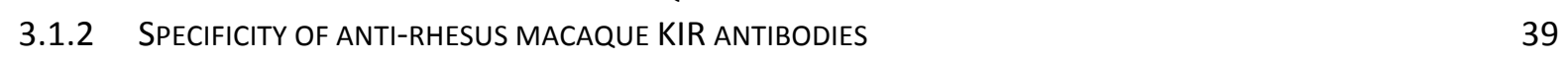

$\begin{array}{lll}3.1 .3 & \text { CROSS-REACTIVITY WITH OTHER SPECIES } & 40\end{array}$

$\begin{array}{lll}3.1 .4 & \text { ISOTYPE DETERMINATION } & 40\end{array}$

3.1.5 RECOGNITION OF KIR MOLECULES EXPRESSED BY HEK293 CELLS 4

3.1.6 FUNCTIONALITY OF ANTI-RHESUS MACAQUE KIR ANTIBODIES IN IMMUNOBLOT 43

3.1.7 DIFFERENT ANTIBODIES DETECT SIMILAR RECOGNITION SITES $\quad 44$

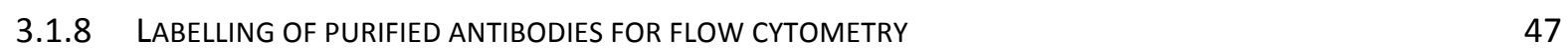

$\begin{array}{lll}3.2 & \text { KIR EXPRESSION PATTERN IN PRIMATES } & \mathbf{4 8}\end{array}$

3.2.1 GENERAL CHARACTERISATION OF RHESUS MACAQUE LYMPHOCYTES USING FLOW CYTOMETRY 48

$\begin{array}{ll}\text { 3.2.2 EXPRESSION OF KIR BY NK CELLS } & 51\end{array}$

3.2.3 KIR EXPRESSION BY DIFFERENT NK CELL SUBSETS $\quad 52$

3.2.4 EXPRESSION OF KIR BY CD8 ${ }^{+} \alpha \beta$ T CELLS $\quad 53$

3.2.5 EXPRESSION OF KIR BY CD4 ${ }^{+} \alpha \beta$ T CELLS $\quad 54$

3.2.6 EXPRESSION OF KIR BY $\gamma \delta$ T CELLS $\quad 55$

3.2.7 EXPRESSION OF INDIVIDUAL KIR BY NK CELLS

3.2.8 EXPRESSION OF INDIVIDUAL KIR BY DIFFERENT T CELL SUBSETS $\quad 59$

3.2.9 KIR EXPRESSION BY NK AND CYTOTOXIC $\alpha \beta$ T CELLS OF OTHER SPECIES 6

3.3 KIR EXPRESSION PATTERN CHANGES DUE TO SIV INFECTION

3.3.1 CHANGES OF NK CELL KIR EXPRESSION IN THE ACUTE PHASE OF SIV INFECTION

3.3.2 CHANGES OF NK CELL KIR EXPRESSION DURING CHRONIC PHASE OF SIV INFECTION 68

3.3.3 CHANGES OF CD8 ${ }^{+} \alpha \beta$ T CELL KIR EXPRESSION IN THE ACUTE PHASE OF SIV INFECTION 69

3.3.4 KIR EXPRESSION OF CD8 ${ }^{+} \alpha \beta$ T CELLS IN THE CHRONIC PHASE OF SIV INFECTION

3.3.5 CHANGES OF $\gamma \delta$ T CELL KIR EXPRESSION IN THE ACUTE PHASE OF SIV INFECTION

3.3.6 KIR EXPRESSION OF $\gamma \delta$ T CELLS IN THE CHRONIC PHASE OF SIV INFECTION

3.3.7 NO SIGNIFICANT CORRELATION IN THE KIR EXPRESSION BETWEEN DIFFERENT CELL POPULATIONS 73

3.3.8 CORRELATION OF KIR EXPRESSION BETWEEN ANIMALS WITH DIFFERENT VIRAL LOADS 74 
4 DISCUSSION

4.1 CHARACTERISTICS OF ANTI-RHESUS MACAQUE KIR ANTIBODIES

4.1.1 NO CROSS-REACTIVITY WITH KIR OF HOMINOIDS 76

4.1.2 BINDING CHARACTERISTICS OF ANTI-RHESUS MACAQUE KIR ANTIBODIES

4.1.3 PREPARATION OF FLUOROCHROM-CONJUGATED ANTIBODIES 80

4.2 SIMILAR KIR EXPRESSION OF RHESUS MACAQUES AND HUMANS

4.2.1 GENERAL KIR EXPRESSION OF RHESUS MACAQUE NK CELLS

4.2.2 CLONAL KIR EXPRESSION BY RHESUS MACAQUE NK CELLS 82

Expression pattern of KIR3DL05 82

Expression of KIR3DLW03 and KIR3DS05 84

Expression of KIR3DSW08, KIR3DS07 and KIR3DL07 85

4.2.3 KIR EXPRESSION OF CD $4^{+}$AND CD $8^{+} \alpha \beta$ T CELLS OF RHESUS MACAQUES 86

4.2.4 KIR EXPRESSION OF $\gamma \delta$ T CELLS OF RHESUS MACAQUES

4.2.5 KIR EXPRESSION PATTERN OF OTHER NON-HUMAN PRIMATE SPECIES 91

4.3 CHANGES IN KIR EXPRESSION DURING SIV INFECTION 93

4.3.1 IMPACT OF HIV/SIV INFECTION ON THE FREQUENCY OF KIR-POSITIVE NK AND T CELL SUBSETS 93

4.3.2 KIR EXPRESSION BY NK AND T CELL SUBSETS IN HIV/SIV INFECTION 94

$\begin{array}{llr}\underline{5} & \text { SUMMARY } & 98 \\ \end{array}$

6 $\quad$ REFERENCES $\quad 100$

$\underline{7}$ SUPPLEMENT $\quad 113$

$\begin{array}{ll}\text { ACKNOWLEDGEMENT } & 116\end{array}$

$\begin{array}{ll}\text { CURRICULUM VITAE } & 117\end{array}$ 


\section{List of Figures}

FIGURE 1. TARGET CELL RECOGNITION BY NK CELLS.

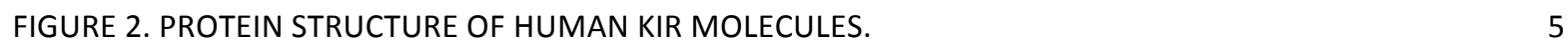

FIGURE 3. VARIATION IN KIR EXPRESSION BETWEEN DIFFERENT INDIVIDUALS. 6

FIGURE 4. DIFFERENT PHASES OF SIV INFECTION. $\quad 11$

FIGURE 5. CLONACELL-HY PROCEDURE OVERVIEW. $\quad 37$

FIGURE 6. CROSS-REACTIVITY OF ANTI-KIR ANTIBODIES WITH RHESUS MACAQUE KIR-FC FUSION PROTEINS. 40

FIGURE 7. MONOCLONAL ANTI-RHESUS MACAQUE KIR ANTIBODIES ARE ABLE TO STAIN THEIR ANTIGEN. 42

FIGURE 8. SPECIFICITY OF MABS FOR RHESUS MACAQUE KIRS IN KIR-ACGFP TRANSFECTED CELLS. 43

FIGURE 9. IMMUNOBLOT ANALYSIS TO TEST THE REACTIVITY OF HYBRIDOMA SUPERNATANT. 44

FIGURE 10. EPITOPE MAPPING USING PEPTIDE SPOT ARRAYS.

FIGURE 11. AMINO ACID SEQUENCES OF THREE KIRS USED FOR THE GENERATION OF ANTIBODIES. $\quad 46$

FIGURE 12. HISTOGRAM OF DYLIGHT LABELLED ANTI-RHESUS MACAQUE KIR ANTIBODIES.

FIGURE 13. CHARACTERISATION OF RHESUS MACAQUE PBMC USING MULTI-COLOUR FLOW CYTOMETRY. 50

FIGURE 14. FLOW CYTOMETRY ANALYSIS OF EXPRESSION OF KIR BY NK CELLS. 252

FIGURE 15. KIR EXPRESSION BY THREE DIFFERENT NK CELL SUBSETS. 253

FIGURE 16. FLOW CYTOMETRY ANALYSIS OF EXPRESSION OF KIR BY CD $8^{+} \alpha \beta$ T CELLS.

FIGURE 17. FLOW CYTOMETRY ANALYSIS OF EXPRESSION OF KIR BY CD $4^{+} \alpha \beta$ T CELLS. 55

FIGURE 18. FLOW CYTOMETRY ANALYSIS OF EXPRESSION OF KIR BY $\gamma \delta$ T CELLS. 56

FIGURE 19. FLOW CYTOMETRY ANALYSIS OF EXPRESSION OF SPECIFIC KIR BY NK CELLS. 57

FIGURE 20. FLOW CYTOMETRY ANALYSIS OF SPECIFIC KIR EXPRESSION BY CD $8^{+} \alpha \beta$ AND $\gamma \delta$ T CELLS. 60

FIGURE 21. FLOW CYTOMETRY ANALYSIS OF KIR EXPRESSION BY NK AND CYTOTOXIC $\alpha \beta$ T CELLS OF THREE NON-HUMAN PRIMATE SPECIES.

FIGURE 22. ALTERATION OF KIR EXPRESSION BY NK CELLS AFTER INFECTION WITH SIV. 67

FIGURE 23. COMPARISON OF THE PERCENTAGE OF KIR POSITIVE NK CELLS WITH THE MFI IN ELITE CONTROLLERS.

FIGURE 24. ALTERATION OF THE NUMBER OF KIR-EXPRESSING NK CELIS DURING SIV INFECTION.

FIGURE 25. KIR EXPRESSION PATTERN OF CD $8^{+} \alpha \beta$ T CELLS IN THE ACUTE PHASE OF SIV INFECTION. 70

FIGURE 26. CHANGES IN KIR EXPRESSION BY CD8 ${ }^{+} \alpha \beta$ T CELLS DURING CHRONIC SIV INFECTION. 71

FIGURE 27. KIR EXPRESSION ALTERATION BY $\gamma \delta$ T CELLS IN THE ACUTE PHASE OF SIV INFECTION 72

FIGURE 28. CHANGES IN KIR EXPRESSION BY $\gamma \delta$ T CELLS DURING CHRONIC SIV INFECTION. 73

FIGURE 29. ANTI-RHESUS MACAQUE KIR ANTIBODY EPITOPES MAPPED ON THE 3D STRUCTURE OF HUMAN KIR3DL1*001-PHLA-B*5701 COMPLEX

FIGURE 30. PHYLOGENETIC TREES OF THE EXTRACELLULAR PART OF RHESUS MACAQUE KIR AMINO ACID SEQUENCES.

FIGURE 31. EXPRESSION OF KIR3DL05 ON TRANSCRIPT AND PROTEIN LEVEL.

FIGURE 32. EXPRESSION OF KIR3DLW03 AND KIR3DS05 ON TRANSCRIPT AND PROTEIN LEVEL.

FIGURE 33. EXPRESSION OF KIR3DSW08, KIR3DS07 AND KIR3DL07 ON TRANSCRIPT AND PROTEIN LEVEL. 85

FIGURE 34. INFLUENCE OF KIR EXPRESSION ON T CELL EFFECTOR FUNCTION.

FIGURE 35. CROSS-REACTIVITY OF ANTI-RHESUS MACAQUE KIR ANTIBODIES WITH KIR-FC FUSION PROTEINS OF OTHER SPECIES USING ELISA. 


\section{List of Tables}

TABLE 1. NONHUMAN PRIMATES USED IN THIS STUDY.

TABLE 2. GATING STRATEGY FOR MULTI-COLOUR FLOW CYTOMETRY

34

TABLE 3. FUSION CONDITIONS.

TABLE 4. SUMMARY OF GENOTYPING, TRANSCRIPT AND PROTEIN SURFACE EXPRESSION OF CERTAIN KIR FOR EIGHT ANALYSED RHESUS MACAQUES.

TABLE 6. PEPTIDE SPOT ARRAY SEQUENCES OF THE THREE RHESUS MACAQUE KIR3D PROTEINS. 


\section{List of Abbreviations}

${ }^{\circ} \mathrm{C}$

ABTS

AcGFP

AICD

AIDS

Amp

APC

APS

bp

BSA

$\mathrm{CCL}$

$C D$

CDNA

$\mathrm{CHO}$

$\mathrm{CXCL}$

Cy

DAP

DMEM

DMSO

DNA

dNTP

DPZ

DTT

E.coli

e.g.

EDTA

ELISA

et al.

FACS

FC

FCS

FITC

FSC

fw

g

G-CSF

GM-CSF

$\mathrm{h}$

HAT

HEK293

hlgG

HIV

HLA

HPLC

HRP

$\mathrm{HVL}$

i.e. degree Celsius

2,2'-azino-bis(3-ethylbenzothiazoline-6-sulphonic acid)

green fluorescent protein from Aequorea victoria

Activation-induced cell death

acquired immune deficiency syndrome

ampicillin

allophycocyanin

ammonium persulphate

base pair

bovine serum albumin

CC chemokine ( $\beta$-chemokine) ligand

cluster of differentiation

complementary DNA

chinese hamster ovary

CXC chemokine ( $\alpha$-chemokine) ligand

cyanine

DNAX-activation protein

Dulbecco's modified eagle serum

dimethyl sulfoxide

deoxyribonucleic acid

deoxyribonucleotide

Deutsches Primatenzentrum

1,4-Dithiothreitol

Escherichia coli

exempli gratia

ethylenediaminetetraacetic acid

enzyme linked immunosorbent assay

et alteri

fluorescence activated cell scanning

fragment crystallisable

foetal calf serum

fluorescein isothiocyanate

forward scatter

forward

gram or gravitational constant $\left(9.81 \mathrm{~m} / \mathrm{s}^{2}\right)$

granulocyte colony-stimulating factor

granulocyte-macrophage colony-stimulating factor

hour

hypoxanthine-aminopterin-thymidine

human embryonic kidney 293

human immunoglobulin $\mathrm{G}$

human immunodeficiency virus

human leukocyte antigen

high performance liquid chromatography

horseradish peroxidase

high viral load

id est 


\begin{tabular}{|c|c|}
\hline IFN & Interferon \\
\hline $\lg$ & immunoglobulin \\
\hline IL & Interleukin \\
\hline IPTG & isopropyl- $\beta$-D-thiogalactopyranosid \\
\hline ITAM & immunoreceptor tryrosine-based activating motif \\
\hline ITIM & immunoreceptor tryrosine-based inhibitory motif \\
\hline Kan & kanamycin \\
\hline KIR & killer immunoglobulin-like receptor \\
\hline kV & kilovolt \\
\hline l & litre \\
\hline LB & Luria-Bertani medium \\
\hline LRC & leucocyte receptor complex \\
\hline LVL & low viral load \\
\hline M & Molar \\
\hline $\mathrm{mA}$ & milliampere \\
\hline $\mathrm{mDC}$ & Myeloid dendritic cell \\
\hline $\mathrm{MFI}$ & mean fluorescence intensity \\
\hline $\mathrm{mg}$ & milligram \\
\hline $\mathrm{MHC}$ & major histocompatibility complex \\
\hline $\min$ & minute \\
\hline $\mathrm{ml}$ & millilitre \\
\hline $\mathrm{mm}$ & millimetre \\
\hline ng & nanogram \\
\hline NK & Natural killer \\
\hline NKG & natural killer group \\
\hline $\mathrm{nm}$ & nanometer \\
\hline OD & optical density \\
\hline PAGE & polyacrylamide gel electrophoresis \\
\hline PBMC & peripheral blood mononuclear cell \\
\hline PBS & Phosphate buffered saline \\
\hline PCR & Polymerase Chain Reaction \\
\hline PE & phycoerythrin \\
\hline PerCP & peridinin chlorphyll protein \\
\hline $\mathrm{pH}$ & potentia Hydrogenii \\
\hline rev & reverse \\
\hline RNA & ribonucleic acid \\
\hline RNase & ribonuclease \\
\hline rpm & revolutions per minute \\
\hline RPMI & Roswell park memorial institute \\
\hline RT & room temperature \\
\hline $\mathrm{S}$ & second \\
\hline SARS & severe acute respiratory syndrom \\
\hline SDS & sodium dodecyl sulfate \\
\hline SHP & Src-homology domain-bearing tyrosine phosphate \\
\hline SIV & simian immunodeficiency virus \\
\hline SOC & super Optimal broth with Catabolite repression \\
\hline SSC & side scatter \\
\hline Taq & Thermus aquaticus \\
\hline TBE & tris/Borate/EDTA buffer \\
\hline TBS & tris-Buffered Saline \\
\hline TCR & T cell receptor \\
\hline
\end{tabular}




$\begin{array}{ll}\text { TEMED } & \text { tetramethylethylenediamine } \\ \text { TLR } & \text { toll-like receptor } \\ \text { TNF } & \text { tumour necrosis factor } \\ \text { Tween } & \text { polyoxyethylene }(20) \text { sorbitan monolaurate } \\ \mathrm{U} & \text { unit } \\ \mathrm{V} & \text { volt } \\ \mathrm{X} \text {-gal } & \text { bromo-4-chloro-indolyl- } \beta \text {-D-galactopyranoside } \\ \mathrm{XCL} & \text { XC chemokine ligand } \\ \mu \mathrm{g} & \text { microgram }\end{array}$

\section{Amino acid abbreviations}

\begin{tabular}{lll} 
Amino acid & 3-Letter & 1-Letter \\
\hline Alanine & Ala & $\mathrm{A}$ \\
Arginine & Arg & $\mathrm{R}$ \\
Asparagine & Asn & $\mathrm{N}$ \\
Aspartic acid & Asp & $\mathrm{D}$ \\
Cysteine & Cys & $\mathrm{C}$ \\
Glutamic acid & Glu & $\mathrm{E}$ \\
Glutamine & Gln & $\mathrm{Q}$ \\
Glycine & Gly & $\mathrm{G}$ \\
Histidine & His & $\mathrm{H}$ \\
Isoleucine & Ile & $\mathrm{I}$ \\
Leucine & Leu & $\mathrm{L}$ \\
Lysine & Lys & $\mathrm{K}$ \\
Methionine & Met & $\mathrm{M}$ \\
Phenylalanine & Phe & $\mathrm{F}$ \\
Proline & Pro & $\mathrm{P}$ \\
Serine & Ser & $\mathrm{S}$ \\
Threonine & Thr & $\mathrm{T}$ \\
Tryptophan & Trp & $\mathrm{W}$ \\
Tyrosine & Tyr & $\mathrm{Y}$ \\
Valine & Val & $\mathrm{V}$
\end{tabular}

DNA-base abbreviations

\begin{tabular}{ll} 
Base & Nucleotide code \\
\hline Adenine & A \\
Cytosine & C \\
Guanine & G \\
Thymine & T
\end{tabular}




\section{Introduction}

\subsection{Natural Killer Cells}

The immune system is classically divided into innate and adaptive immunity. The innate immunity consists of a variety of myeloid and lymphoid cells containing a limited germline-encoded receptor repertoire with a fast response to infections. $\mathrm{T}$ and $\mathrm{B}$ cells are the two cell types of adaptive immunity, expressing receptors arisen from somatic recombination ( $\mathrm{T}$ cell receptor - TCR and B cell receptor - BCR). These receptors are clonally expressed and antigen-specific. Due to this definition natural killer cells (NK cells) belong to the innate immune system because of the lack of antigen-specific receptors. NK cells are large, granular, bone marrow-derived lymphocytes. They are involved in the early response against tumour cells, virally or with bacterial pathogens infected cells (Bashirova et al., 2006). Similar to the killing mechanism of cytotoxic $\mathrm{T}$ lymphocytes, the contact with a target cell causes the activation of the NK cell and leads to the release of cytotoxic granules. These contain the lytic enzymes granzyme B and perforin that induce apoptosis of the target cell (Delves and Roitt, 2000).

NK cells produce proinflammatory and immunosuppressive cytokines like TNF- $\alpha$, IL-10 and growth factors such as GM-CSF, G-CSF and IL-3, but they are major producers of IFN- $\gamma$. Besides this, NK cells secrete chemokines such as CCL2, CCL3, CCL4, CCL5, XCL1, CXCL8 which are important e.g. for the co-localisation with other hematopoietic cells, like dendritic cells, at sites of inflammation (Walzer et al., 2005, Moretta et al., 2005). NK cells express inhibitory and activating receptors that recognise either soluble ligands like cytokines or cell surface molecules. A rough classification of NK cell receptors results in two groups. One group of receptors that recognise major histocompatibility complex (MHC) class I molecules and a second group that do not recognise these ligands. The second group comprises, besides others, the natural cytotoxicity receptors that are potent activating receptors linked to ITAM (immunoreceptor tyrosine-based activating motif) bearing adaptor molecules. NK cells are also able to detect antibody-coated cells by CD16 (Fc $\gamma$ RIIIA) and induce antibodydependent cell cytotoxicity (ADCC) and cytokine production (Perussia et al., 1983). The 
MHC class I recognising receptors can be divided into lectin-like receptors such as CD94:NKG2A heterodimers and killer immunoglobulin-like receptors (KIR). NK cell activation is depended on the integration of the signals from all these receptors (Lanier, 2005). The activating receptor NKG2D for example, recognises ligands that are expressed at very low levels. Under normal conditions this will not lead to activation but with the occurrence of cellular stress e.g. DNA damage (Gasser et al., 2005) this will lead to an overexpression of the stress-induced ligand and the NK cell gets activated. Furthermore, an important feature of NK cells is the "missing-self" recognition, the ability to detect a lack (or down-regulation) of MHC class I molecules as is frequently observed upon viral infections or cellular transformation (Kärre et al., 1986) (Figure 1). ITIM (immunoreceptor tyrosine-based inhibitory motif) bearing inhibitory receptors including inhibitory KIRs and CD94/NKG2A heterodimers that recognise their ligand will lead to an inhibition of the NK cell. In the absence of the ligand ("missing-self") inhibitory signals are not present any longer and the NK cells are activated and will selectively kill the ligand-devoid target cell (Lanier, 2005).

As receptor and ligand genes are encoded on different chromosomes, they are inherited independently. Thus, it can occur that the inhibitory receptor for a MHC class I molecule is missing or an activating receptor specific for a self-ligand is expressed by NK cells. This would lead to autoreactivity of these NK cells. Therefore, the effector responses must be controlled to avoid inadvertent attack against "self". This acquisition of effector function is called education. For fully functional NK cells, interactions between inhibitory receptors and MHC class I molecules are required (arming model). In contrast, the presence of self-specific activating receptors will lead to an anergic-like hypofunctional state of the NK cell (disarming model) (Raulet and Vance, 2006)).

A recent focus of NK cell research is on NK cell memory. Immunological memory is a hallmark of the adaptive immune system but it is getting clear that also NK cells have the ability upon restimulation to produce cytokines more rapidly and in higher amounts and to show enhanced cytolytic function (Sun et al., 2009). From this it is concluded that NK cells share characteristics of both, innate (germline encoded receptors) and adaptive (education and memory) immunity. 

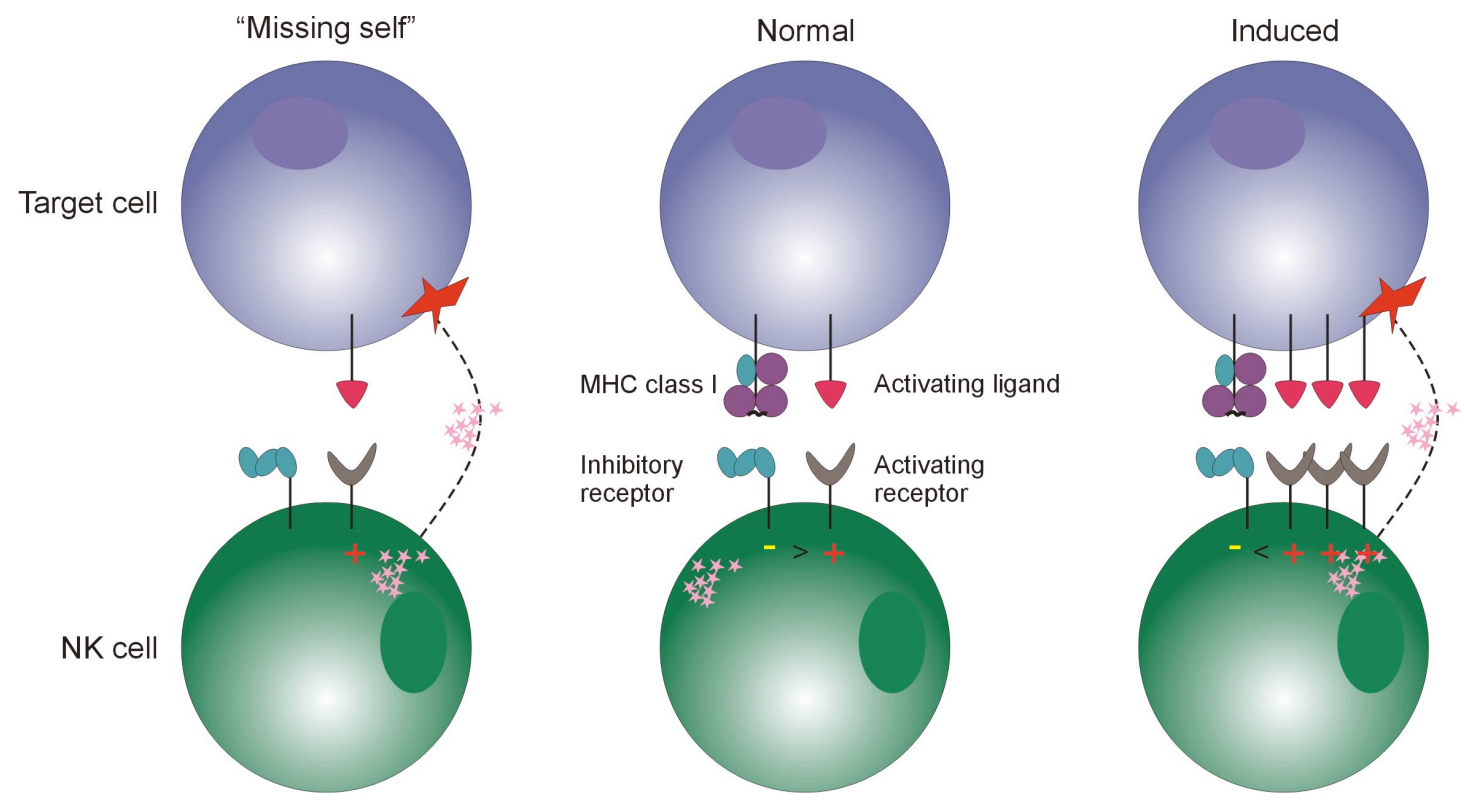

Figure 1. Target cell recognition by NK cells.

Under healthy conditions (normal, middle panel), the inhibitory signal given by an inhibitory receptor recognising its ligand leads to dephosphorylation of components of the activating signalling cascade and, thereby to repression of activation. Down-regulation of MHC class I surface expression leads to a "missing" signal for the inhibitory KIR and the NK cell gets activated ("missingself", left panel). Induction of activating ligands due to stress or infection leads to a stronger activating signal that dominates the inhibitory signal (induced, right panel). Besides cytotoxicity through granule release (depicted here as stars), NK cells also respond with cytokine secretion (modified after Elliott and Yokoyama, 2011).

\subsection{Killer Immunoglobulin-Like Receptors}

KIR molecules are type I glycoproteins with two or three immunoglobulin (Ig)-domains and belong to the Ig superfamily (Colonna and Samaridis, 1995; D'Andrea et al., 1995; Wagtmann et al., 1995). KIRs are regulatory molecules mainly expressed by NK cells but also by CD8 ${ }^{+} \alpha \beta$ T cells and $\gamma \delta$ T cells (Moretta et al., 1990; Snyder et al., 2004). The human KIR genes are located in a dense gene cluster on chromosome 19q13.4 and are part of the leucocyte receptor complex (LRC), which in addition to KIR codes also for other Ig-like receptors (Wende et al., 1999). Human KIR haplotypes differ by presence and absence of KIR genes and by allelic variability. To clearly distinguish between these two types of genetic variability this is also referred to as diversity (presence/absence of genes) and polymorphism (alleles). The diversity of KIR genes is based on expansions/contractions and recombination of KIR genes. Therefore, KIR molecules with similar ligand specificities but with different signalling pathways have evolved (e.g. inhibitory KIR2DL1 and activating KIR2DS1). Polymorphism is often accompanied 
with amino acid changes and can even lead to drastic functional changes as it is seen for KIR3DL1 and KIR3DS1 that are alleles of the same KIR gene (Crum et al., 2000; Gardiner et al., 2001; Uhrberg et al., 1997; Wilson et al., 2000). In 2004, it was shown by Rajalingam and colleagues that recombination of whole intact protein domains leads to the formation of new genes by exon shuffling. This exceptionally high level of genetic variability results in the rather unusual situation that unrelated individuals rarely have the same KIR genotype (Hsu et al., 2002; Martin et al., 2004; Shilling et al., 2002; Yawata et al., 2002).

As already mentioned above KIR molecules can transmit inhibitory or activating signals to the NK cell (Moretta et al., 1995). Inhibitory KIRs bear one or two ITIM in their cytoplasmic domain. Recognition of the self-ligand leads to phosphorylation of a conserved tyrosine residue of the ITIM followed by an association of SHP (Srchomology domain-bearing tyrosine phosphatase). SHP dephosphorylates molecules important for activation signals and thereby the inhibitory signal suppresses the activation of a NK cell (Burshtyn et al., 1996). Activating KIR molecules have a short cytoplasmic tail without ITIM. However, the transmembrane region contains a positively charged amino acid residue for association with the ITAM bearing adaptor molecule DAP12 (DNAX-activation protein 12) that contains a negatively charged amino acid residue in its transmembrane region (Lanier et al., 1998). Upon binding of a ligand by the activating KIR, the ITAM of DAP12 gets phosphorylated and ZAP70/Syk kinase is recruited and induces a signalling cascade leading to the activation of the NK cell (Brumbaugh et al., 1997; Leibson, 1997).

\subsubsection{Structure of KIR molecules}

The nomenclature of KIR molecules and their genes are based on the structure of the corresponding protein. The abbreviation "KIR" is followed by the number of Ig domains ("D") followed by a letter describing the length of the cytoplasmic tail "S" (short activating) and "L" (long - inhibitory). The last number stands for the gene that is coding for the KIR molecule. All KIR molecules originate from a long-tailed 3D KIR (Sambrook et al., 2006). This KIR is organised in 9 exons that correspond to the functional areas of the KIR molecule (Martin et al., 2000). Exons 1 and 2 code for the signal sequence and the following exons (exon 3-5) for the Ig domains (D0, D1 and D2). 
The stem region is encoded by exon 6 and the transmembrane part by exon 7 . The cytoplasmic domain is encoded by exons 8 and 9 (Trowsdale et al., 2001; Wilson et al., 1997).

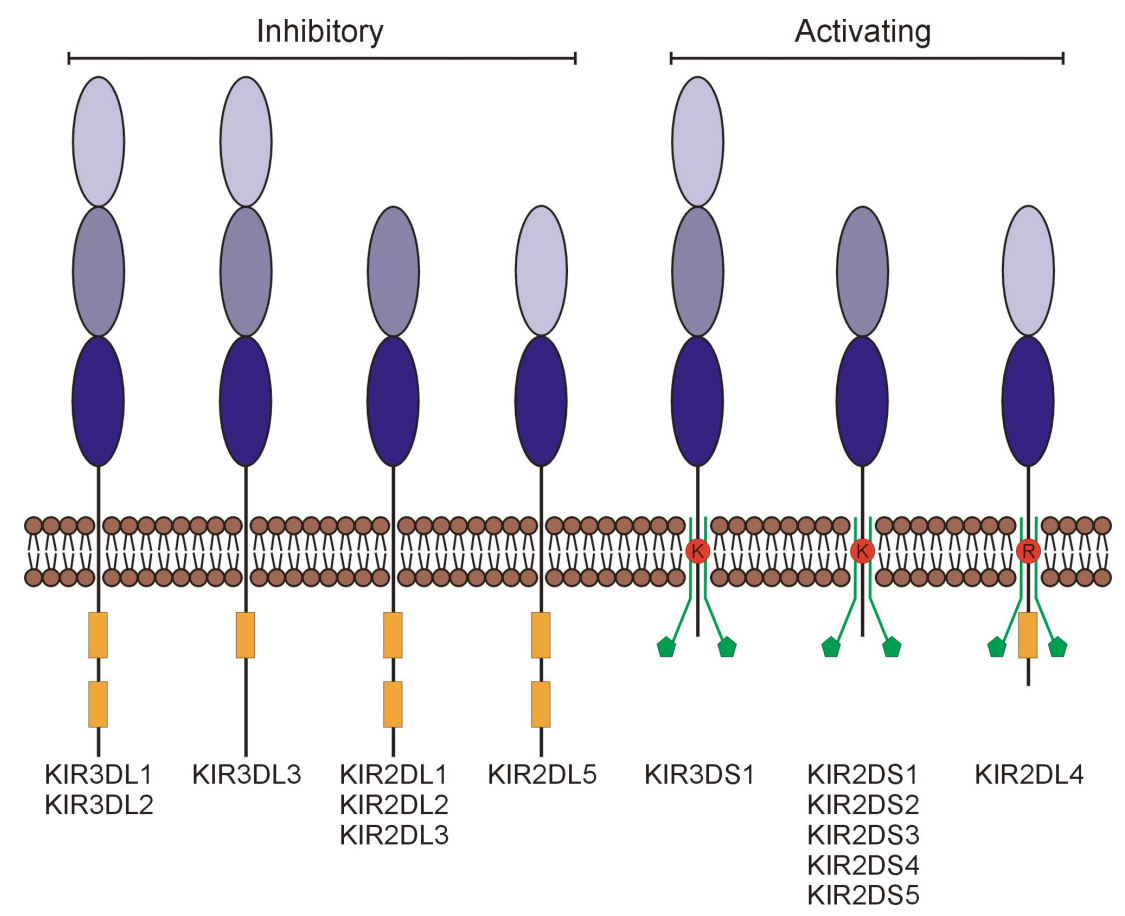

Figure 2. Protein structure of human KIR molecules.

KIR molecules belong to the Ig superfamily and have two or three Ig domains (blue ovals). The cytoplasmic part of inhibitory KIR contains ITIM (yellow rectangles). For activating KIR the cytoplasmic part is shortened and the transmembrane part contains a charged amino acid residue (red ball, $\mathrm{R}$ - arginine and $\mathrm{K}$ - lysine), which allows interaction with adaptor molecules e.g. DAP12 (green). KIR2DL4 contains motives of inhibitory and activating KIRs (ITIM and charged amino acid residue) (modified after IPD homepage www.ebi.ac.uk/ipd/kir/introduction.html).

Human KIR molecules occur mostly with two Ig domains (KIR2D) that can be classified into two groups (Figure 2). KIR molecules containing the D1 and D2 domain are called type 1 KIRs and have the same genomic arrangement as 3D KIRs. They possess the D0 domain encoding exon 3 that behaves like a "pseudo-exon" whereby the D0 domain is missing in type 1 KIRs (Vilches and Parham, 2002). Type 2 KIRs such as KIR2DL4 and KIR2DL5 have the D0 and D2 domain. However, due to deletion of exon 4, the D1 domain is absent (Selvakumar et al., 1997; Vilches et al., 2000). Crystal structures for KIR2DL1, KIR2DL2 and very recent for KIR3DL1 in complex with their MHC class I ligands showed the three-dimensional structure of those molecules and provided information about their ligand-binding characteristics (Boyington et al., 2000; Fan et al., 2001; Vivian et al., 2011). 


\subsubsection{KIR expression by NK cells}

The main KIR-expressing lymphocytes are NK cells. Besides other inhibitory and activating receptors, KIR molecules help to distinguish between self and non-self and the signalling pathway initiated by either an activating or inhibitory KIR in combination with other NK cell receptors decides if the NK cell gets activated and will kill the target cell. Human NK cells are traditionally characterised by the presence of CD56 and the lack of CD3. The two main NK cell subsets are discriminated by the level of expressed CD56 (Lanier et al., 1986). The minor population (around 10\%) does express CD56 at bright levels (CD56 $6^{\text {bright) }}$ ) with only dim or complete lack of CD16 expression. The major population of NK cells shows only a dim CD56 expression (CD56 dim) but high levels of CD16. These two main NK cell subsets differ in their natural killer receptor repertoires. CD56 bright NK cells express CD94/NKG2 C-type lectin receptors at high levels whereas CD56 dim NK cells mainly express KIR (around $85 \%$ ) and only low levels of CD94/NKG2 receptors (Voss et al., 1998; André et al., 2000).
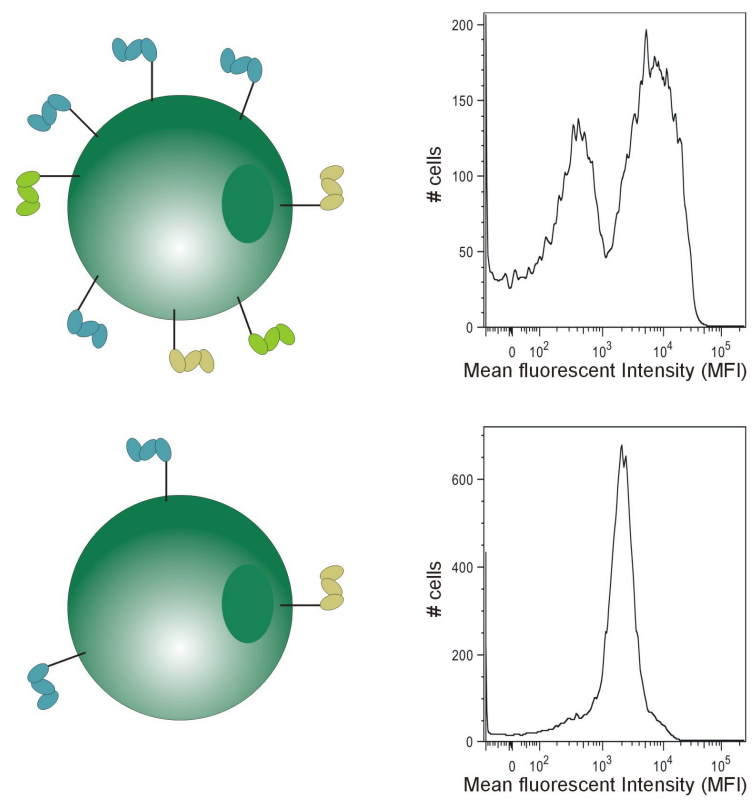

Figure 3. Variation in KIR expression between different individuals.

Comparison of KIR expressing NK cells of two different individuals shows differences in the amount of expressed KIR. The upper donor shows a high number of KIRs expressed by a single NK cell. This is also shown by the histogram on the right side. The depicted mean fluorescence intensity differs between those two individuals (modified after Gardiner, 2007). 
The KIR expression is not homogenous as frequency and levels of KIR expression on NK cells varies. Individual NK cells express different combinations of KIR proteins (Vilches and Parham, 2002). Therefore, KIRs show a clonal expression pattern. Comparison of two individuals both having the KIR3DL1 gene revealed that the frequency of NK cells expressing the KIR3DL1 protein varies (Gumperz et al., 1996).

Not only the frequency varies but also the amount or density of a given KIR that is expressed by a NK cell (Figure 3). The number of KIR-positive cells and the level of cell surface expression (mean fluorescence intensity) are measured by flow cytometry. Within an individual the percentage as well as the amount of a given KIR remain stable over time (Gumperz et al., 1996; Shilling et al., 2002).

\subsubsection{KIR expression by $T$ cell subsets}

KIRs are not only expressed by NK cells but also by specific T cell subsets (Moretta et al., 1990; Snyder et al., 2004). Within the $\alpha \beta$ TCR T cell subset KIR molecules are mainly expressed by $\mathrm{CD}^{+} \alpha \beta \mathrm{T}$ cells and at a very low level by $\mathrm{CD}^{+} \alpha \beta \mathrm{T}$ cells. Additionally, KIRs are expressed by $\gamma \delta$ T cells. In total, around $4.5 \%$ of all T cells are KIR positive and up to $30 \%$ of all $\mathrm{CD}^{+} \alpha \beta$ T cells do express KIR (Anfossi et al., 2001). Only $0.2 \%$ of all $\mathrm{CD}^{+} \alpha \beta$ T cells express KIRs (van Bergen et al., 2004) and a varying amount of $\gamma \delta$ T cells (Battistini et al., 1997). KIR expression by $\mathrm{T}$ cells is most likely acquired after rearrangement of the TCR because $\mathrm{T}$ cell clones expressing the same TCR rearrangement differ in their KIR expression pattern (Uhrberg et al., 2001; Vely et al., 2001; Snyder et al., 2002). The regulations for KIR expression differ for NK and T cells, therefore, the KIR repertoire of NK and T cells differ even within individuals (Uhrberg et al., 2001). The KIR expressed by T cells tend to modulate signals driven by the TCR rather than to act independently.

From an evolutionary point of view, activating KIR evolved from inhibitory KIR (AbiRached and Parham, 2005). Therefore, van Bergen and Koning (2010) proposed the following hypothesis for KIR expression on T cells: To limit collateral damage due to anti-viral responses $\mathrm{T}$ cells may have acquired the ability to express inhibitory KIRs. However, also activating KIRs are expressed by T cells. In contrast to NK cells that are strictly controlled, no such tolerance inducing mechanisms exist for expression of 
activating KIRs by T cells, especially because KIR expression is acquired after thymic selection. The consequences of activating KIR expression might be to boost $\mathrm{T}$ cell responses after viral infection and not a limitation of the response. Along the same line, activating KIRs may also facilitate a rapid induction of secondary $\mathrm{T}$ cell-mediated immune responses because KIRs are found especially on $\mathrm{T}$ cells with memory phenotype. This might also be the reason for the increase of KIR expressing $\mathrm{T}$ cells with age (van Bergen et al., 2004; Anfossi et al., 2001). On the other hand, KIR expression by $\mathrm{T}$ cells may lead to tissue damage or may trigger the onset of autoimmune diseases.

\subsection{KIR and Disease}

\subsubsection{Disease association studies}

NK cells, defined as part of innate immunity, can influence or modify the course of a disease early after occurrence. They are able to eliminate viral infections (Orange, 2004) by killing infected cells, secrete inflammatory cytokines such as IFN- $\gamma$ and interact with dendritic cells to recruit cells of the adaptive immune system (Moretta, 2002). As for all immune cells, NK cells can also negatively influence the course of a disease. This is mainly analysed by disease-association studies. Already shown are associations of distinct KIR/ligand combinations with viral infections, autoimmune diseases and cancer (Martin et al., 2002; Naumova et al., 2005; Nelson et al., 2004; van der Slik et al., 2003). It was found that homozygosity for KIR2DL3 and for HLA-C1 are particularly found in patients that clear hepatitis C infections (Khakoo et al., 2004). In contrast, the appearance of the autoimmune disease psoriatic arthritis is more common in patients that are homozygous for HLA-C in combination with KIR2DS1 and/or KIR2DS2 (Nelson et al., 2004). The occurrence of type 1 diabetes can also be influenced by certain KIR/MHC combinations (van der Slik et al., 2003). NK cells are also important for reproduction and certain KIR/MHC combinations can influence the success of implantation of the embryo or cause preeclampsia (Hiby et al., 2004). 


\subsubsection{KIR and HIV}

The human immunodeficiency virus (HIV) was identified in 1983 (Barre-Sinoussi et al., 1983; Gallo et al., 1983) after combining immunodeficiency syndroms, observed by homosexual men, as acquired immunodeficiency syndrome (AIDS) by the Center for Disease Control (CDC, Atlanta). Two types of HIV are described so far: HIV-type 1 (HIV1) and HIV-type 2 (HIV-2). It is supposed that HIV arose from interspecies transmission from simian immunodeficiency virus (SIV) (Hahn et al., 2000), with HIV-1 and HIV-2 being derived from different SIV types (Gao et al., 1999; Hirsch et al., 1989). SIV and HIV belong to the family of Retroviridae and are further classified as lentiviruses.

Many species of African nonhuman primates (e.g. sooty mangabeys or African green monkeys) are naturally infected with SIV. However, in contrast to humans these nonhuman primates usually do not develop AIDS, most likely due to a long time of coevolution between these natural hosts and the virus.

Over the last years, strong attention is directed towards NK cells and their receptors and the course of infection with HIV. Certain combinations of KIR and their MHCligands can either cause a delayed or an accelerated progression to AIDS (Martin et al., 2002; Gaudieri et al., 2005). In HIV-infected children an increased expression of KIR2DL3 on NK cells correlates inversely with disease severity (Ballan et al., 2007). The expression of KIR3DL1 or KIR3DS1 alleles in combination with certain HLA-Bw4 class I alleles causes delayed progression to AIDS (Martin et al., 2002; Martin et al., 2007). Also a strong influence of NK cells and their KIR genes in the control of HIV-1 infection was determined by the group of Markus Altfeld (Alter and Altfeld, 2009; Alter et al., 2009). The difficulty in studying human HIV infection is the absence of pre infection data to get information about the changes in the immune system in the course of infection and disease.

\subsection{Rhesus macaque}

\subsubsection{Rhesus macaque NK cells and KIR}

Because rodents do not have corresponding KIR genes, rhesus macaques provide important animal models of human diseases where NK cells and KIR proteins play 
essential roles. Nevertheless, despite having similar functions, there are differences in the phenotype of NK cells and also in the KIR (Blokhuis et al. 2011, Kruse et al. 2010) and MHC class I (Otting et al. 2005, 2007) genes. While human NK cells express CD56 and CD16, NK cells in rhesus macaques have only a small population of CD56 expressing cells (Webster and Johnson, 2005) and express NKG2A as more dominant marker together with CD16 (Mavilio et al., 2005). The KIR expression pattern of rhesus macaque NK cells is unknown so far due to the absence of appropriate anti-rhesus macaque KIR antibodies and lack of cross-reactivity of anti-human KIR antibodies.

With the exception of KIR2DL4, KIR2DL5 and KIR1D, all rhesus macaque KIRs consist of three Ig domains (Hershberger et al., 2001). Similar to their human homologs these KIRs are highly polymorphic (Blokhuis et al. 2010, Kruse et al. 2010). Clear differences between human and macaque KIRs are seen in the structure of activating KIR. These KIR molecules combine characteristics of KIR3DL and KIR2DL4 molecules. Due to a 53 bp deletion in exon 8 resulting in a frame shift they have a short cytoplasmic tail and miss any ITIM. The transmembrane region contains the charged residue arginine (Hershberger et al., 2001) that is also found in human KIR2DL4 (and not lysine like the human activating KIR). The adaptor molecule FcR $\gamma$ (encoded by the FCERG1 gene) associates with human KIR2DL4 (Lanier et al., 1998; Kikuchi-Maki et al., 2005). The adaptor molecule for rhesus macaque activating KIR is not known yet. Because rhesus macaque activating KIR have an arginine residue in their transmembrane region, this adaptor might be FcR $\gamma$.

\subsubsection{Rhesus macaques and SIV infection}

Similar to human immunodeficiency virus (HIV), the macaque SIV (SIVmac) arose from interspecies transmission meaning that rhesus macaques and humans are no natural hosts for these viruses (Letvin et al., 1983). SIVmac-infected rhesus macaques also show symptoms of acquired immunodeficiency syndrome (AIDS) (Letvin and King, 1990). Therefore, the rhesus macaque is a suitable animal model for understanding HIV pathogenesis.

The course of SIV infection is divided into different phases (personal communication by Prof. Ansari and Ansari et al., 2011). The infection is followed by an eclipse phase 
where plasma viral load is low and difficult to detect. Between weeks 4-6 a log phase is reached after rapid replication of the virus. It follows the phase where the viral load stabilises (viral load set point phase), which is also the phase the animals differ clearly. Animals with high plasma viral loads (HVL) are mostly fast disease progressors that die within the first year of infection. The elite controller group is able to control plasma viremia and stay alive for up to seven years and a third group shows variable levels of viral load and are called normal progressors that die within two to four years post infection (Figure 4).

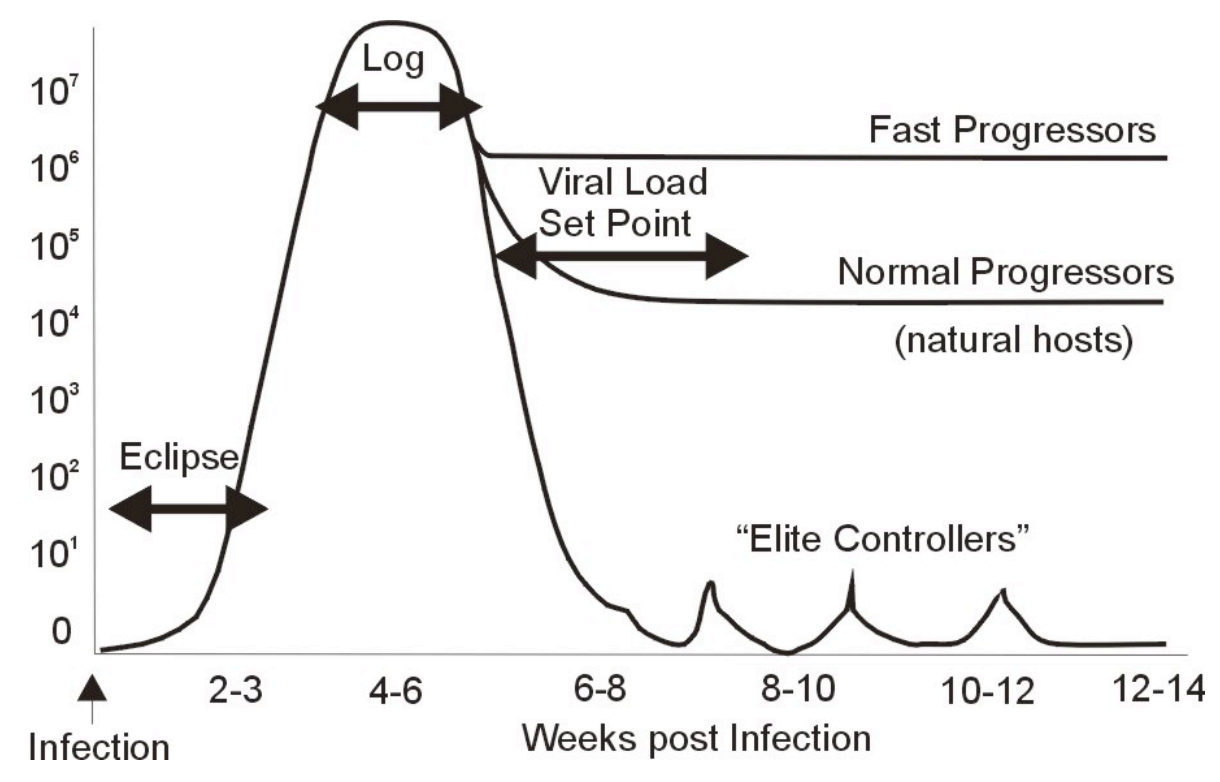

Figure 4. Different phases of SIV infection.

Different phases of viremia during SIV infection in rhesus macaques are depicted. The eclipse phase where plasma viral loads are nearly undetectable is followed by a log phase with a high detectable plasma viral load level. At the viral load set point phase the plasma viral load stabilises but differs between different animals. Fast progressors show a high viral load and die within nine month post infection. Elite controller are able to control the virus and normal progressors have variable levels of plasma viral loads. Natural hosts like sooty mangabeys show a similar viral load to normal progressors without developing AIDS (adapted from Ansari et al., 2011).

The characterisation of elite controller, slow, normal and fast progressors is based on the kinetics of disease progression and not strictly on viral loads. Normally, there is also accordance with plasma viral load and fast progression (high viral loads greater than 100,000 viral copies/ml of plasma) and the same is true for the slow progressors having plasma viral loads of 10,000 to 50,000 copies/ml plasma. The elite controllers are able to self-control the virus to very low levels of virus (less than 1000-2000 viral copies/ml plasma). Because of these different characteristics in disease progression it 
is important to analyse why the elite controllers are able to contain the virus. The development of these different phenotypes occurs within 5-6 weeks post infection, therefore, an involvement not only by the adaptive but also by the innate immunity is assumed. For this reason the current SIV research is also focussing on the influence of NK cells on the outcome of SIV such as in human and HIV. The benefit of rhesus macaques as animal model for HIV research is the shortened time of disease progression compared to human (8-12 years) and the possibility to analyse the pre infection status compared to post infection.

For rhesus macaques associations between certain KIR3DL alleles with high plasma viral loads were shown and in an additional analysis of the same laboratory it was shown that KIR3DS alleles are stronger associated with high plasma viral loads than KIR3DL alleles (Bostik et al., 2009; Chaichompoo et al., 2010). Recently, Moreland and colleagues (2011) established a new typing system. They developed a novel pyrosequencing-based technique for KIR genotyping. This method may help to estimate the frequency of KIR transcript levels and compare changes due to infection for a large cohort of animals. This will help to explain the influence of stable or changing KIR expression pattern during infection.

\subsection{Aim of the study}

KIR expressing lymphocytes are characterised for human. NK cells are described as the main KIR-expressing population besides $\alpha \beta$ T cells, mainly $\mathrm{CD}^{+}$, and $\gamma \delta \mathrm{T}$ cells. KIRs have a clonal expression pattern and the frequency as well as the amounts of expressed KIRs differ between single NK cells and between different individuals. Wellcharacterised monoclonal antibodies for most of the human KIRs are available. In contrast, such tools are lacking for rhesus macaques and, therefore, the expression patterns of KIR proteins are currently unknown. The aim of this work was therefore, to establish and to characterise monoclonal anti-rhesus macaque KIR antibodies. Such antibodies should then be used to study expression patterns and cellular distributions of KIR in peripheral blood mononuclear cell (PBMC) samples of rhesus macaque individuals. Furthermore, KIR expression in SIV-infected rhesus macaques should be studied. 


\section{Material and Methods}

\subsection{Material}

\subsubsection{Laboratory Animals}

\section{Primate Species}

Rhesus macaques (Macaca mulatta) used in this work are housed at the German Primate Center (Deutsches Primatenzentrum, DPZ) and are of Indian origin. Blood samples were taken by Dr. Annette Schrod or Dr. Tamara Becker, veterinarians working at the DPZ. Blood of eight rhesus macaques was used for DNA, RNA and cell separation. Heparin blood was used for DNA isolation and EDTA blood was used for RNA isolation and cell separation. Additionally, blood of three other Old World monkey species was analysed, four cynomolgus macaques (Macaca fascicularis), nine hamadryas baboons (Papio hamadryas) and four African green monkeys (Chlorocebus sabaeus) (Table 1).

Table 1. Nonhuman primates used in this study*.

\begin{tabular}{llll}
\hline Rhesus macaque & Cynomolgus macaque & Hamadryas baboon & African green monkey \\
\hline & & & \\
2136 (Gerdi) & 12331 & 11619 & 14624 \\
2146 (Bibbi) & 12401 & 12044 & 14625 \\
2405 (Kalle) & 12466 & 12101 & 14632 \\
2425 (Happy) & 12400 & 12184 & 14633 \\
14225 (King) & & 12343 & \\
14218 (Benno) & & 12347 & \\
14229 (Jogi) & & 12935 & \\
14223 (Franz) & & 12992 & \\
& & 13528 &
\end{tabular}

*The DPZ animal number is indicated and in the case of rhesus macaques, also a given name for easier distinction 
PBMC samples of SIV-infected rhesus macaques were frozen and stored with DMSO in liquid nitrogen at the Department of Pathology, Emory University School of Medicine, Atlanta. All animals were of Indian origin and housed at Yerkes National Primate Research Center, Atlanta (Table 5).

\section{Mouse strains}

For the generation of monoclonal antibodies $\mathrm{C} 3 \mathrm{H} / \mathrm{HeN}$ and $\mathrm{C} 57 \mathrm{BL} / 6$ mice were used. All mice were housed at the animal facility at the University of Göttingen. Injections and euthanisation were performed by Prof. Dr. Ralf Dressel (Department of Cellular and Molecular Immunology, University of Göttingen).

\subsubsection{Equipment}

\begin{tabular}{|c|c|c|}
\hline Equipment & Model & Manufacturer \\
\hline Autoclave & Varioklav $^{\circledR} 400 \mathrm{E}$ & H+P Labortechnik \\
\hline Blotter, tank & XCell II ${ }^{\mathrm{TM}}$ Blot Module & Invitrogen \\
\hline Cell Counter & Casy Counter & Innovatis \\
\hline \multirow[t]{3}{*}{ Centrifuges } & Multifuge 1S-R & Heraeus \\
\hline & Biofuge pico & Heraeus \\
\hline & Centrifuge 5415 R & Eppendorf \\
\hline \multirow[t]{2}{*}{ Centrifuge rotors } & TTH 400 & Heraeus \\
\hline & F45-24-11 & Eppendorf \\
\hline Hemocytometer & Neubauer improved & Marienfeld superior \\
\hline Cryo container & Mister Frosty & Nalgene \\
\hline Electrophoresis chamber & Horizon 58 & Gibco BRL \\
\hline Electroporation device & Gene Pulser II & Bio Rad \\
\hline ELISA Reader & MR580 & Dynatech \\
\hline Emulsifying Needle & 2-7/8" long & Scientific Commodites, Inc. \\
\hline Film processor & Ecomax $^{\mathrm{TM}}$ & Protec \\
\hline Flow Cytometer & BD LSR II & Becton Dickinson \\
\hline Gel imager & Gel Jet Imager 2000 & Intas \\
\hline Hamilton syringe & Microliter ${ }^{\mathrm{TM}}$ Syringes & Hamilton \\
\hline
\end{tabular}




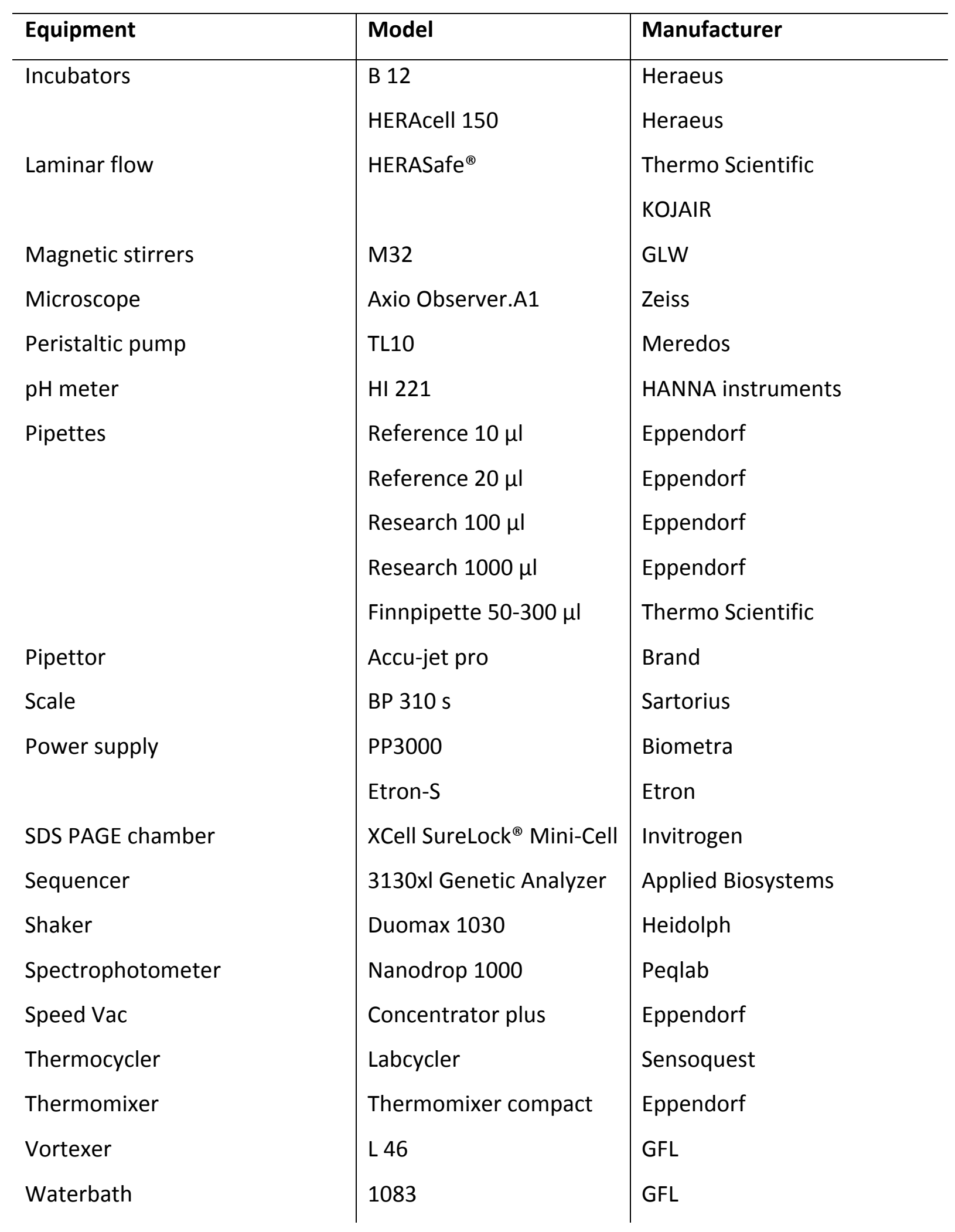




\subsubsection{Consumables and Chemicals}

\begin{tabular}{|c|c|}
\hline Consumables and chemicals & Manufacturer \\
\hline $0.45 \mu \mathrm{m}$ filter & Heinemann Labortechnik \\
\hline 1,4-Dithiothreitol (DTT) & Merck \\
\hline 2,2'-azino-bis(3-ethylbenzothiazoline-6-sulphonic & \\
\hline acid) (ABTS) & Sigma \\
\hline 6 well plate & Sarstedt \\
\hline 96 well plate & Nunc \\
\hline Agar Agar & Roth \\
\hline Agarose & Biozym \\
\hline Amersham Hyperfilm ${ }^{\circledast} \mathrm{ECL}$ & GE Healthcare \\
\hline Amicon Ultra-30 centrifugal filter unit & Millipore \\
\hline Ammonium persulphate (APS) & Sigma \\
\hline Ampicillin & Sigma \\
\hline $\mathrm{BamH1}$ & New England Biolabs \\
\hline BioTherm ${ }^{\mathrm{TM}} 10 \times$ reaction buffer & GeneCraft \\
\hline BioTherm ${ }^{\text {TM }}$ Taq-DNA Polymerase & GeneCraft \\
\hline Bovine serum albumin & Sigma \\
\hline Bromphenol blue & Sigma \\
\hline Casy tone & Innovatis \\
\hline Cell culture flasks, T 25 & Greiner Bio-One \\
\hline Cell culture flasks, T125 & Greiner Bio-One \\
\hline Cell culture flasks, T75 & Greiner Bio-One \\
\hline Cell culture freeze medium & Gibco \\
\hline Chloroform & J.T. Baker \\
\hline Cryopreservation tube & Sarstedt \\
\hline Developer solution & Kodak \\
\hline Dimethylformamid & Roth \\
\hline dNTP & GeneCraft \\
\hline Dulbecco's modified eagle medium (DMEM) & PAA \\
\hline EcoR1 & New England Biolabs \\
\hline
\end{tabular}




\begin{tabular}{|c|c|}
\hline Consumables and chemicals & Manufacturer \\
\hline Electroporation cuvette, $1 \mathrm{~mm}$ & Biozym \\
\hline Ethanol & Merck \\
\hline Ethanol, denatured & Roth \\
\hline Ethidium bromide & Roth \\
\hline Ethylenediaminetetraacetic acid (EDTA) & Sigma \\
\hline Falcon tube, $15 \mathrm{ml}$ & Becton Dickinson \\
\hline Falcon tube, $50 \mathrm{ml}$ & Greiner Bio-One \\
\hline Filter paper & Sartorius \\
\hline Fixer solution & Tetenal \\
\hline Formaldehyde & Roth \\
\hline Glycerol & Sigma \\
\hline HiTrap ${ }^{\text {TM }}$ Protein G HP & GE Healthcare \\
\hline human IgG & Sigma \\
\hline Hydrogen peroxide, $30 \%$ & Roth \\
\hline Hyperfilm & Amersham \\
\hline Interleukin 6 & Immunotools \\
\hline Isopropyl & Roth \\
\hline Isopropyl- $\beta$-D-thiogalactopyranosid (IPTG) & DakoCytomation \\
\hline Leucosep ${ }^{\circledR}, 50 \mathrm{ml}$ & Greiner Bio-One \\
\hline Liquid nitrogen & Vesper \\
\hline Luminol & Fluka \\
\hline M-MLV $5 \times$ buffer & Promega \\
\hline M-MLV reverse transcriptase & Promega \\
\hline Magnesium chloride & Roth \\
\hline Magnesium sulphate & Merck \\
\hline Metafectene & Biontex \\
\hline Milk powder & Roth \\
\hline Nitrocellulose membrane & Macherey-Nagel \\
\hline oligo(dT) Primer & Promega \\
\hline p-coumaric acid & Sigma \\
\hline
\end{tabular}




\begin{tabular}{|c|c|}
\hline Consumables and chemicals & Manufacturer \\
\hline Penicillin/Streptomycin & PAA \\
\hline Percoll & Biochrom AG \\
\hline Phosphoric acid & Roth \\
\hline Pipette Tip $100 \mu \mathrm{l}$ & Sarstedt \\
\hline Pipette Tip $1000 \mu \mathrm{l}$ & Sarstedt \\
\hline Pipette Tip $2.5 \mu \mathrm{l}$ & Biozym \\
\hline Pipette Tip $20 \mu \mathrm{l}$ & Biozym \\
\hline Polyacrylamide $30 \%$ & Roth \\
\hline Potassium acetate & Roth \\
\hline Potassium chloride & Merck \\
\hline Pronase E & Sigma \\
\hline pUC19 DNA & Roth \\
\hline Reaction tube $0.2 \mathrm{ml}$ & Sarstedt \\
\hline Reaction tube $0.5 \mathrm{ml}$ & Sarstedt \\
\hline Reaction tube $1.5 \mathrm{ml}$ & Sarstedt \\
\hline Reaction tube $2 \mathrm{ml}$ & Roth \\
\hline RNase A & Sigma \\
\hline RNase Inhibitor & Promega \\
\hline Roswell Park Memorial Institute Medium (RPMI) & Paa \\
\hline Round bottom tube, $5 \mathrm{ml}$ & Becton Dickinson \\
\hline Saccharose & Merck \\
\hline SDS-PAGE Cassettes & Invitrogen \\
\hline Serological pipettes, $10 \mathrm{ml}$ & Sarstedt \\
\hline Serological pipettes, $5 \mathrm{ml}$ & Sarstedt \\
\hline Silica milk & Sigma \\
\hline Slide-A-Lyzer Dialysis Unit, 3.5K MWCO & Thermo Scientific \\
\hline Sodium acetate & Roth \\
\hline Sodium chloride & Roth \\
\hline Sodium hydroxide & Roth \\
\hline Sodium iodide & Roth \\
\hline
\end{tabular}




\begin{tabular}{l|l}
\hline Consumables and chemicals & Manufacturer \\
\hline Sodium lauryl sulphate (SDS) & Roth \\
Sodium phosphate & Merck \\
T4-DNA ligase & Promega \\
Tetramethylethylenediamine (TEMED) & Sigma \\
TiterMax Gold & Sigma \\
Triple flasks & Nunc \\
Tris & Roth \\
Triton X-100 & Roth \\
TRIzol ${ }^{\circledR}$ & Invitrogen \\
Trypan blue & PAA \\
Tryptone & Becton Dickinson \\
Tween 20 & Sigma \\
ultraCHO media & Lonza \\
Water (HPLC quality) & Merck \\
Wax & Adamas Instruments \\
X-gal & Roth \\
Yeast extract & Becton Dickinson \\
\hline
\end{tabular}

\subsubsection{Bacterial Strains}

Electrocompetent: Escherichia coli TOP10 (Invitrogen) F-mcrAs (mrr-hsdRMS-mcrBC) Ф80lacZ4M15 Alac74 recA1 deoR araD139 4(ara, leu) 7697 galK rpsL (Str $^{R}$ ) end A1 nupG

Chemically competent: Escherichia coli DH5 $\alpha^{\mathrm{TM}}$ (Invitrogen) F- $\varphi 80$ lacZ $\Delta M 15 \Delta$ (lacZYAargF)U169 recA1 endA1 hsdR17(rk-, mk+) phoAsupE44 thi-1 gyrA96 relA1 $\lambda$ -

\subsubsection{Cell Lines}

The human cell line HEK293 was cultured in DMEM media supplemented with $15 \%$ FCS and $1 \%$ Penicillin/Streptomycin at $37^{\circ} \mathrm{C}$ and $5 \% \mathrm{CO}_{2}$ atmosphere.

The mouse myeloma cell line X63AG8.653 was cultured in DMEM media supplemented with $10 \% \mathrm{FCS}$ and $1 \%$ Penicillin/Streptomycin at $37^{\circ} \mathrm{C}$ and $5 \% \mathrm{CO}_{2}$ atmosphere. 
The hybridoma cells derived from the fusion of X63AG8.653 cells and primary mouse spleen cells were cultured in DMEM media supplemented with $20 \%$ FCS, $1 \%$ Penicillin/Streptomycin and $100 \mathrm{U} / \mathrm{ml}$ IL 6 at $37{ }^{\circ} \mathrm{C}$ and $5 \% \mathrm{CO}_{2}$ atmosphere.

\subsubsection{Plasmids}

\begin{tabular}{ll}
\hline Plasmid & Manufacturer \\
\hline pGEM $^{\circledR}-\mathrm{T}$ Easy & Promega \\
pAcGFP-N1 & Clontech \\
pFUSE-hlgG-Fc2 & Invivogen
\end{tabular}

\subsubsection{Size Standards}

\begin{tabular}{ll}
\hline Size standard & Manufacturer \\
\hline GeneRuler 100bp ladder plus & Fermentas \\
PageRuler prestained protein ladder & Fermentas
\end{tabular}

\subsubsection{Buffers and Solutions}

\begin{tabular}{|c|c|}
\hline Buffer/Solution & Preparation \\
\hline BSA/Triton-X-100 buffer & $\begin{array}{l}500 \mathrm{mg} \text { BSA } \\
350 \mathrm{mg} \text { Triton-X-100 } \\
\text { adjust volume to } 50 \mathrm{ml} \text { with } \mathrm{HPLC}-\mathrm{H}_{2} \mathrm{O}\end{array}$ \\
\hline ELISA - Blocking solution & $4 \%$ milk powder in PBS \\
\hline ELISA - Coating buffer & $\begin{array}{l}\text { A: } 0.2 \mathrm{M} \mathrm{Na}_{2} \mathrm{CO}_{3} \\
\text { B: } 0.2 \mathrm{M} \mathrm{NaHCO}_{3} \\
\text { Mix } 85 \mathrm{ml} \mathrm{A} \text { with } 40 \mathrm{ml} \mathrm{B} \text { and adjust to } \\
500 \mathrm{ml} \text { with } \mathrm{H}_{2} \mathrm{O} \text { before use }\end{array}$ \\
\hline ELISA - Reaction buffer & $0.1 \mathrm{M} \mathrm{NaAc}$ \\
\hline
\end{tabular}




\begin{tabular}{|c|c|}
\hline Buffer/Solution & Preparation \\
\hline & $\begin{array}{l}0.20 .05 \mathrm{M} \mathrm{NaH}_{2} \mathrm{PO}_{4} \\
\mathrm{pH} 4.0\end{array}$ \\
\hline ELISA - Substrate reaction & $\begin{array}{l}10 \mathrm{ml} \text { Reaction buffer } \\
500 \mu \mathrm{l} 40 \mathrm{mM} \text { ABTS } \\
10 \mu \mathrm{l} \mathrm{H}_{2} \mathrm{O}_{2}(30 \%)\end{array}$ \\
\hline Erythrocyte lysis buffer & $\begin{array}{l}8.29 \mathrm{~g} \mathrm{NH}_{4} \mathrm{Cl} \\
1 \mathrm{~g} \mathrm{KHCO}_{3} \\
0.2 \mathrm{ml} \text { of } 0.5 \mathrm{M} \mathrm{EDTA} \\
\text { adjust } \mathrm{pH} \text { to } 8.0\end{array}$ \\
\hline Flow cytometry buffer & $\begin{array}{l}1 \% \text { BSA and small amount (covering } \\
\text { the tip of a spatula) NaAc } \\
\text { in PBS }\end{array}$ \\
\hline Flow cytometry fixing solution & $\begin{array}{l}7 \% \text { Formaldehyde in flow cytometry } \\
\text { buffer } \\
\text { For fixing cells: } 1.5 \mathrm{ml} \text { Buffer }+1.5 \mathrm{ml} \\
\text { Formaldehyde }(7 \%)\end{array}$ \\
\hline Immunoblot - Blocking solution & $\begin{array}{l}\text { 1x TBS } \\
5 \% \text { milk powder } \\
0.05 \% \text { Tween } 20\end{array}$ \\
\hline Immunoblot - Developing solution 1 & $\begin{array}{l}2.5 \mathrm{mM} \text { Luminol } \\
0.9 \mathrm{mM} \text {-coumaric acid } \\
10 \mathrm{mM} \text { Tris/HCl (pH 8.5) }\end{array}$ \\
\hline Immunoblot - Developing solution 2 & $6 \mu \mathrm{l} \mathrm{H}_{2} \mathrm{O}_{2}(30 \%)$ \\
\hline
\end{tabular}




\begin{tabular}{|c|c|}
\hline Buffer/Solution & Preparation \\
\hline & $\begin{array}{l}10 \mathrm{mM} \text { Tris/HCl (pH 8.5) } \\
9 \mathrm{ml} \mathrm{H} \mathrm{H}_{2} \mathrm{O}\end{array}$ \\
\hline Immunoblot - TBS (10 x) & $\begin{array}{l}1.37 \mathrm{M} \mathrm{NaCl} \\
100 \mathrm{mM} \mathrm{Tris} / \mathrm{HCl}(\mathrm{pH} 7.2)\end{array}$ \\
\hline Immunoblot - Wash solution & $\begin{array}{l}1 \times \text { TBS } \\
0.05 \% \text { Tween } 20\end{array}$ \\
\hline Immunoblot- Running buffer & $\begin{array}{l}15.1 \mathrm{~g} \text { Trisbase } \\
94 \mathrm{~g} \text { Glycine } \\
50 \mathrm{ml} 10 \% \text { SDS }\end{array}$ \\
\hline Loading buffer for DNA (10x) & $\begin{array}{l}6.6 \mathrm{~g} \text { Sucrose } \\
0.04 \mathrm{~g} \text { Bromphenol blue } \\
\text { dissolve in } 10 \mathrm{ml} \mathrm{H}_{2} \mathrm{O}\end{array}$ \\
\hline Mini prep solution 1 & $\begin{array}{l}50 \mathrm{mM} \text { Tris (pH 8.0) } \\
10 \mathrm{mM} \text { EDTA (pH 8.0) } \\
\text { add } 100 \mu \mathrm{g} / \mathrm{ml} \text { RNase A before use }\end{array}$ \\
\hline Mini prep solution 2 & $\begin{array}{l}\text { P2a: } 400 \mathrm{mM} \mathrm{NaOH} \\
\text { P2b: } 2 \% \text { PBS } \\
\text { mix 1:1 before use }\end{array}$ \\
\hline Mini prep solution 3 & $3 \mathrm{M} \mathrm{Kac}, \mathrm{pH} 4.8$ \\
\hline PBS $(10 x)$ & $\begin{array}{l}1.37 \mathrm{M} \mathrm{NaCl} \\
27 \mathrm{mM} \mathrm{KCl} \\
81 \mathrm{mM} \mathrm{Na}_{2} \mathrm{HPO}_{4}\end{array}$ \\
\hline
\end{tabular}




\begin{tabular}{|c|c|}
\hline Buffer/Solution & Preparation \\
\hline Protein purification - Binding buffer $(10 \mathrm{x})$ & $\begin{array}{l}14.7 \mathrm{mM} \mathrm{KH}_{2} \mathrm{PO}_{4} \\
0.2 \mathrm{M} \mathrm{Na}_{3} \mathrm{PO}_{4} \\
\mathrm{pH} 7,0\end{array}$ \\
\hline Protein purification - Elution buffer (10 x) & $\begin{array}{l}1 \mathrm{M} \mathrm{Glycin-HCl} \\
\mathrm{pH} 2.7\end{array}$ \\
\hline Protein purification - Neutralising buffer & $\begin{array}{l}1 \mathrm{M} \text { Tris- } \mathrm{HCl} \\
\mathrm{pH} 9.0\end{array}$ \\
\hline SDS PAGE - Electrophoresis buffer (5 x) & $\begin{array}{l}125 \text { mM Trisbase } \\
1.25 \text { M Glycine } \\
0.5 \% \text { SDS }\end{array}$ \\
\hline SDS-PAGE - Laemmli buffer $(2 \mathrm{x})$ & $\begin{array}{l}374 \mathrm{mM} \text { Tris } \\
416 \mathrm{mM} \text { SDS } \\
438 \mathrm{mM} \text { Saccharose } \\
\text { adjust to pH } 6.8 \\
\text { add } 1,34 \mathrm{mM} \text { Bromphenol blue }\end{array}$ \\
\hline SDS-PAGE - SDS separation gel (10 \%) & $\begin{array}{l}7.9 \mathrm{ml} \mathrm{H}_{2} \mathrm{O} \\
6.7 \mathrm{ml} \text { Polyacrylamide (30 \%) } \\
5 \mathrm{ml} \text { Tris/SDS (pH 8.8) } \\
200 \mu \mathrm{l} \text { APS } \\
20 \mu \mathrm{l} \text { TEMED }\end{array}$ \\
\hline SDS-PAGE - SDS stacking gel & $\begin{array}{l}2.185 \mathrm{ml} \mathrm{H} \mathrm{O}_{2} \\
0.375 \mathrm{ml} \text { Polyacrylamide (30 \%) } \\
0.38 \mathrm{ml} \text { Tris/SDS (pH 6.8) }\end{array}$ \\
\hline
\end{tabular}




\begin{tabular}{|c|c|}
\hline Buffer/Solution & Preparation \\
\hline & $\begin{array}{l}30 \mu \mathrm{APS} \\
3 \mu \mathrm{l} \text { TEMED }\end{array}$ \\
\hline SDS-PAGE - Tris/SDS (pH 6.8) $4 x$ & $\begin{array}{l}499 \text { mM Tris } \\
139 \text { mM SDS } \\
\text { pH } 6.8\end{array}$ \\
\hline SDS-PAGE - Tris/SDS (pH 8.8) $4 x$ & $\begin{array}{l}1.5 \mathrm{M} \text { Tris } \\
13.9 \mathrm{mM} \text { SDS } \\
\mathrm{pH} 8.8\end{array}$ \\
\hline SE buffer & $\begin{array}{l}21,95 \text { g } 75 \mathrm{mM} \mathrm{NaCl} \\
5 \mathrm{ml} 0.5 \mathrm{M} \mathrm{EDTA} \\
\text { fill-up to } 500 \mathrm{ml} \text { with } \mathrm{H}_{2} \mathrm{O}\end{array}$ \\
\hline Silica milk (100 mg/ml) & $\begin{array}{l}0.1 \mathrm{~g} / \mathrm{ml} \text { Silica in PBS } \\
\text { incubation for } 2 \mathrm{~h} \text {, centrifuge, take } \\
\text { supernatant }(2 \mathrm{x}) \text { and adjust with } 3 \mathrm{M} \\
\mathrm{NaJ}\end{array}$ \\
\hline TBE Agarose gel (1 \%) & $\begin{array}{l}1 \times \mathrm{TBE} \\
1 \% \text { Agarose } \\
0.5 \mu \mathrm{g} / \mathrm{ml} \text { Ethidium bromide }\end{array}$ \\
\hline TBE buffer $(10 \mathrm{x})$ & $\begin{array}{l}1 \mathrm{M} \text { Tris } \\
0.8 \mathrm{M} \text { boric acid } \\
10 \mathrm{mM} \text { EDTA } \\
\mathrm{pH} 8.0\end{array}$ \\
\hline TE buffer & $1 \mathrm{ml} 1 \mathrm{M}$ Tris \\
\hline
\end{tabular}




\begin{tabular}{l|l}
\hline Buffer/Solution & Preparation \\
\hline & $\begin{array}{l}0.2 \mathrm{ml} 0.5 \mathrm{M} \text { EDTA } \\
\text { fill-up to } 100 \mathrm{ml} \text { with } \mathrm{H}_{2} \mathrm{O} \\
\text { adjust } \mathrm{pH} \text { to } 7.4\end{array}$ \\
Trypan blue solution & $\begin{array}{l}1 \times \mathrm{PBS} \\
0.5 \% \text { Trypan blue }\end{array}$ \\
\end{tabular}

\subsubsection{Media}

All media except DMEM and RPMI were autoclaved and sterile antibiotics were added afterwards.

\begin{tabular}{|c|c|}
\hline Medium & Preparation \\
\hline DMEM $(10,15$ or 20$)$ & $\begin{array}{l}1 \times \text { DMEM (High Glucose) } \\
10,15 \text { or } 20 \% \text { heat inactivated FCS } \\
\left.\text { Gold ( } 45 \text { min at } 56^{\circ} \mathrm{C}\right) \\
1 \% \text { Penicillin/Streptomycin }\end{array}$ \\
\hline RPMI & $\begin{array}{l}1 \times \mathrm{RPMI} \\
10 \% \text { heat inactivated FCS Gold ( } 45 \mathrm{~min} \\
\text { at } 56^{\circ} \mathrm{C} \text { ) } \\
1 \% \text { Penicillin/Streptomycin }\end{array}$ \\
\hline LB medium & $\begin{array}{l}10 \mathrm{mg} / \mathrm{ml} \text { Tryptone } \\
5 \mathrm{mg} / \mathrm{ml} \text { Yeast extract } \\
10 \mathrm{mg} / \mathrm{ml} \mathrm{NaCl}\end{array}$ \\
\hline LB-Amp Agar with IPTG and X-Gal & $\begin{array}{l}\text { LB medium } \\
15 \mathrm{mg} / \mathrm{ml} \text { Agar-Agar } \\
0.05 \mathrm{mg} / \mathrm{ml} \text { Ampicillin }\end{array}$ \\
\hline
\end{tabular}




\begin{tabular}{|c|c|}
\hline Medium & Preparation \\
\hline & $\begin{array}{l}0.2 \% \text { X-Gal (2 \% in Dimethylformamid) } \\
0.024 \mathrm{mg} / \mathrm{ml} \mathrm{IPTG}\end{array}$ \\
\hline LB-Amp medium & $\begin{array}{l}\text { LB medium } \\
0.05 \mathrm{mg} / \mathrm{ml} \text { Ampicillin }\end{array}$ \\
\hline LB-Kan medium & $\begin{array}{l}\text { LB medium } \\
0.1 \mathrm{mg} / \mathrm{ml} \text { Kanamycin }\end{array}$ \\
\hline LB-Kan Agar & $\begin{array}{l}\text { LB medium } \\
15 \text { mg/ml Agar-Agar } \\
0.1 \mathrm{mg} / \mathrm{ml} \text { Kanamycin }\end{array}$ \\
\hline SOC media & $\begin{array}{l}20 \mathrm{ml} / \mathrm{mg} \text { Tryptone } \\
5 \mathrm{mg} / \mathrm{ml} \text { Yeast extract } \\
10 \mathrm{mM} \mathrm{NaCl} \\
2.5 \mathrm{KCl} \\
10 \mathrm{mM} \mathrm{MgCl} \\
20 \mathrm{mM} \mathrm{Glucose}\end{array}$ \\
\hline
\end{tabular}

\subsubsection{Kits}

\begin{tabular}{l|l}
\hline Kit & Manufacturer \\
\hline BigDye Terminator ${ }^{\circledR}$ V1.1 CycleSequencing Kit & Applied Biosystems \\
pGEM-T Easy Cloning kit & Promega \\
QIAquick ${ }^{\circledR}$ Plasmid Midi / Maxi Kit & Qiagen \\
ClonaCell ${ }^{\circledR}$-HY Hybridoma Kit & Stem Cell Technologies \\
Pierce Rapid ELISA Mouse mAb Isotyping Kit & Thermo Scientific \\
DyLight Antibody Labeling Kit (for Dylight 488, & Thermo Scientific
\end{tabular}




\begin{tabular}{l|l}
\hline Kit & Manufacturer \\
\hline 633 and 405 &
\end{tabular}

\subsubsection{Antibodies}

\begin{tabular}{|c|c|c|c|}
\hline Name & Clone & Application & Manufacturer \\
\hline Alexa Fluor ${ }^{\oplus 700}$ Mouse Anti-Human CD3 & SP34-2 & Flow cytometry & $\mathrm{BD}$ \\
\hline V450 Mouse Anti-Human CD4 & L200 & Flow cytometry & $\mathrm{BD}$ \\
\hline V500 Mouse Anti-Human CD8 & RPA-T8 & Flow cytometry & $\mathrm{BD}$ \\
\hline APC Mouse Anti-Human CD11c & B-ly6 & Flow cytometry & $\mathrm{BD}$ \\
\hline PerCP-Cy5.5 Mouse Anti-Human CD14 & M5E2 & Flow cytometry & $\mathrm{BD}$ \\
\hline APC-Cy ${ }^{\mathrm{TM}} 7$ Mouse Anti-Human CD16 & $3 G 8$ & Flow cytometry & $\mathrm{BD}$ \\
\hline PE-Cy7 Mouse Anti-Human CD20 & L27 & Flow cytometry & $\mathrm{BD}$ \\
\hline FITC Mouse Anti-Human CD56 & NCAM16.2 & Flow cytometry & $\mathrm{BD}$ \\
\hline PE Mouse Anti-Human CD159a & Z199 & Flow cytometry & Beckman Coulter \\
\hline FITC-Mouse Anti-Human $\gamma \delta$ TCR & SA6.E9 & Flow cytometry & Invitrogen \\
\hline PE-Cy5 Goat Anti-Mouse IgG, F(ab' $)_{2}$ & & Flow cytometry & Santa Cruz \\
\hline Rabbit Anti-Human IgG HRP & & Immunoblot & Dako \\
\hline Goat Anti-Mouse IgG HRP & & Immunoblot & Santa Cruz \\
\hline Peroxidase Anti-Mouse IgG & & ELISA & Dianova \\
\hline
\end{tabular}

\subsubsection{Oligonucleotides}

\begin{tabular}{l|l}
\hline Name & Sequence $\left(\mathbf{5}^{\prime}\right.$-> $\left.\mathbf{3}^{\prime}\right)$ \\
\hline G23 & GTTTTCCCAGTCACGAC \\
G24 & GGATAACAATTTCACACAGG \\
pFUSE-IgG1-Fc2 fw & GCGCCTACCTGAGATCACC \\
pFUSE-IgG1-Fc1 rev & GGGAAGAGGAAGACTGACG \\
KIR pFUSE2 fw & GGTGAATTCGCACACGGGTGGTCAGGAC \\
KIR inh pFUSE2 rev & GGTGAATTCGAATGCAGGTGTCTGGGGATAC \\
KIR akt pFUSE2 rev & GGTGAATTCACAGGCAGGTGTCTGGTGATAC \\
KIR bes akt pFUSE2 rev & GGTGAATTCACAGGTACCTGGAGG
\end{tabular}




\begin{tabular}{l|l}
\hline Name & Sequence $\left(\mathbf{5}^{\prime} \boldsymbol{~} \boldsymbol{\prime}^{\mathbf{3}} \mathbf{)}\right.$ \\
\hline KIR2 AcGFP fw & GATGAATTCAGCACCATGTCGCTCATGG \\
KIR2 AcGFP rev & GGTGGATCCGGATAGAAGACAACTTTCGATC \\
KIR9 AcGFP fw & GATGAATTCAGCACCATGTCGCTCATAG \\
KIR9 AcGFP rev & GGTGGATCCAGTCTCTTTTTGTCGG \\
KIR23 AcGFP rev & CCAGGATCCCGCTGTTCTGTCCCCACAGG \\
pAcGFP fw & CAAATGGGCGGTAGGCGTG \\
pAcGFP rev & GTGGCCATTCACATCGCCAT
\end{tabular}

\subsubsection{Software and Databases}

Software

4 Peaks (mekentosj.com)

FlowJo 8.8.7 (Tree Star Inc.)

BD FACSDiva (BD Bioscience)

Microsoft Word (Microsoft Office 2008)

Microsoft Excel (Microsoft Office 2008)

MEGA 5.0 (Tamura et al., 2011)

ClustalX (Thompson et al., 1997)

\section{Generation of a phylogenetic tree}

Amino acid sequences were aligned with Clustal $\mathrm{X}$ and a phylogenetic tree was reconstructed with the neighbor joining method using JTT model, provided by the software package MEGA 5.0, with 1000 bootstrap replications.

Database

NCBI $\quad$ http://www.ncbi.nlm.nih.gov/

\section{Online programme}

Reverse complement

Translate tool http://www.bioinformatics.org/sms/rev_comp.html http://web.expasy.org/translate/ 


\subsection{Methods}

\subsubsection{Molecular Genetic Techniques}

\subsubsection{Polymerase chain reaction}

For the amplification of specific DNA fragments hot-start PCR was performed. To avoid amplification artefacts template and polymerase were separated from oligonucleotides and dNTPs by a wax layer, which melted when reaching the denaturation temperature. The PCR reaction was set up as follows:

\begin{tabular}{|c|c|c|}
\hline & $\begin{array}{l}1 \mu \mathrm{l} \\
0.2 \mu \mathrm{l} \\
1 \mu \mathrm{l} \\
1 \mu \mathrm{l} \\
6.8 \mu \mathrm{l}\end{array}$ & $\begin{array}{l}\text { BioTherm }{ }^{\mathrm{TM}} 10 \times \text { reaction buffer } \\
\text { dNTP-Mix ( } 25 \mathrm{mM} \text { each) } \\
\text { forward primer } \\
\text { reverse primer } \\
\mathrm{HPLC}-\mathrm{H}_{2} \mathrm{O}\end{array}$ \\
\hline & $\begin{array}{l}2 \mu \mathrm{l} \\
4 \mu \mathrm{l} \\
0.2 \mu \mathrm{l} \\
\text { ad. } 20 \mu \mathrm{l}\end{array}$ & $\begin{array}{l}\text { BioTherm }{ }^{\mathrm{TM}} 10 \text { x reaction buffer } \\
\text { BSA/Triton-X } 100 \text { buffer } \\
\text { BioTherm }{ }^{\mathrm{TM}} \text { Taq-DNA-Polymerase }(5 \mathrm{U} / \mu \mathrm{l}) \\
\text { DNA solution / HPLC- } \mathrm{H}_{2} \mathrm{O}\end{array}$ \\
\hline
\end{tabular}

Mixture 1 had to be covered with wax before mixture 2 was added.

The PCR started with an initial denaturation step at $94^{\circ} \mathrm{C}$ for $3 \mathrm{~min}$, followed by 30 cycles of denaturation at $94^{\circ} \mathrm{C}$ for $30 \mathrm{~s}$, annealing at the primer specific temperature for $45 \mathrm{~s}$ and elongation for $90 \mathrm{~s}$ at $72^{\circ} \mathrm{C}$. The reaction was finished by a final elongation step at $72^{\circ} \mathrm{C}$ for $5 \mathrm{~min}$.

\subsubsection{Sequencing analysis}

Sequencing of DNA was performed using the BigDye®Terminator v1.1 Cycle Sequencing Kit. For the sequencing reaction 200-300 ng of plasmid DNA was used. In a final volume of $10 \mu \mathrm{l}, 1 \mu \mathrm{l}$ of an appropriate primer (3.3 pmol), $1.5 \mu \mathrm{l} 5 \mathrm{x}$ sequencing buffer and $1 \mu \mathrm{l}$ BigDye were added in addition to the DNA. The sequencing reaction was performed for 25 cycles each, with $30 \mathrm{~s}$ at $95^{\circ} \mathrm{C}$ (denaturation,) $15 \mathrm{~s}$ at $50^{\circ} \mathrm{C}$ (annealing) and $4 \mathrm{~min}$ at $60{ }^{\circ} \mathrm{C}$ (elongation). Afterwards, the DNA was precipitated by adding $90 \mu \mathrm{l}$ $\mathrm{H}_{2} \mathrm{O}, 250 \mu \mathrm{l}$ ethanol (99 \%) and $10 \mu \mathrm{l} 3 \mathrm{M}$ sodium acetate followed by centrifugation $(16,000 \times \mathrm{g}, \mathrm{RT}, 15 \mathrm{~min})$. The DNA pellet was washed by adding $250 \mu \mathrm{l} 70 \%$ Ethanol 
and centrifugation $(16,000 \mathrm{x}$, RT, $5 \mathrm{~min})$. After drying the pellet in a speed vac it was resolved in $10 \mu \mathrm{l} \mathrm{Hi}^{-\mathrm{Di}^{\mathrm{TM}}}$ formamide and analysed with the $\mathrm{ABI} 3130 \mathrm{xl}$ sequencer. Sequence analysis was performed with 4 Peaks.

\subsubsection{Separation of DNA fragments}

For the separation of DNA fragments by size the DNA samples were run in a $1 \%$ agarose gel alongside a 100 bp DNA ladder under constant voltage conditions (60$120 \mathrm{~V}$ ). The DNA fragments were visualised using ultraviolet light.

\subsubsection{DNA Extraction from agarose gels}

Following the electrophoretic separation, DNA fragments of interest were cut from the gel and incubated in $300 \mu \mathrm{l} 6 \mathrm{M}$ sodium iodide $\left(800 \mathrm{rpm}, 55^{\circ} \mathrm{C}, 10 \mathrm{~min}\right) .10 \mu \mathrm{l}$ of silica milk was added and the incubation $\left(800 \mathrm{rpm}, 55^{\circ} \mathrm{C}, 10 \mathrm{~min}\right)$ was followed by centrifugation $(16,000 \mathrm{x}$ g, $1 \mathrm{~min}, \mathrm{RT})$. After washing the pellet with $250 \mu \mathrm{l} 70 \%$ ethanol (16,000 x g, 1 min, RT) it was dried and solved in 15-30 $\mu$ l HPLC- $\mathrm{H}_{2} \mathrm{O}(10 \mathrm{~min}$, $55{ }^{\circ} \mathrm{C}$ ). Using a final centrifugation step (16 $000 \mathrm{x} \mathrm{g}, 1 \mathrm{~min}, \mathrm{RT}$ ) the supernatant containing the DNA was collected.

\subsubsection{Quantification of DNA concentrations}

DNA concentrations were either determined by using a spectrophotometer or by performing gel electrophoresis including the control plasmid pUC19 with defined concentration $(50 \mathrm{ng} / \mu \mathrm{l})$. In the latter method the DNA concentration is determined by comparing the intensity of the control with the sample DNA.

\subsubsection{Cloning of PCR products}

The pGEM-T Easy cloning Kit was used for cloning of PCR products according to the manufacturer's instructions. 


\subsubsection{DNA restriction by endonucleases}

For the digestion of DNA, restriction enzymes were used with their appropriate buffers and BSA was added according to the manufacturer's recommendation. The volume of the reaction was dependent on the amount of DNA that had to be digested. The reaction was performed following the protocols provided.

\subsubsection{Ligation of restricted DNA fragments}

For the insertion of DNA fragments into an expression vector, 200-300 ng of digested DNA fragments and 50-100 ng of linearised expression vector were mixed with $2 \mu \mathrm{l}$ $10 \mathrm{x}$ T4-DNA-ligase buffer and $0.2 \mu \mathrm{l}$ T4-DNA-ligase and brought to a final volume of $20 \mu \mathrm{l}$ by adding $\mathrm{HPLC}-\mathrm{H}_{2} \mathrm{O}$. The reaction was incubated over night at $16^{\circ} \mathrm{C}$.

\subsubsection{Transformation of prokaryotic cells}

For the transformation of electrocompetent cells $50 \mu \mathrm{l}$ of E.coli TOP10 cells were thawed on ice. Two $\mu \mathrm{l}$ of ligation reaction was added and the mixture was transferred to a pre-cooled cuvette. The electroporation conditions were $1.6 \mathrm{kV}, 25 \mu \mathrm{F}$ and $200 \Omega$. $800 \mu \mathrm{l} \mathrm{SOC}$ media was added and after incubation for $1 \mathrm{~h}$ at $37^{\circ} \mathrm{C}$ and shaking, 50 $200 \mu \mathrm{l}$ cell suspension was plated on agar plates with the corresponding antibiotic and incubated over night.

The transformation with chemically competent cells was performed with $50 \mu \mathrm{l}$ E.coli DH5 $\alpha$ cells as recommended by the manufacturer.

\subsubsection{Mini preparation of plasmid DNA}

Over-night cultured bacteria $\left(37^{\circ} \mathrm{C}, 240 \mathrm{rpm}\right)$ were centrifuged $(16,000 \mathrm{x} \mathrm{g}, 30 \mathrm{~s}, \mathrm{RT})$ and the pellets were resuspended in $150 \mu \mathrm{l}$ solution 1. A 5 min incubation (RT) after adding $150 \mu \mathrm{l}$ solution 2 was followed by the addition of $150 \mu \mathrm{l}$ solution 3 and two centrifugation steps (16 $000 \mathrm{xg}, 10 \mathrm{~min}, \mathrm{RT}$ ). The supernatant was transferred in a new cup for each time and plasmid DNA was precipitated by adding one volume of isopropanol $(16,000 \mathrm{x} \mathrm{g}, 15 \mathrm{~min}, \mathrm{RT})$ followed by washing with $300 \mu \mathrm{l} 70 \%$ ethanol 
$(16,000 \mathrm{x} g, 15 \mathrm{~min}, \mathrm{RT})$. After drying the pellet using a speed vac the plasmid DNA was dissolved in HPLC- $\mathrm{H}_{2} \mathrm{O}$.

\subsubsection{Midi preparation of plasmid DNA}

For the purification of larger quantities of DNA the QIAquick Plasmid Kit was used according to the manufacturer's recommendations.

\subsubsection{DNA extraction from blood}

For the extraction of DNA, EDTA blood samples were incubated with erythrocyte lysis buffer for around $15 \mathrm{~min}$ and centrifuged for $10 \mathrm{~min}\left(7^{\circ} \mathrm{C}, 200 \mathrm{x}\right.$ g). After washing the pellet with lysis buffer it was incubated with $5 \mathrm{ml} \mathrm{SE}$ buffer, $250 \mu \mathrm{l} 20 \%$ SDS and $20 \mu \mathrm{l}$ Pronase E over night $\left(140 \mathrm{rpm}, 37^{\circ} \mathrm{C}\right)$. After adding $2 \mathrm{ml} 5 \mathrm{M} \mathrm{NaCl}$ the reaction was centrifuged (10 min, 1,300 x g) and the DNA was precipitated from the supernatant by adding 2-2.5 times the volume of $99 \%$ ethanol, washed with $70 \%$ ethanol and solved in TE buffer.

\subsubsection{RNA extraction from blood}

The RNA was extracted from purified PBMC (2.2.2.2) that were resuspended in TRIzol®. After efficient mixing, chloroform was added followed by 15 min centrifugation $\left(16,000 \times \mathrm{g}, 4^{\circ} \mathrm{C}\right)$. The RNA was precipitated by adding isopropanol (30 min, 16,000 x g, $4^{\circ} \mathrm{C}$ ) and washed with $70 \%$ ethanol. After drying, the RNA was dissolved in RNase free water.

\subsubsection{Reverse transcription of RNA}

The reverse transcription of mRNA to cDNA was performed using 1-2.5 $\mu \mathrm{g}$ RNA that was first incubated with $0.5 \mu \mathrm{g}$ oligo(dT)-primer in a volume of $15 \mu \mathrm{l}$ for $5 \mathrm{~min}$ at $70^{\circ} \mathrm{C}$. Afterwards, $5 \mu \mathrm{l}$ M-MLV $5 \mathrm{x}$ buffer, $0.5 \mu \mathrm{l}$ dNTP mix, $0.7 \mu \mathrm{l}$ RNase inhibitor and $1 \mu \mathrm{M}$ MLV reverse transcriptase was added and filled to a volume of $25 \mu \mathrm{l}$ with RNase free water. The reaction was incubated for $1 \mathrm{~h}$ at $42^{\circ} \mathrm{C}$ and heat inactivated for $15 \mathrm{~min}$ at $70^{\circ} \mathrm{C}$. 


\subsubsection{Tissue Culture Techniques}

\subsubsection{Transfection of eukaryotic cells}

HEK293 cells were transfected with plasmid DNA using metafectene for lipofection. Exponentially growing cells were seeded into a 6-well plate the day before transfection. The used DNA/metafectene ratio was 1:4. Plasmid DNA and metafectene were diluted in serum-free media each, mixed carefully and incubated for $15 \mathrm{~min}$ at RT before dropping it slowly to the cells. After $48 \mathrm{~h}$ the cells were stained for flow cytometry.

\subsubsection{PBMC isolation from whole blood}

PBMCs were isolated from heparinised blood using a ficoll density gradient. The blood was diluted 1:1 with RPMI medium and $30 \mathrm{ml}$ were transferred to a Leucosep® tube containing $15 \mathrm{ml}$ ficoll. PBMC were separated from erythrocytes and thrombocytes with centrifugation (human: $20 \mathrm{~min}$, rhesus macaque: $40 \mathrm{~min}, 800 \mathrm{xg}$ ). The PBMC layer was transferred to another tube and washed with RPMI (200 x g, $10 \mathrm{~min}$ ) before counting the cells.

\subsubsection{Quantification of viable cells}

To determine the viable cell number of PBMC a Casy® Cell Counter was used according to the manufacturer's information. For cell lines, the cells were mixed 1:1 with trypan blue solution and counted using a hemocytometer.

\subsubsection{Cryopreservation}

The cells were spun down (200 x g, $10 \mathrm{~min}$ ) and resuspended in freezing medium. A cryo container containing isopropanol was used to provide the critical slow cooling rate. The cells were transferred to liquid nitrogen.

\subsubsection{Antibody staining of HEK293 cells for flow cytometry}

Supernatants of anti-KIR antibody secreting hybridomas were used for staining of KIRAcGFP expressing HEK293 cells. Cells $\left(2 \times 10^{5}\right)$ were incubated for 30 min at $4{ }^{\circ} \mathrm{C}$ with 
$50 \mu \mathrm{L}$ of supernatant and binding was detected with goat anti-mouse IgG-PE-Cy5 polyclonal antibody that was added after washing with PBS (200 x g, $5 \mathrm{~min}$ ). At least 10,000 KIR-AcGFP positive cells were recorded using a flow cytometer (LSR II) and analysed using FlowJo 8.8.7 software.

\subsubsection{Antibody staining of PBMC for flow cytometry}

Different leukocyte markers were used for the staining of PBMC and analysis of KIR expression of different cell populations. For each sample 1-2 × $10^{6}$ cells were stained as shown in Table 2 and different anti-macaque KIR antibodies were used. The PBMC samples were incubated with the according antibody mixture for $30 \mathrm{~min}$ at $4{ }^{\circ} \mathrm{C}$, fixed with $3.5 \%$ formaldehyde in FACS-buffer for $10 \mathrm{~min}$ at RT and centrifuged for $5 \mathrm{~min}$ (200 x g). The cell pellets were resuspended in $50 \mu$ FACS-buffer, measured on a LSR II and further analysed using FlowJo 8.8.7 software.

Table 2. Gating strategy for multi-colour flow cytometry

\begin{tabular}{|llll} 
& KIR - NK cell I & KIR - NK cell II & KIR - T cell \\
\hline FITC & - & CD56 & TCR g/d \\
\hline PE & CD159a & CD159a & CD159a \\
PerCP-Cy5.5 & CD14 & CD14 & CD14 \\
PE-Cy7 & CD20 & CD20 & CD20 \\
\hline APC & - & - & - \\
\hline Alexa700 & CD3 & CD3 & CD3 \\
APC-Cy7 & CD16 & CD16 & CD16 \\
Alexa450 & - & - & CD4 \\
\hline V500 & CD8 & CD8 & CD8 \\
\hline
\end{tabular}

\subsubsection{Biochemical Techniques}

\subsubsection{SDS-PAGE}

For the separation of proteins in a SDS gel the samples were mixed with 1 volume of Laemmli buffer and 1 volume DTT and incubated for $5 \mathrm{~min}$ at $95^{\circ} \mathrm{C}$. Then, the samples were transferred to a $10 \%$ SDS gel and run under reducing conditions for about $1 \mathrm{~h}$ at $30 \mathrm{~mA}$. 


\subsubsection{Immunoblot}

Following the separation of protein samples in a SDS gel the proteins were transferred to a nitrocellulose membrane by tank blotting for $1 \mathrm{~h}$. Afterwards, the membrane was blocked with $5 \%$ milk powder dissolved in TBS for about $1 \mathrm{~h}$, washed three times with TBS followed by the addition of antibody over night. After three washing steps the membrane was incubated with a second antibody for $1 \mathrm{~h}$ and washed again with TBS five times. The membrane was developed by mixing the two developing solutions 1:1 followed by the incubation of the membrane for $1 \mathrm{~min}$. The membrane was exposed to a Hyperfilm for varying time periods depending on the intensity of the detected signal. The film was developed using a film processor.

\subsubsection{Protein purification}

The supernatant of either KIR-Fc fusion protein expressing HEK293 cells or antibody producing hybridoma cells that were both grown in serum-free ultraCHO medium for three days was collected, centrifuged (10 min, $200 \mathrm{x} \mathrm{g}$ ) and filtered $(0.45 \mu \mathrm{m})$ before purifying it using a protein G sepharose column. The column was equilibrated with $5 \mathrm{ml}$ distilled $\mathrm{H}_{2} \mathrm{O}$ followed by $3 \mathrm{ml}$ of binding buffer. Afterwards, the supernatant was passed through the column, eluted with $8 \mathrm{ml}$ elution buffer and the $\mathrm{pH}$ of the eluate was neutralised with $75 \mu \mathrm{l}$ per ml neutralising buffer. For further applications the eluate was concentrated using Amicon Ultra-30 centrifugal filter units.

\subsubsection{Quantification of protein concentrations}

The protein concentration was measured using a spectrophotometer according to the manufacturer's recommendation.

\subsubsection{Enzyme-linked immunosorbent assay (ELISA)}

ELISA plates were coated over night at $4{ }^{\circ} \mathrm{C}$ with $0.5 \mu \mathrm{g}$ of antigen diluted in $100 \mu \mathrm{l}$ of coating buffer. After washing three times with PBS the plate was blocked with $4 \%$ milk powder in PBS for $1 \mathrm{~h}$ at room temperature. Subsequently, the plate was washed for three times with PBS before the incubation with the first antibody for $1 \mathrm{~h}$ at $4{ }^{\circ} \mathrm{C}$. As 
negative control only PBS was added. The plate was washed three times with PBS and incubated with the second HRP-conjugated antibody. After at least three times of washing the substrate reaction was added and incubated for around 10 min before being read at OD $405 \mathrm{~nm}$ in the ELISA reader.

\subsubsection{Immunisation of mice with antigen}

$\mathrm{C} 3 \mathrm{H} / \mathrm{HeN}$ or C57BL/6 mice were immunised with $100 \mu \mathrm{g}$ KIR-Fc protein as antigen. The first immunisation was performed using Titermax Gold (Sigma) by subcutaneous injection followed by two intra-peritoneal injections and a final boost by intravenous injection only using the antigen. Blood samples were collected before the first and after the third injection.

\subsubsection{Fusion of cells}

X63Ag8.653 mouse myeloma cells were used and fused to isolated mouse spleen cells that were prepared by Prof. Dr. Ralf Dressel (University of Göttingen). Generation, selection and cloning of hybridoma cells were performed using the ClonaCell-HY Hybridoma Kit following the manufacturer's protocol (Figure 5). Antibody-secreting hybridoma significantly binding the coated appropriate antigen and not the coated human IgG using indirect ELISA, were selected and cultured in the presence of DMEM $/ 20 \%$ fetal calf serum $/ 1 \%$ penicillin/streptavidin.

\subsubsection{Antibody labelling}

The purified antibodies were first dialysed against PBS over night at $4{ }^{\circ} \mathrm{C}$ using Slide-ALyzer dialysis units from Thermo Scientific to remove the elution buffer and to create better conditions for the conjugation with a fluorochrome. Afterwards, the labelling of purified and dialysed antibodies was performed using the DyLight Fluor Antibody Labeling Kit according to the manufacturer's recommendation. 


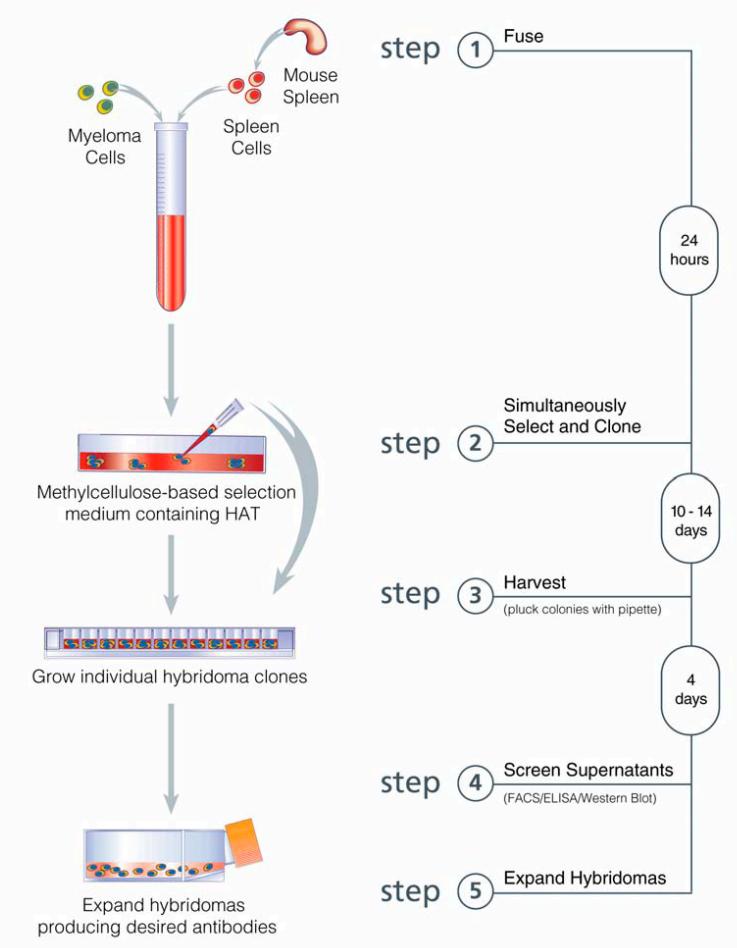

Figure 5. ClonaCell-HY procedure overview.

Step 1: Fusion of spleen cells with X63Ag8.653 mouse myeloma cells. Step 2: Culturing and selection of cells in methylcellulose-based medium containing HAT for around 14 days. Step 3: Harvesting of colonies derived of single cells. Step 4: Screening of hybridoma clones for antigen specificity using ELISA. Step 5: Expansion of selected hybridoma clones for the production of monoclonal antibodies (figure taken from ClonaCell-HY, hybridoma cloning kit technical manual, Stemcell Technologies). 


\section{Results}

\subsection{Characterisation of monoclonal anti-rhesus macaque KIR antibodies}

Monoclonal antibodies are important tools to detect or study the protein expression of certain molecules and to help to purify them. They are used in biochemistry and molecular biology but also in medicine where monoclonal antibodies are applied for therapy. The first and most important step when working with antibodies is their characterisation. The antigen specificity and the methodical application need to be determined. Depending on whether a specific epitope is linear or conformational, certain antibodies are only suitable for specific methods.

Anti-rhesus macaque KIR antibodies were generated by using KIR-Fc fusion proteins to immunise mice and also for the first screening steps of the newly generated hybridoma clones. Supernatants of around 1700 clones were checked for reactivity with the respective KIR protein used for immunisation and with human IgG using ELISA. IgGreactive supernatants were excluded from further analysis. The anti-KIR antibody producing hybridomas were further characterised for their ability to cross-react with other KIR molecules than their specific antigen using ELISA, their applicability in immunoblot analyses, the recognition of KIR molecules expressed by transfected HEK293 cells and finally, the recognised epitope was determined.

\subsubsection{Establishment of anti-rhesus macaque KIR antibodies}

For the generation of monoclonal anti-rhesus macaque KIR antibodies mice were immunised with KIR-Fc fusion proteins (Rosner et al., 2011). Before the final boost with antigen, serum was taken and compared with pre-immunisation serum using ELISA. The ELISA plates were coated either with the appropriate antigen or human IgG to exclude mice only producing antibodies against human IgG, because of the Fc portion, which is part of the fusion protein. All mice used for the generation of antibodies turned out to be reactive against the antigen and after the final 
immunisation the fusion was performed as described (2.2.3.7). Table 3 summarises the fusion details for three different experiments.

Table 3. Fusion conditions.

\begin{tabular}{|l|l|l|l|l|}
\hline Mousestrain & $\begin{array}{l}\text { Antigen used for the } \\
\text { immunisation }\end{array}$ & $\begin{array}{l}\text { Cells from } \\
\text { spleen }\end{array}$ & $\begin{array}{l}\text { Picked } \\
\text { clones }\end{array}$ & KIR Positive Clones \\
\hline C3H/HeN & KIR3DL05*007 & $1.25 \times 10^{8}$ & 720 & 8 \\
\hline C57BL/6 & KIR3DSW08*006 & $5.7 \times 10^{7}$ & 240 & 12 \\
\hline C3H/HeN & KIR3DLW03*004 & $2 \times 10^{8}$ & 750 & 14 \\
\hline
\end{tabular}

After cloning and culturing the hybridoma cells, $50 \mu \mathrm{l}$ of the first supernatant was used for the screening of anti-rhesus macaque KIR antibody-producing hybridoma clones. This was also done using ELISA with the corresponding antigen and human IgG. All clones with human IgG-reactive supernatant were excluded from further analyses. Antiserum and PBS were used as positive and background control, respectively. Clones producing KIR-reactive antibodies, which was defined with an OD threefold above the background, were grown for further characterisations.

\subsubsection{Specificity of anti-rhesus macaque KIR antibodies}

After analysing the reactivity for their respective antigen the hybridoma clones were checked for cross-reactivity with other macaque KIR molecules. ELISA plates were coated with different KIR-Fc fusion proteins and $50 \mu$ of supernatant of every clone was added. Hybridoma clones with different specificities were found. Some antibodies with a low KIR specificity (= broad reactivity), like 1C7, 2C6, $2 \mathrm{E} 11$ and 1C10, bind to every tested KIR-Fc fusion protein in ELISA. Additionally, antibodies with intermediate specificity/reactivity, like $1 \mathrm{H} 4$ and $4 \mathrm{H} 11$ that not only detected their respective antigen used for immunisation but also some other KIR-Fc fusion proteins as well as antibodies with a high KIR specificity like 2F9, 2H5, 2A4, 2H3, 2H9 and 5H11 could be identified (Figure 6). 


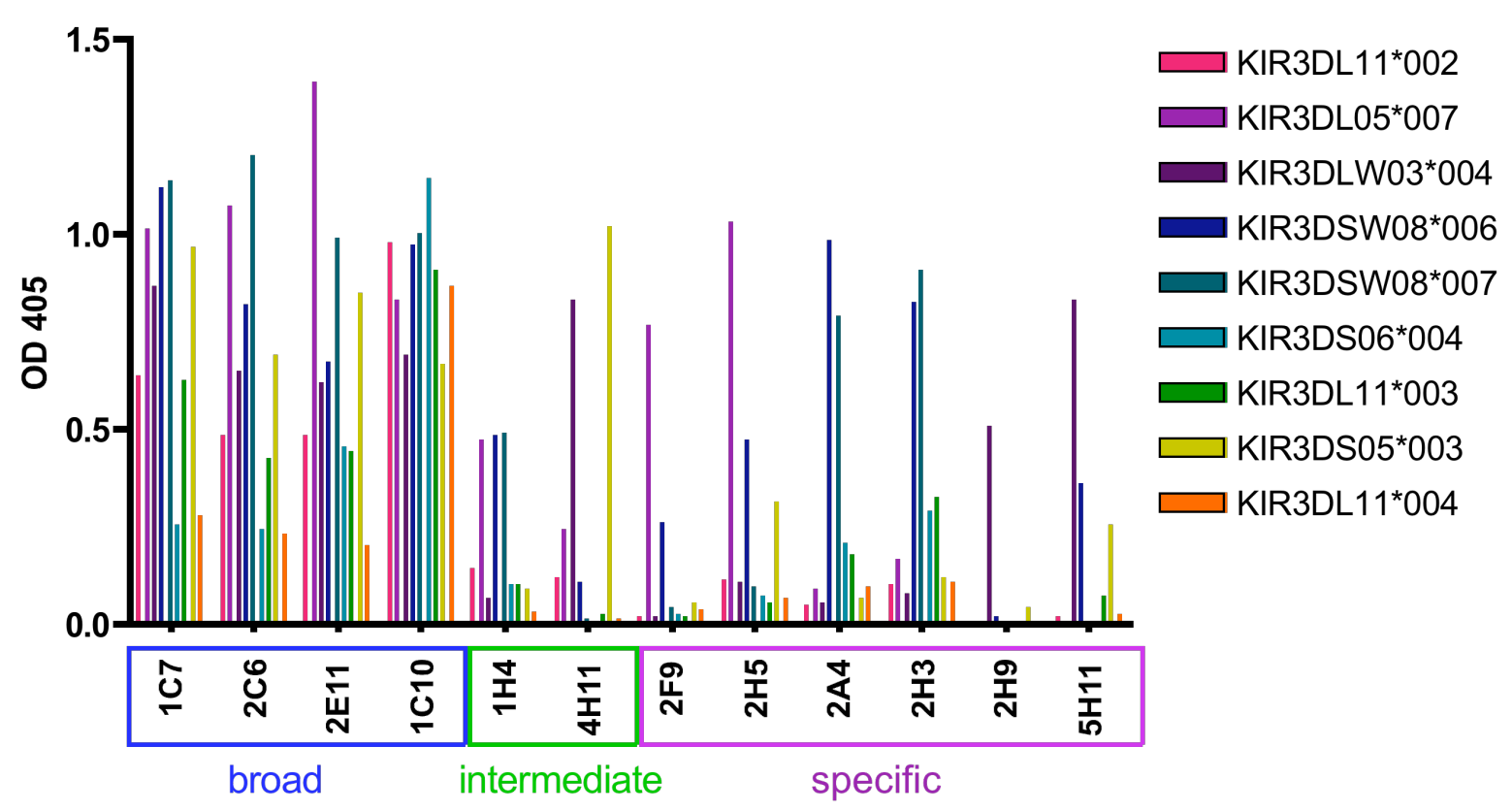

Figure 6. Cross-reactivity of anti-KIR antibodies with rhesus macaque KIR-Fc fusion proteins.

All values were corrected for the background. $50 \mu$ of hybridoma supernatant was used for binding the antigen ( $0.5 \mu \mathrm{g}$ per well) coated to the ELISA plate. The OD was measured at $405 \mathrm{~nm}$. Antibodies with a high reactivity for all tested KIR-Fc fusion proteins could be detected but also antibodies with intermediate or high specificity.

\subsubsection{Cross-reactivity with other species}

The antibodies derived from the hybridoma clones were also analysed for their crossreactivity with KIR-Fc fusion proteins of hominoids (chimpanzee, orangutan and human). Peter Parham, Stanford University, provided these KIR-Fc fusion proteins. Only weak binding of the antibodies to the KIR-Fc fusion proteins could be detected (supplementary Figure 35), suggesting that all these antibodies do not have the optimal capacity to recognise KIR molecules of great apes and human.

\subsubsection{Isotype determination}

The determination of the isotype of each monoclonal antibody was performed with the Rapid ELISA Mouse mAb Isotyping Kit. The isotype had to be analysed to determine the appropriate second antibody for further studies like immunoblot and flow cytometry and also to identify the most appropriate purification method. All tested antibodies that were used for further characterisations had an IgG $\mathrm{I}_{1}$ heavy chain and $\mathrm{a} \kappa$ light chain. 


\subsubsection{Recognition of KIR molecules expressed by HEK293 cells}

ELISA was used for a preselection of hybridoma clones that were then included in further characterisation steps. ELISA was performed with KIR-Fc fusion proteins. These proteins might have small differences in their folding compared to KIR molecules expressed on the surface of eukaryotic cells because of the Fc-part or can be degraded due to storage or buffer environment and different batches of protein might have more or less background. Therefore, ELISA is a good method for the first screening steps and can give a first hint about the specificity of an antibody. As these monoclonal antibodies were generated for the application for multi-colour flow cytometry with PBMC, the preferred method to characterise the specificity of these monoclonal antibodies is to use KIR-expressing eukaryotic cells for flow cytometry analysis.

To analyse the ability of the antibodies for their KIR-binding capacity more precisely, HEK293 cells were transfected with different KIR-AcGFP constructs to express AcGFPtagged KIR molecules on their surface. The KIR-expressing cells were then stained with $50 \mu \mathrm{l}$ of hybridoma supernatant followed by an anti-mouse IgG-PE-Cy5 antibody for detection in flow cytometry. At least 10,000 GFP-positive cells were collected and analysed for binding of the respective antibody (Figure 7).

With all tested supernatants it was possible to stain the specific antigen. Additionally, the results of the ELISA measurements could be confirmed (Figure 8). Antibodies with a broad reactivity for KIR-Fc fusion proteins did also recognise all tested KIR molecules expressed by HEK293 cells. The same correlation was obtained for antibodies with intermediate specificity recognising only some KIR molecules and also for antibodies with high specificity for certain KIRs. The signal obtained with an anti-KIR antibody correlates only weakly with the GFP expression (Pearson $r=0.5031$; data not shown). That means, if there is a strong signal with the antibody it is not only caused by the high density of the expressed KIR, as visualised by the GFP signal, but also by the avidity the antibody has for its antigen. 

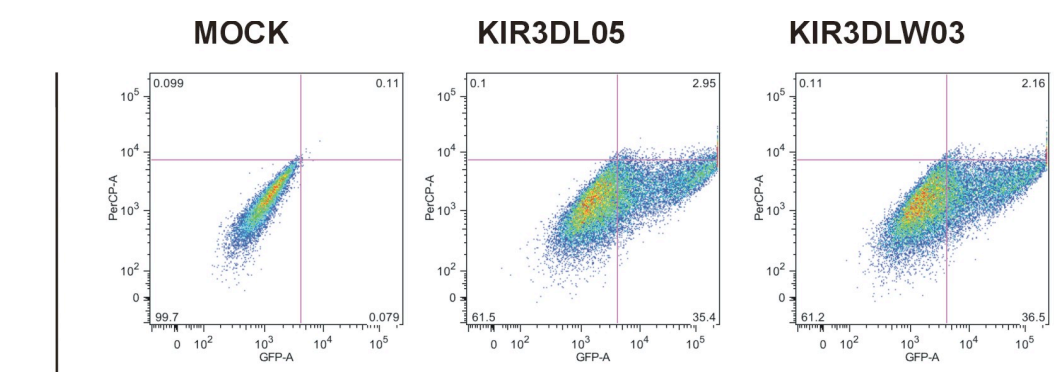

\section{KIR3DSW08}
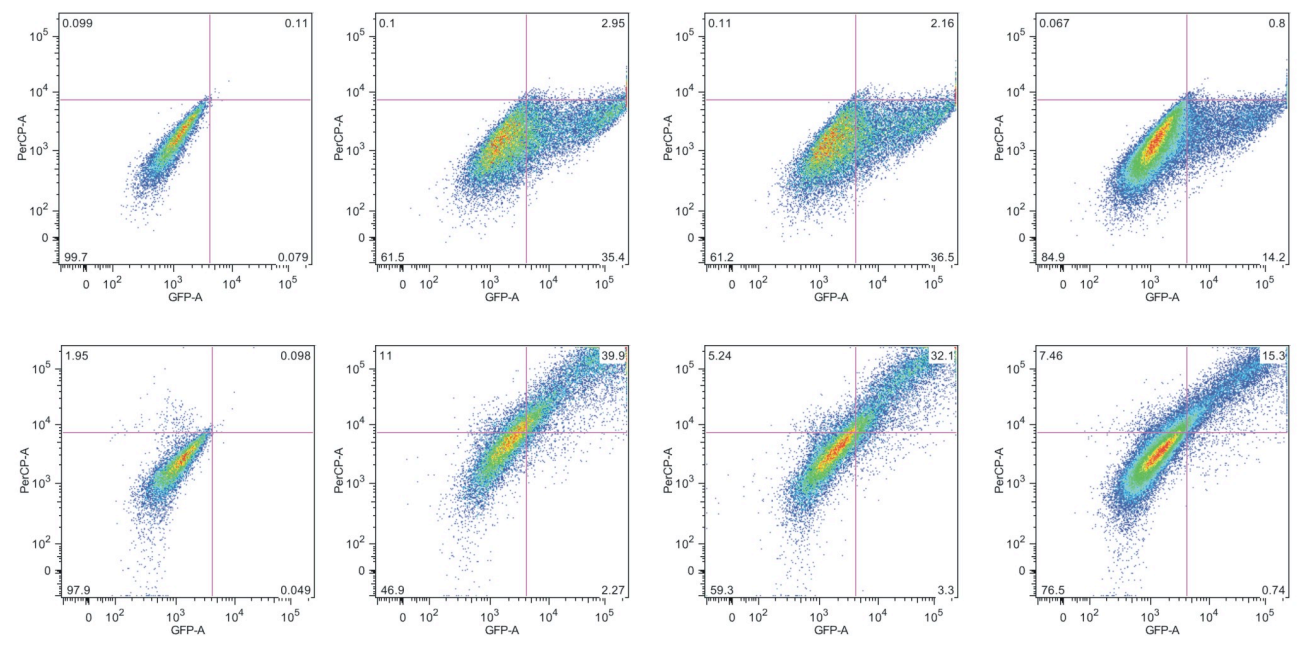

$\frac{N}{2}$
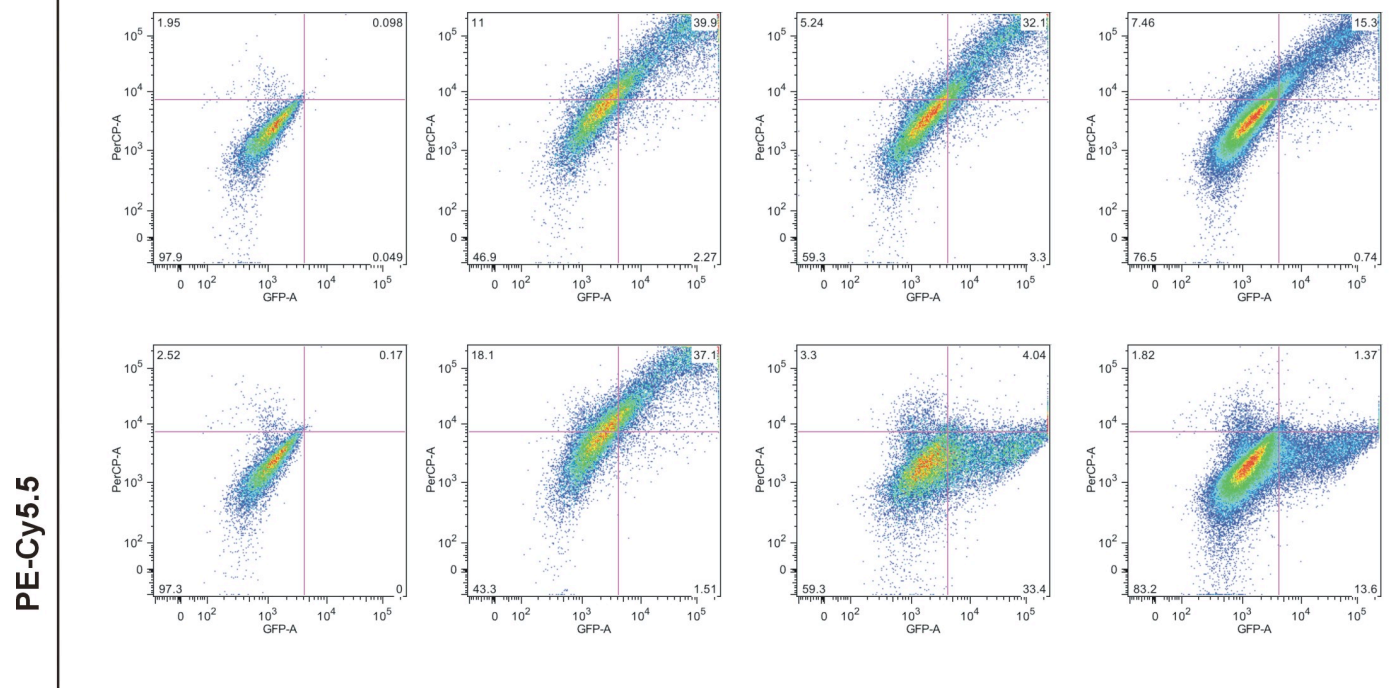

$\vec{\Im}$

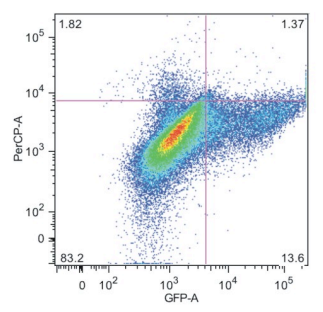

Nㅗㄴ
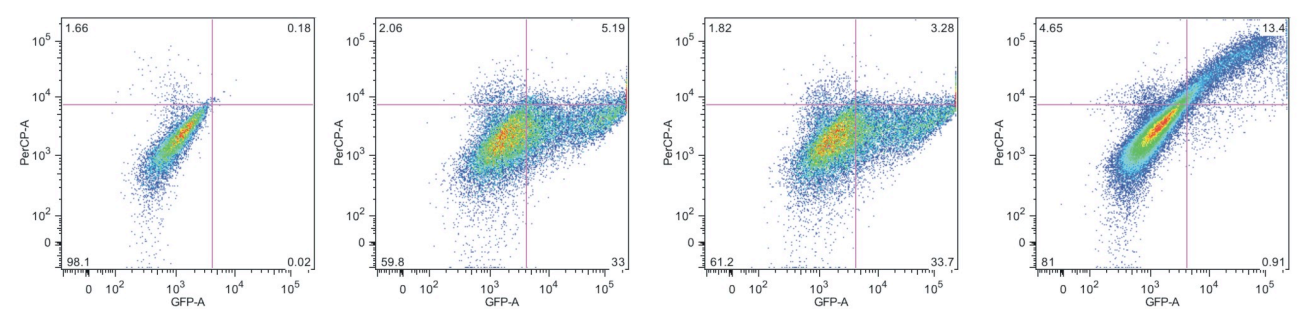

$\frac{N}{\omega}$
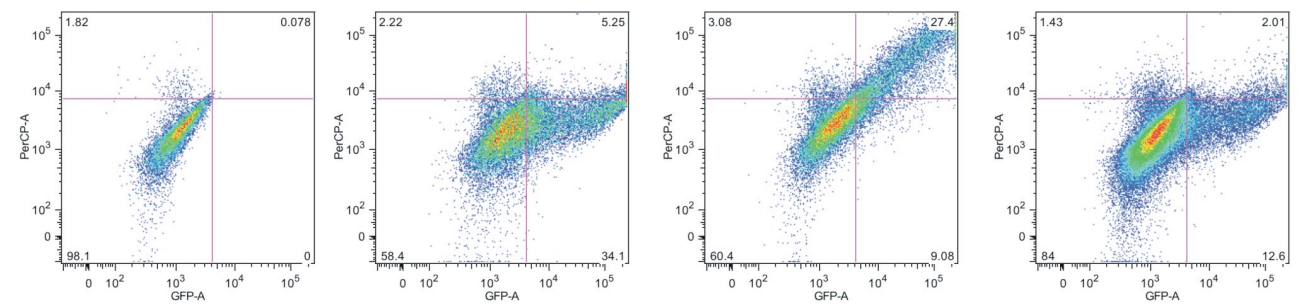

Nㅗㅂ

GFP

Figure 7. Monoclonal anti-rhesus macaque KIR antibodies are able to stain their antigen.

KIR-AcGFP transfected HEK293 cells were used for flow cytometry. Examples of dot plots for 4 different monoclonal antibodies are shown and as control the dot plot for the $2^{\text {nd }}$ antibody. For the staining $50 \mu \mathrm{l}$ of hybridoma supernatant was used. 
a

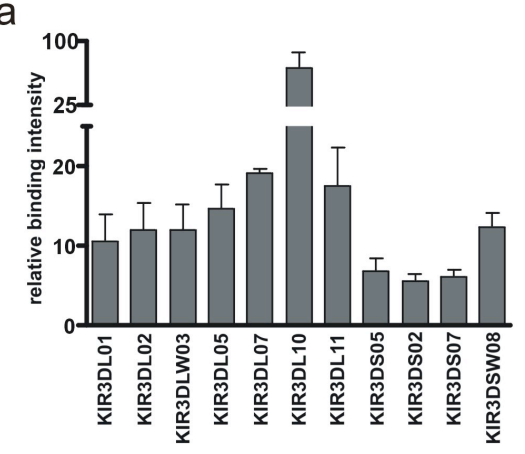

b

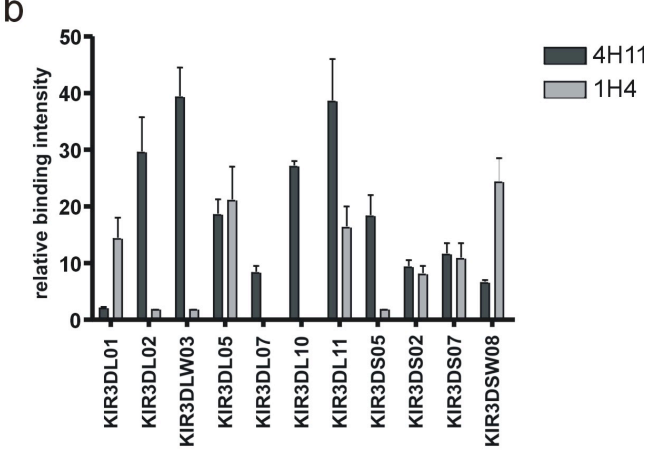

C

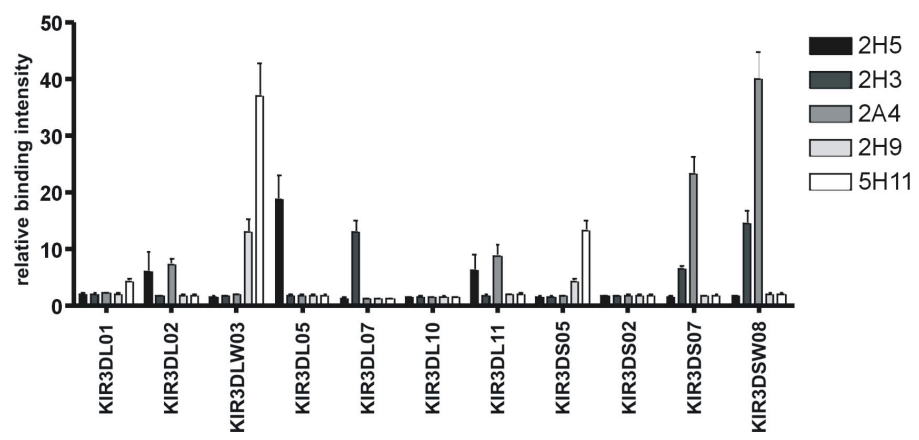

Figure 8. Specificity of mAbs for rhesus macaque KIRs in KIR-AcGFP transfected cells.

The relative binding intensity (median fluorescence intensity of KIR transfectants divided by the median fluorescence intensity of mock transfected HEK293 cells) of three experiments is shown for each antibody and KIR. (a) The monoclonal antibody $1 \mathrm{C} 7$ is recognising every tested KIR. (b) $4 \mathrm{H} 11$ and $1 \mathrm{H} 4$ monoclonal antibodies with intermediate specificity do not detect all KIRs. (c) Antibodies with specificity only for a limited number of KIR. Mean and SEM of at least three experiments are shown.

\subsubsection{Functionality of anti-rhesus macaque KIR antibodies in immunoblot}

The antibodies selected by ELISA and flow cytometry were also analysed for their suitability for immunoblotting. KIR-Fc fusion proteins were separated by SDS-PAGE under reducing conditions, transferred to a membrane and stained with $2 \mathrm{ml}$ of hybridoma supernatant (plus $1 \mathrm{ml}$ PBS i.e. total volume of $3 \mathrm{ml}$ ) followed by an antimouse IgG antibody. All tested supernatants were able to detect their denatured antigen (Figure 9). There was no cross-reactivity detected with human IgG, which was always included as a negative control. Not all KIR-Fc fusion proteins used for ELISA were tested with the antibodies but for those that were tested with the appropriate antigen no cross-reactivity could be observed using immunoblotting. The antibodies with broad (1C7) or intermediate reactivity (1H4 and 4H11) were able to detect all analysed KIR-Fc fusion proteins. 
Low specificity (broad reactivity)

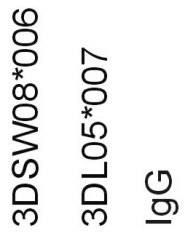

$95 \mathrm{kDa}-$

$1 \mathrm{C7}$

Intermediate specificity
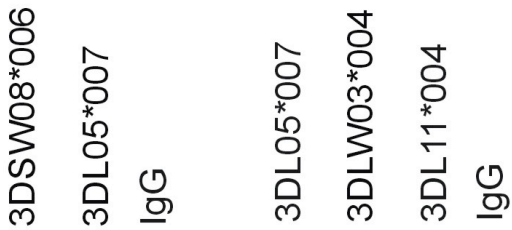

$95 \mathrm{kDa}-$

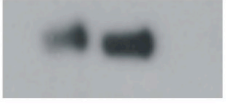

$1 \mathrm{H} 4$

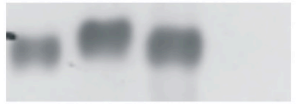

4H11

High specificity
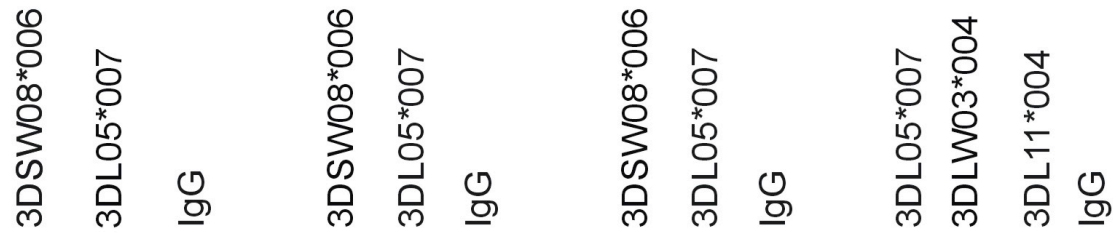

$95 \mathrm{kDa}-$
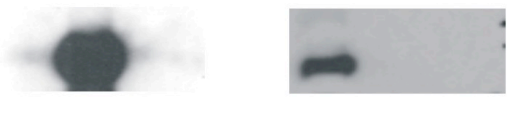

$2 \mathrm{H} 5$

$$
2 \mathrm{H} 3
$$

2A4

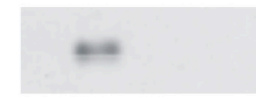

$2 \mathrm{H} 9$

Figure 9. Immunoblot analysis to test the reactivity of hybridoma supernatant.

Denatured KIR-Fc fusion proteins (around $95 \mathrm{kDa}$ ) were stained with anti-rhesus macaque KIR antibodies using $2 \mathrm{ml}$ of supernatant and $1 \mathrm{ml} \mathrm{PBS}$. Staining was performed over night, followed by $1 \mathrm{~h}$ incubation with the second antibody. Antibodies with low (upper row), intermediate (middle row) and high (lower row) specificity were analysed.

\subsubsection{Different antibodies detect similar recognition sites}

The epitope of an antibody can be continuous (linear) or discontinuous (conformational). The determination of the specific epitope is important for the characterisation of antibodies. To determine the epitopes, recognised by the different anti-rhesus macaque KIRs, an epitope mapping was performed by Sandra Weil, Ariane Groth and Joachim Koch from the Institute of Biomedical Research (Georg-Speyer-Haus, Frankfurt). They performed a linear epitope mapping with a peptide spot array. 18-mer 
synthetic peptides were anchored to a membrane. The peptides were shifted by three residues causing a 15 residue overlap for the following peptide. Peptides for KIR3DL5*007, KIR3DLW03*004 and KIR3DSW08*006, for which highly significant antibodies are available, were synthesised. In total, 102 (KIR3DLW03) or 103 (KIR3DL05, KIR3DSW08) peptides were analysed per antigen (supplementary Table 6). For every membrane $4 \mu \mathrm{g} / \mathrm{ml}$ antibody was used.

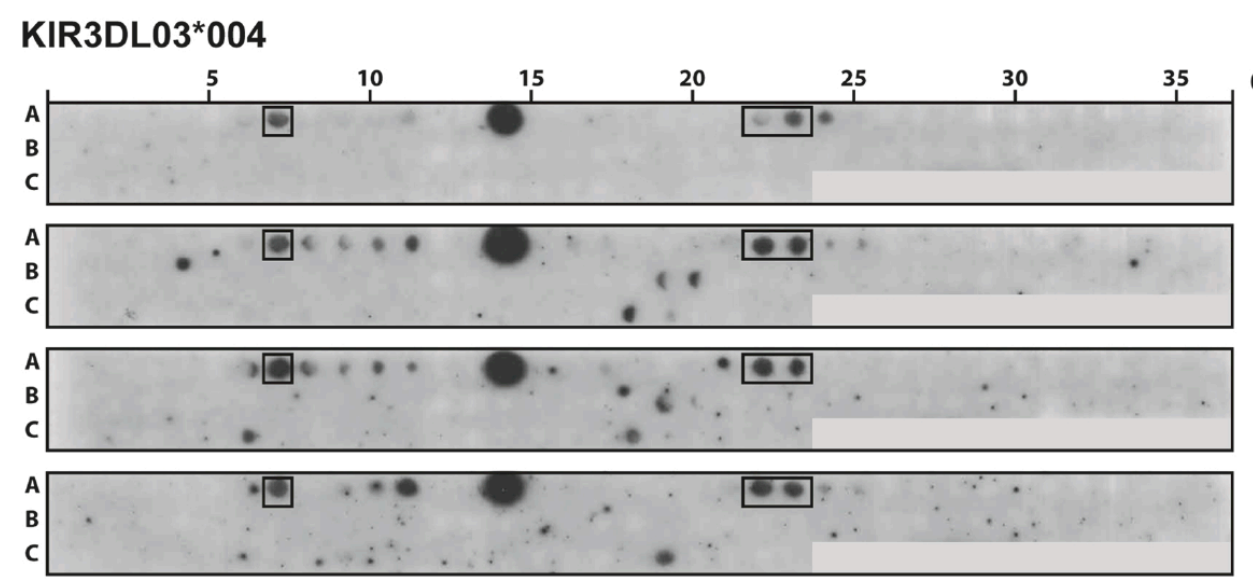

mAb clones

4H11

$2 \mathrm{H} 9$

$1 \mathrm{C7}$

$5 \mathrm{H} 11$

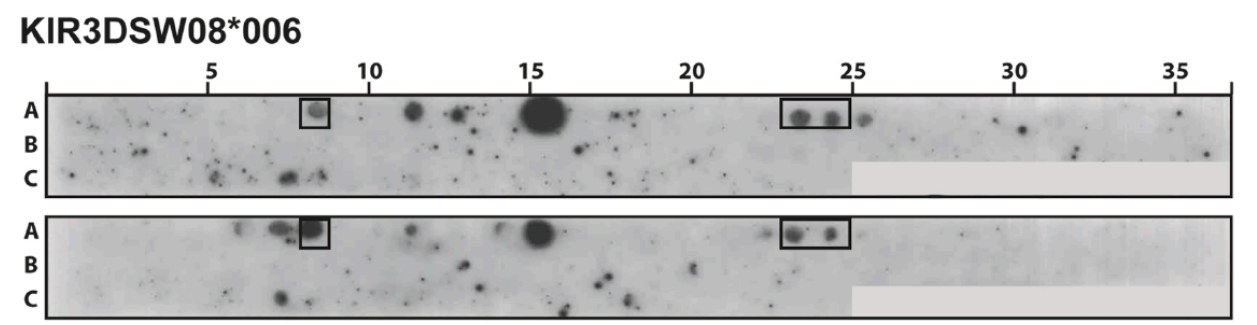

$2 \mathrm{H} 3$

2A4

\section{KIR3DL05*007}

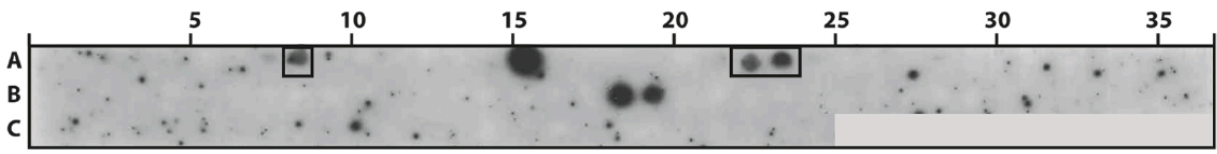

$2 \mathrm{H} 5$

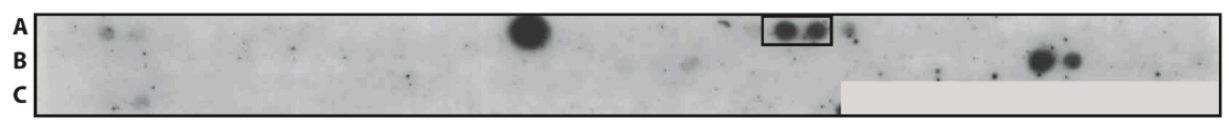

$1 \mathrm{H} 4$

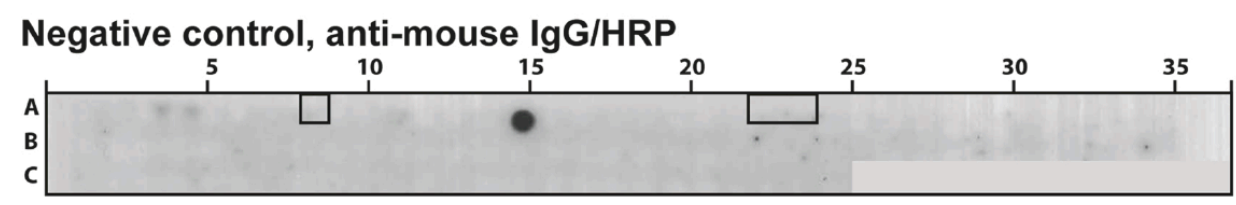

Figure 10. Epitope mapping using peptide spot arrays.

102-103 18-mer peptides with a 15 residue overlap were anchored to the membrane. Peptide spot arrays were incubated with $4 \mu \mathrm{g} / \mathrm{ml}$ anti-rhesus macaque KIR antibody or anti-mouse IgG/HRP as negative control (one representative array shown). Black spots indicated a detection of a peptide with the tested antibody. Specific epitopes are shown in a box, for KIR3DLW03 at position A7 and A22/23 and for KIR3DSW08 and KIR3DL05 at positions A8 and A23/24. The spot at position A15 is background as it appears in the negative control (Figure is provided by Joachim Koch and colleagues, who performed and analysed the epitope mapping). 
One pan-KIR antibody (1C7), two antibodies with an intermediate specificity (4H11 and 1H4) and four antibodies with high specificity (2H5, 2A4, 2H3, 2H9) were analysed for their epitopes using the peptides of the same KIR that were used for immunisation and ELISA screening. Figure 10 shows the spots for all analysed antigens and their antibodies.

The spot at position A15 is considered as background signal as it also appeared in the negative control (peptide spot array performed with anti-mouse IgG/HRP only). Comparison of the detected spot positions showed that the different antibodies recognised similar peptides. For KIR3DLW03 spots at positions A7 and A22/23 and for KIR3DSW08 and KIR3DL05 spots at positions A8 and A23/24 were detected. Additional spots were observed for KIR3DL05 with antibody 2H5 at B18/19 and antibody $1 \mathrm{H} 4$ at B31/32. These peptides differ depending on the KIR they are derived from. In summery, the detected peptides are derived from similar positions in the protein but differ in their protein sequences for different KIR. For all antibodies more than one epitope was detected meaning that the antibodies may have a conformational epitope. Detected sequence stretches common in all reactive peptides were determined by alignment of reactive peptide sequences (Figure 11).
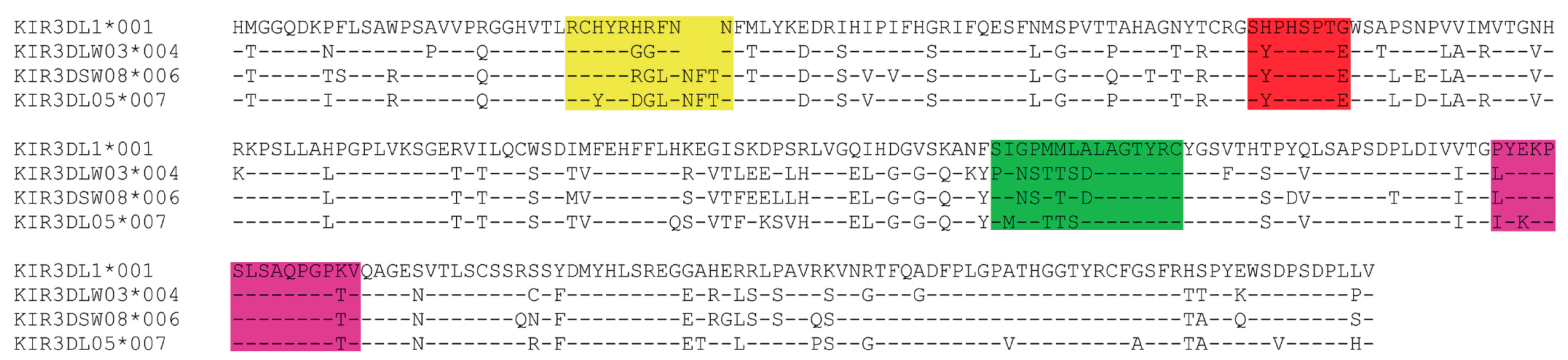

Figure 11. Amino acid sequences of three KIRs used for the generation of antibodies.

Coloured areas depict the areas showing reactivity in the epitope mapping. Rhesus macaque sequences were aligned together with human KIR3DL1*001 due to the knowledge of the 3Dstructure. Yellow and red areas show the two dominantly reacting peptide stretches derived from sport $A 7 ; 8$ and $A 22 / 23 ; 23 / 24$ (Figure 10). The $2 \mathrm{H} 5$ detected sequence stretch (spots $B 18 / 19$ ) is depicted in green and for $1 \mathrm{H} 4$ (spots B31/32) in magenta (Figure provided by Joachim Koch and colleagues).

All tested antibodies were able to detect the yellow and the red stretches (Figure 11) belonging to the D0 domain of KIR (yellow: RCHYRHRFNN and red: SHPHSPTG; both sequences derived from human KIR3DL1, which was used for alignment). The green sequence is detected by $2 \mathrm{H} 5$, whereas the magenta stretch is only recognised by $1 \mathrm{H} 4$ 
(Figure 11). Not all antibodies were tested with all peptides, only with the peptides of the KIR they were originally made for.

\subsubsection{Labelling of purified antibodies for flow cytometry}

Following characterisation the monoclonal anti-rhesus macaque KIR antibodies were purified using affinity chromatography with Protein G coupled columns. From $100 \mathrm{ml}$ hybridoma supernatant 0.5 - $4 \mathrm{mg}$ antibody could be purified depending on the hybridoma clone. After dialysis against PBS to remove the elution buffer the antibodies were labelled with fluorochromes using different DyLight antibody labelling kits. All fluorochrome-coupled antibodies were controlled for proper labelling before using them for multi-colour flow cytometry of PBMCs. Beads available for the compensation of different fluorochromes were loaded with the labelled anti-rhesus macaque KIR antibodies and analysed by flow cytometry. A custom antibody in the same channel as the tested labelled antibody was always measured in parallel for comparison (Figure 12). Only antibodies with a clear peak for its fluorochrome were used for the analysis of KIR expression by different lymphocyte subsets.
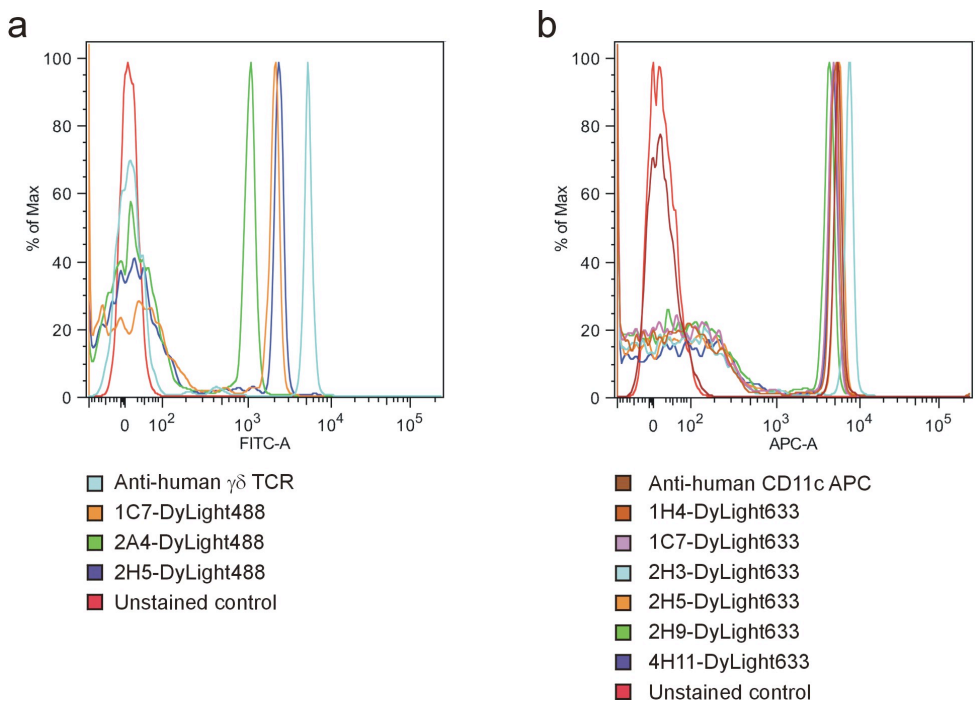

Figure 12. Histogram of DyLight labelled anti-rhesus macaque KIR antibodies.

Antibodies are coupled to compensation beads and analysed with an LSR II. DyLight488-labelled antibodies (a) and DyLight633-labelled antibodies (b) measured in the FITC and APC channel of the flow cytometer, respectively.

The best and most constant labelling was always achieved with DyLight633 (Figure 12). These antibodies were compared with a custom antibody measured in the same channel of the flow cytometer (anti-CD11c APC). Few DyLight488 antibodies were used 
but these differ in their labelling quality compared among each other and to anti- $\gamma \delta$ TCR FITC. No proper labelling could be performed with DyLight405 (data not shown). Therefore, most of the experiments were performed using the anti-rhesus macaque KIR antibodies in the APC channel (DyLight633) of the flow cytometer.

\subsection{KIR expression pattern in primates}

A lot is known about the expression pattern of KIR molecules on different lymphocyte subsets in humans. However, the rhesus macaque as important animal model is not well studied for the expression of these receptors so far. There are studies analysing the expression level of KIR mRNA (Bostik et al., 2009; Moreland et al., 2011) but not the protein expression, due to the absence of specific anti-rhesus macaque KIR antibodies and lack of cross reactivity of anti-human KIR antibodies with rhesus macaque KIR proteins.

The characterisation of monoclonal anti-rhesus macaque KIR antibodies (3.1) was followed by their application to analyse the KIR expression on lymphocyte subsets of rhesus macaques with purified and fluorochrome-labelled antibodies in multi-colour flow cytometry. Eight animals were analysed for their KIR expression on NK cells and different T cell subsets like CD8 ${ }^{+}, \mathrm{CD}^{+} \alpha \beta \mathrm{T}$ cells and $\gamma \delta \mathrm{T}$ cells. For all animals the KIR genotype was known and the frequency of transcript level was analysed as described by Moreland and colleagues, 2011 (KIR transcript genotyping performed by Christina Albrecht).

\subsubsection{General characterisation of rhesus macaque lymphocytes using flow cytometry}

Rhesus macaque PBMC are similar to human PBMC, therefore, it is possible to use the same markers for most of the surface molecules to characterise specific cell populations. All non-KIR antibodies used here were established for human cell surface markers but it was already shown that they also cross-react with corresponding rhesus macaque proteins (Mavilio et al., 2005). For all analysed PBMC samples of this work the following gating strategy was applied (Figure 13).

First, all doublets were excluded using the FSC-H against FSC-A (Monettes), granulocytes and most of the monocytes were separated by size using the SSC-A against 
the FSC-A (Lymphocytes). The lymphocyte population was then controlled for remaining monocytes by using a CD14 antibody (Lymphoctes exact) and further analysed with CD20 (B cells) and CD3 (T cells) to exclude the CD20+ B cells (Figure 13a). To characterise the NK cells and different T cell subsets the remaining CD20- and CD14population was used.

NK cells of rhesus macaques express only small amounts of CD56 on their surface (around $2 \%$ of all NK cells are $\mathrm{CD}^{+} 6^{+}$, Webster and Johnson, 2005) so that the traditional human NK marker CD56 is not the appropriate marker for the characterisation of rhesus NK cells. However, nearly all rhesus macaque NK cells express NKG2A (around 97 \%, Mavilio et al., 2005). Therefore, NKG2A was used as standard marker for the analysis of rhesus macaque NK cells in this work. All NK cells are also CD8 positive and most express CD16, so these markers were used in combination with NKG2A. Myeloid dendritic cells (mDC) also express CD16 in rhesus macaques. Because of this, all CD16 positive cells had to be further analysed by gating these cells with CD16 against CD8 to exclude the CD8 negative mDCs (CD16 exact population). After these gating steps a Boolean gate was generated with the NKG2A positive population and the CD16 exact population and these cells were defined as NK cells (Figure 13b).

Different $\mathrm{T}$ cell subsets were analysed like it is done for the human system using CD4, CD8 and $\gamma \delta$-TCR (Figure 13c).

As a result of the analysis rhesus macaque lymphocytes have a similar composition as human lymphocytes. There are between 3-15\% NK cells and 30-70\% of all lymphocytes are T cells. 37-75 \% are $\mathrm{CD}^{+} \alpha \beta$ T cells, $17-47 \%$ of all T cells are $\mathrm{CD}^{+} \alpha \beta$ T cells and 2-15\% express the $\gamma \delta$ TCR (Figure 13d). 

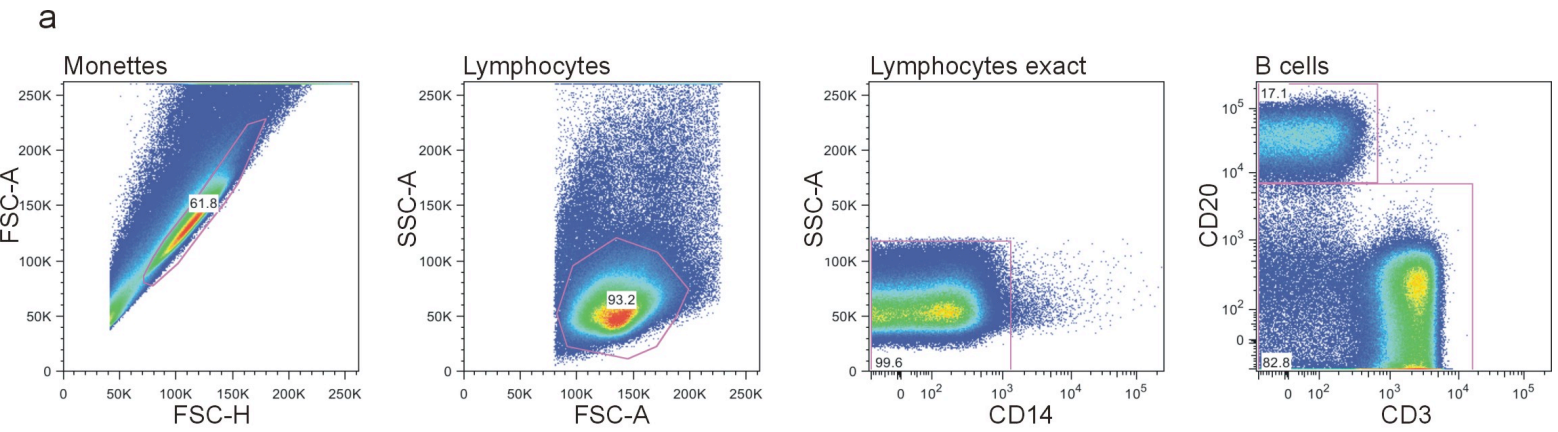

b
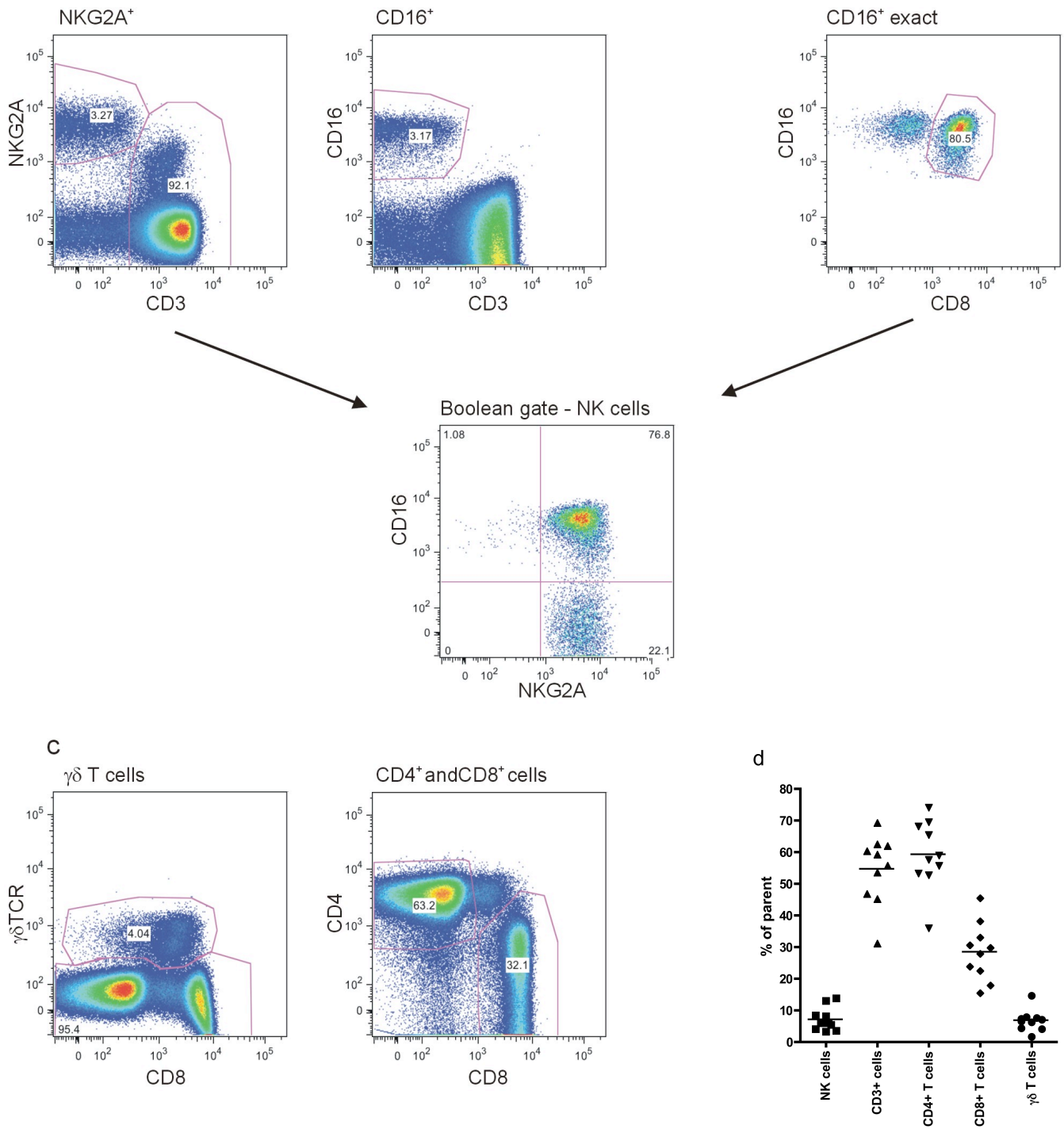

Figure 13. Characterisation of rhesus macaque PBMC using multi-colour flow cytometry.

(a) Gating to exclude doublets, granulocytes (size), monocytes (CD14) and B cells (CD20). (b) NK cell gating using NKG2A and CD16 as markers. CD16 positive cells are additionally analysed against CD8 to exclude mDCs. All NKG2A and/or CD16 positive cells were combined using a Boolean gate. (c) T cell gating using CD4, CD8 and $\gamma \delta$ TCR antibodies. (d) Overview of the percentage of all analysed lymphocyte populations. Shown is always the percentage of the parental population. The mean value for each data set is shown as a horizontal bar $(n=8)$. 


\subsubsection{Expression of KIR by NK cells}

Human NK cells express KIRs in a clonal pattern, i.e. each individual NK cell can express a unique set of KIR and the KIR expression differs between individuals. So far, for rhesus macaques it was not possible to characterise the KIR expression due to the lack of antibodies. Here, NK cells were analysed for their KIR expression by flow cytometry using pan-KIR antibody 1C7, which recognises all tested KIR (3.1.5). The antibody was labelled with DyLight633 for all experiments shown in this chapter. The already described NK cell population (chapter 3.2.1) was analysed for its KIR expression as it is shown as dot plots for four animals (Figure 14a). Figure 14b summarises the percentage of KIR-expressing NK cells for 8 different animals. Most of the animals were analysed for more than three times and the mean of the percentage of these experiments is shown in this chart. The KIR expression over time was very constant for healthy individuals e.g. Gerdi (51.80-55.7\%) or Happy (85.3-85.7\%) (Figure 36). Further, animals differ in their percentage of KIR-expressing NK cells (30-80 \%) and also in density, which is defined by the mean fluorescence intensity of KIR expression by these NK cells (Figure 14c). Some animals have many KIR-expressing NK cells but the density of the expressed KIR is very low per cell, for example for Kalle ( $80 \%$ KIR positive NK cells, low MFI). The opposite of this is Benno where $50 \%$ of all NK cells express KIR but with the highest density of all animals (Figure $14 \mathrm{~b} / \mathrm{c}$ ).

In conclusion, the frequency of KIR-expressing NK cells as well as the amount of expressed KIR on NK cells differ between animals. There is no clear correlation between the number of KIR-expressing NK cells and the density of expressed KIRs (Pearson $\mathrm{r}=0.3409, \mathrm{p}=0.4086$ ). 

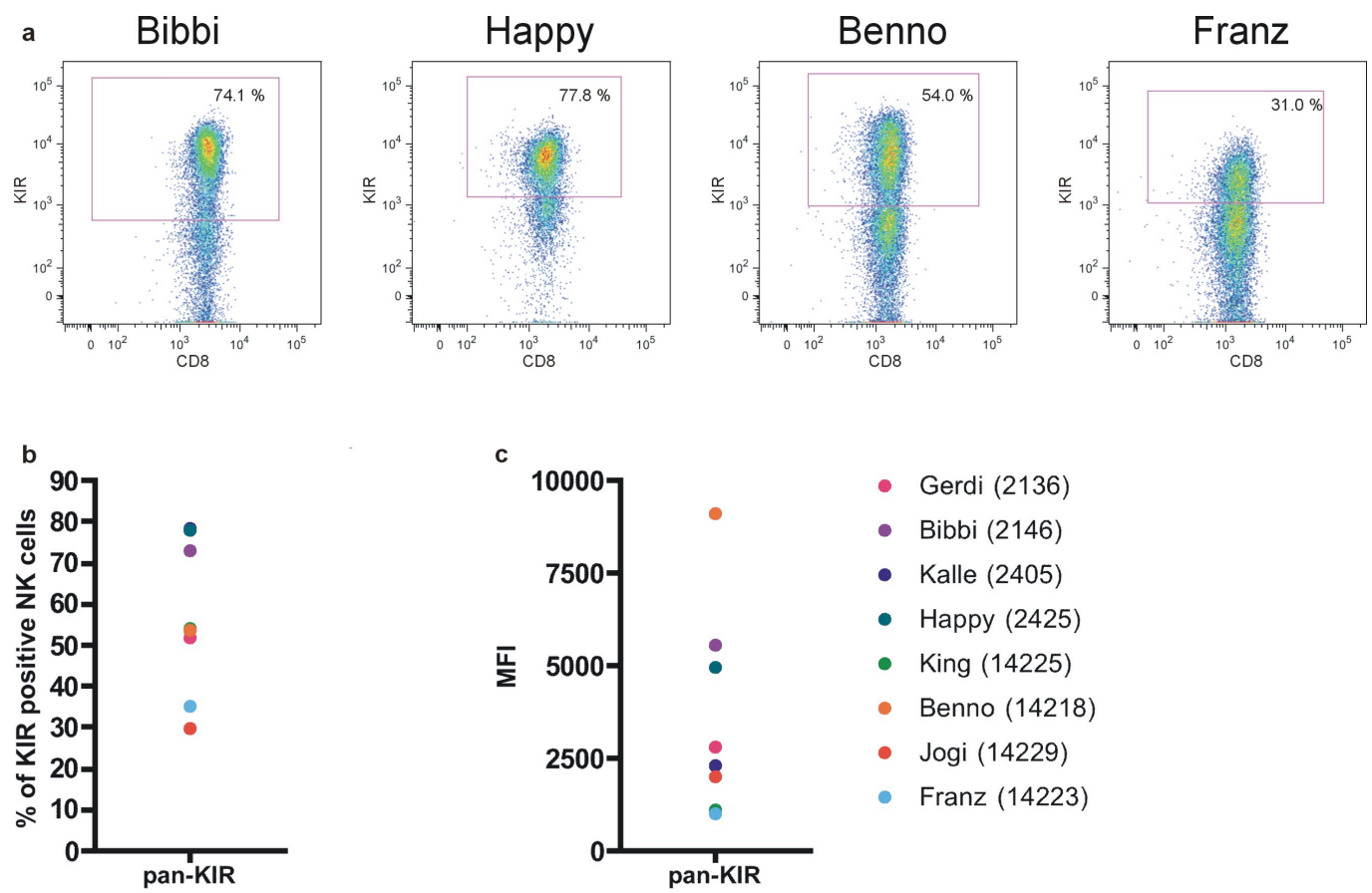

Figure 14. Flow cytometry analysis of expression of KIR by NK cells.

Antibody 1C7 with a broad KIR reactivity (pan-KIR) was used. (a) NK cell dot plot examples of different animals using the pan-KIR antibody are depicted. Gates for KIR positive cells were defined referring to the control without anti-KIR antibody. (b) Comparison of the percentage of KIR positive NK cells and (c) mean fluorescence intensity (MFI) using 1C7-DyLight633 are shown.

\subsubsection{KIR Expression by different NK cell subsets}

As already described (1.4.1) rhesus macaques show a small population of CD56 ${ }^{+} / \mathrm{CD}^{-} 6^{-}$ NK cells. NK cell populations (NKG2A and CD8 positive) of four animals were analysed for their CD56 expression. Between these animals the number of CD56 ${ }^{+} / \mathrm{CD}_{16}{ }^{-} \mathrm{NK}$ cells ranged from 1.6 to $12 \%$ (mean $4.87 \%$ ). 5.6 -16\% (mean 9.7\%) of all NK cells were CD56 /CD16- and the main NK cell population 69-92\% (mean $83 \%$ ) was CD56 ${ }^{-} /$CD16 ${ }^{+}$. Around $18 \%$ (15-33 \%) of all CD56-expressing NK cells did also express KIR using the pan-KIR antibody 1C7-DyLight633, 40 \% (30-57 \%) of all CD56-/CD16- NK cells were KIR positive and $73 \%\left(55-84 \%\right.$ ) of the main NK cell population (CD56 /CD16 ${ }^{+}$). To different extent, for all tested NK cell populations KIR expression was observed (Figure 15). Because of the very low number of CD56 positive NK cells (only one tested animal had above $3 \%$ ) the following experiments were performed using NKG2A together with CD16 for the characterisation of rhesus macaques NK cells. 


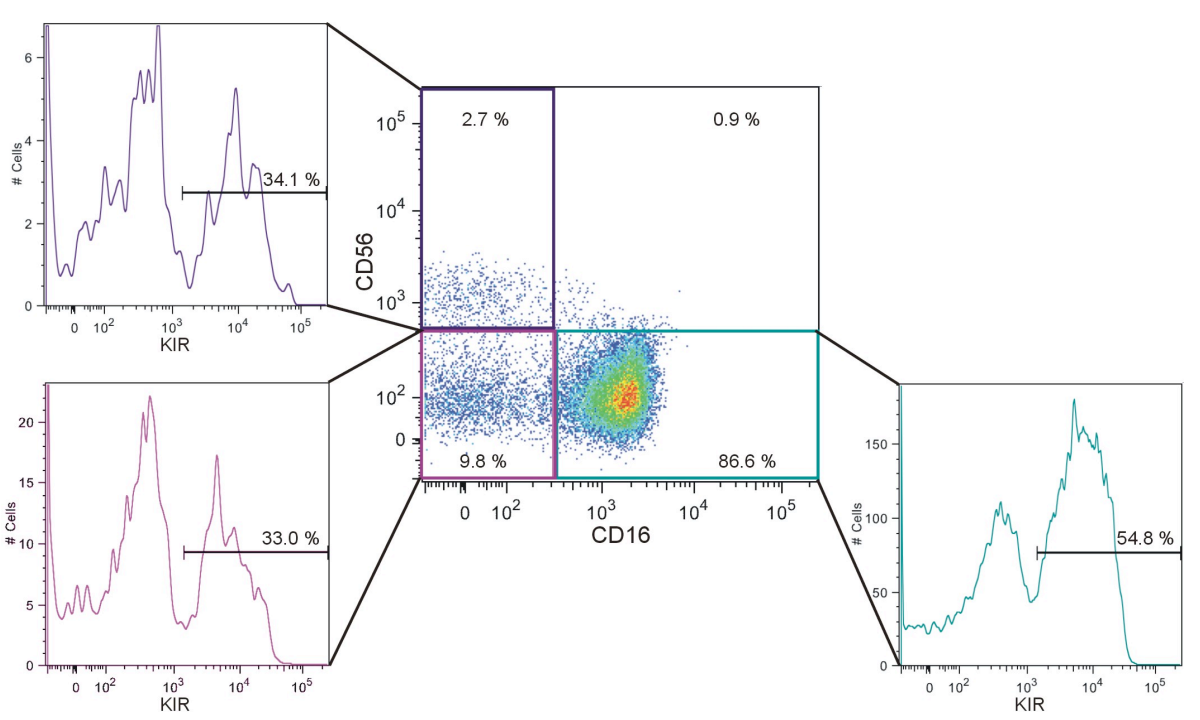

Figure 15. KIR expression by three different NK cell subsets.

Different rhesus macaque NK cell subsets defined by the CD56 expression show all KIR expression. The populations $\mathrm{CD}^{+} 6^{+} \mathrm{CD}^{-} 6^{-}$(violet) and $\mathrm{CD}^{-} 6^{-} \mathrm{CD} 16^{-}$(magenta) show similar frequencies in KIR expression. The main NK cell population (turquoise), defined as $\mathrm{NKG} \mathrm{A}^{+} \mathrm{CD} 16^{+} \mathrm{C}$, shows a higher frequency of expressed KIR.

\subsubsection{Expression of KIR by $\mathrm{CD}^{+} \alpha \beta \mathrm{T}$ cells}

KIRs are not only expressed by NK cells but also by subsets of T cells, e.g. CD8 ${ }^{+} \alpha \beta \mathrm{T}$ cells in human (1.2.3). Therefore, rhesus macaque $\mathrm{CD}^{+} \alpha \beta \mathrm{T}$ cells were analysed for their KIR expression with the pan-KIR antibody 1C7, labelled with DyLight633. Interestingly, also rhesus macaque $\mathrm{CD}^{+} \alpha \beta \mathrm{T}$ cells do express $\mathrm{KIR}$ on their surface (Figure 16). Between $4-27 \%$ of all $\mathrm{CD}^{+} \alpha \beta$ T cells are KIR positive and, similar to NK cells, also the amount (MFI) of expressed KIR varies. Like for NK cells there is no significant positive correlation between the numbers of KIR positive cells and the density of expressed KIR (Pearson $r=0.5102, p=0.1964)$. 

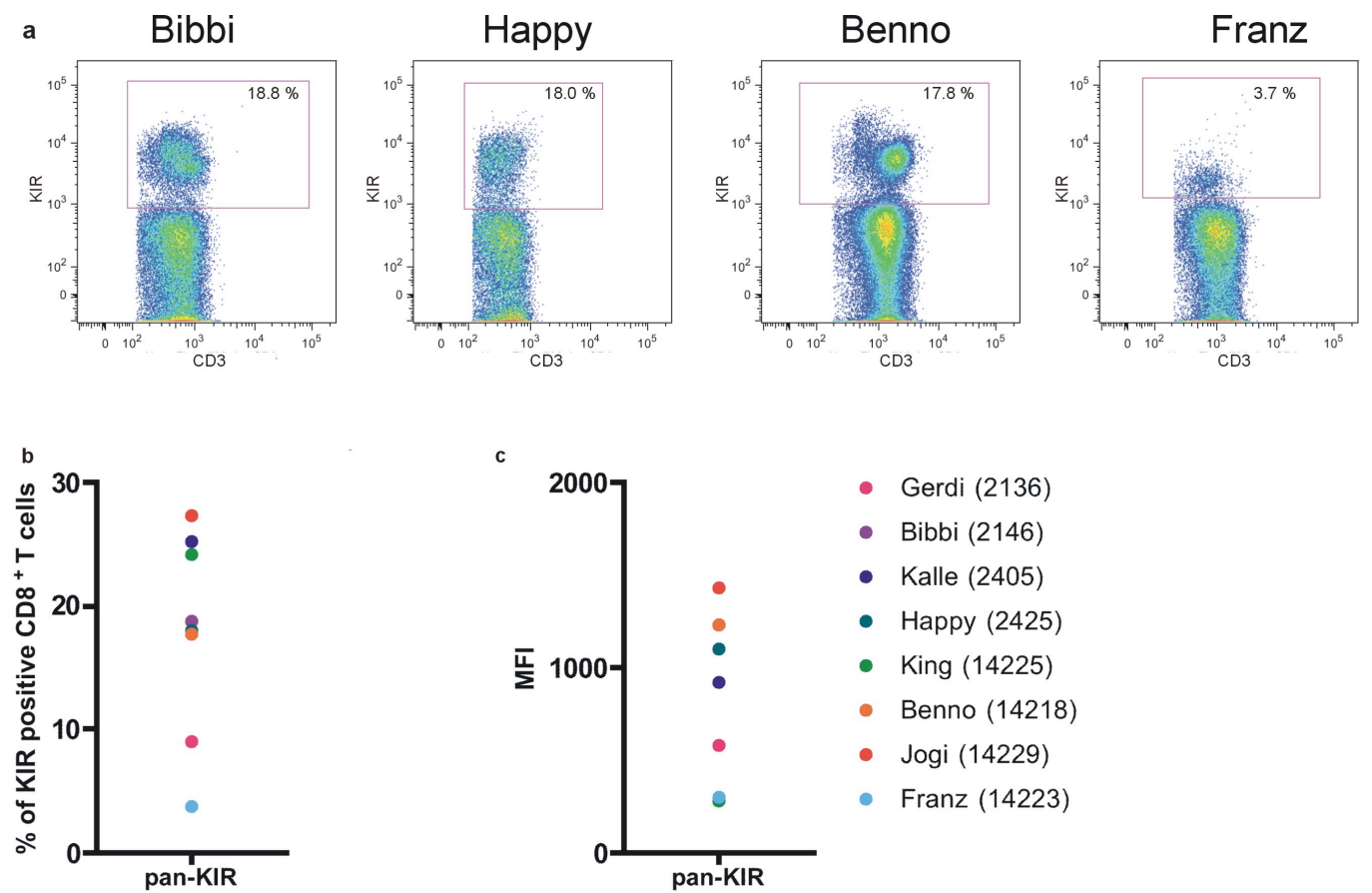

- Gerdi (2136)

- Bibbi (2146)

- Kalle (2405)

- Happy (2425)

- King (14225)

- Benno (14218)

- Jogi (14229)

- Franz (14223)

Figure 16. Flow cytometry analysis of expression of KIR by $\operatorname{CD8^{+}} \alpha \beta$ T cells.

Antibody $1 \mathrm{C7}$ with a broad KIR reactivity (pan KIR) was used. (a) Dot plot examples of the analysed $\mathrm{CD}^{+} \alpha \beta$ T cell population of different animals using the pan-KIR antibody are shown. Gates for KIR positive cells were defined referring to the control without anti-KIR antibody. (b) Comparison of the percentage of KIR positive $\mathrm{CD}^{+} \alpha \beta$ T cells and (c) mean fluorescence intensity (MFI) of all tested animals using $1 \mathrm{C} 7$ are shown.

\subsubsection{Expression of KIR by $\mathrm{CD}^{+} \alpha \beta$ T cells}

Only a very weak KIR expression was observed for human $\mathrm{CD}^{+} \alpha \beta \mathrm{T}$ cells. Therefore, the KIR expression of rhesus macaque $\mathrm{CD}^{+} \alpha \beta \mathrm{T}$ cells was also analysed (Figure 17). Only a very weak number of KIR positive $C D 4^{+} \alpha \beta$ T cells were observed in the rhesus macaque PBMC population (0.5-3 \%). Due to the low number of KIR positive $C D 4^{+} \alpha \beta \mathrm{T}$ cells, they were not included in detailed KIR expression analyses, especially for the expression of individual KIRs. 

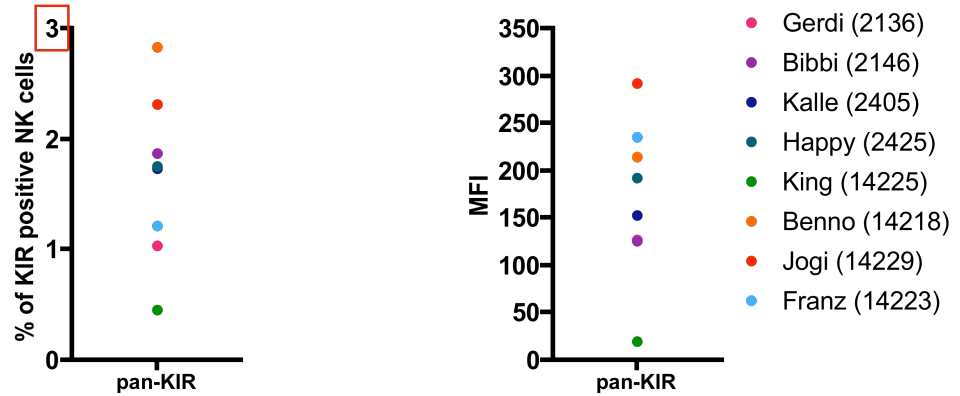

Figure 17. Flow cytometry analysis of expression of KIR by $C D 4^{+} \alpha \beta$ T cells.

Antibody 1C7-DyLight633 with a broad KIR reactivity (pan KIR) was used. (a) Comparison of the percentage of KIR positive $\mathrm{CD}^{+} \alpha \beta$ T cells and (b) mean fluorescence intensity (MFI) of all tested animals using are shown.

\subsubsection{Expression of KIR by $\gamma \delta \mathrm{T}$ cells}

KIRs are expressed by $\mathrm{CD}^{+} \alpha \beta$ T cells but also by $\gamma \delta \mathrm{T}$ cells in the human system, so that this T cell subset was analysed for KIR expression in rhesus macaque too. Between $10-58 \%$ of all $\gamma \delta \mathrm{T}$ cells (Figure 18) express KIR molecules on their cell surface. The amount of the expressed KIR also differs between animals but in contrast to $\mathrm{CD}^{+} \alpha \beta \mathrm{T}$ cells there is a highly significant positive correlation for the frequency and the density (Pearson $r=0.9871, p<0.0001$ ) in the case of $\gamma \delta$ T cells. 

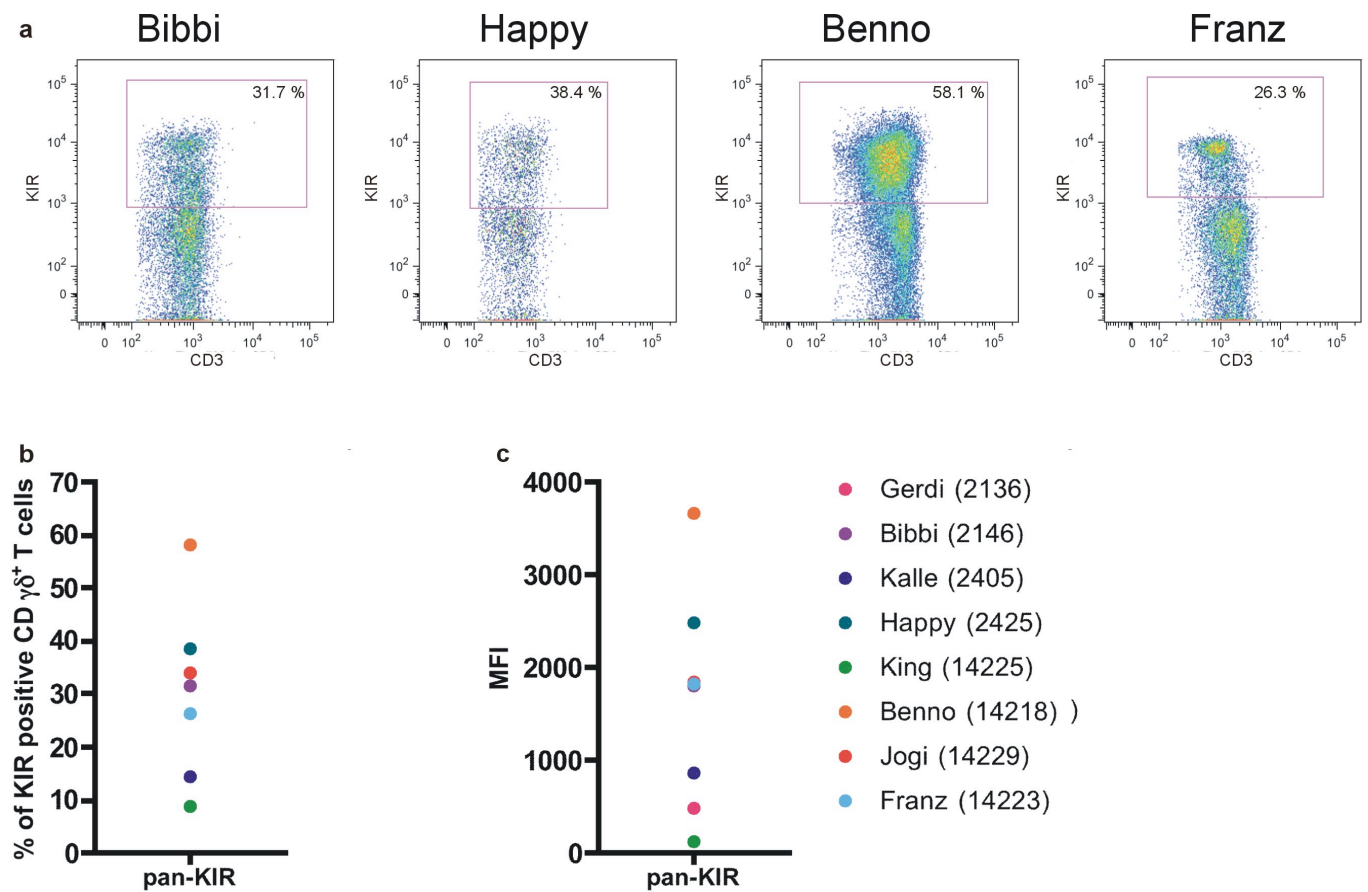

- Gerdi (2136)

- Bibbi (2146)

- Kalle (2405)

- Happy (2425)

- King (14225)

- Benno (14218))

- Jogi (14229)

- Franz (14223)

Figure 18. Flow cytometry analysis of expression of KIR by $\gamma \delta \mathrm{T}$ cells.

An antibody with a broad KIR specificity (pan-KIR) was used. (a) Dot plot examples of the analysed $\gamma \delta T$ cell population of different animals using the pan-KIR antibody. Gates for KIR positive cells were defined referring to the control without anti-KIR antibody. (b) Comparison of the percentage and (c) mean fluorescence intensity (MFI) of all tested animals using $1 \mathrm{C7}$.

\subsubsection{Expression of individual KIR by NK cells}

\section{KIR3DL05 Expression}

KIR3DL05 expression was analysed using 2H5-DyLight633 antibody. Between 0.9 to $15.6 \%$ of all NK cells did express this KIR in eight tested animals (Figure 19). The MFI of expressed KIR3DL05 varied between 167 and 662 for the tested animals. For some animals, there was only background signal detected with 2H5 (Bibbi, Gerdi, Kalle and Happy). Therefore, all eight animals were genotyped for KIR3DLO5 and two out of eight (Gerdi and Happy) were KIR3DL05 negative. Transcript analysis showed KIR3DL05 mRNA expression for five animals (Kalle, King, Benno, Jogi and Franz) (Table 4). Clear surface expression was only observed for King and Benno (12.1 and $15.6 \%$ ). All other animals showed only low numbers of KIR3DL05 positive NK cells (less than $3 \%$ ). Comparison with the total number of KIR-positive NK cells (3.2.2) it is seen that not all KIR-expressing NK cells did express KIR3DL05. Therefore, KIR3DL05 is expressed in a clonal pattern. In addition, the variance in the MFI of different animals showed differences in the amount of expressed KIR3DL05. No correlation between the percentage of KIR3DL05-positive NK cells and the amount of this KIR was detected 
(Pearson $\mathrm{r}=0.4979, \mathrm{p}=0.3933$ ). Meaning, the animal with the highest number of KIRpositive NK cells did not automatically have the highest amount of this KIR. Furthermore, the presence of the gene or mRNA did not always lead to detectable cell surface expression of KIR3DL05 in these animals.
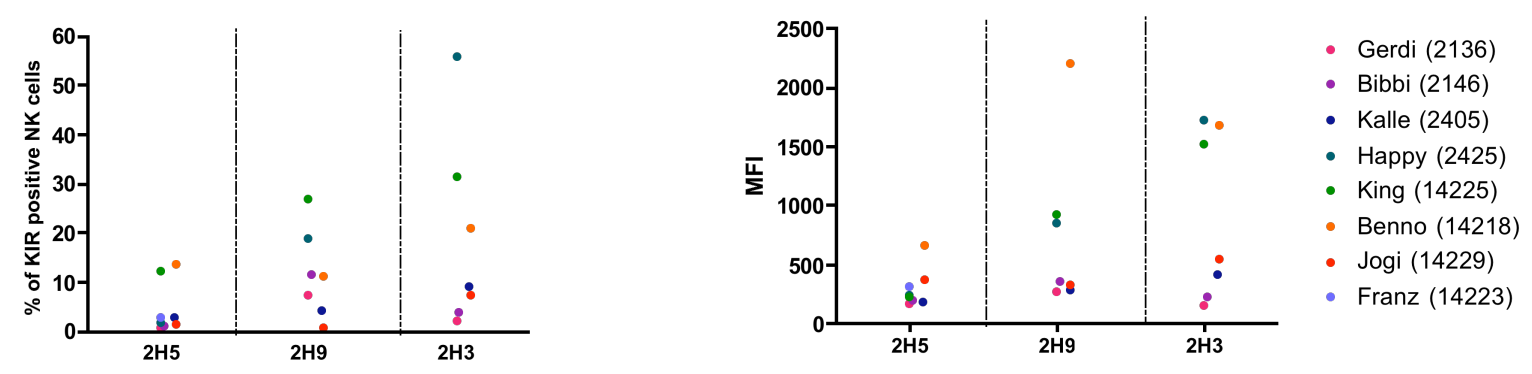

Figure 19. Flow cytometry analysis of expression of specific KIR by NK cells.

Three different antibodies were used. Shown is the number of KIR-expressing NK cells (\%, left panel) and the level of KIR expression (MFI, right panel) for KIR3DL05 (2H5), KIR3DLW03/KIR3DS05 (2H9), and KIR3DSW08/KIR3DS07/KIR3DL07 (2H3) ( $\mathrm{n}=8$ for $2 \mathrm{H} 5$ and $\mathrm{n}=7$ for $2 \mathrm{H} 9$ and $2 \mathrm{H} 3$ ).

\section{KIR3DLW03/KIR3DS05 Expression}

The expression of KIR3DLW03/KIR3DS05 was observed for six out of seven animals using 2H9-DyLight633 antibody (Franz was so far not analysed with this antibody). Jogi did not show any KIR3DLW03/KIR3DS05-positive NK cells (Figure 19). The range of positive NK cells for the other animals was between 4.3 to $26.9 \%$, with a varying amount of KIR surface expression between animals (MFI 271-2204) (Figure 19). Genotyping identified KIR3DLW03/KIR3DS05 in all animals. Transcripts of KIR3DS05 were observed for all animals except Jogi and KIR3DLW03 mRNA was only found for Happy and Jogi (Table 4). Jogi did not show any surface expression of KIR3DLW03 and for Happy it was not possible to distinguish between KIR3DLW03 and KIR3DS05 expression using 2H9. For all other animals the detected expression was due to KIR3DS05 because of the absence of KIR3DLW03 transcripts. As for KIR3DL05, the expression pattern of KIR3DLW03/KIR3DS05 was observed to be clonal with a varying amount of KIR for different animals. No correlation between the two values was found (Pearson $r=0.4069$, $\mathrm{p}=0.4233$ ). 
Table 4. Summary of genotyping, transcript and protein surface expression of certain KIR for eight analysed rhesus macaques.

Shown are the data for the KIR genotyping, where + indicates the presence and - the absence of a gene. The transcript data were derived from 454 amplicon sequencing analysing cDNA from total mRNA of PBMCs (data provided by Christina Albrecht, Abteilung Primatengenetik, DPZ). The percentage of the total read number is shown. - indicates the absence of any transcript. Protein expression was analysed by three different antibodies $(2 \mathrm{H} 5,2 \mathrm{H} 9$ and $2 \mathrm{H} 3)$ labelled with DyLight633. Shown are the percentage of positive cells and the MFI for NK cells, $\operatorname{CD}^{+} \alpha \beta$ T cells and $\gamma \delta$ T cells.

\begin{tabular}{|c|c|c|c|c|c|c|c|c|c|c|}
\hline & & & $\begin{array}{l}\text { Gerdi } \\
(2136)\end{array}$ & $\begin{array}{l}\text { Bibbi } \\
(2146)\end{array}$ & $\begin{array}{l}\text { Kalle } \\
\text { (2405) }\end{array}$ & $\begin{array}{l}\text { Happy } \\
\text { (2425) }\end{array}$ & $\begin{array}{l}\text { King } \\
\text { (14225) }\end{array}$ & $\begin{array}{l}\text { Benno } \\
(14218)\end{array}$ & $\begin{array}{l}\text { Jogi } \\
(14229)\end{array}$ & $\begin{array}{l}\text { Franz } \\
\text { (14223) }\end{array}$ \\
\hline \multirow{6}{*}{ 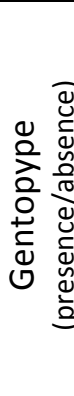 } & \multicolumn{2}{|c|}{ KIR3DL05 } & - & + & + & - & + & + & + & + \\
\hline & \multicolumn{2}{|c|}{ KIR3DSW08 } & + & + & + & + & + & + & + & + \\
\hline & \multicolumn{2}{|c|}{ KIR3DS07 } & - & - & - & + & + & + & + & + \\
\hline & \multicolumn{2}{|c|}{ KIR3DLW03 } & + & + & + & + & + & + & + & + \\
\hline & \multicolumn{2}{|c|}{ KIR3DS05 } & + & + & + & + & + & + & + & + \\
\hline & \multicolumn{2}{|c|}{ KIR3DL07 } & - & - & + & + & - & - & + & + \\
\hline \multirow{6}{*}{ 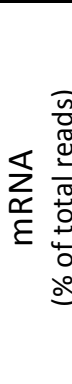 } & \multicolumn{2}{|c|}{ KIR3DL05 } & - & - & 2.08 & - & 29.83 & 7.30 & 2.42 & 13.71 \\
\hline & \multicolumn{2}{|c|}{ KIR3DSW08 } & - & - & - & - & - & - & 5.84 & - \\
\hline & \multicolumn{2}{|c|}{ KIR3DS07 } & - & - & - & - & - & - & - & - \\
\hline & \multicolumn{2}{|c|}{ KIR3DLW03 } & - & - & - & 9.08 & - & - & 9.15 & - \\
\hline & \multicolumn{2}{|c|}{ KIR3DS05 } & 3.78 & 8.51 & 8.72 & 33.41 & 8.20 & 7.14 & - & 18.10 \\
\hline & \multicolumn{2}{|c|}{ KIR3DL07 } & - & 1.87 & 27.77 & - & 11.00 & 10.45 & 21.76 & 2.30 \\
\hline \multirow{9}{*}{ 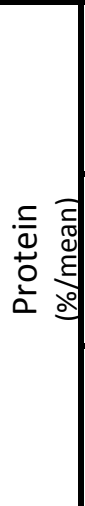 } & \multirow{3}{*}{$2 \mathrm{H} 5$} & NK cells & $0.9 / 167$ & $1.1 / 205$ & $2.8 / 189$ & $1.7 / 250$ & $12.1 / 229$ & $15.6 / 662$ & $1.5 / 377$ & $2.8 / 310$ \\
\hline & & $\mathrm{CD}^{+} \mathrm{T}$ cells & $0.7 / 62$ & $0.6 / 122$ & $1.3 / 85$ & $1.8 / 140$ & $4.1 / 42$ & $2.7 / 267$ & $1.7 / 264$ & $0.8 / 267$ \\
\hline & & $\gamma \delta \mathrm{T}$ cells & $2.2 / 112$ & $4.1 / 218$ & $3.4 / 122$ & $3.5 / 186$ & $2.0 / 27$ & $14.6 / 690$ & $8.2 / 505$ & $19.4 / 727$ \\
\hline & \multirow{3}{*}{$2 \mathrm{H} 9$} & NK cells & $7.3 / 271$ & $11.6 / 359$ & $4.3 / 283$ & $18.9 / 860$ & $26.9 / 925$ & $11.2 / 2204$ & $0.8 / 330$ & - \\
\hline & & $\mathrm{CD}^{+} \mathrm{T}$ cells & $0.8 / 118$ & $1.7 / 110$ & $1.3 / 139$ & $4.4 / 196$ & $4.9 / 217$ & $0.6 / 127$ & $1.7 / 275$ & - \\
\hline & & $\gamma \delta \mathrm{T}$ cells & $2.7 / 182$ & $13.8 / 476$ & $2.7 / 215$ & $10.4 / 331$ & $34.1 / 1575$ & $1.9 / 167$ & $7.7 / 528$ & - \\
\hline & \multirow{3}{*}{$2 \mathrm{H} 3$} & NK cells & $2.2 / 163$ & $3.7 / 233$ & $9.2 / 416$ & $55.9 / 1725$ & $31.4 / 1525$ & $20.9 / 1677$ & $7.2 / 546$ & - \\
\hline & & $\mathrm{CD}^{+}{ }^{+} \mathrm{T}$ cells & $1.2 / 118$ & $2.9 / 158$ & $5.2 / 233$ & $11.1 / 372$ & $5.98 / 289$ & $2.7 / 244$ & $16.2 / 688$ & - \\
\hline & & $\gamma \delta$ T cells & $4.9 / 245$ & $17.5 / 665$ & $6.8 / 317$ & $14.8 / 559$ & $35.9 / 1863$ & $17.7 / 625$ & $26.1 / 1155$ & - \\
\hline
\end{tabular}

\section{KIR3DSW08/KIR3DS07/KIR3DL07 Expression}

The expression of these KIRs was analysed for seven animals (all except Franz) and observed for 2.2-55.9\% of all NK cells with a varying amount (MFI 163-1725) using 2H3-DyLight633 (Figure 19).

The KIR3DS07 gene was detected in genomic DNA of Happy, King, Benno, Franz, and Jogi but no mRNA of this KIR gene was observed for any of the animals (Table 4). The KIR3DL07 gene was found in genomic DNA of Kalle, Happy, Franz, and Jogi, which all 
express KIR3DL07 on mRNA level, except for Happy. Whereas the DNA genotyping for KIR3DL07 was negative for Bibbi, King, and Benno, respective mRNA was detected (Table 4). The DNA genotyping might miss the detection of certain KIR3DL07 alleles; therefore, this method needs to be optimised. Happy, the animal with the most positive NK cells for KIRs as measured with 2H3 (Figure 19), did not show transcripts for any of the three analysed KIRs (Table 4). Therefore, either the amplicon sequencing needs to be improved, or $2 \mathrm{H} 3$ might detect KIR proteins that are not known or not covered by any of the methods applied here. In those cases where the specific gene was typed as "present" and mRNA was not detected, the respective KIR is either not expressed or only on very low levels that preclude detection by 454 amplicon sequencing. This might be the case for the KIR3DSW08 gene, which is obviously present in all animals analysed, but only Jogi showed KIR3DSW08 transcripts (Table 4).

For the expression of the KIR molecules detected by $2 \mathrm{H} 3$ a significant correlation of the frequency of KIR3DSW08/KIR3DS07/KIR3DL07 positive NK cells and the amount of expressed KIR was observed (Pearson $r=0.8468$, p=0.0334).

\subsubsection{Expression of individual KIR by different $\mathrm{T}$ cell subsets}

Different $\mathrm{T}$ cell subsets were also analysed for their expression of individual KIR using the antibodies $2 \mathrm{H} 5,2 \mathrm{H} 9$, and $2 \mathrm{H} 3$. All $\mathrm{CD}^{+} \alpha \beta$ and $\gamma \delta \mathrm{T}$ cells were characterised for their expression of KIR3DL05, KIR3DLW03/KIR3DS05 and KIR3DSW08/KIR3DS07/KIR3DL07, respectively. The animals included in this analysis were the same as for the NK cells in the chapter before.

KIR3DL05 is expressed by $0.5-4 \%$ of $\mathrm{CD}^{+} \alpha \beta$ T cells and by $2-20 \%$ of $\gamma \delta$ T cells (Figure 20). $1.5-16 \%$ of all $\mathrm{CD}^{+} \alpha \beta \mathrm{T}$ cells were positive for KIR3DSW08/KIR3DS07/ KIR3DL07 with the $2 \mathrm{H} 3$ antibody and 5-37 \% of the $\gamma \delta$ T cells. KIR3DLW03/KIR3DS05 was detected on $0.3-5 \%$ of $\mathrm{CD}^{+} \alpha \beta$ T cells and on 2-35 \% of $\gamma \delta$ T cells using the $2 \mathrm{H} 9$ antibody. Comparison of the detected percentages for certain KIRs with the total KIR expression of both $\mathrm{CD}^{+} \alpha \beta$ and $\gamma \delta \mathrm{T}$ cells $(3.2 .4,3.2 .6)$ showed similar to NK cells a clonal expression pattern of certain KIRs for these cell subsets. Furthermore, the amount of expressed KIRs differs between animals. 
a
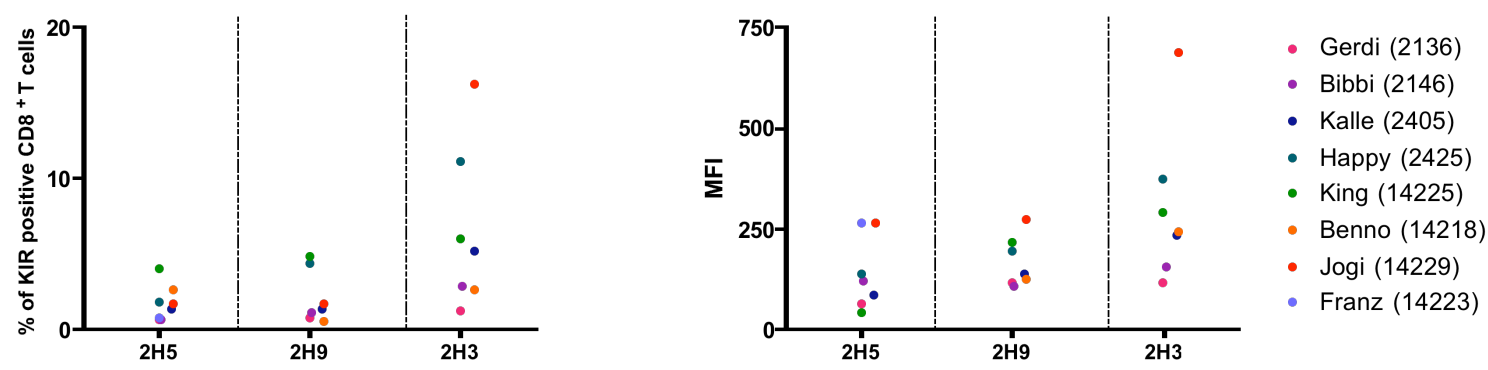

b
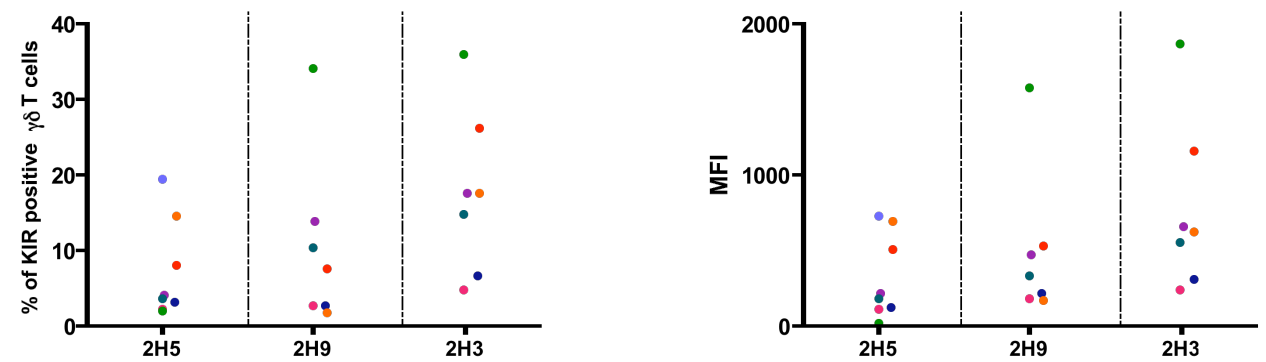

- Gerdi (2136)

- Bibbi (2146)

- Kalle (2405)

- Happy (2425)

- King (14225)

- Benno (14218)

- Jogi (14229)

- Franz (14223)

Figure 20. Flow cytometry analysis of specific KIR expression by $C D 8^{+} \alpha \beta$ and $\gamma \delta$ T cells.

Shown are the percentages of KIR-expressing T cells (\%, left panel) and the level of KIR expression (MFI, right panel) for $\mathrm{CD} 8^{+} \alpha \beta$ (a) and $\gamma \delta$ T cells (b) using three different antibodies, $2 \mathrm{H} 5$ (KIR3DL05), 2H3 (KIR3DSW08/KIR3DS07/KIR3DL07) and 2H9 (KIR3DLW03/KIR3DS05).

With the $2 \mathrm{H} 3$ antibody it was possible to detect a highly significant correlation between the expression level of KIR3DSW08/KIR3DS07/KIR3DL07 by CD8 ${ }^{+} \alpha \beta$ T cells and $\gamma \delta \mathrm{T}$ cells and the percentage of KIR3DSW08/KIR3DS07/KIR3DL07 positive CD8 ${ }^{+} \alpha \beta$ T cells (Pearson $r=0.9599, p=0.0024$ ) and $\gamma \delta \mathrm{T}$ cells (Pearson $\mathrm{r}=0.9753, \mathrm{p}=0.0009$ ). For KIR3DLW03/KIR3DS05 no significant correlation could be shown neither for $\operatorname{CD}^{+} \alpha \beta$ T cells (Pearson $r=0.4553, p=0.3642$ ) nor $\gamma \delta$ T cells (Pearson $r=0.8007, p=0.0556$ ). For KIR3DL05 only for $\gamma \delta$ T cells (Pearson $r=0.9488, p=0.0138$; CD8 ${ }^{+} \alpha \beta$ T cells: Pearson $r=-0.5108, p=0.3791$ ) a significant correlation on the percentage and the density of KIR was observed.

\subsubsection{KIR expression by NK and cytotoxic $\alpha \beta$ T cells of other species}

Additionally to rhesus macaques, PBMC samples of other non-human primates were analysed for cross-reactivity with the pan-KIR antibody 1C7. PBMCs of baboons, cynomolgus macaques and African green monkeys were analysed for their KIR expression. These monkey species are also important animal models for diseases and 
therapies. Therefore, it would be an important information if the rhesus macaque antiKIR antibodies also cross-react with other non-human primate species.

For all monkeys the same gating strategy was performed as for rhesus macaque (Figure 13) with the exception of the exact $\mathrm{CD}_{16} 6^{+}$population. CD11c-APC was used as an additional marker to exclude mDCs because the CD16/CD8 gating did not work for all the tested monkey species (data not shown). Therefore, the $1 \mathrm{C7}$ antibody had to be used conjugated with DyLight488.

For all tested animals it was possible to detect KIR, which means that at least the panKIR antibody $1 \mathrm{C7}$ is able to detect KIR of other non-human primates. Due to limited amount of samples, the other antibodies could not be tested so far.

$55-75 \%$ of all cynomolgus macaque NK cells are KIR positive and 2-22 \% of CD8 ${ }^{+} \alpha \beta$ T cells. The frequency and density of KIRs expressed neither correlate for NK cells (Pearson $r=0.7109, p=0.2891$ ) nor for $\mathrm{CD}^{+} \alpha \beta$ T cells (Pearson $r=0.9333, p=0.0667$ ) (Figure 21a).

In baboons 60-95 \% of all NK cells express KIR and most of them are highly similar in their KIR frequency (around $90 \%$ ), which is different to rhesus macaques (Figure 21b). In contrast, the amount of expressed KIR (MFI) varies between different animals. No significant correlation between KIR positive NK cells and the level of expression could be found (Pearson $r=0.5266, p=0.1452$ ). $\mathrm{CD}^{+} \alpha \beta \mathrm{T}$ cells of baboons are also able to express KIR (6-20\%) and like for rhesus macaque the frequency and the amount of KIR correlates significantly (Pearson $\mathrm{r}=0.8305$, $\mathrm{p}=0.0056$ ).

NK cells of African green monkeys show a similar KIR expression like cynomolgus macaques and baboons. Between 72-90 \% of all NK cells are positive with the pan-KIR antibody 1C7. The frequency does not correlate with the expressed density of KIR on NK cells (Pearson $r=-0.1311, p=0.8689$ ). Surprisingly, only very few $\operatorname{CD}^{+} \alpha \beta$ T cells (1.8-3.7 \%) express KIR in this species (Figure 21c). 
a

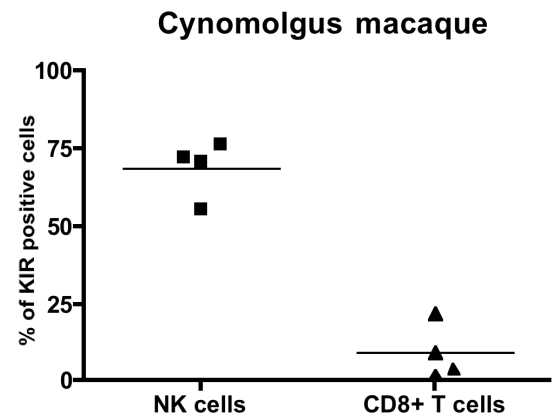

$\mathrm{b}$

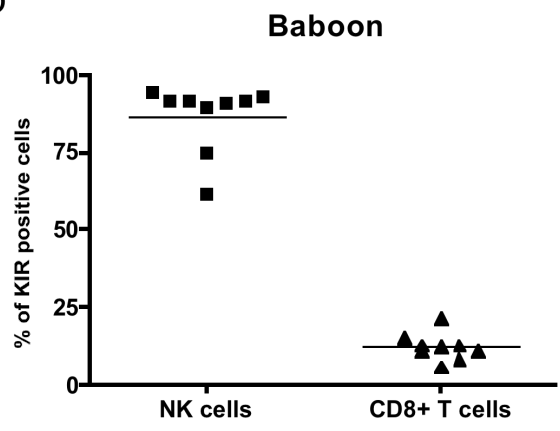

C

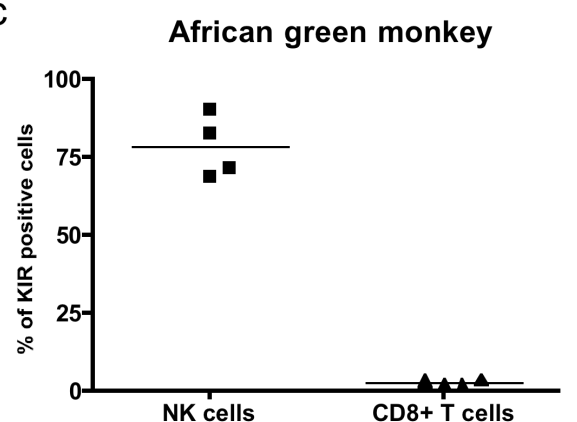

Cynomolgus macaque

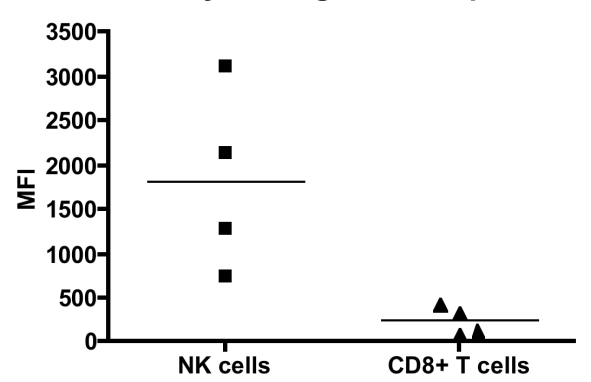

Baboon

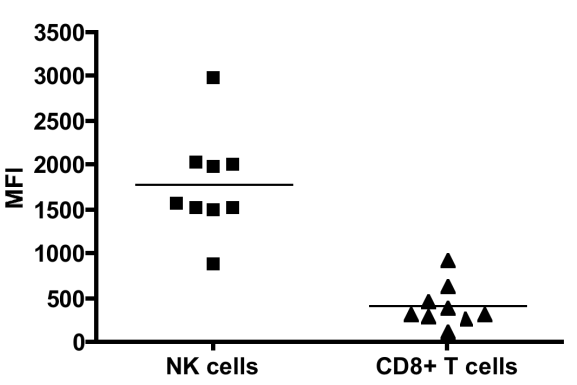

African green monkey

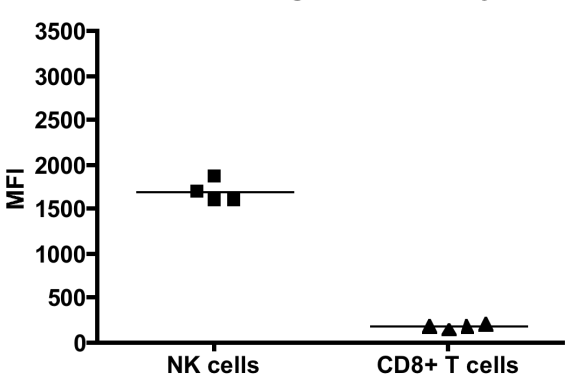

Figure 21. Flow cytometry analysis of KIR expression by NK and cytotoxic $\alpha \beta$ T cells of three nonhuman primate species.

(a) Baboon ( $n=9)$, (b) cynomolgus macaque $(n=4)$ and (c) African green monkey $(n=4)$ were analysed for KIR expression. Shown is the number of KIR-expressing NK and $\mathrm{CD}^{+} \alpha \beta$ T cells (\%, left panel) and the corresponding level of KIR expression (MFI, right panel) using the pan-KIR antibody 1C7DyLight488.

Comparison of all tested Old World monkey species showed a similar KIR expression for NK cells and differ in their frequency of KIR expressing NK cells. Additionally, for none of the species a correlation between the percentage of KIR-expressing NK cells and the amount of expressed KIR was observed. Cynomolgus macaques and baboons show higher percentages of KIR-expressing $\mathrm{CD}^{+} \alpha \beta$ T cells compared to African green monkeys. There is always a positive correlation between the frequency and density of KIR expression. Because of the detection of KIR on NK cells of African green monkeys a missing cross-reactivity for this species can be excluded. 


\subsection{KIR expression pattern changes due to SIV infection}

The analysis of KIR expression in a disease model was facilitated by cooperation with Professor Aftab Ansari (Department of Pathology, Emory University School of Medicine, Atlanta). As part of this cooperation, samples of SIV infected rhesus macaques were analysed for their KIR expression using the anti-rhesus macaque KIR antibody 1C7DyLight633. The advantages of working with rhesus macaques as animal models for HIV research were:

I. The animals were infected with a defined virus (SIVmac239 or SIVmac251).

II. The infection took place under controlled conditions with a known dose and defined route of infection (mucosal route).

III. The infection was performed at a defined time point and therefore knowledge of the infection phase existed.

IV. Information about the pre infection status were available.

As a result of the frequent PBMC sampling post infection, the animals could be divided in different groups. The grouping parameters were the viral load at and after viral load set point where a relative constant value of plasma viral load was observed (chronic phase of infection). Another grouping criterion was the amount of $\mathrm{CD}^{+} \alpha \beta \mathrm{T}$ cells during acute phase of infection. Fast progressors show high viral loads $(>100,000$ copies $/ \mathrm{ml}$ ) at the chronic phase and a massive loss of $\mathrm{CD}^{+} \alpha \beta \mathrm{T}$ cells during acute phase of infection. These animals usually die within nine months post infection. High viral load (HVL) animals show high levels of plasma viral load (>100,000 copies $/ \mathrm{ml})$ at two consecutive time points during infection but depending on the $\mathrm{CD}^{+} \alpha \beta \mathrm{T}$ cell counts during acute phase of infection not all HVL animals are classified as fast progressors. They can survive up to two years post infection. Normal progressors show plasma viral loads from 50,000 to 100,000 copies/ml throughout chronic infection and modest but significant $\mathrm{CD}^{+} \alpha \beta \mathrm{T}$ cell loss during acute phase of infection. These animals usually die within two to four years post infection. Animals with a low plasma viral load (LVL) also show modest $\mathrm{CD}^{+} \alpha \beta$ T cell loss during acute phase of infection but have lower plasma viral loads during chronic infection $(<50,000$ copies $/ \mathrm{ml})$. LVL animals usually survive three to six years post infection. Elite controller animals have variable plasma viral loads during chronic infection (1000-2000 copies/ml, for "super" elite controller even less to undetectable). Only a decline of $10-20 \%$ of $\mathrm{CD}^{+} \alpha \beta$ T cells 
during acute phase of infection is usually observed and they can survive for up to seven years post infection ("super" elite controller even longer - "long term surviver"). The Ansari group classified three different groups (HVL, LVL and elite controller) for the animals analysed in the following.

The aim of analysing samples of SIV-infected rhesus macaques was to identify changes or similarities in the KIR expression caused by SIV infection. Therefore, a pre infection sample, one sample of the acute phase and one of the chronic phase of infection was analysed for each animal of all three groups. However, limitations of this study arose due to different reasons. All samples were frozen in liquid nitrogen and, therefore, differ in quality. For this reason, always the influence of the total cell numbers on the number of KIR-expressing cells was analysed. For none of the animals and for no time point any correlation was observed. Therefore, an influence of the total cell number on the observed changes in KIR expression seems to be excludable. Additionally, because of the sample quality no clear gating as it is possible for fresh samples could be performed and no clear separated population of KIR-positive cells was observed, only a shift of the cell population. This might be the reason for the low percentage of KIR positive cells compared to fresh samples. Due to the rapid development of AIDS for HVL animals, some samples of the chronic phase of infection had to be excluded from analysis due to low numbers of NK cells and T cells. For the comparison of animals belonging to one group the sampling time points of the acute samples differed. The samples showed a variation from two to twelve weeks post infection. This might already influence the data set. Difficulties in statistic and therefore the explanatory power arose from the small sample size. Six elite controller, six LVL and twelve HVL animals were analysed for their KIR expression at different time points. To make things more complicated, two animals (RuR7-mm48 and RJv9-mm4) of the LVL group showed plasma viral loads above 50,000 copies/ml and should be defined as "normal" (Table 5). Because of the small sample size of two animals and the grouping as LVL animals for other studies, these animals were combined with the four remaining LVL animals as LVL group. 
Table 5. Summary of all tested SIV infected animals.

Animals were grouped due to their viral loads in elite controller, LVL (low viral load)/normal and HVL (high viral load). All animals were infected with 200 TCID50 (tissue culture infective dose 50) and the viral loads (copies/ml) are shown for the acute and the chronic phase of infection. The LVL and "normal" group were combined in the following analyses.

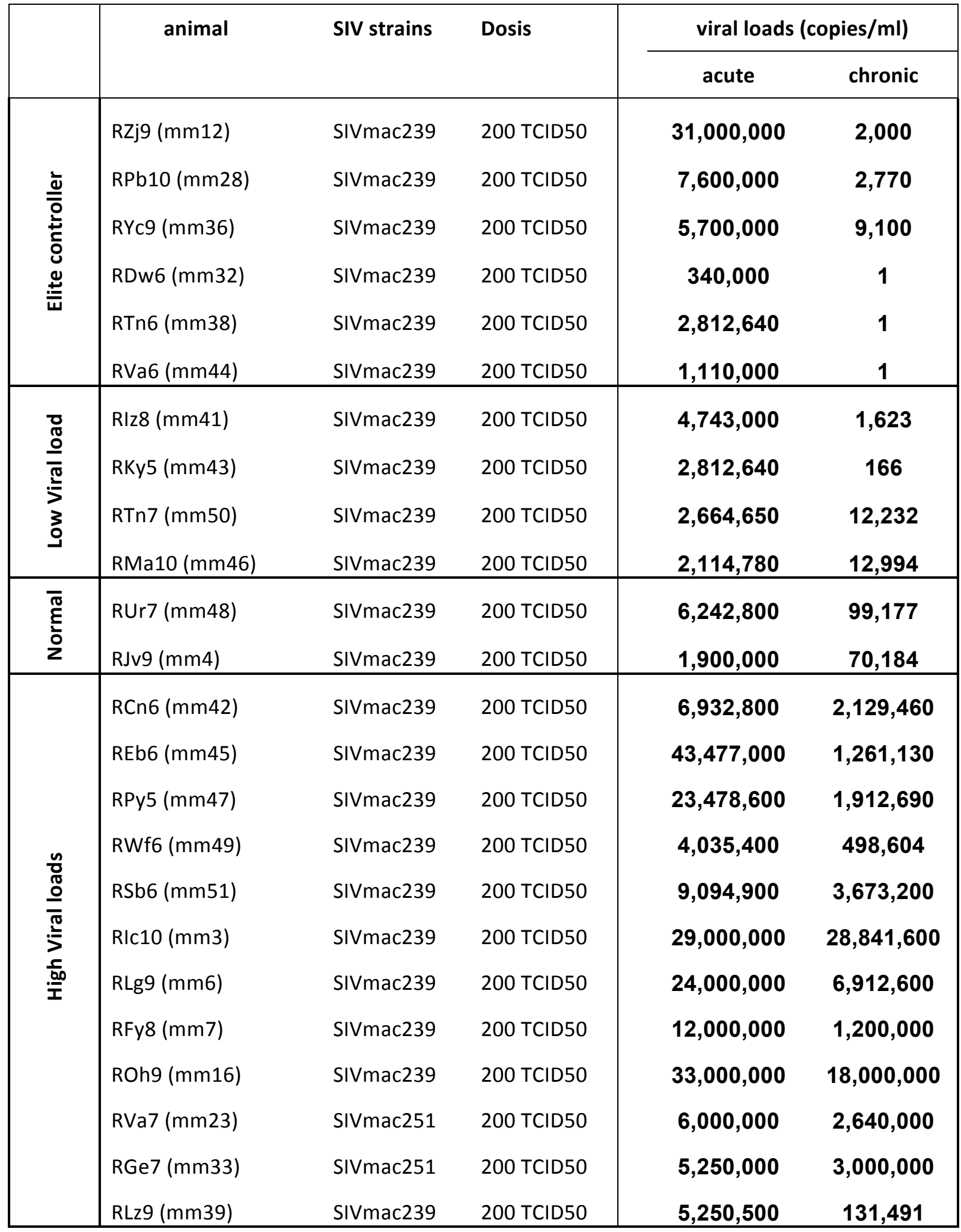


In the following, 24 rhesus macaques were analysed for their KIR expression pre infection, in the acute and in the chronic phase of infection. The percentage of KIRpositive cells and the MFI for the amount of expressed KIR were always analysed. The correlation of these two values was tested as for the healthy animals. The changes in the KIR expression (pre to acute as well as acute to chronic) were analysed for statistic significance using the paired $t$ test and for correlation between the number of KIRpositive cells and the amount of expressed KIR (Pearson correlation). Furthermore, it was tested if the changes in KIR expression correlate between different cell populations (NK, CD8 ${ }^{+} \alpha \beta$ and $\gamma \delta$ T cells) within a group and if there is a correlation within a cell population but between the different viral load groups (HVL, LVL and elite controller). Table 5 summarises the grouping of the animals, the virus strain, the dose virus and the viral load for the acute and the chronic sample.

\subsubsection{Changes of NK cell KIR expression in the acute phase of SIV infection}

NK cells of all three groups were analysed for their number of KIR-positive NK cells and the amount of expressed KIR. The pre and acute samples were compared to detect alterations in the KIR expression due to SIV infection.

Elite controller animals (Figure 22a) showed a slight reduction of KIR-expressing NK cells, except for animal RYc9 that showed a strong reduction. Differences in the KIR expression after SIV infection were statistically significant (paired $t$-test; $\mathrm{p}=0.0244$ ).

The LVL group (Figure 22b) also showed a reduction of KIR-expressing NK cells with the exception of animal RUr7, which had an increased number of KIR-expressing NK cells $(p=0.4081)$. For the HVL group (Figure 22c) no clear trend neither towards reduction nor increase of KIR-expressing NK cells after infection could be observed. Only four animals had a change in KIR expression of less than $5 \%$. All other animals had a clear increase or decrease up to $60 \%$ (RLz9). No significance ( $p=0.1929)$ either for the increase or reduction of KIR-expressing NK cells was found with the paired $t$ test. 
a

Elite controller
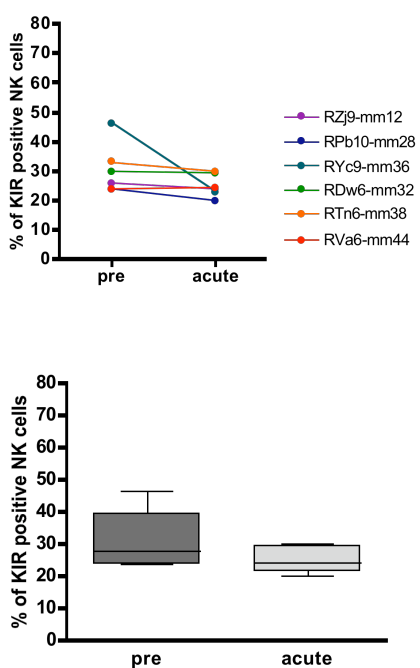

b LVL
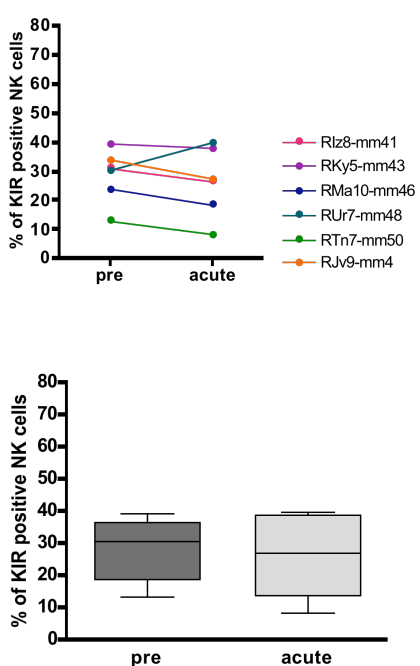

c $\mathrm{HVL}$
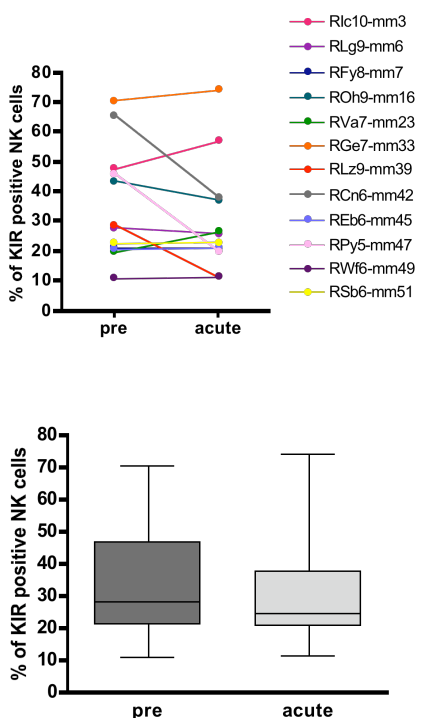

Figure 22. Alteration of KIR expression by NK cells after infection with SIV.

Shown are the changes in the KIR expression of NK cells from pre to post infection with SIV for three different groups: elite controller (a), LVL (b) and HVL (c). In the upper row the changes for each individual animal are depicted (percentage before and after infection). The bottom row shows box plots with whiskers and the median for all samples per group combined.

However, the animals differ in their mean fluorescence intensity of expressed KIRs as well as in their percentage of KIR-positive NK cells like it was already shown for the healthy rhesus macaques (Figure 23).
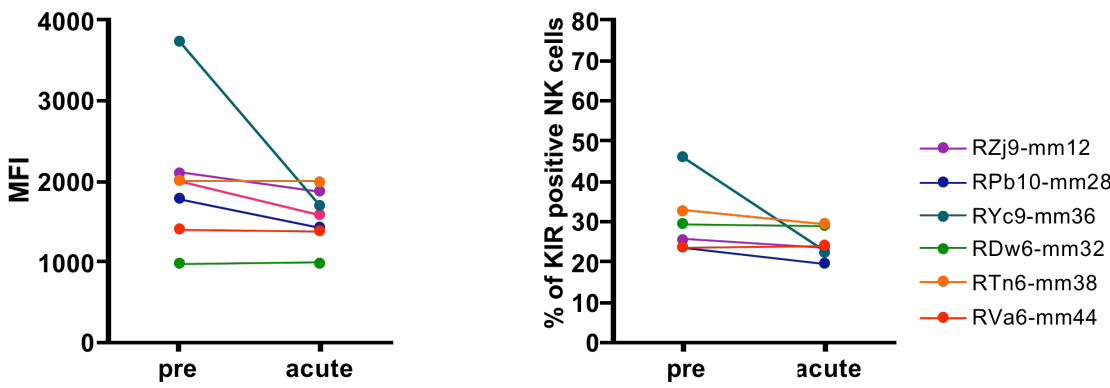

Figure 23. Comparison of the percentage of KIR positive NK cells with the MFI in elite controllers. Shown are the MFI (left panel) and the percentage (right panel) of KIR expression for elite controller animals. The change in KIR expression for pre to post infection samples did positively correlate (Pearson $r=0.9719, p=0.0012$ ).

The difference between the pre and acute values of the percentage was correlated with the difference of the pre-MFI to the acute-MFI. A significant positive correlation was observed for all analysed groups (elite controller: Pearson $r=0.9719, p=0.0012$; LVL: Pearson $r=0.9842, p=0.0004$; HVL: Pearson $r=0.9696, p<0.0001)$. From this it follows 
that all animals with a change in the number of KIR-expressing NK cells showed also a change in the density (MFI) of expressed KIRs.

\subsubsection{Changes of NK cell KIR expression during chronic phase of SIV infection}

The KIR expression during the chronic phase of SIV infection was also analysed for the same animals as shown before. For elite controller animals changes in KIR expression from $3 \%$ (RJv9) to $50 \%$ (RYC9) were observed. But no clear trend compared to the data of the acute infection (3.3.1) was found. Two animals (RZj9 and RPb10) had a reduction of KIR-expressing NK cells and four showed a more or less clear increase of KIR-positive NK cells (RYc9, RDw6, RTn6 and RVa6) (Figure 24a). Therefore, no significant change in the number of KIR-expressing NK cells in the phase from acute to chronic SIV infection could be detected ( $\mathrm{p}=0.3505)$. But the KIR expression pattern in general changed during infection either by increase or decrease: in the LVL group two animals (RMa10 and RUr7) showed a clear reduction in KIR-expressing NK cells and for the others the decrease was less then $10 \%$ (Figure 24b). No significant alteration in number of KIR-expressing NK cells could be observed for LVL animals ( $p=0.2004)$. Again, animals of the HVL group showed no clear trend. Some animals had an increased number of KIR-expressing NK cells and some a decreased number but no animal expressed the KIR on the same level as for the acute sample (Figure 24c). For some animals (RVa7, RLz9 and REb6) the chronic samples had to be excluded from analysis due to dramatically reduced cell numbers of $\mathrm{T}$ and NK cells during progression to AIDS. Also for the acute and chronic samples a significant correlation for the alteration in the KIR expression percentage and the MFI was observed for all three groups (Elite controller: Pearson $r=0.9720, p=0.0012$; LVL: Pearson $r=0.8405, p=0.0361$; HVL: Pearson $r=0.9195, p=0.0005$ ). 

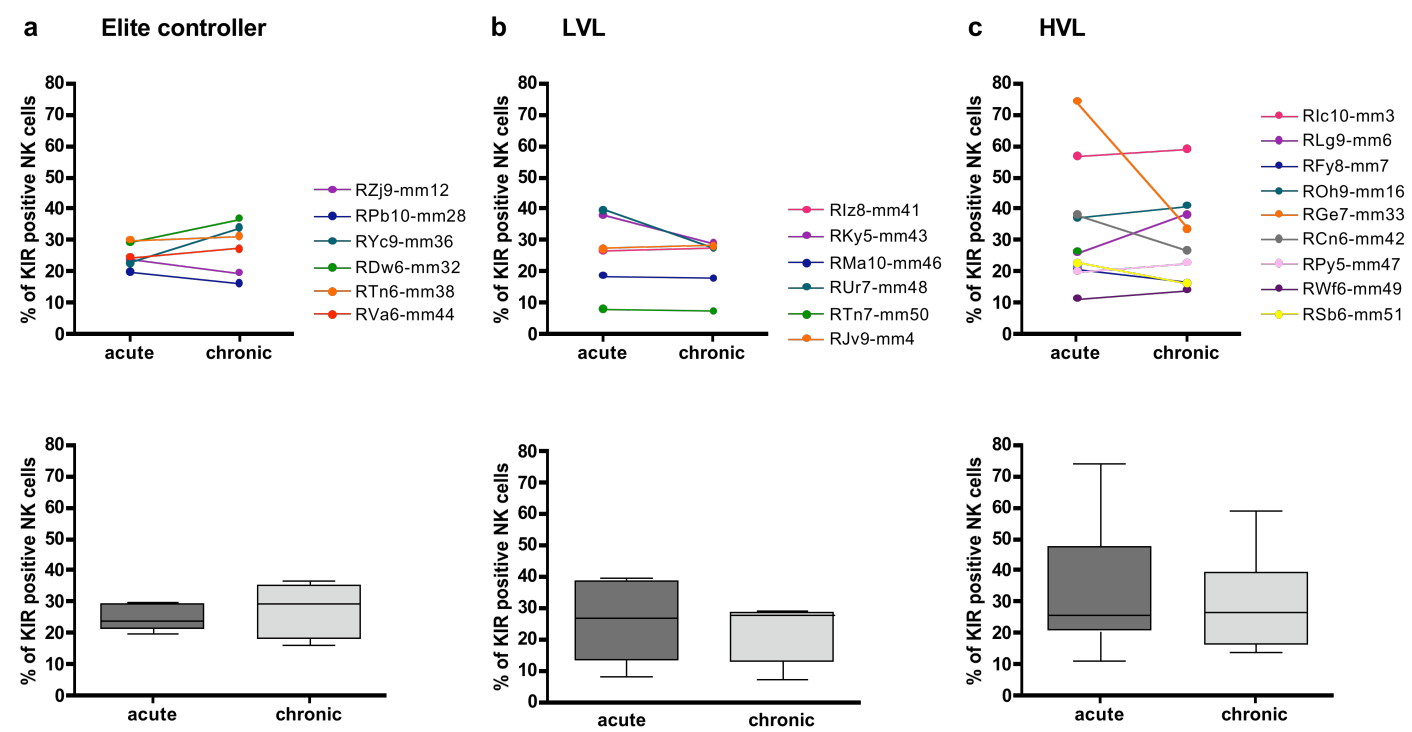

Figure 24. Alteration of the number of KIR-expressing NK cells during SIV infection.

Shown are the changes in the KIR expression of NK cells in the course of SIV infection for three different groups: elite controller (a), LVL (b) and HVL (c). In the upper row the changes for each individual animal are depicted (percentage before and after infection). The bottom row shows box plots with whiskers and the median for all samples per group combined.

\subsubsection{Changes of $\mathrm{CD}^{+} \alpha \beta$ T cell KIR expression in the acute phase of SIV infection}

In addition to NK cells, $\mathrm{CD}^{+} \alpha \beta$ T cells were analysed for their KIR expression pattern in the acute phase of SIV infection (Figure 25). For the elite controller group no significant trend was seen for the number of KIR-expressing $\mathrm{CD}^{+} \alpha \beta$ T cells due to SIV infection ( $\mathrm{p}=0.9591)$. Changes with $30 \%$ decrease (RYc9) and also with $30 \%$ increase (RDw6) of KIR-expressing CD8 ${ }^{+} \alpha \beta$ T cells were observed. For the LVL group also no clear changes were found. There was a slight trend towards a reduction of KIRexpressing $\mathrm{CD}^{+} \alpha \beta \mathrm{T}$ cells but no significant shift $(\mathrm{p}=0.2202)$. An increase in the number of KIR-expressing $\mathrm{CD}^{+} \alpha \beta$ T cells was observed for the HVL group. Only three animals showed a slight decrease (RGe7, RPy5, RCn6) . The paired $t$-test did not show a significant increase of KIR positive $\mathrm{CD}^{+} \alpha \beta \mathrm{T}$ cells in the acute phase of SIV infection $(\mathrm{p}=0.0733)$. A significant correlation in the change of the percentage of KIR-positive $\mathrm{CD}^{+} \alpha \beta \mathrm{T}$ cells and the mean fluorescence intensity was observed (Elite controller: Pearson $r=0.9499, p=0.0037$; LVL: Pearson $r=0.0 .8743, p=0.0227$; HVL: Pearson $\mathrm{r}=0.822, \mathrm{p}=0.0010$ ). As for NK cells a change in the percentage of KIR-positive cells correlates positively with the changes in the amount of expressed KIRs. 

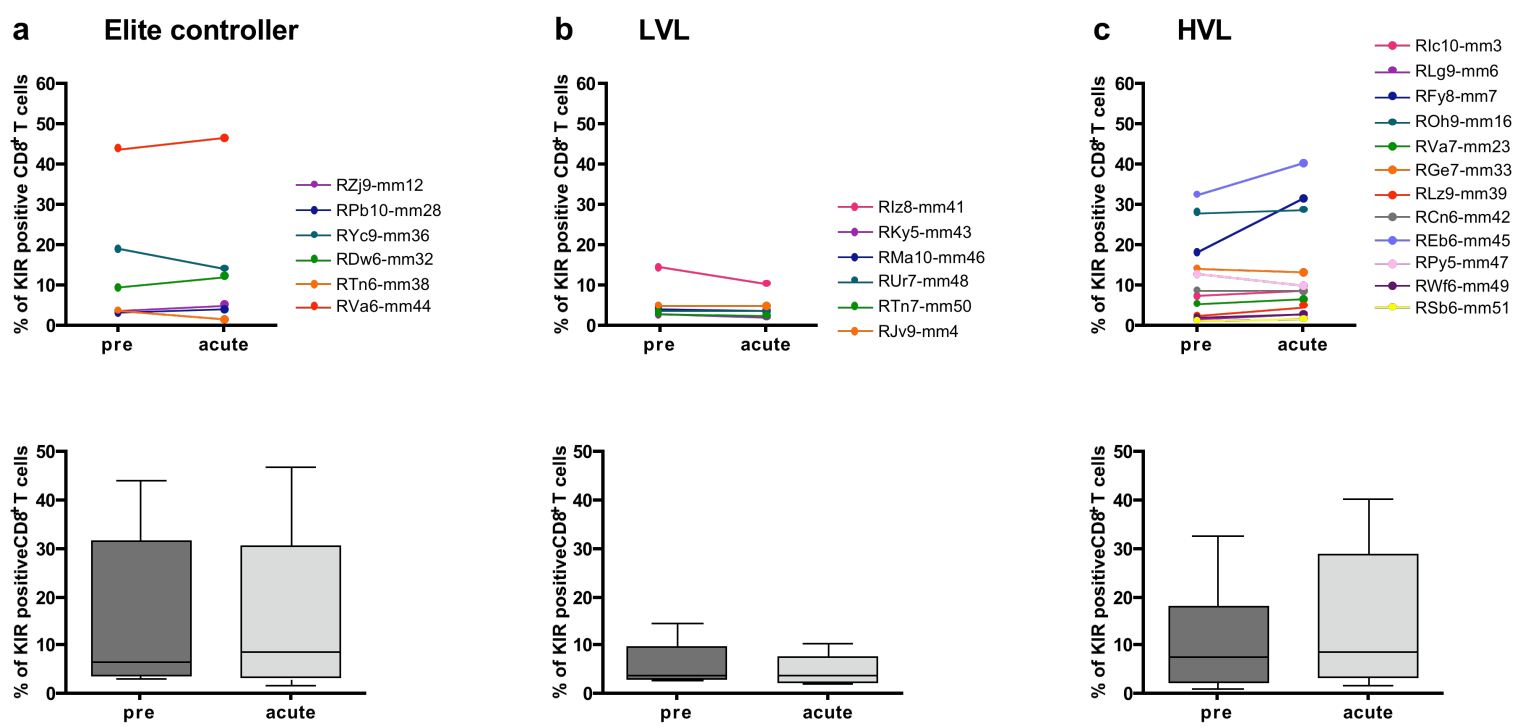

Figure 25. KIR expression pattern of $\mathrm{CDB}^{+} \alpha \beta$ T cells in the acute phase of SIV infection.

Shown are the changes in the KIR expression of $\mathrm{CD}^{+} \alpha \beta$ T cells before and after infection with SIV for three different groups: elite controller (a), LVL (b) and HVL (c). Samples were analysed with the 1C7-DyLight633 antibody. In the upper row the changes for each individual animal are depicted (percentage before and after infection). The bottom row shows box plots with whiskers and the median for all samples per group combined.

\subsubsection{KIR expression of $\mathrm{CD}^{+} \alpha \beta \mathrm{T}$ cells in the chronic phase of SIV infection}

The KIR expression of $\mathrm{CD}^{+} \alpha \beta$ T cells during chronic SIV infection did not reveal clear differences between the three animal groups (Figure 26). The elite controller group showed increased numbers of KIR-positive $\mathrm{CD}^{+} \alpha \beta \mathrm{T}$ cells but also a reduction for some animals, so there is no significant trend $(\mathrm{p}=0.3508)$. The KIR expression changed and was not constant over time, but not in a clear direction (Figure 26a). For the LVL group the same was true as for the elite controller animals $(\mathrm{p}=0.1614)$. Three animals showed a clear increase (RIz8, RJv9, RUr7) and three a slight reduction or constant numbers (RMa10, RKy5 and RTn7) of KIR-expressing CD8 ${ }^{+} \alpha \beta$ T cells during chronic SIV infection (Figure 26b). In general, the number of KIR-expressing CD8 ${ }^{+} \alpha \beta$ T cells was low for the LVL animals (1.5-5\%) except for RIz8 (more than $10 \%)$. Due to the fast progression to AIDS, some samples of the HVL group had to be excluded. Also for the HVL group no unique trend in change of KIR expression was observed $(p=0.6716)$ (Figure 26c). The KIR-positive $\mathrm{CD}^{+} \alpha \beta$ T cells did not maintain the same number as at the acute phase of infection, but five out of eight animals had a decreased percentage of KIR-positive CD8 ${ }^{+} \alpha \beta$ T cells and three animals an increased number. 
The change in the percentage and the mean value of expressed KIR pre and post infection correlated significantly (Elite controller: Pearson $r=0.9843, p=0.0004$; LVL: Pearson $r=0.8308$, p=0.0405; HVL: Pearson $r=0.7113$, p=0.0479).
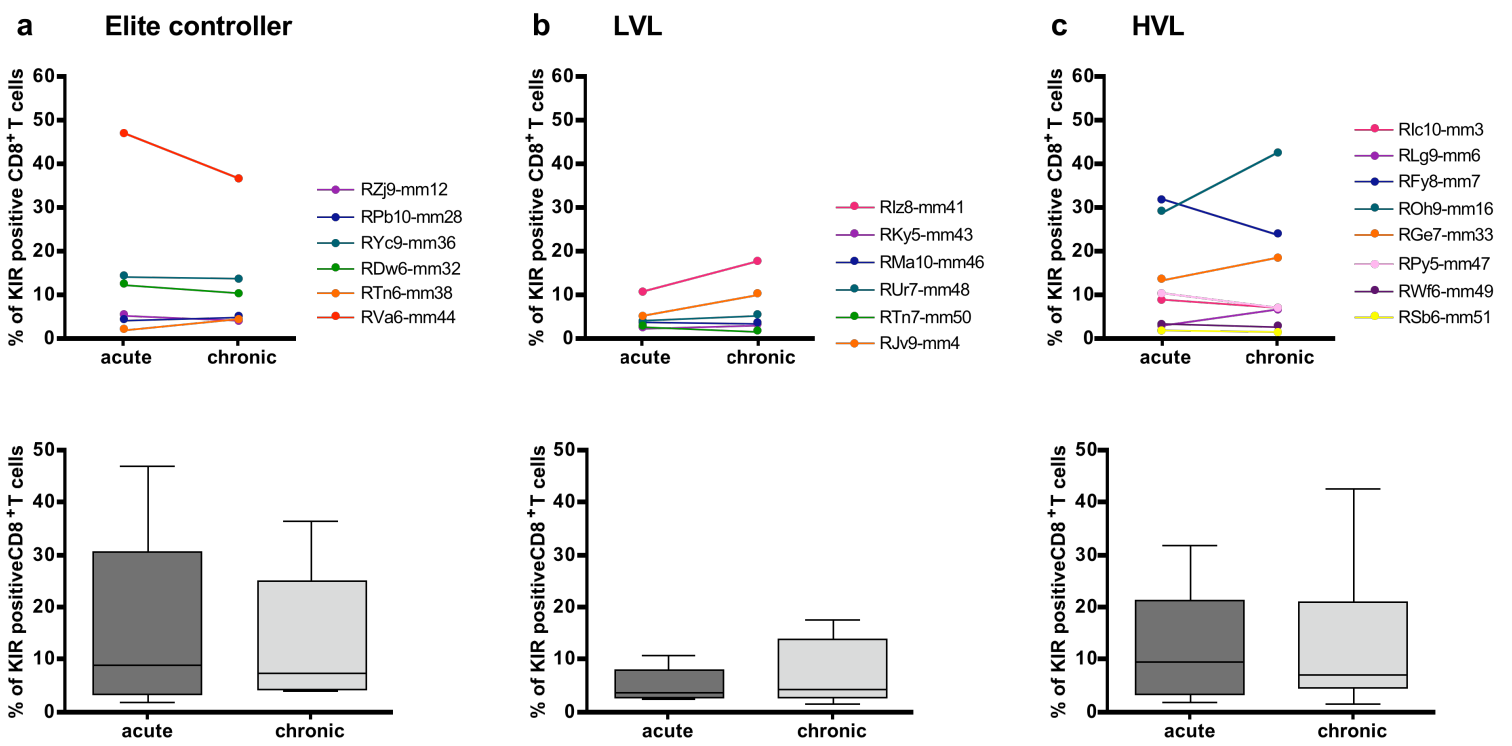

Figure 26. Changes in KIR expression by $\mathrm{CDB}^{+} \alpha \beta$ T cells during chronic SIV infection.

Changes in KIR expression of $\mathrm{CD}^{+} \alpha \beta$ T cells during chronic SIV infection for three different groups are shown: elite controller (a), LVL (b) and HVL (c). Samples were analysed using 1C7-DyLight633 antibody. In the upper row the changes for each individual animal are depicted (percentage in acute and in chronic infection). The bottom row shows box plots with whiskers and the median for all samples per group combined.

\subsubsection{Changes of $\gamma \delta T$ cell KIR expression in the acute phase of SIV infection}

The influence of SIV infection on the number of KIR-expressing $\gamma \delta \mathrm{T}$ cells was analysed as well. The elite controller group showed an increase in KIR-positive $\gamma \delta$ T cells in the acute phase of SIV infection except for RYc9 and RTn6 that showed a clear decrease (Figure 27a). No significant changes in the KIR expression were found $(p=0.8120)$. A similar situation occurred for the LVL animals where also an increase of KIR-expressing $\gamma \delta$ T cells was observed with the exception of RTn7 $(p=0.3274)$ (Figure 27b). Elite controller as well as the LVL group included outliers that showed clear reduction of KIR expressing cells while all other animals showed a clear increase. 

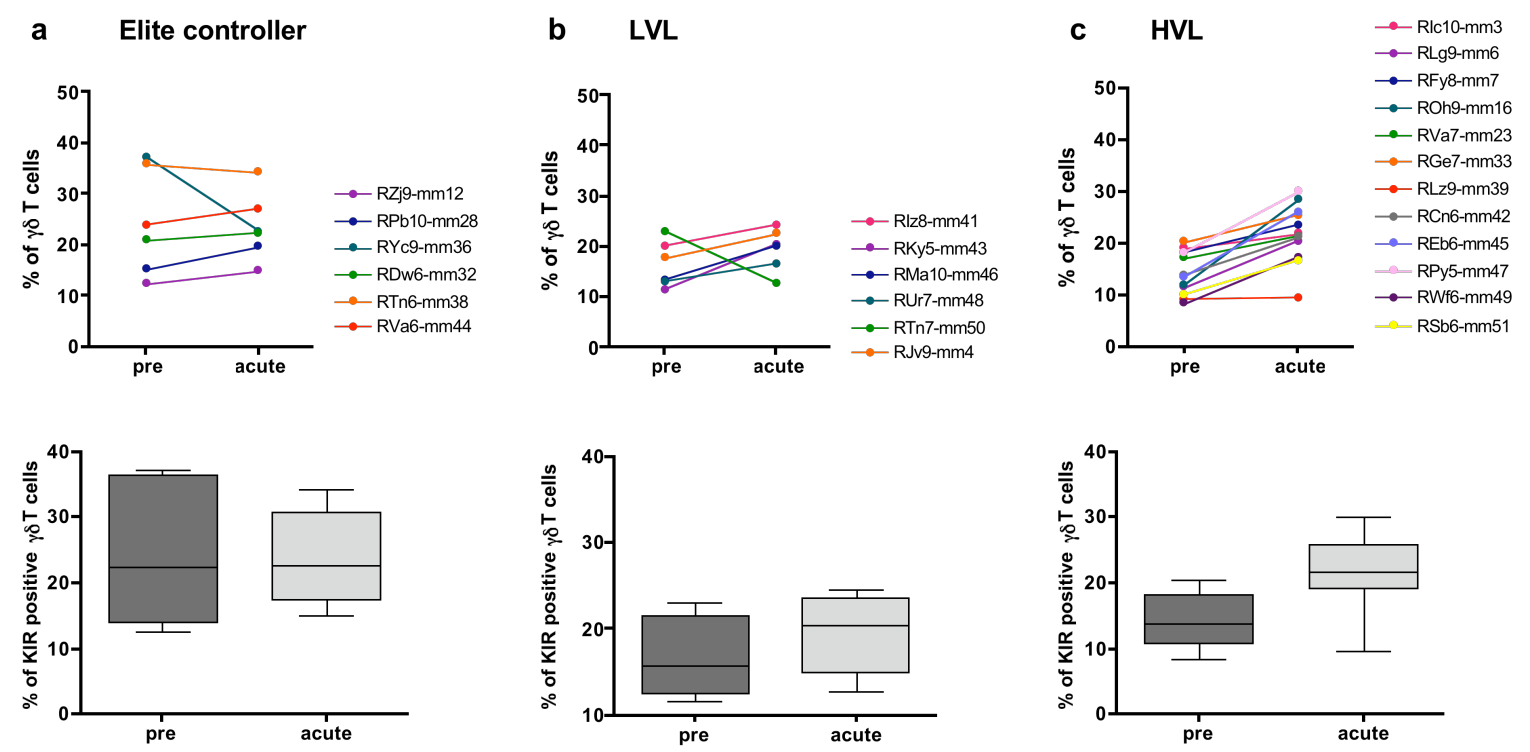

Figure 27. KIR expression alteration by $\gamma \delta$ T cells in the acute phase of SIV infection

Changes in the KIR expression of $\gamma \delta$ T cells pre to post infection with SIV for three different groups are shown: Elite controller (a), LVL (b) and HVL (c). Samples were analysed using the 1C7-DyLight633 antibody. In the upper row the changes for each individual animal are depicted (percentage before and after infection). The bottom row shows box plots with whiskers and the median for all samples per group combined. The HVL group showed a significant trend to an increased number of KIR expressing $\gamma \delta$ T cells in the acute phase of SIV infection ( $p=0.0001)$.

A clear result was obtained for the HVL group (Figure 27c). A highly significant increase in KIR-expressing $\gamma \delta \mathrm{T}$ cells in the acute phase of SIV infection was seen for all tested animals without any exclusion $(\mathrm{p}=0.0001)$.

As for all other tested lymphocyte populations, the change in the percentage and the MFI of expressed KIR correlated (Elite controller: Pearson $r=0.9285$, p=0.0075; LVL: Pearson $r=0.0031, p<0.0001$; HVL: Pearson $r=0.9337$. $p<0.0001$ ).

\subsubsection{KIR expression of $\gamma \delta$ T cells in the chronic phase of SIV infection}

In the chronic phase of SIV infection, the KIR-positive $\gamma \delta$ T cell number was reduced in the elite controller group with the exception of RYc9 $(\mathrm{p}=0.8698)$ (Figure 28a). For LVL animals no clear trend could be observed $(p=0.9856)$. Two animals had reduced numbers of KIR-positive $\gamma \delta$ T cells (RIz8 and RTn7) and four had an increased number (RKy5, RMa10, RUr7 and RJv9) (Figure 28b). The same was observed for the HVL animals (Figure 28c). Some animals showed an increase and some a decrease of KIRexpressing $\gamma \delta \mathrm{T}$ cells and for only two animals the KIR expression stayed nearly 
constant. Two animals of the HVL group had to be excluded for the chronic phase of infection analysis (RLz9 and REb6) due to very low cell numbers of these animals.

In the chronic phase of SIV infection for $\gamma \delta \mathrm{T}$ cells no significant correlation between the changes of the KIR expression for the percentage and the MFI was found (Elite controller: Pearson $r=0.6581, p=0.1553$; LVL: Pearson $r=0.5960, p=0.2118$; HVL: Pearson $r=0.5636, p=0.0898)$.
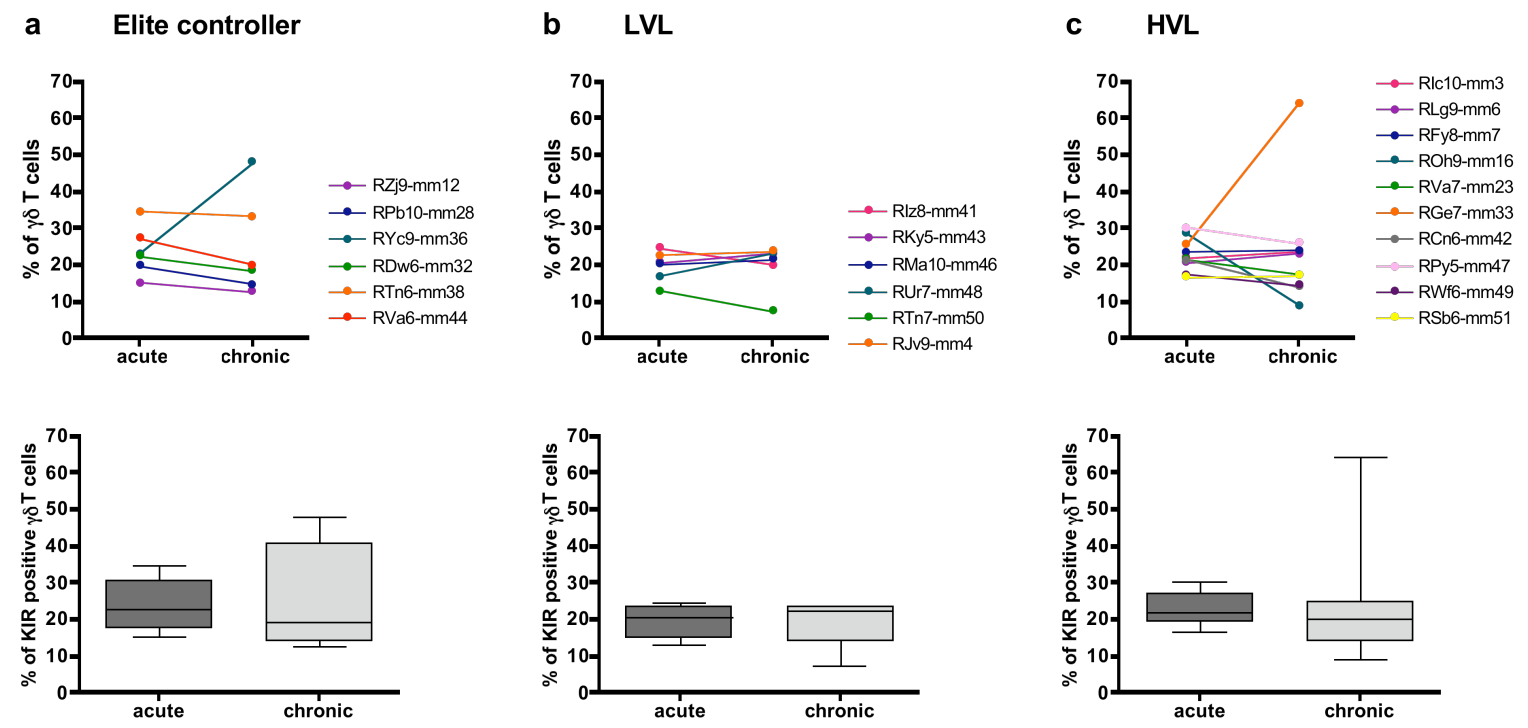

Figure 28. Changes in KIR expression by $\gamma \delta$ T cells during chronic SIV infection.

Changes in the KIR expression of $\gamma \delta$ T cells in the course of SIV infection for three different groups are shown: elite controller (a), LVL (b) and HVL (c). Samples were analysed using 1C7-DyLight633 antibody. In the upper row the changes for each individual animal are depicted (percentage in acute and in chronic infection). The bottom row shows box plots with whiskers and the median for all samples per group combined.

\subsubsection{No significant correlation in the KIR expression between different cell populations}

To study a putative correlation in the KIR expression of different cell populations, the changes from pre to acute and acute to chronic for each cell type were compared using the Pearson correlation. NK cells, $\mathrm{CD}^{+}$cells and $\gamma \delta \mathrm{T}$ cells were all checked for correlation among each other. The analysis was performed for the change in the acute phase of SIV infection (pre to acute) and during chronic SIV infection (acute to chronic) in all three groups elite controller, LVL and HVL. For none of the groups a significant correlation between the three analysed cell populations was observed. Comparison of the three analysed cell populations among each other did not show any connection. The 
KIR expression and its changes in the course of SIV infection appear to be independent for each of them.

\subsubsection{Correlation of KIR expression between animals with different viral loads}

Besides the comparison of different cell populations the cell populations of different viral load groups were compared using a $t$-test. For NK cells no significant difference was found for elite controller, LVL and HVL animals. The comparison of CD8 ${ }^{+} \alpha \beta$ T cells showed a significant difference for LVL and HVL animals for the KIR expression alteration after infection with SIV (pre to acute, $\mathrm{p}=0.0173$ ). All other groups did not show any clear differences. The $\gamma \delta$ T cells had a significant difference for the elite controller group and the LVL animals (pre to acute, $p=0.0086$ ) but no other clear correlations could be observed for this cell population. For most of the analysed comparisons the $\mathrm{p}$ value was quite high which means that the compared groups show a similar change in KIR expression. 


\section{Discussion}

The KIR3DL family of humans and also rhesus macaques originated in simian primates and is about 40-58 million years old (Parham et al., 2010). The KIR3DL gene and its diversity is a specific product of primate evolution (Sambrook et al., 2006). Nevertheless, Old World monkeys and human diverged about 28-30 million years ago and their KIR genes evolved differently (Parham et al., 2010). Lineage II KIR that specifically bind to MHC-A and MHC-B molecules (Parham, 2005) in humans and great apes and to MHC-A in macaques are expanded in macaques, whereas lineage III KIRs that specifically bind to MHC-C are expanded in humans and great apes. In line with these observations, the changes in the KIR lineages are mirrored by lack of a MHC-C gene and expansion of MHC-A genes in macaques. This expansion is also seen in African green monkeys (Hershberger et al., 2005). Despite the species-specific differences between human and rhesus macaques especially in the activating KIR (1.4.1), the rhesus macaque and also other Old World monkeys like African green monkey and cynomolgus macaques are useful and informative models for the human immune system and associated diseases. The rapid evolution of KIR genes might be the reason

for the missing cross-reactivity of any human anti-KIR antibody with rhesus macaque KIR. Even the antibody (Dx9) against human lineage II KIR3DL1 does not show any reactivity.

Today, few genotyping methods (Kruse et al, 2010, Blokhuis et al., 2010) are established and also the analysis of the transcript level of KIR mRNA is now possible (Moreland et al., 2011). The effort in optimising these rhesus macaque specific methods is currently not as advanced as for human KIR, but they should get first information of the variability of KIR genes and the expression of KIR on transcript level. So far, nothing was known about the surface expression of rhesus macaque KIR. As KIRs are known to influence the progress of certain human diseases (1.3) the rhesus macaque as animal model has to be characterised to clarify the differences and similarities in the KIR expression pattern. Therefore, as the main topic of this work, monoclonal anti-macaque KIR antibodies were established, characterised and further used for the analysis of the KIR expression pattern of healthy rhesus macaques. 


\subsection{Characteristics of anti-rhesus macaque KIR antibodies}

\subsubsection{No cross-reactivity with KIR of hominoids}

Anti-rhesus macaque KIR antibodies were established and initially characterised using ELISA. At the level of ELISA it was already possible to observe antibodies with different specificities for certain KIR molecules. Due to the high sequence similarity among the various rhesus macaque KIR proteins (up to 97\% identity) and the complete lack of corresponding KIR in mice, it was unexpected to obtain antibodies with single or rather limited specificity such as $2 \mathrm{H} 5,2 \mathrm{H} 9,2 \mathrm{~A} 4$ and $2 \mathrm{H} 3$. For the same reason it was surprising to find only a little number of antibodies with a broad specificity for all analysed KIR molecules. As no cross-reactivity of anti-human KIR antibodies with rhesus macaque KIR could be observed, KIR-Fc fusion proteins of different hominoids (chimpanzee, orangutan and human) were tested with the anti-rhesus macaque KIR antibodies using ELISA and no or only very weak recognition was observed. Taken together, neither anti-human nor anti-rhesus macaque KIR antibodies recognise KIR molecules of the other species. This points out to the rapid evolution of hominoid and Old World monkey KIR with numerous gene expansions and contractions and accumulation of allelic polymorphism.

\subsubsection{Binding characteristics of anti-rhesus macaque KIR antibodies}

The main application of the newly established antibodies is flow cytometry. Therefore, the screening using ELISA was only used for the first selection of suitable hybridoma clones and the more important analysis tool was flow cytometry. HEK293 cells transfected with constructs for recombinant expression of AcGFP-tagged rhesus macaque KIR were tested with the antibodies. At least one allele from each of seven inhibitory KIR molecules and of four different activating KIRs was tested. No antibody could be identified that is able to distinguish between activating or inhibitory KIR. The different specificities seen in ELISA were confirmed by flow cytometry analysis. Nevertheless, using flow cytometry is the more efficient method to identify suitable antibodies for the intended application of these antibodies. 
Additionally, epitope mapping was performed to get detailed information about the binding sites of the antigen. The reaction patterns of the analysed antibodies were quite similar (Figure 10). In particular, the peptide stretches RCHYRHRFNN (Figure 11 and Figure 29, in yellow) and SHPHSPTG (Figure 11 and Figure 29, in red) were recognized with the antibodies. This indicates that amino acids of these stretches contribute to the epitope. The recently published 3D-structure of human KIR3DL1 (Vivian et al., 2011) was used by Joachim Koch and colleagues to identify the location of the detected peptides. The aforementioned peptide stretches are both surface exposed and located next to each other in the N-terminal region of the KIR3D protein, indicating a conformational epitope.
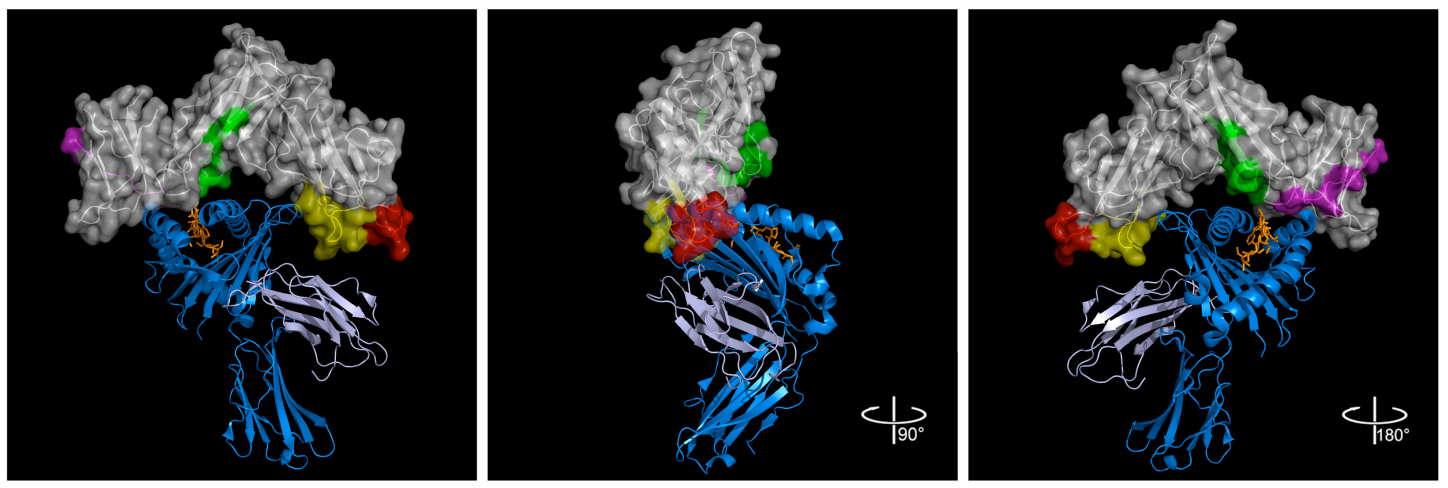

Figure 29. Anti-rhesus macaque KIR antibody epitopes mapped on the 3D structure of human KIR3DL1*001-pHLA-B*5701 complex (Vivian et al., 2011: PDB accession number 3VH8).

KIR surface is coloured in grey, HLA structure in blue, $\beta_{2}$ microglobulin in light blue and HLApresented peptide in orange. Identified epitopes for all antibodies are coloured in yellow (spots $\mathrm{A} 7 / 8$ ) and red (spots $\mathrm{A} 22 / 23$ and 23/24). Spots B18/19 recognised by $2 \mathrm{H} 5$ is coloured in green and spot $31 / 32$ recognised by $1 \mathrm{H} 4$ is coloured in magenta. Structure is rotated by $90^{\circ}$ and $180^{\circ}$ (Figure provided by Joachim Koch and colleagues, who performed and analysed the epitope mapping).

Additional reactive peptides for 2H5 (Figure 11 and Figure 29: spots B18/19, green) and 1H4 (Figure 11 and Figure 29: spots B31/32, magenta) were identified, and presumably represent methodical artefacts (personel communication with Joachim Koch).

To analyse if pairs for certain KIRs could be found, the extracellular parts of rhesus macaque KIRs were analysed by generating a phylogenetic tree (Figure 30). For human, pairs with similar ligand-binding specificity, but distinct signalling pathways, evolved, such as KIR2DL1/S1 and KIR2DL2/S2. KIR3DL1 and KIR3DS1 segregate as alleles (Vilches and Parham, 2002; Abi-Rached and Parham, 2005). Due to the similar extracellular parts of the pairs, most antibodies recognise such KIR pairs. The antirhesus macaque KIR antibodies also showed specificity for inhibitory and activating 
KIR with the exception of 2H5, which only recognises KIR3DL05. This result is confirmed by a phylogenetic tree (Figure 30a) where the extracellular part of KIR3DL05 is separated from all other KIRs. A pair of KIRs is observed for KIR3DLW03 and KIR3DS05, which are both recognised by 2H9. The clustering of these KIRs is due to their high sequence similarity in their extracellular portion, the most probable explanation for the observed antibody specificity for both KIRs with 2H9. A little bit more complicated appears the explanation for the detected KIRs by antibody 2H3. This antibody showed specificity for KIR3DSW08, KIR3DS07 and KIR3DL07, which do not cluster together in a pair when the complete sequences are analysed. The phylogenetic comparison of only the amino acid sequences of the recognised epitopes (Figure 30b) and in contrast the amino acid sequences without the epitope sequences (Figure 30c) clarify the situation a little bit. If analysing only the epitope sequences, the sequences of KIR3DL07 and KIR3DS07 cluster together and for the sequences without epitope KIR3DSW08 and KIR3DS07 cluster together. An explanation for the specificity of all three KIRs by $2 \mathrm{H} 3$ might trace back to evolutionary processes leading to certain sequence homologies between these three KIRs. Also additional KIR specificities of this antibody cannot be excluded like KIR3DS03, which was not tested so far but branches together with KIR3DS07 (Figure 30a). While 2H5 and 2H9 are highly specific for one KIR or a single pair, the $2 \mathrm{H} 3$ does not show these clear results and might be an antibody with an intermediate specificity for a group of KIRs evolving somehow similar. 
a

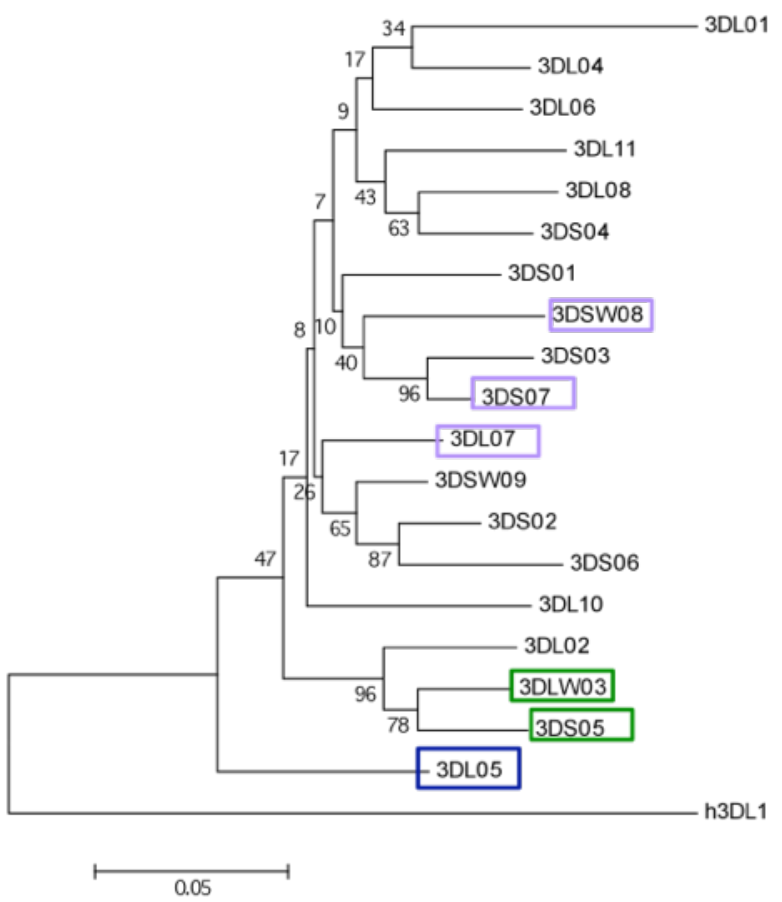

b

C
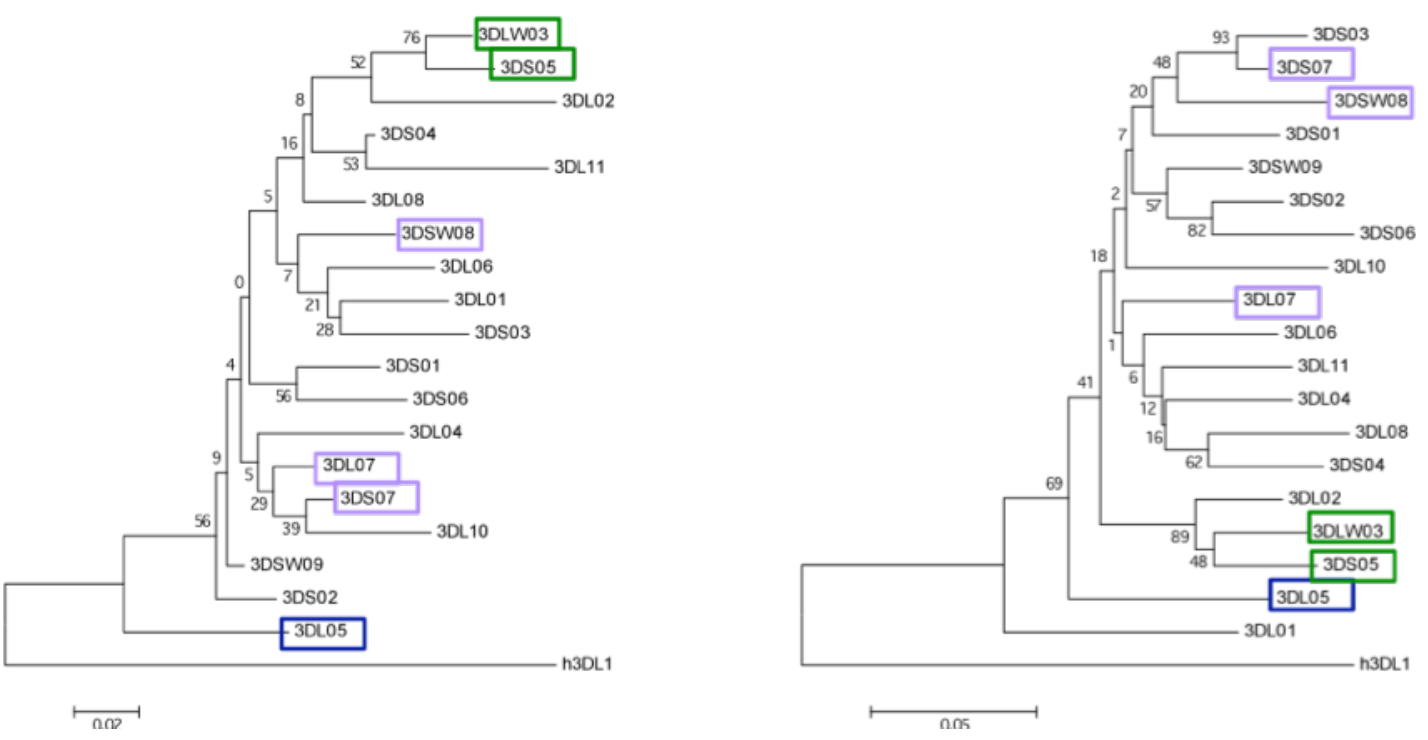

Figure 30. Phylogenetic trees of the extracellular part of rhesus macaque KIR amino acid sequences.

The extracellular part of amino acid sequences of rhesus macaque KIRs were aligned using Clustal $X$ and a phylogenetic tree was reconstructed with the neighbor joining method using JTT model by the software MEGA 5.0 (1000 bootstrap replications) (a). Additionally, phylogenetic trees either for only the epitope sequences (yellow and red in Figure 30) (b) or the amino acid sequences with excluded epitope sequences (c) were reconstructed the same way as for (a). KIR3DL05 is marked in blue, KIR3DLW03/KIR3DS05 in green and KIR3DSW08/KIR3DS07/KIR3DL07 in violet. 


\subsubsection{Preparation of fluorochrom-conjugated antibodies}

For the use of anti-macaque KIR antibodies in multi-colour flow cytometry it was necessary to couple them with a fluorochrome. All other used custom antibodies were also derived from mice therefore working with a second antibody was not possible and in general not practicable because of additional staining steps. Three different fluorochroms (DyLight405, 488, 633) were used and tested for efficient labelling using flow cytometry. The most important step before the labelling is efficient dialysis of the purified antibodies to remove the elution buffer and changing against PBS. The outcome of the dialysis influences the quality of the labelling strongly. The first rounds of labelling were not really sufficient and because of working with a kit the only part having an effect on this was the dialysis. After changing the dialysis conditions the fluorochrome conjugation was optimal and comparable to custom antibodies at least for DyLight633. This fluorochrome was then chosen because of the best staining strategy to combine the characterisation of NK and T cells in one sample. This was not possible for DyLight488 and DyLight405.

\subsection{Similar KIR expression of rhesus macaques and humans}

\subsubsection{General KIR expression of rhesus macaque NK cells}

The KIR expression is quite diverse within individuals. NK cells of an individual differ in their pattern of expressed KIRs. This results in NK cell subsets with random combinations of expressed KIRs although all possess the same genotype. This clonal KIR expression pattern results in NK cell subsets that will differ in their functional responses. Therefore, they can influence the individual immune response to certain diseases differently. In addition to the clonal expression of KIR molecules within individuals, comparison of different individuals show differences in KIR expression. Even with having the same genotype the frequency of expressed KIRs can vary considerably (Schönberg et al., 2011).

For rhesus macaque NK cells no such expression pattern and variations in the KIR expression within and between individuals was known so far, due to the lack of appropriate antibodies. Here, antibodies were established either recognising all tested 
KIRs or a limited set of KIR molecules. By analysing eight rhesus macaques with the pan-KIR antibody 1C7 it could be shown that the percentage of KIR-positive NK cells ranged from 29 to $78 \%$ (mean $56 \%$ ). Additionally, also the mean fluorescence intensity (1028-9089, mean 3610), which shows the density of expressed KIR proteins on the cell surface, varies within the tested group (Figure 14).

For human KIR molecules no pan-KIR antibody is described so far. Several anti-human KIR antibodies are well characterised but they all show high specificity for certain KIR. Most of the known anti-KIR antibodies recognise the inhibitory and associated activating KIR, which are highly similar in their extracellular regions (supplementary Table 7). The mixture of several antibodies would allow a general characterisation of the KIR expression frequency in humans, but those analyses were not performed so far. The most studies focus on the expression of single KIRs or combinations of defined KIR molecules. Therefore, no comparison of the overall KIR expression on human and rhesus macaque NK cells could be made. Human and rhesus macaque NK cells differ in their CD56 expression. In rhesus macaques a small $\mathrm{CD}^{+} 6^{+} \mathrm{NK}$ cell population was observed but for most of the animals it was less than $3 \%$ of the whole NK cell population (Figure 15). Up to $30 \%$ of this NK cell subset expresses KIR whereas in human it is only around $10 \%$ of the CD56 $6^{\text {bright }}$ NK cells (André et al., 2000). As also the CD56/CD16- NK cell subset in rhesus macaques does express KIR, no NK cell population could be observed that completely lack KIR expression or shows only very limited KIR expression like human CD56 bright NK cells.

In humans, the two NK cell populations, defined by their CD56 expression, are associated with different functions. CD56 ${ }^{\text {bright }}$ NK cells have a more immuno-regulatory function by secreting cytokines such as IFN- $\gamma$, whereas CD56 dim NK cells have direct cytotoxic activity (Cooper et al., 2001). Webster and Johnson (2005) described the expression of homing markers for $\mathrm{CD}^{2} 6^{+} / \mathrm{CD} 16^{-} \mathrm{NK}$ cells of rhesus macaques and additionally, the cytotoxic activity of CD56 $/$ CD $16^{+}$NK cells. Different rhesus macaque and human NK cell subsets show similarities in their functional activities. A major difference is shown by the KIR expression, which is present in all tested NK cell subsets of rhesus macaques. The reason for the overall KIR expression of rhesus macaque NK cells is not clear yet. There might be additional characterisation markers that can help to distinguish between different NK cell populations more clearly than CD56 does. In this study additional NK cell receptors like natural cytotoxicity receptors were not 
included but also for rhesus macaque the expression for some of these receptors was already shown (Mavilio et al., 2005). The difficulty in analysing new receptors in rhesus macaques is always the missing knowledge about cross-reactivity between antibodies established for human. Therefore one has to be careful with negative results. A first step in analysing additional NK cell markers would be to analyse them on transcript level.

Other reasons for the general KIR expression in rhesus macaques might be in different or additional functional activity of these NK cell subsets or in the expression of KIR2DL4. For human it was shown that KIR2DL4 is mainly expressed by CD56 $6^{\text {bright }}$ NK cells (Goodridge et al., 2007). The cross-reactivity of the established antibodies with rhesus macaque KIR2DL4 was not analysed in this study therefore no conclusion about that could be made. Unfortunately, also the amplicon sequencing for analysing KIR2DL4 mRNA expression is not established so far. It would take future work to analyse the anti-rhesus macaque KIR antibodies for reactivity with KIR2DL4.

\subsubsection{Clonal KIR expression by rhesus macaque NK cells}

\section{Expression pattern of KIR3DL05}

As already mentioned (4.1.2), KIR3DL05 is separated from other rhesus macaque KIRs when generating a phylogenetic tree using only the extracellular amino acid sequences of different KIRs. This finding supports the observed specificity of antibody $2 \mathrm{H} 5$, which only recognises KIR3DL05 so far. The expression of KIR3DL05 was analysed on transcript level as also on protein level. Comparison of the percentage of KIR3DL05 mRNA from total detected KIR mRNA and the level of KIR3DL05 positive NK cells of the total number of KIR positive NK cells showed no correlation between these two values (Figure 31a), indicating that the relative amount of mRNA of a particular KIR gene is not indicative of the frequency of NK cells expressing this particular KIR. 
a

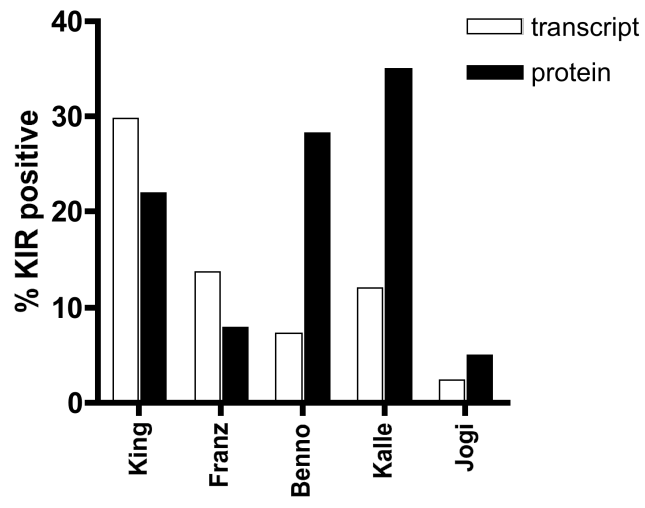

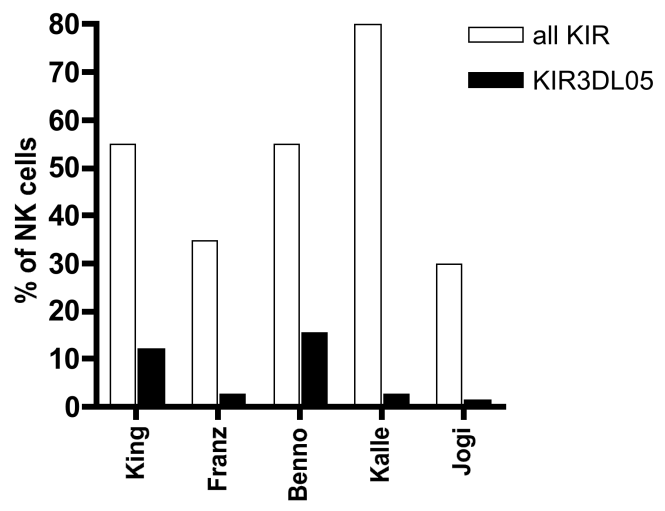

Figure 31. Expression of KIR3DL05 on transcript and protein level.

a) Comparison of transcript and protein level of KIR3DL05. Shown is the percentage of KIR3DL05 reads of total detected reads using amplicon sequencing, compared to the percentage of KIR3DL05positive NK cells of the total number of KIR-positive NK cells. b) Comparison of the total number of KIR positive NK cells with the number of KIR3DL05 positive NK cells. Shown is the percentage of KIRpositive NK cells from total NK cells compared to the number of KIR3DL05-positive NK cells. Not all KIR positive NK cells express KIR3DL05, it is expressed in a clonal pattern. Results for five KIR3DL05 positive animals are shown.

The analysed mRNA was isolated from PBMC and not from isolated NK cells. As it was already shown, KIRs are also expressed by different rhesus macaque $\mathrm{T}$ cell subsets $(3.2 .4,3.2 .5,3.2 .6)$. Therefore, the transcript level does not differentiate between the different KIR expressing cell populations. With isolated NK cells the mRNA level might differ.

Comparison of the total number of KIR-expressing NK cells with the percentage of KIR3DL05-positive NK cells shows a clonal expression of this KIR (Figure 31b). This observation is already described for human KIR (Valiante et al., 1997).

Five out of eight animals were positive for the KIR3DL05 gene and expressed mRNA to different percentages. The same is seen for the surface expression. All analysed animals show different levels of KIR3DL05 protein expression. The same can be observed by comparison of different human donors for KIR3DL1 expression using Dx9 antibody (Gumperz et al., 1996). Most of the studies of the influence of certain KIRs on the outcome of diseases are performed by gene association studies (Boyton and Altmann, 2007). Few studies were performed by studying the KIR surface expression. Currently, most of them are focussing on HIV (Ballan et al., 2007). At least for the expression of rhesus macaque KIR3DL05 using 2H5 antibody, changes in the KIR expression can be analysed in future. KIR3DL05 might have an influence in the progression of an SIV 
infection, because changes in the transcript levels were observed for SIV infected animals compared to their pre-infection status (personal communication by Christina Albrecht).

\section{Expression of KIR3DLW03 and KIR3DSO5}

The surface expression of KIR3DLW03 and KIR3DS05 is recognised by 2H9 antibody but cannot be distinguished. KIR transcript level analysis shows a variable amount of KIR3DS05 mRNA for all tested animals except for one animal (Jogi). Jogi and Happy are the only animals expressing KIR3DLW03 mRNA (Figure 32, Table 4). The surface expression of KIR3DLW03 for Jogi is quite low with only $0.8 \%$ of all NK cells. Thus, $2 \mathrm{H} 9$ specifically detects KIR3DLW03 in Jogi due to absence of KIR3DS05. Such subtractive analyses are also frequently carried out for human KIR molecules due to crossreactivity of anti-human KIR antibodies. As for KIR3DL05 no correlation can be observed between the transcript and the protein level, due to already described reasons (4.2.2 - KIR3DL05 expression). It is not clear if the 2H9-detected KIR protein for Happy is derived from KIR3DS05, KIR3DLW03 or from a combination of both.

a

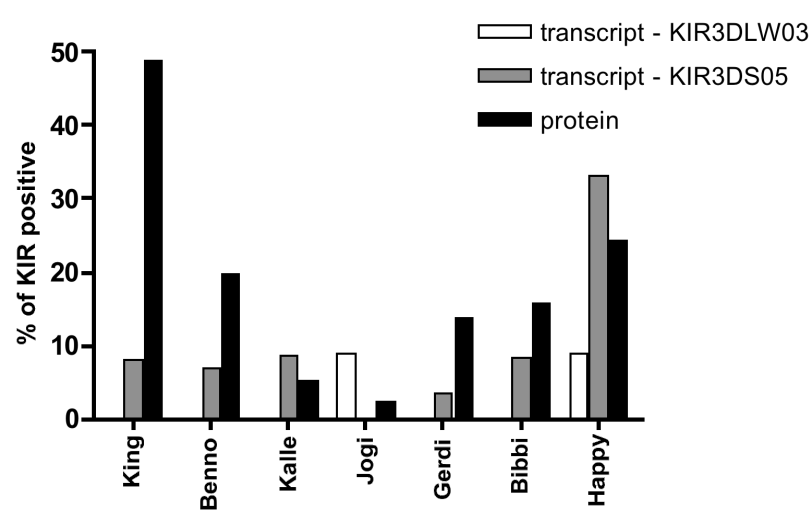

b

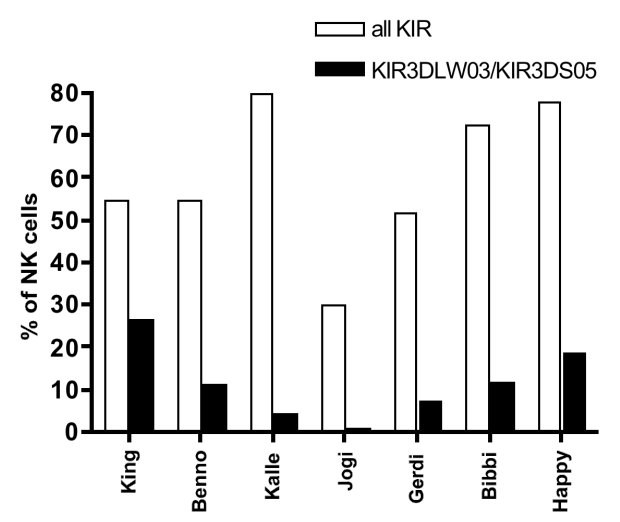

Figure 32. Expression of KIR3DLW03 and KIR3DS05 on transcript and protein level.

a) Comparison of transcript and protein level of KIR3DLW03/KIR3DS05. The percentage of KIR3DLW03/KIR3DS05 reads of total detected reads using amplicon sequencing, compared to the percentage of KIR3DLW03/KIR3DS05 positive NK cells of the total number of KIR positive NK cells. b) Comparison of the total number of KIR positive NK cells with the number of KIR3DLW03/KIR3DS05 positive NK cells. Shown is the percentage of KIR positive NK cells from the total number of NK cells compared to the number of KIR3DLW03/KIR3DS05 positive NK cells. Not all KIR positive NK cells express KIR3DLW03/KIR3DS05, it is expressed in a clonal pattern. Results for seven KIR3DLW03/KIR3DS05 positive animals are shown. 
Also for KIR3DLW03/KIR3DS05 a clonal expression pattern can be observed and in addition a variation in the frequency of expressed KIRs between animals (Figure 32). The expression pattern for KIR3DLW03/KIR3DS05 is comparable to that of KIR3DL05 and of human KIRs.

\section{Expression of KIR3DSW08, KIR3DS07 and KIR3DL07}

The specificity of antibody $2 \mathrm{H} 3$ is not really clear yet. The three detected antigens do not show clear clustering in one group using a phylogenetic tree (Figure 30). An additional problem occurs in analysing the mRNA expression level of KIR3DS07, because of the complete absence of mRNA of this KIR. It is not clear yet, if KIR3DS07 is not expressed at all or if the primer setting is not optimal for this KIR and overlaps with KIR3DS03 (personal communication by Christina Albrecht who performed the amplicon sequencing). KIR3DSW08 is only expressed by one animal (Jogi) (Figure 33, Table 4). Animals Gerdi and Happy show surface expression in the absence of mRNA for all three analysed KIR. This would indicate the expression of KIR3DS07 or of an additional, so far unknown, KIR that is bound by $2 \mathrm{H} 3$.
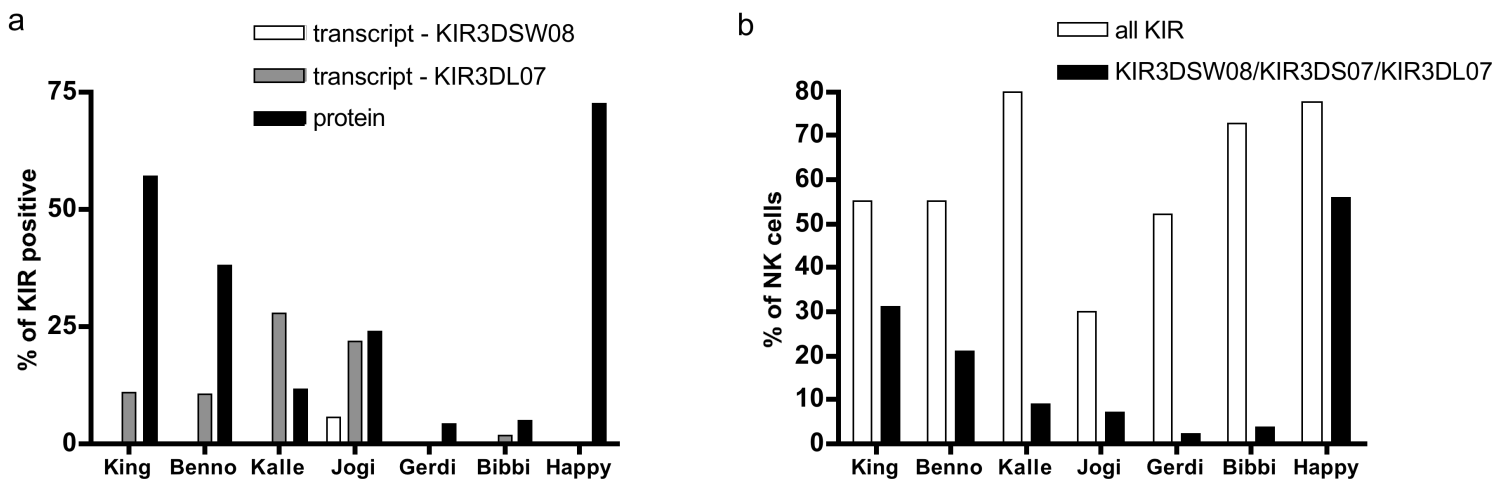

Figure 33. Expression of KIR3DSW08, KIR3DS07 and KIR3DL07 on transcript and protein level.

a) Comparison of transcript and protein level of KIR3DSW08/KIR3DS07/KIR3DL07. The percentage of KIR3DSW08/KIR3DS07/KIR3DL07 reads of total detected reads using amplicon sequencing, compared to the percentage of KIR3DSW08/KIR3DS07/KIR3DL07 positive NK cells of the total number of KIR positive NK cells. b) Comparison of the total number of KIR positive NK cells with the number of KIR3DSW08/KIR3DS07/KIR3DL07 positive NK cells. Shown is the percentage of KIR positive NK cells from the total number of NK cells compared to the number of KIR3DSW08/KIR3DS07/KIR3DL07 positive NK cells. Not all KIR positive NK cells express KIR3DSW08/KIR3DS07/KIR3DL07, it is expressed in a clonal pattern. Results for seven KIR3DSW08/KIR3DS07/KIR3DL07 positive animals are shown. 
As for the other tested KIR molecules no correlation between the transcript and the protein level is observed (Figure 33a). The clonal expression pattern is also found for KIR3DSW08/KIR3DS07/KIR3DL07 and also differences in the expression of these KIRs between animals (Figure 33b).

\subsubsection{KIR expression of $C D 4^{+}$and $C D 8^{+} \alpha \beta$ T cells of rhesus macaques}

KIRs are characterised as NK cell receptors. The integration of inhibitory and activating signals upon binding of corresponding ligands expressed by a target cell will determine the functional response given by the NK cell. However, KIR expression is also found in the peripheral blood on 1-27 \% (mean $5.1 \%$ ) $\mathrm{CD}^{+} \mathrm{T}$ cells in different human donors. This detected number is based on the number of the expression of the most represented KIR given in a donor (Mingari et al., 1996). As already described for KIR expression by human NK cells, no pan-KIR antibody for human KIR is available, therefore, the expression studies refer to the expression of certain KIR detected with specific antibodies. In rhesus macaques, KIR expression using the pan-KIR antibody $1 \mathrm{C7}$ is found for $4-17 \%$ of all $\mathrm{CD}^{+} \mathrm{T}$ cells with a varying density within the group of tested animals. $4-28 \%$ of $\mathrm{CD}^{+} \alpha \beta$ T cells are KIR positive, $0.4-2.8 \%$ of $\mathrm{CD}^{+} \alpha \beta$ T cells and 8-58 \% of $\gamma \delta \mathrm{T}$ cells. Similar frequencies are also found for the human $\mathrm{T}$ cell subsets. Up to $30 \%$ of $\mathrm{CD}^{+} \alpha \beta$ T cells (Anfossi et al., 2001), $0.2 \%$ of $\mathrm{CD}^{+} \alpha \beta$ T cells (van Bergen et al., 2004) and a variable amount of $\gamma \delta$ T cells express KIR in human (about $20 \%$ detected with antibodies GL183 and EB6) (Battistini et al., 1997).

The reason why $\mathrm{T}$ cells express KIR is not clear yet. Several hypotheses arose and studies were performed with a special focus on KIR-positive CD8 ${ }^{+} \alpha \beta$ T cells (Vivier and Anfossi, 2004; van Bergen and Koning, 2010). KIR expression of T cells is acquired after TCR rearrangement, because a highly diverse KIR pattern could be observed for $\mathrm{T}$ cell clones with identical TCR rearrangement (Uhrberg et al., 2001; Vely et al., 2001). In accordance with this, the frequency of KIR positive $C D 8^{+} \alpha \beta$ T cells increases with age (Anfossi et al., 2001) and is not constant over time like for NK cells. The induction of KIR expression by $\mathrm{T}$ cells is not known so far. Inhibitory KIR expressed by $\mathrm{T}$ cells are thought to influence the TCR-induced cytotoxicity and IFN- $\gamma$ production (Anfossi et al., 2001). Thus, inhibitory KIR can influence T cell effector functions by "fine-tuning" of 
the $\mathrm{T}$ cell response via raising or lowering the threshold of TCR triggering (McMahon and Raulet, 2001). Expression of inhibitory KIR on mature $\operatorname{CD}^{+} \alpha \beta$ T cells that react to self antigens might help to prevent autoimmunity by the recognition of "self" and therefore, inhibiting the TCR signal (Figure 34a). KIR-positive self-specific $\operatorname{CD}^{+} \alpha \beta \mathrm{T}$ cells are found in healthy individuals as well as in melanoma patients (Speiser et al., 1999; Huard and Karlsson, 2000). In this case, KIR expression might represent active silencing by the recognition of self-MHC and the induction of "T cell tolerance" to selfantigens in the periphery and prevention of autoimmunity. With the loss of MHC class I expression in tumour cells, TCR triggering will be not inhibited anymore and lysis of these cells would take place (Figure 34b). It is known that inhibitory KIR can modulate activation-induced cell death (AICD, "clonal exhaustion"), which is an important process for termination and controlling the expansion of activated T cells (Gati et al., 2003). The role of activating KIR is not clear yet. AICD of KIR-positive CD8 ${ }^{+} \alpha \beta$ T cells is decreased by affecting the Fas pathway, which normally will lead to apoptosis (Gati et al., 2003) (Figure 34d). This might be an explanation for the observed effector memory phenotype (CD28-, CD45RA-, CD45R0 ${ }^{+}$) of most KIR-positive CD8 ${ }^{+} \alpha \beta$ T cells (Mingari et al., 1996). KIR-expressing $\mathrm{T}$ cells that are prevented from AICD might have an advantage during the phase of memory cell development.

Rhesus macaque KIR-positive T cells were not further analysed for a potential memory phenotype. The characterisation of central and effector memory $\mathrm{T}$ cells is possible using cross-reactive anti-human antibodies. Effector memory $\mathrm{T}$ cells of rhesus macaques are best defined by the lack of CD28. Additional markers like $\beta_{7}$ integrin, CD11a, CD62L and CD45RA are expressed at variable levels. All effector memory cells are CD95 positive, but this is also true for central memory T cells (Pitcher et al., 2002). A future field of application for the anti-rhesus macaque KIR antibodies besides the characterisation of NK cell subsets is the detailed analyses of $\mathrm{T}$ cell populations and similarities to the expression of KIR in human effector memory T cells. 
a

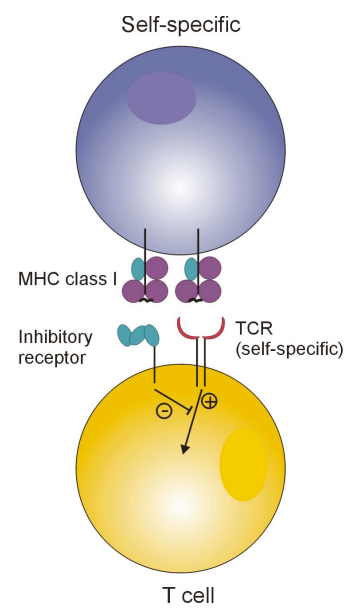

b

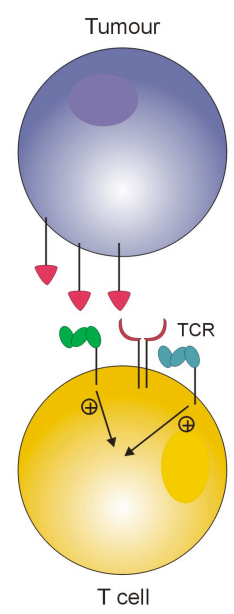

C

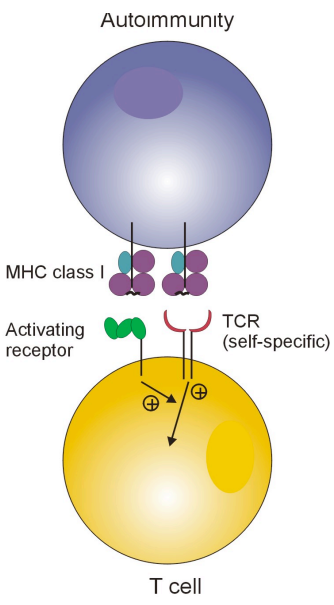

d

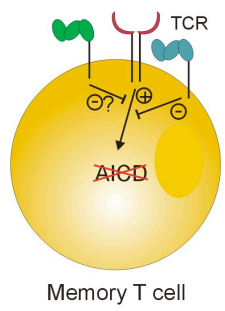

Figure 34. Influence of KIR expression on T cell effector function.

a) Inhibitory KIR expressed by T cells can "fine-tune" the signal derived by the TCR. In the case of self-specific TCR recognition the inhibitory KIR might inhibit the TCR-mediated activating signal, thereby avoiding autoimmunity. b) Down-regulation of MHC class I surface expression in tumour cells avoid TCR recognition. Inhibitory KIR might activate T cells due to the absence of the ligand and activating KIR might activate $T$ cell due to the up-regulation of certain stress-induced ligand. c) Selfspecific TCR together with activating KIR might increase the risk of autoimmunity. d) KIR-derived inhibitory and maybe activating signals influencing the TCR response, might influence the expression of Fas and therefore influence the AICD and favour the generation of memory $T$ cells.

The main focus of research was on inhibitory KIR due to the assumption that human T cells express only inhibitory KIRs. However, also activating KIR are expressed by human $\mathrm{T}$ cells. The reason for this wrong assumption can be that inhibitory KIRs were identified before the activating form. It is also difficult to discriminate between certain pairs of inhibitory and activating KIRs because antibodies usually recognise both forms due to high sequence similarity in the extracellular. Mandelboim and colleagues (1996) already showed the expression of KIR2DS4 by T cell clones. While inhibitory KIRs are thought to fine-tune the TCR-mediated response, the role of activating KIR expressed by T cells is even less clear. Activating KIR might function as a co-stimulatory receptor and facilitate the rapid secondary T cell-mediated response to antigens (Mandelboim et al., 1996). The appearance predominantly on T cells with effector memory phenotype would support this hypothesis. As already mentioned in chapter 1.2.3 van Bergen and Koning (2010) proposed the hypothesis that T cells first acquired inhibitory KIR and with the evolution of activating KIR they automatically expressed also activating KIR. Due to the missing control of this KIR-induced activation signal a risk for uncontrolled $\mathrm{T}$ cell responses would appear if they have some specificity for self antigens. This 
potential risk might also increase by age, as does the number of KIR-expressing T cells (Figure 34c).

Only 0.5-3\% of all $\mathrm{CD}^{+} \alpha \beta \mathrm{T}$ cells are KIR-positive in rhesus macaques. This observation is similar to human, where the average of KIR-positive CD4+ $\alpha \beta$ T cells is about 0.2 \% (van Bergen et al., 2004). In human, KIR3DL2 is a selective marker for Sezary cutaneous lymphoma $\mathrm{CD}^{+} \alpha \beta$ T cells (Bagot et al., 2001). Interestingly, human KIR3DL2 is able to bind to CpG-oligonucleotides and to hand over these ligands to tolllike receptor (TLR) 9 (Sivori et al. 2010). Thus, presence of (inhibitory) KIR3DL2 on human $\mathrm{CD}^{+} \mathrm{T}$ cells obviously does not lead to inhibition of the $\mathrm{T}$ cell, but to activation of TLR signalling and, thus, activation of the T cell. Certain diseases are characterised by clonal expansion of $\mathrm{CD}^{+} \alpha \beta$ T cells expressing certain activating KIR. In the example of rheumatoid arthritis the activating KIR2DS2 transcripts were identified in $\mathrm{CD}^{+} \alpha \beta \mathrm{T}$ cell clones but not for healthy individuals (van Bergen et al. 2004). The expression of this KIR might act as a co-stimulatory receptor leading to the proliferation and IFN- $\gamma$ production by $\mathrm{CD}^{+} \alpha \beta$ T cells, what may cause complications in rheumatoid arthritis patients (van Bergen and Koning, 2010). No such observations have so far been made in healthy rhesus macaques. If certain diseases can also cause expansion of KIRexpressing $\mathrm{CD}^{+} \alpha \beta$ T cells in rhesus macaques, such phenomena are highly interesting and need to be analysed. Notably, rhesus macaques are already used as animal models for arthritic diseases (Vierboom et al., 2005) and therefore, the newly established antirhesus macaque KIR antibodies are an important tool for comparison of disease progression between human and rhesus macaques.

Due to different regulation mechanisms for the KIR expression of NK and T cells in humans, these cell types can differ in their KIR repertoire within individuals (Uhrberg et al. 2001; van Bergen and Koning, 2010). With the pan anti-KIR antibody 1C7 no correlation in the KIR expression of NK cells and $C D 8^{+} \alpha \beta$ T cells is observed. The animal with the most KIR-positive NK cells does not automatically have the highest frequency in KIR-positive $\mathrm{CD}^{+} \alpha \beta$ T cells. The same is observed for certain KIR detected with specific antibodies.

For rhesus macaque T cells, the expression of inhibitory but also activating KIR could be detected. Antibody 2H5 recognises only KIR3DL05, an inhibitory KIR, which is expressed on $\mathrm{NK}$ and $\mathrm{CD}^{+} \alpha \beta$ T cells (up to $4 \%$ for $\mathrm{CD}^{+} \alpha \beta$ T cells, low density). The confirmation of the expression of activating KIR on T cells is possible with the $2 \mathrm{H} 9$ 
antibody that recognises KIR3DLW03 and KIR3DS05. Due to the absence of KIR3DLW03 transcripts in five out of seven analysed animals, the 2H9-detected KIR is KIR3DS05. Up to $5 \%$ of $\mathrm{CD}^{+} \alpha \beta$ T cells express KIR3DS0 5 at low density.

The importance in analysing not only KIR expression in NK cells but also different T cells of rhesus macaques is of interest for rhesus macaques as animal model of certain human diseases. The KIR expression of T cells seems to be highly similar between these species and is therefore thought to have a similar influence in immune responses. It has to be investigated whether this similarity has any influence on disease-associated $\mathrm{T}$ cells in rhesus macaque disease models.

\subsubsection{KIR expression of $\gamma \delta$ T cells of rhesus macaques}

T cells bearing the $\gamma \delta$ form of TCR represent a small population of T cells. In contrast to $\alpha \beta \mathrm{T}$ cells, they share several features with innate immune cells like NK cells and macrophages (Boismenu and Havran, 1997). For example, V $\gamma 9 \mathrm{~V} \delta 2$ T cells use their TCR as a pattern recognition receptor for pyrophosphates. Low levels of pyrophosphates are produced by normal cells, only the detection of high levels due to infection or malignant transformation will lead to an activation of V $\gamma 9 \mathrm{~V} \delta 2 \mathrm{~T}$ cells (Kabelitz, 2011). $\gamma \delta$ T cells produce cytokines like TNF- $\alpha$ and IFN- $\gamma$, they can present antigens to CD4+ and $\mathrm{CD}^{+} \alpha \beta \mathrm{T}$ cells, they show potent killer cell activity and can have regulatory functions (Kabelitz, 2011). In addition, $\gamma \delta$ T cells express KIRs like NK cells but also $\alpha \beta$ T cells. In contrast to $\alpha \beta$ T cells, the majority of $\gamma \delta$ T cells express at least one NK cell receptor. About 80 \% express CD94/NKG2A, and about 20 \% NKR-P1A and KIR2DL1 (Battistini et al., 1997). So far, nothing is known about a possible memory phenotype of the KIR-expressing $\gamma \delta \mathrm{T}$ cells like it is shown for $\alpha \beta \mathrm{T}$ cells. In general, only one description on IL-15-induced $\gamma \delta$ T cell effector memory phenotype is published so far (Eberl et al., 2002). Unfortunately, CD28, which is absent in KIR-expressing effector memory $\mathrm{T}$ cells in human, was not analysed for presence or absence.

Rhesus macaque $\gamma \delta \mathrm{T}$ cells show a range of 8-58 \% KIR-positive cells according to analysis with the pan-KIR antibody $1 \mathrm{C} 7$, partially with a very high density of expressed KIRs. As already shown for $\alpha \beta$ T cells, inhibitory and activating KIR can be expressed 
and single KIRs are expressed clonally, so that $\gamma \delta \mathrm{T}$ cells with different KIR combinations can be found.

The whole function of KIR on $\gamma \delta$ T cells is not known yet. KIRs might influence the TCR signalling like for $\alpha \beta$ T cells (Figure 34). Another possibility might be a more NK cell-like function. $\gamma \delta \mathrm{T}$ cells are described as an innate-like $\mathrm{T}$ cell population, recognising antigens that are not detected by other immune cells including $\alpha \beta$ T cells. Like NK cells they might have the ability to distinguish between "self" and "non-self". In addition, they may function as a source of IFN- $\gamma$, like NK cells, influencing the immune response (Battistini et al., 1997).

In chronic diseases, like chronic hepatitis $C$ infection, $\gamma \delta \mathrm{T}$ cells are associated with tissue damage and pathology (Par et al., 2002). Therefore a rapid control of $\gamma \delta \mathrm{T}$ cell activation after acute infection is important. Activating KIRs might boost already existing activation signals triggered by TCR. Inhibitory KIRs could inhibit TCR triggering but also boost activation when lacking the "self" ligand in chronic diseases. Since not much is known about the function of KIR-positive $\gamma \delta \mathrm{T}$ cells in human, comparison with rhesus macaque is quite challenging. In summary, the expression of KIR by $\gamma \delta$ T cells, to the current knowledge, appears to be similar in rhesus macaques. At present, disease association of KIR-positive $\gamma \delta$ T cells is mainly focussing on HIV what will be discussed in chapter 4.3 .

\subsubsection{KIR expression pattern of other non-human primate species}

Not only the rhesus macaque is used as animal model for human diseases. Therefore, also baboons, cynomolgus macaques and African green monkeys were tested for crossreactivity with the anti-rhesus macaque KIR antibodies. The same gating strategy as for rhesus macaques was applied even not much is known of theses species about the surface markers for NK cells and cross-reactivity with anti-human antibodies. Fortunately, all antibodies used for the characterisation of rhesus macaque NK cells worked also for these species. Cynomolgus macaques are closely related to rhesus macaques. Therefore, it was not surprising that besides standard surface markers also the pan-KIR antibody 1C7 shows cross-reactivity. Cynomolgus macaque KIRs are expressed by NK cells at similar levels to rhesus macaques (55-75\%). Additionally, also 
KIR-positive $\mathrm{CD}^{+} \alpha \beta$ T cells (2-22 \%) were detected for this species. Together with rhesus macaques, cynomolgus macaques are important animal models for the characterisation and therapy-applications of human diseases like HIV, SARS (severe acute respiratory syndrome), measles virus, hepatitis and much more (Letvin, 1992; Gao et al., 2003; Premenko-Lanier et al., 2004; Verthelyi et al., 2004; Li et al., 2003). For HIV, SARS and hepatitis already a correlation of certain KIR and disease progression were identified for human (Martin et al., 2002; National Research Project for SARS, Beijing Group, 2004; Khakoo et al, 2004).

Nine baboons were analysed for KIR expression using the pan-KIR antibody 1C7. Not much is known about baboon KIR. Mager and colleagues (2001) found at least six KIR genes in one analysed animal. Baboon KIRs share amino acid sequence homology with human for around 75-80 \%. About 60-95 \% of all baboon NK cells and 6-15\% of $\mathrm{CD}^{+} \alpha \beta \mathrm{T}$ cells showed KIR expression. In contrast to macaque species, baboons are favoured models for gene therapies (McTiernan et al., 2007; $\mathrm{Ni}$ et al., 2005), transplantation (Bartholomew et al., 2002) and xenotransplantation (Tai et al., 2007; Pierson, 2006). For human, several studies for the influence of KIR on the outcome of haematopoetic stem cell transplantation were performed and showed a clear effect of certain KIR/MHC combinations or KIR/MHC mismatch (Ruggeri et al., 2002; Leung et al., 2004; Bishara et al., 2004; Schaffer et al., 2004). Therefore, the newly established anti-KIR antibodies might be an important tool for studying the contribution of KIR in baboon transplantation models.

African green monkeys and rhesus macaques form a distinct group compared to hominoids like chimpanzee, orangutan and human. Therefore, it is also not surprising to find cross-reactivity with the pan-KIR antibody 1C7. 72-90 \% of all NK cells of four analysed African green monkeys were KIR positive but surprisingly almost no KIR expression could be detected for $\mathrm{CD}^{+} \mathrm{ab} \mathrm{T}$ cells. African green monkeys are natural hosts of SIV. They show normal plasma viral loads (similar to "normal progressors" Figure 4) but normally do not develop AIDS (Sodora et al., 2009). Comparison of their immune response to SIV to non-natural hosts like rhesus macaques might give important insights in the coexistence between the virus and the host immune system. This can help to identify new vaccination strategies or therapeutic approaches. In the following chapter a more detailed perspective on animal models and SIV progression will be given, focussing on rhesus macaques and potential differences to natural hosts. 


\subsection{Changes in KIR expression during SIV infection}

\subsubsection{Impact of HIV/SIV infection on the frequency of KIR-positive NK and T cell subsets}

The scientific attention since the appearance of HIV is focussing on the development of efficient strategies for preventing HIV infection. Substantial efforts were made in studying $\mathrm{CD}^{+} \alpha \beta \mathrm{T}$ cell responses in the acute phase of viral infection. The findings suggest an effect of $\mathrm{CD}^{+} \alpha \beta$ T cells on containment of HIV-1 infection. HIV-1-specific T cell responses contribute to reduction of viral replication to set point and $\operatorname{CD}^{+} \alpha \beta$ T cell depletion in SIV-infected rhesus macaques results in increased viral replication (Alter and Altfeld, 2009). MHC class I alleles can influence the disease course via their peptide-presentation function, in extreme cases leading to slow or fast progression to HIV-1-mediated AIDS, and additionally affect innate immunity (NK activity). Adaptive immune responses appear after HIV-1 infection is already established, therefore, the innate immune response is thought to have an influence on viral replication in the early phase of infection when the adaptive immune system is not yet effective. In the last years, much more attention was paid to the role of innate immunity in viral infections, especially HIV-1. Besides macrophages, monocytes, and dendritic cells, NK cells play an important role in containment of viral infections by direct killing of infected cells and cytokine secretion that trigger adaptive immune responses. Acute HIV-1 infection results in activation and expansion of NK cells partially due to the secretion of proinflammatory cytokines by dendritic cells and monocytes (e.g. IL-15 and TNF- $\alpha$ ) (Chang and Altfeld, 2010). Thus, an exact knowledge about the interplay of innate and adaptive immunity might help to develop efficient therapies or vaccines to enhance viral control.

Similar to natural hosts such as sooty mangabeys, rhesus macaques as non-natural hosts also show an increase in frequency of total NK cells during acute SIV infection. Sooty mangabeys display a rapid increase in NK cell numbers and later on maintain a low plasma viral load $(<10,000$ copies/ml), whereas rhesus macaques have lower NK cell numbers and higher viral loads after viral load set point $(>50,000$ copies $/ \mathrm{ml})$. Therefore, differences in the kinetics of NK cell numbers might already indicate disease resistance (natural host) or the rate of disease progression (non-natural host) (Ansari et al., 2011). The samples from SIV-infected rhesus macaques analysed here showed a 
significant increase $(\mathrm{p}=0.0177)$ of NK cell numbers during acute infection in all infected animals, regardless of whether they possess a high or low viral load after viral load set point. No significant changes were observed during chronic infection. For $\operatorname{CD}^{+} \alpha \beta \mathrm{T}$ cells a significant increase is found during acute infection $(\mathrm{p}<0.0001)$, followed by an additional increase during chronic infection $(\mathrm{p}=0.0345)$. For $\gamma \delta \mathrm{T}$ cells no significant changes in cell number were observed (acute $\mathrm{p}=0.2225$; chronic $\mathrm{p}=0.6327$ ), whereas Gan and colleagues (1995) observed an increase of $\gamma \delta \mathrm{T}$ cells in the first weeks of infection, but this declined back to pre-infection levels after 6 weeks.

\subsubsection{KIR expression by NK and T cell subsets in HIV/SIV infection}

KIRs have been shown to influence clinical outcome in various cancer diseases, transplantations, and infectious diseases (Bashirova et al., 2006). Due to their clonal expression pattern, an individual possesses NK cell clones expressing different KIRs, thereby recognising their targets differently (Gardiner, 2007). Regulation of NK cell function by KIR is associated with protection but also susceptibility in human diseases. Activating and inhibitory KIR can both have positive or negative effects on the outcome of the aforementioned diseases, but no general rule can be applied. Besides the expressed KIRs, also absence or presence of the specific MHC class I ligand and its presented peptide have an impact on disease progression (Alter and Altfeld, 2009). Analysing KIR expression in human during HIV-1 infection has the disadvantage that corresponding pre infection data are missing. Healthy individuals are compared with infected or early phases of infection with disease progression. Working with rhesus macaques facilitates the direct comparison of pre- and post-infection data within an individual. In this study 24 SIV-infected animals were analysed for their KIR expression during acute and chronic SIV infection compared to their pre infection status. Animals were grouped in elite controller, LVL and HVL cohorts. Overall KIR expression by NK cells for elite controller and LVL animals decreased during acute infection, whereas for the HVL group no trend towards increase or decrease of KIR-positive NK cells was observed. During chronic infection no clear shift of the frequency of KIR-expressing NK cells for any of the analysed groups was observed. All samples were analysed using pan-KIR antibody 1C7 that recognises both inhibitory and activating KIRs. Therefore, 
no clear statement can be made if only inhibitory or activating KIR expression is changed or both. Animals from the same cohort analysed here, were already characterised for their KIR gene transcription and PCR with sequence-specific primers (Chaichompoo et al., 2010; Bostik et al., 2009). Different activating and inhibitory KIRs were found to correlate with plasma viral load. In particular, KIR3DL05 was found to be increased on transcript level during SIV infection for all tested animals, but showed a fourfold increase in the HVL group compared to LVL animals. Altogether, both studies reported changes in the KIR mRNA expression but no clear trend to increased levels of activating or inhibitory KIRs could be observed.

For human, a significant increase in inhibitory KIR levels during HIV-1 infection was shown, together with a decreased level of the activating natural cytotoxicity receptors (Mavilio et al., 2003). However, it was shown by Alter and colleagues (2007) that human activating KIR3DS1 in presence of its (assumed) ligand HLA-Bw4-80I is associated with slower disease progression in HIV-1 infection. Similar observations were made for KIR3DL1, the (allelic) inhibitory form of this receptor (Alter et al., 2009). KIR3DS1- and to a lesser extend KIR3DL1-expressing NK cells were shown to be disproportionately expanded in HIV-1-infected individuals, but only in presence of the cognate ligand HLA-BW4-80I. No increased numbers of KIR3DS1/KIR3DL1-expressing NK cells were observed in individuals lacking HLA-Bw4-80I (Alter et al., 2009).

The observation of decreasing numbers of KIR-expressing NK cells during acute phase of infection for elite controller and LVL rhesus macaques raises the question why KIR down regulation is protective during SIV infection? For human it was shown that KIRs were down regulated after engagement with their specific ligands (Huard et al., 2001). This down regulation is observed only for inhibitory and not activating KIR, which might be caused by the low affinity of activating KIR for their ligands (Vales-Gomez et al., 1998). Down regulation of inhibitory KIR might be a mechanism to lower the activation threshold when recognising altered MHC molecules or stress-induced ligands on target cells.

For a detailed study of the effect of KIR-expression changes during SIV infection, additional analyses are necessary. Fresh samples instead of frozen samples should be used and, together with the pan-KIR antibody, also antibodies with high specificities for certain KIR can be used. Especially, antibodies 2H5 and 2H9 may help to identify 
differences in the expression of inhibitory KIR (KIR3DL05 using 2H5) and activating KIR (KIR3DS05 using 2H9 in KIR3DLW03 negative animals).

In healthy rhesus macaques KIR expression by $\operatorname{CD}^{+} \alpha \beta \mathrm{T}$ cells and $\gamma \delta \mathrm{T}$ cells was observed. Analysis of SIV-infected animals did not show significant changes in the number of KIR-expressing $\mathrm{CD}^{+} \alpha \beta \mathrm{T}$ cells for the elite controller and the LVL group. However, most of the HVL animals showed increased numbers of KIR-positive CD ${ }^{+} \alpha \beta$ $\mathrm{T}$ cells during acute SIV infection. As already mentioned it cannot be differentiated between increased numbers of activating or inhibitory KIRs. Activating KIR might have a supportive effect, stimulating the activation of $\mathrm{CD}^{+} \alpha \beta$ T cells during acute SIV infection, whereas inhibitory KIRs might raise the threshold of activation leading to a less efficient $C D 8^{+} \alpha \beta$ T cell response. On the other hand, sustained activation of $C D 8^{+} \alpha \beta$ $\mathrm{T}$ cells via activating KIR might contribute to immune pathology that is frequently observed in rapid progressors. Indeed, increased KIR expression by $\operatorname{CD}^{+} \alpha \beta \mathrm{T}$ cells seems to be associated with accelerated disease progression in the case of SIV. During chronic infection no trend at all was observed for any of the analysed animal groups, suggesting a limited influence of KIR in this phase of infection.

SIV-infected rhesus macaques showed increased frequencies of KIR-positive $\gamma \delta$ T cells during acute infection in all three groups (elite controller, LVL and HVL). No clear trend was detected for the KIR expression during chronic infection. Different from human, a relatively low percentage of $\gamma \delta \mathrm{T}$ cells in rhesus macaques express the V $\gamma 9 \mathrm{~V} \delta 2 \mathrm{TCR}$. Human $\mathrm{V} \gamma 9 \mathrm{~V} \delta 2 \mathrm{~T}$ cells are decreased in HIV infection, become anergic and fail to proliferate. For rhesus macaque $\gamma \delta$ T cells at least a reduced response to stimulation with IL-2 was observed (Gan et al., 1995). However, in general the role of $\gamma \delta \mathrm{T}$ cells in acute HIV/SIV progression is still not well understood, in particular the influence of KIR expression. Due to the similarities between NK and $\gamma \delta$ T cells they both might influence the adaptive immunity by secretion of cytokines. The KIR expression of these two cell types shows inverse directions. KIR-positive NK cells are decreased during acute infection (elite controller and LVL), whereas $\gamma \delta$ T cells show an expansion of the KIRpositive population (elite controller, LVL and HVL). Similar to $\mathrm{CD}^{+} \alpha \beta \mathrm{T}$ cells, KIR expression by $\gamma \delta$ T cells might have a regulatory effect by increasing or decreasing the threshold of activation mediated by the TCR. As there is no difference in the KIR expression observed with different plasma viral loads after viral load set point, the 
influence of KIR to the immune response of $\gamma \delta$ T cells might not be that important in the chronic phase of SIV infection.

It is thought that the definition of disease progression of HIV/SIV already takes place in early stages of infection (eclipse to viremia peak, see Figure 4). Here, the decision of the "point-of-no-return" threshold is made (Agrati et al., 2011). Therefore, analysing innate immunity is an important step for understanding these processes. It will be quite challenging to understand the whole process of HIV disease progression due to the complexity of the virus, its ability to escape immunosurveillance (Funke et al., 2011), genetic heterogeneity of MHC class I and KIR, peptide presentation by MHC molecules, TCR response by $\mathrm{T}$ cells as well as other cell types, cytokines, and cross-talk of the whole immune system. A helpful system can be the analysis of natural SIV hosts like sooty mangabeys or African green monkeys. Knowledge about the differences of the immune response compared to non-natural hosts would help to identify starting points for therapy development. It is known that natural hosts show also high plasma viral loads (Figure 4) but do not progress to disease and develop AIDS. A fundamental difference between progressive HIV/SIV infection (e.g. human and rhesus macaques) and nonprogressive SIV infection (e.g. sooty mangabeys, African green monkeys) is the absence of immune activation during chronic infection. Immune activation is nowadays regarded a better predictor of disease outcome than plasma viral load (Brenchley et al., 2010). More efforts are necessary in analysis of natural hosts to get a detailed view of the mechanisms leading to nonprogressive HIV/SIV infection. One advantage of the newly characterised anti-rhesus macaque KIR antibody is the cross-reactivity with African green monkey KIR. Only four animals could be analysed so far, but a clear difference to rhesus macaques was observed in the KIR expression by $\operatorname{CD} 8^{+} \alpha \beta$ T cells. A distinct population of KIR-positive $\mathrm{CD}^{+} \alpha \beta \mathrm{T}$ cells was found in rhesus macaques, whereas nearly no KIR-positive $\mathrm{CD}^{+} \alpha \beta \mathrm{T}$ cells were identified in African green monkeys. This needs to be further analysed with more animals to confirm this finding, but it gives a first hint on differences between natural and non-natural hosts with regards of KIR expression in SIV infection. 


\section{Summary}

Rhesus macaques are important animal models of human diseases in which NK cells play significant roles. Whereas data on KIR genetic variability were recently published, data on KIR protein expression was not available until now due to lack of specific (or cross-reactive) antibodies. Therefore, mouse monoclonal antibodies against one activating and two inhibitory rhesus macaque KIR3D molecules were established and characterised.

Specificity of the obtained antibodies was determined using various rhesus macaque KIR-Fc fusion proteins (ELISA), cells transfected with single rhesus macaque KIR genes as well as lymphocytes of KIR-typed rhesus macaques (flow cytometry). Besides broadly reacting ones, also antibodies with intermediate and with high specificity for single KIRs were obtained. Epitope mapping revealed a conformational epitope for all analysed antibodies. The antibodies were conjugated with suitable dyes and multicolour flow cytometry was performed with lymphocytes from different rhesus macaque individuals. Anti-human antibodies against CD3, CD4, CD8, CD11c, CD14, CD16, CD20, TCR $\gamma \delta$, NKG2A, were used together with the newly established antirhesus macaque KIR antibodies. Boolean gating was used to identify rhesus macaque NK cells and NK cell subpopulations expressing single KIRs as well as KIR-expressing T cell subsets. The analysis revealed a clonal expression pattern of rhesus macaque KIR that is similar to human KIR. Differences were seen between individuals: $29-78 \%$ of NK cells were positive with a pan-KIR antibody, whereas $2-56 \%$ of NK cells were positive with antibodies specific for single KIRs. For T cell subpopulations $12-27 \%$ of all $\mathrm{CD}^{+} \alpha \beta$ $\mathrm{T}$ cells and $6-58 \%$ of all $\gamma \delta \mathrm{T}$ cells reacted specifically with the pan-specific KIR antibody. Also T cells expressed KIR at a clonal expression pattern using antibodies specific for single KIRs. Similar results were obtained with lymphocytes from cynomolgus macaques, baboons and African green monkeys.

Analysis of blood samples from SIV-infected rhesus macaques identified changes in the number of KIR-expressing cells during the acute phase of infection. KIR-expressing NK cells were decreased in animals with low viral load and in elite controllers, whereas for $\gamma \delta \mathrm{T}$ cells an increase could be detected. 
In conclusion, the established monoclonal antibodies are important tools for future studies in which the role of NK cells in infectious and autoimmune diseases are studied in macaques or other Old World monkeys. 


\section{References}

Abi-Rached L, Parham P (2005). Natural selection drives recurrent formation of activating killer cell immunoglobulin-like receptor and Ly49 from inhibitory homologues. J Exp Med. 201:1319-1332

Agrati C, D'Offizi G, Gougeon ML, Malkovsky M, Sacchi A, Casetti R, Bordoni V, Cimini E, Martini F (2011). Innate gamma/delta T-cells during HIV infection: Terra relatively Incognita in novel vaccination strategies? AIDS Rev. 13:3-12

Alter G, Altfeld M (2009). NK cells in HIV-1 infection: evidence for their role in the control of HIV-1 infection. J Intern Med. 265:29-42

Alter G, Martin MP, Teigen N, Carr WH, Suscovich TJ, Schneidewind A, Streeck H, Waring M, Meier A, Brander C, Lifson JD, Allen TM, Carrington M, Altfeld M (2007). Differential natural killer cell-mediated inhibition of HIV-1 replication based on distinct KIR/HLA subtypes. J Exp Med. 204:3027-3036

Alter G, Rihn S, Walter K, Nolting A, Martin M, Rosenberg ES, Miller JS, Carrington M, Altfeld M (2009). HLA class I subtype-dependent expansion of KIR3DS1+ and KIR3DL1+ NK cells during acute human immunodeficiency virus type 1 infection. $J$ Virol. 83:6798-6805

André P, Spertini O, Guia S, Rihet P, Dignat-George F, Brailly H, Sampol J, Anderson PJ, Vivier E (2000). Modification of P-selectin glycoprotein ligand-1 with a natural killer cell-restricted sulfated lactosamine creates an alternate ligand for L-selectin. Proc Natl Acad Sci U S A. 97:3400-3405

Anfossi N, Pascal V, Vivier E, Ugolini S (2001). Biology of T memory type 1 cells. Immunol Rev. 181:269-278

Ansari AA, Mayne AE, Takahashi Y, Pattanapanyasat $K$ (2011). Incorporation of innate immune effector mechanisms in the formulation of a vaccine against HIV-1. Adv Exp Med Biol. 780:143-159

Bagot M, Moretta A, Sivori S, Biassoni R, Cantoni C, Bottino C, Boumsell L, Bensussan A (2001). CD4(+) cutaneous T-cell lymphoma cells express the p140-killer cell immunoglobulin-like receptor. Blood. 97:1388-1391

Ballan WM, Vu BA, Long BR, Loo CP, Michaëlsson J, Barbour JD, Lanier LL, Wiznia AA, Abadi J, Fennelly GJ, Rosenberg MG, Nixon DF (2007). Natural killer cells in perinatally HIV-1-infected children exhibit less degranulation compared to HIV-1exposed uninfected children and their expression of KIR2DL3, NKG2C, and NKp46 correlates with disease severity. J Immunol. 179:3362-3370 
Barré-Sinoussi F, Chermann JC, Rey F, Nugeyre MT, Chamaret S, Gruest J, Dauguet C, Axler-Blin C, Vézinet-Brun F, Rouzioux C, Rozenbaum W, Montagnier L (1983). Isolation of a T-lymphotropic retrovirus from a patient at risk for acquired immune deficiency syndrome (AIDS). Science. 220:868-671

Bartholomew A, Sturgeon C, Siatskas M, Ferrer K, Mclntosh K, Patil S, Hardy W, Devine S, Ucker D, Deans R, Moseley A, Hoffman R (2002). Mesenchymal stem cells suppress lymphocyte proliferation in vitro and prolong skin graft survival in vivo. Exp Hematol. 30:42-48

Bashirova AA, Martin MP, McVicar DW, Carrington M (2006). The killer immunoglobulin-like receptor gene cluster: tuning the genome for defense. Annu Rev Genomics Hum Genet. 7:277-300

Battistini L, Borsellino G, Sawicki G, Poccia F, Salvetti M, Ristori G, Brosnan CF (1997). Phenotypic and cytokine analysis of human peripheral blood gamma delta $T$ cells expressing NK cell receptors. J Immunol. 159:3723-3730

Bishara A, De Santis D, Witt CC, Brautbar C, Christiansen FT, Or R, Nagler A, Slavin $S$ (2004). The beneficial role of inhibitory KIR genes of HLA class I NK epitopes in haploidentically mismatched stem cell allografts may be masked by residual donoralloreactive T cells causing GVHD. Tissue Antigens. 63:204-211

Blokhuis JH, van der Wiel MK, Doxiadis GG, Bontrop RE (2010). The mosaic of KIR haplotypes in rhesus macaques. Immunogenetics. 62:295-306

Blokhuis JH, van der Wiel MK, Doxiadis GG, Bontrop RE (2011). The extreme plasticity of killer cell Ig-like receptor (KIR) haplotypes differentiates rhesus macaques from humans. Eur J Immunol. 41:2719-2278

Boismenu R, Havran WL (1997). An innate view of gamma delta T cells. Curr Opin Immunol. 9:57-63

Bostik P, Kobkitjaroen J, Tang W, Villinger F, Pereira LE, Little DM, Stephenson ST, Bouzyk M, Ansari AA (2009). Decreased NK cell frequency and function is associated with increased risk of KIR3DL allele polymorphism in simian immunodeficiency virusinfected rhesus macaques with high viral loads. J Immunol. 182:3638-3649

Boyington JC, Motyka SA, Schuck P, Brooks AG, Sun PD (2000). Crystal structure of an NK cell immunoglobulin-like receptor in complex with its class I MHC ligand. Nature. 405:537-543

Boyson JE, Shufflebotham C, Cadavid LF, Urvater JA, Knapp LA, Hughes AL, Watkins DI (1996). The MHC class I genes of the rhesus monkey. Different evolutionary histories of MHC class I and II genes in primates. J Immunol. 156:4656- 4665 
Boyton RJ, Altmann DM (2007). Natural killer cells, killer immunoglobulin-like receptors and human leucocyte antigen class I in disease. Clin Exp Immunol. 149:1-8

Brenchley JM, Silvestri G, Douek DC (2010). Nonprogressive and progressive primate immunodeficiency lentivirus infections. Immunity. 32:737-742

Brumbaugh KM, Binstadt BA, Billadeau DD, Schoon RA, Dick CJ, Ten RM, Leibson PJ (1997). Functional role for Syk tyrosine kinase in natural killer cell-mediated natural cytotoxicity. J Exp Med. 186:1965-1974

Burshtyn DN, Scharenberg AM, Wagtmann N, Rajagopalan S, Berrada K, Yi T, Kinet JP, Long EO (1996). Recruitment of tyrosine phosphatase HCP by the killer cell inhibitor receptor. Immunity. 4:77-85

Chaichompoo P, Bostik P, Stephenson S, Udompunturuk S, Kobkitjaroen J, Pattanapanyasat K, Ansari AA (2010). Multiple KIR gene polymorphisms are associated with plasma viral loads in SIV-infected rhesus macaques. Cell Immunol. 263:176-187

Chang JJ, Altfeld M (2010). Innate immune activation in primary HIV-1 infection. J Infect Dis. 202 Suppl 2:S297-301

Colonna M, Samaridis J (1995). Cloning of immunoglobulin-superfamily members associated with HLA-C and HLA-B recognition by human natural killer cells. Science. 268:405-408

Cooper MA, Fehniger TA, Turner SC, Chen KS, Ghaheri BA, Ghayur T, Carson WE, Caligiuri MA (2001). Human natural killer cells: a unique innate immunoregulatory role for the CD56(bright) subset. Blood. 97:3146-3151

Crum KA, Logue SE, Curran MD, Middleton D (2000). Development of a PCR-SSOP approach capable of defining the natural killer cell inhibitory receptor (KIR) gene sequence repertoires. Tissue Antigens. 56:313-326

D'Andrea A, Chang C, Franz-Bacon K, McClanahan T, Phillips JH, Lanier LL (1995). Molecular cloning of NKB1. A natural killer cell receptor for HLA-B allotypes. J Immunol. 155:2306-2310

Delves PJ, Roitt IM (2000). The immune system. First of two parts. N Engl J Med. 343:37-49

Eberl M, Engel R, Beck E, Jomaa H (2002). Differentiation of human gamma-delta $T$ cells towards distinct memory phenotypes. Cell Immunol. 218:1-6

Elliott JM , Yokoyama WM (2011). Unifying concepts of MHC-dependent natural killer cell education. Trends Immunol. 32:364-372 
Fan QR, Long EO, Wiley DC (2001). Crystal structure of the human natural killer cell inhibitory receptor KIR2DL1-HLA-Cw4 complex. Nat Immunol. 2:452-460

Funke J, Dürr R, Dietrich U, Koch J (2011). Natural killer cells in HIV-1 infection: a double-edged sword. AIDS Rev. 13:67-76

Gallo RC, Sarin PS, Gelmann EP, Robert-Guroff M, Richardson E, Kalyanaraman VS, Mann D, Sidhu GD, Stahl RE, Zolla-Pazner S, Leibowitch J, Popovic M (1983). Isolation of human T-cell leukemia virus in acquired immune deficiency syndrome (AIDS). Science. 220:865-867

Gan YH, Pauza CD, Malkovsky M (1995). Gamma delta T cells in rhesus monkeys and their response to simian immunodeficiency virus (SIV) infection. Clin Exp Immunol. 102:251-255

Gao F, Bailes E, Robertson DL, Chen Y, Rodenburg CM, Michael SF, Cummins LB, Arthur LO, Peeters M, Shaw GM, Sharp PM, Hahn BH (1999). Origin of HIV-1 in the chimpanzee Pan troglodytes troglodytes. Nature. 397:436-441

Gao W, Tamin A, Soloff A, D'Aiuto L, Nwanegbo E, Robbins PD, Bellini WJ, BarrattBoyes S, Gambotto A (2003). Effects of a SARS-associated coronavirus vaccine in monkeys. Lancet. 362:1895-1896

Gardiner CM (2007). Killer cell immunoglobulin-like receptors on NK cells: the how, where and why. Int J Immunogenet. 35:1-8

Gardiner CM, Guethlein LA, Shilling HG, Pando M, Carr WH, Rajalingam R, Vilches C) Parham P (2001). Different NK cell surface phenotypes defined by the DX9 antibody are due to KIR3DL1 gene polymorphism. J Immunol. 166:2992-3001

Gasser S, Orsulic S, Brown EJ, Raulet DH (2005). The DNA damage pathway regulates innate immune system ligands of the NKG2D receptor. Nature. 436:11861190

Gati A, Guerra N, Gaudin C, Da Rocha S, Escudier B, Lécluse Y, Bettaieb A, Chouaib S, Caignard A (2003). CD158 receptor controls cytotoxic T-lymphocyte susceptibility to tumor-mediated activation-induced cell death by interfering with Fas signaling. Cancer Res. 63:7475-7482

Gaudieri S, DeSantis D, McKinnon E, Moore C, Nolan D, Witt CS, Mallal SA, Christiansen FT (2005). Killer immunoglobulin-like receptors and HLA act both independently and synergistically to modify HIV disease progression. Genes Immun. 6:683-690

Goodridge JP, Lathbury L, Steiner NK, Shulse CN, Pullikotil P, Seidah NG, Hurley CK, Christiansen FT, Witt CS (2007). Three common alleles of KIR2DL4 (CD158d) encode constitutively expressed, inducible and secreted receptors in NK cells. Eur J Immunol. 37:199-211 
Gumperz JE, Valiante NM, Parham P, Lanier LL, Tyan D (1996). Heterogeneous phenotypes of expression of the NKB1 natural killer cell class I receptor among individuals of different human histocompatibility leukocyte antigens types appear genetically regulated, but not linked to major histocompatibililty complex haplotype. J Exp Med. 183:1817-1827

Hahn BH, Shaw GM, De Cock KM, Sharp PM (2000). AIDS as a zoonosis: scientific and public health implications. Science. 287:607-614

Hershberger KL, Kurian J, Korber BT, Letvin NL (2005). Killer cell immunoglobulinlike receptors (KIR) of the African-origin sabaeus monkey: evidence for recombination events in the evolution of KIR. Eur J Immunol. 35:922-935

Hershberger KL, Shyam R, Miura A, Letvin NL (2001). Diversity of the killer cell Iglike receptors of rhesus monkeys. J Immunol. 166:4380-4390

Hiby SE, Walker JJ, O'shaughnessy KM, Redman CW, Carrington M, Trowsdale J, Moffett A (2004). Combinations of maternal KIR and fetal HLA-C genes influence the risk of preeclampsia and reproductive success. J Exp Med. 200:957-965

Hirsch VM, Edmondson P, Murphey-Corb M, Arbeille B, Johnson PR, Mullins JI (1989). SIV adaptation to human cells. Nature. 341:573-574

Hsu KC, Liu XR, Selvakumar A, Mickelson E, O'Reilly RJ, Dupont B (2002). Killer Iglike receptor haplotype analysis by gene content: evidence for genomic diversity with a minimum of six basic framework haplotypes, each with multiple subsets. $J$ Immunol. 169:5118-5129

Huard B, Karlsson L (2000). KIR expression on self-reactive CD8+ T cells is controlled by T-cell receptor engagement. Nature. 403:325-328

Huard B, Karlsson L, Triebel F (2001). KIR down-regulation on NK cells is associated with down-regulation of activating receptors and NK cell inactivation. Eur J Immunol. 31:1728-1735

Kabelitz D (2011). $\gamma \delta$ T-cells: cross-talk between innate and adaptive immunity. Cell Mol Life Sci. 68:2331-2333

Kärre K, Ljunggren HG, Piontek G, Kiessling R (1986). Selective rejection of H-2deficient lymphoma variants suggests alternative immune defence strategy. Nature. 319:675-678

Khakoo SI, Thio CL, Martin MP, Brooks CR, Gao X, Astemborski J, Cheng J, Goedert JJ, Vlahov D, Hilgartner M, Cox S, Little AM, Alexander GJ, Cramp ME, O'Brien SJ, Rosenberg WM, Thomas DL, Carrington M (2004). HLA and NK cell inhibitory receptor genes in resolving hepatitis $C$ virus infection. Science. 305:872-874 
Kikuchi-Maki A, Catina TL, Campbell KS (2005). Cutting edge: KIR2DL4 transduces signals into human NK cells through association with the Fc receptor gamma protein. J Immunol. 174:3859-3863

Kruse PH, Rosner C, Walter L (2010). Characterization of rhesus macaque KIR genotypes and haplotypes. Immunogenetics. 62:281-293

Lanier LL (1998). NK cell receptors. Annu Rev Immunol. 16:359-393

Lanier LL (2005). NK cell recognition. Annu Rev Immunol. 23:225-274

Lanier LL, Corliss BC, Wu J, Leong C, Phillips JH (1998). Immunoreceptor DAP12 bearing a tyrosine-based activation motif is involved in activating NK cells. Nature. 391:703-707

Lanier LL, Le AM, Civin Cl, Loken MR, Phillips JH (1986). The relationship of CD16 (Leu-11) and Leu-19 (NKH-1) antigen expression on human peripheral blood NK cells and cytotoxic T lymphocytes. J Immunol. 13:4480-4486

Leibson PJ (1997). Signal transduction during natural killer cell activation: inside the mind of a killer. Immunity. 6:655-661

Letvin NL (1992). Animal models for the study of human immunodeficiency virus infections. Curr Opin Immunol. 4:481-485

Letvin NL, Eaton KA, Aldrich WR, Sehgal PK, Blake BJ, Schlossman SF, King NW, Hunt RD (1983). Acquired immunodeficiency syndrome in a colony of macaque monkeys. Proc Natl Acad Sci U S A. 80:2718-2722

Letvin NL, King NW (1990). Immunologic and pathologic manifestations of the infection of rhesus monkeys with simian immunodeficiency virus of macaques. J Acquir Immune Defic Syndr. 3:1023-1040

Leung $\mathbf{W}$, lyengar $\mathbf{R}$, Turner $\mathbf{V}$, Lang $\mathbf{P}$, Bader $\mathbf{P}$, Conn $\mathbf{P}$, Niethammer $\mathbf{D}$, Handgretinger R (2004). Determinants of antileukemia effects of allogeneic NK cells. J Immunol. 172:644-650

Li Q, Dong C, Wang J, Che Y, Jiang L, Wang J, Sun M, Wang L, Huang J, Ren D (2003). Induction of hepatitis $C$ virus-specific humoral and cellular immune responses in mice and rhesus by artificial multiple epitopes sequence. Viral Immunol. 16:321-333

Mager DL, McQueen KL, Wee V, Freeman JD (2001). Evolution of natural killer cell receptors: coexistence of functional Ly49 and KIR genes in baboons. Curr Biol. 11:626-630 
Mandelboim O, Davis DM, Reyburn HT, Valés-Gómez M, Sheu EG, Pazmany L, Strominger JL (1996). Enhancement of class II-restricted $T$ cell responses by costimulatory NK receptors for class I MHC proteins. Science. 274:2097-2100

Martin AM, Freitas EM, Witt CS, Christiansen FT (2000). The genomic organization and evolution of the natural killer immunoglobulin-like receptor (KIR) gene cluster. Immunogenetics. 51:268-280

Martin AM, Kulski JK, Gaudieri S, Witt CS, Freitas EM, Trowsdale J, Christiansen FT (2004). Comparative genomic analysis, diversity and evolution of two KIR haplotypes A and B. Gene. 335:121-131

Martin MP, Gao X, Lee JH, Nelson GW, Detels R, Goedert JJ, Buchbinder S, Hoots K, Vlahov D, Trowsdale J, Wilson M, O'Brien SJ, Carrington M (2002). Epistatic interaction between KIR3DS1 and HLA-B delays the progression to AIDS. Nat Genet. 31:429-434

Martin MP, Qi Y, Gao X, Yamada E, Martin JN, Pereyra F, Colombo S, Brown EE, Shupert WL, Phair J, Goedert JJ, Buchbinder S, Kirk GD, Telenti A, Connors M, O'Brien SJ, Walker BD, Parham P, Deeks SG, McVicar DW, Carrington M (2007). Innate partnership of HLA-B and KIR3DL1 subtypes against HIV-1. Nat Genet. 39:733740

Mavilio D, Benjamin J, Daucher M, Lombardo G, Kottilil S, Planta MA, Marcenaro E, Bottino C, Moretta L, Moretta A, Fauci AS (2003). Natural killer cells in HIV-1 infection: dichotomous effects of viremia on inhibitory and activating receptors and their functional correlates. Proc Natl Acad Sci U S A. 100:15011-15016

Mavilio D, Benjamin J, Kim D, Lombardo G, Daucher M, Kinter A, Nies-Kraske E, Marcenaro E, Moretta A, Fauci AS (2005). Identification of NKG2A and NKp80 as specific natural killer cell markers in rhesus and pigtailed monkeys. Blood. 106:17181725

McMahon CW, Raulet DH (2001). Expression and function of NK cell receptors in CD8+ T cells. Curr Opin Immunol. 13:465-470

McTiernan CF, Mathier MA, Zhu X, Xiao X, Klein E, Swan CH, Mehdi H, Gibson G, Trichel AM, Glorioso JC, Feldman AM, McCurry KR, London B (2007). Myocarditis following adeno-associated viral gene expression of human soluble TNF receptor (TNFRII-Fc) in baboon hearts. Gene Ther. 14:1613-1622

Mingari MC, Schiavetti F, Ponte M, Vitale C, Maggi E, Romagnani S, Demarest J, Pantaleo G, Fauci AS, Moretta L (1996). Human CD8+ T lymphocyte subsets that express HLA class I-specific inhibitory receptors represent oligoclonally or monoclonally expanded cell populations. Proc Natl Acad Sci U S A. 93:12433-12438 
Moreland AJ, Guethlein LA, Reeves RK, Broman KW, Johnson RP, Parham P, O'Connor DH, Bimber BN (2011). Characterization of killer immunoglobulin-like receptor genetics and comprehensive genotyping by pyrosequencing in rhesus macaques. BMC Genomics. 12:295

Moretta A (2002). Natural killer cells and dendritic cells: rendezvous in abused tissues. Nat Rev Immunol. 2:957-964

Moretta A, Bottino C, Pende D, Tripodi G, Orengo AM, Millo R, Pelicci PG, Ciccone E, Moretta, L (1990). Human T lymphocytes expressing TCR gamma/delta. Res Immunol. 141:630-635

Moretta A, Marcenaro E, Sivori S, Della Chiesa M, Vitale M, Moretta L (2005). Early liaisons between cells of the innate immune system in inflamed peripheral tissues. Trends Immunol. 26:668-675

Moretta A, Sivori S, Vitale M, Pende D, Morelli L, Augugliaro R, Bottino C, Moretta L (1995). Existence of both inhibitory ( $p 58$ ) and activatory ( $p 50)$ receptors for HLA-C molecules in human natural killer cells. J Exp Med. 182:875-884

National Research Project for SARS, Beijing Group (2004). The involvement of natural killer cells in the pathogenesis of severe acute respiratory syndrome. Am J Clin Pathol. 121:507-511

Naumova E, Mihaylova A, Stoitchkov K, Ivanova M, Quin L, Toneva M (2005). Genetic polymorphism of NK receptors and their ligands in melanoma patients: prevalence of inhibitory over activating signals. Cancer Immunol Immunother. 54:172-178

Nelson GW, Martin MP, Gladman D, Wade J, Trowsdale J, Carrington M (2004). Cutting edge: heterozygote advantage in autoimmune disease: hierarchy of protection/susceptibility conferred by HLA and killer Ig-like receptor combinations in psoriatic arthritis. J Immunol. 173:4273-4276

Ni S, Bernt K, Gaggar A, Li ZY, Kiem HP, Lieber A (2005). Evaluation of biodistribution and safety of adenovirus vectors containing group $B$ fibers after intravenous injection into baboons. Hum Gene Ther. 16:664-677

Orange JS (2004). Human natural killer cell deficiencies and susceptibility to infection. Microbes Infect. 4:1545-1558

Otting N, de Vos-Rouweler AJ, Heijmans CM, de Groot NG, Doxiadis GG, Bontrop RE (2007). MHC class I A region diversity and polymorphism in macaque species. Immunogenetics.59:367-375

Otting N, Heijmans CM, Noort RC, de Groot NG, Doxiadis GG, van Rood JJ, Watkins DI, Bontrop RE (2005). Unparalleled complexity of the MHC class I region in rhesus macaques. Proc Natl Acad Sci U S A. 102:1626-1631 
Pár G, Rukavina D, Podack ER, Horányi M, Szekeres-Barthó J, Hegedüs G, Paál M, Szereday L, Mózsik G, Pár (2002). Decrease in CD3-negative-CD8dim(+) and Vdelta2/Vgamma9 TcR+ peripheral blood lymphocyte counts, low perforin expression and the impairment of natural killer cell activity is associated with chronic hepatitis $C$ virus infection. J Hepatol. 37:514-522

Parham P (2005). MHC class I molecules and KIRs in human history, health and survival. Nat Rev Immunol. 5:201-214

Parham P, Abi-Rached L, Matevosyan L, Moesta AK, Norman PJ, Older Aguilar AM, Guethlein LA (2010). Primate-specific regulation of natural killer cells. J Med Primatol. 39:194-212

Perussia B, Starr S, Abraham S, Fanning V, Trinchieri G (1983). Human natural killer cells analyzed by B73.1, a monoclonal antibody blocking Fc receptor functions. I. Characterization of the lymphocyte subset reactive with B73.1. J Immunol. 130:2133-2141

Pierson RN (2006). Primate T-cell responses to porcine antigens: implications for clinical xenotransplantation. Xenotransplantation. 13:14-18

Pitcher CJ, Hagen SI, Walker JM, Lum R, Mitchell BL, Maino VC, Axthelm MK, Picker $\amalg$ (2002). Development and homeostasis of $T$ cell memory in rhesus macaque. $J$ Immunol. 168:29-43

Premenko-Lanier M, Rota PA, Rhodes GH, Bellini WJ, McChesney MB (2004). Protection against challenge with measles virus (MV) in infant macaques by an MV DNA vaccine administered in the presence of neutralizing antibody. J Infect Dis. 189:2064-2071

Rajalingam R, Parham P, Abi-Rached L (2004). Domain shuffling has been the main mechanism forming new hominoid killer cell Ig-like receptors. J Immunol. 172:356369

Raulet DH, Vance RE (2006). Self-tolerance of natural killer cells. Nat Rev Immunol. 6:520-531

Rosner C, Kruse PH, Hermes M, Otto N, Walter L (2011). Rhesus macaque inhibitory and activating KIR3D interact with Mamu-A-encoded ligands. J Immunol. 186:21562163

Ruggeri L, Capanni M, Urbani E, Perruccio K, Shlomchik WD, Tosti A, Posati S, Rogaia D, Frassoni F, Aversa F, Martelli MF, Velardi A (2002). Effectiveness of donor natural killer cell alloreactivity in mismatched hematopoietic transplants. Science. 295:2097-2100 
Sambrook JG, Bashirova A, Andersen H, Piatak M, Vernikos GS, Coggill P, Lifson JD, Carrington $M$, Beck $S$ (2006). Identification of the ancestral killer immunoglobulinlike receptor gene in primates. BMC Genomics. 7:209

Schaffer M, Malmberg KJ, Ringdén O, Ljunggren HG, Remberger M (2004). Increased infection-related mortality in KIR-ligand-mismatched unrelated allogeneic hematopoietic stem-cell transplantation. Transplantation. 78:1081-1085

Schönberg K, Sribar M, Enczmann J, Fischer JC, Uhrberg M (2011). Analyses of HLA$\mathrm{C}$-specific KIR repertoires in donors with group $\mathrm{A}$ and $\mathrm{B}$ haplotypes suggest a ligandinstructed model of NK cell receptor acquisition. Blood. 117:98-107

Selvakumar A, Steffens U, Palanisamy N, Chaganti RS, Dupont B (1997). Genomic organization and allelic polymorphism of the human killer cell inhibitory receptor gene KIR103. Tissue Antigens. 49:564-573

Shilling HG, Guethlein LA, Cheng NW, Gardiner CM, Rodriguez R, Tyan D, Parham P (2002). Allelic polymorphism synergizes with variable gene content to individualize human KIR genotype. J Immunol. 168:2307-2315

Shilling HG, Young N, Guethlein LA, Cheng NW, Gardiner CM, Tyan D, Parham P (2002). Genetic control of human NK cell repertoire. J Immunol. 169:239-247

Sivori S, Falco M, Carlomagno S, Romeo E, Soldani C, Bensussan A, Viola A, Moretta L, Moretta A (2010). A novel KIR-associated function: evidence that CpG DNA uptake and shuttling to early endosomes is mediated by KIR3DL2. Blood. 116:1637-1647

Snyder MR, Muegge LO, Offord C, O'Fallon WM, Bajzer Z, Weyand CM, Goronzy JJ (2002). Formation of the killer Ig-like receptor repertoire on CD4+CD28null T cells. J Immunol. 168:3839-3846

Snyder MR, Weyand CM, Goronzy JJ (2004). The double life of NK receptors: stimulation or co-stimulation? Trends Immunol. 25:25-32

Sodora DL, Allan JS, Apetrei C, Brenchley JM, Douek DC, Else JG, Estes JD, Hahn BH, Hirsch VM, Kaur A, Kirchhoff F, Muller-Trutwin M, Pandrea I, Schmitz JE, Silvestri G (2009). Toward an AIDS vaccine: lessons from natural simian immunodeficiency virus infections of African nonhuman primate hosts. Nat Med. 15:861-865

Speiser DE, Pittet MJ, Valmori D, Dunbar R, Rimoldi D, Liénard D, MacDonald HR, Cerottini JC, Cerundolo V, Romero P (1999). In vivo expression of natural killer cell inhibitory receptors by human melanoma-specific cytolytic T lymphocytes. J Exp Med. 190:775-782

Sun JC, Beilke JN, Lanier LL (2009). Adaptive immune features of natural killer cells. Nature. 457:557-561 
Tai HC, Zhu X, Hara H, Lin YJ, Ezzelarab M, Long C, Ball S, Ayares D, Cooper DK (2007). The pig-to-primate immune response: relevance for xenotransplantation. Xenotransplantation. 14:227-235

Tamura K, Peterson D, Peterson N, Stecher G, Nei M, and Kumar S (2011). MEGA5: Molecular Evolutionary Genetics Analysis using Maximum Likelihood, Evolutionary Distance, and Maximum Parsimony Methods. Molecular Biology and Evolution. 28: 2731-2739

Thompson JD, Gibson TJ, Plewniak F, Jeanmougin F, Higgins DG (1997). The CLUSTAL_X windows interface: flexible strategies for multiple sequence alignment aided by quality analysis tools. Nucleic Acids Res. 25:4876-4882

Trowsdale J, Barten R, Haude A, Stewart CA, Beck S, Wilson MJ (2001). The genomic context of natural killer receptor extended gene families. Immunol Rev. 181:20-38

Uhrberg M, Valiante NM, Shum BP, Shilling HG, Lienert-Weidenbach K, Corliss B, Tyan D, Lanier LL, Parham P (1997). Human diversity in killer cell inhibitory receptor genes. Immunity. 7:753-763

Uhrberg M, Valiante NM, Young NT, Lanier LL, Phillips JH, Parham P (2001). The repertoire of killer cell Ig-like receptor and CD94:NKG2A receptors in T cells: clones sharing identical alpha beta TCR rearrangement express highly diverse killer cell Iglike receptor patterns. J Immunol. 166:3923-3932

Valés-Gómez M, Reyburn HT, Erskine RA, Strominger J (1998). Differential binding to HLA-C of p50-activating and p58-inhibitory natural killer cell receptors. Proc Natl Acad Sci U S A. 95:14326-14331

Valiante NM, Uhrberg M, Shilling HG, Lienert-Weidenbach K, Arnett KL, D'Andrea A, Phillips JH, Lanier LL, Parham P (1997). Functionally and structurally distinct NK cell receptor repertoires in the peripheral blood of two human donors. Immunity. 7:739-751

van Bergen J, Koning F (2010). The tortoise and the hare: slowly evolving T-cell responses take hastily evolving KIR. Immunology. 131:301-309

van Bergen J, Thompson A, van der Slik A, Ottenhoff TH, Gussekloo J, Koning F (2004). Phenotypic and functional characterization of CD4 T cells expressing killer lglike receptors. J Immunol. 173:6719-6726

van der Slik AR, Koeleman BP, Verduijn W, Bruining GJ, Roep BO, Giphart MJ (2003). KIR in type 1 diabetes: disparate distribution of activating and inhibitory natural killer cell receptors in patients versus HLA-matched control subjects. Diabetes. 52:2639-2642 
Vely F, Peyrat M, Couedel C, Morcet J, Halary F, Davodeau F, Romagne F, Scotet E, Saulquin X, Houssaint E, Schleinitz N, Moretta A, Vivier E, Bonneville M (2001). Regulation of inhibitory and activating killer-cell Ig-like receptor expression occurs in T cells after termination of TCR rearrangements. J Immunol. 166:2487-2494

Verthelyi D, Wang VW, Lifson JD, Klinman DM (2004). CpG oligodeoxynucleotides improve the response to hepatitis B immunization in healthy and SIV-infected rhesus macaques. AIDS. 18:1003-1008

Vierboom MP, Jonker M, Bontrop RE, 't Hart B (2005). Modeling human arthritic diseases in nonhuman primates. Arthritis Res Ther. 7:145-154

Vilches C, Pando MJ, Parham P (2000). Genes encoding human killer-cell Ig-like receptors with D1 and D2 extracellular domains all contain untranslated pseudoexons encoding a third Ig-like domain. Immunogenetics. 51:639-646

Vilches C, Parham P (2002). KIR: diverse, rapidly evolving receptors of innate and adaptive immunity. Annu Rev Immunol. 20:217-251

Vivian JP, Duncan RC, Berry R, O'Connor GM, Reid HH, Beddoe T, Gras S, Saunders PM, Olshina MA, Widjaja JM, Harpur CM, Lin J, Maloveste SM, Price DA, Lafont BA, McVicar DW, Clements CS, Brooks AG, Rossjohn J (2011). Killer cell immunoglobulin-like receptor 3DL1-mediated recognition of human leukocyte antigen B. Nature. 479:401-405

Vivier E, Anfossi N (2004). Inhibitory NK-cell receptors on T cells: witness of the past, actors of the future. Nat Rev Immunol. 4:190-198

Voss SD, Daley J, Ritz J, Robertson MJ (1998). Participation of the CD94 receptor complex in costimulation of human natural killer cells. J Immunol. 160:1618-1626

Wagtmann N, Biassoni R, Cantoni C, Verdiani S, Malnati MS, Vitale M, Bottino C, Moretta L, Moretta A, Long EO (1995). Molecular clones of the p58 NK cell receptor reveal immunoglobulin-related molecules with diversity in both the extra- and intracellular domains. Immunity. 2:439-349

Walzer T, Dalod M, Robbins SH, Zitvogel L, Vivier E (2005). Natural-killer cells and dendritic cells: "I'union fait la force". Blood. 106:2252-2258

Webster RL, Johnson RP (2005). Delineation of multiple subpopulations of natural killer cells in rhesus macaques. Immunology. 115:206-214

Wende H, Colonna M, Ziegler A, Volz A (1999). Organization of the leukocyte receptor cluster (LRC) on human chromosome 19q13.4. Mamm Genome. 10:154160 
Wilson MJ, Torkar M, Haude A, Milne S, Jones T, Sheer D, Beck S, Trowsdale J (2000). Plasticity in the organization and sequences of human KIR/ILT gene families. Proc Natl Acad Sci U S A. 97:4778-4783

Wilson MJ, Torkar M, Trowsdale J (1997). Genomic organization of a human killer cell inhibitory receptor gene. Tissue Antigens. 49:574-579

Yawata M, Yawata N, Abi-Rached L, Parham P (2002). Variation within the human killer cell immunoglobulin-like receptor (KIR) gene family. Crit Rev Immunol. 22:463482 


\section{Supplement}
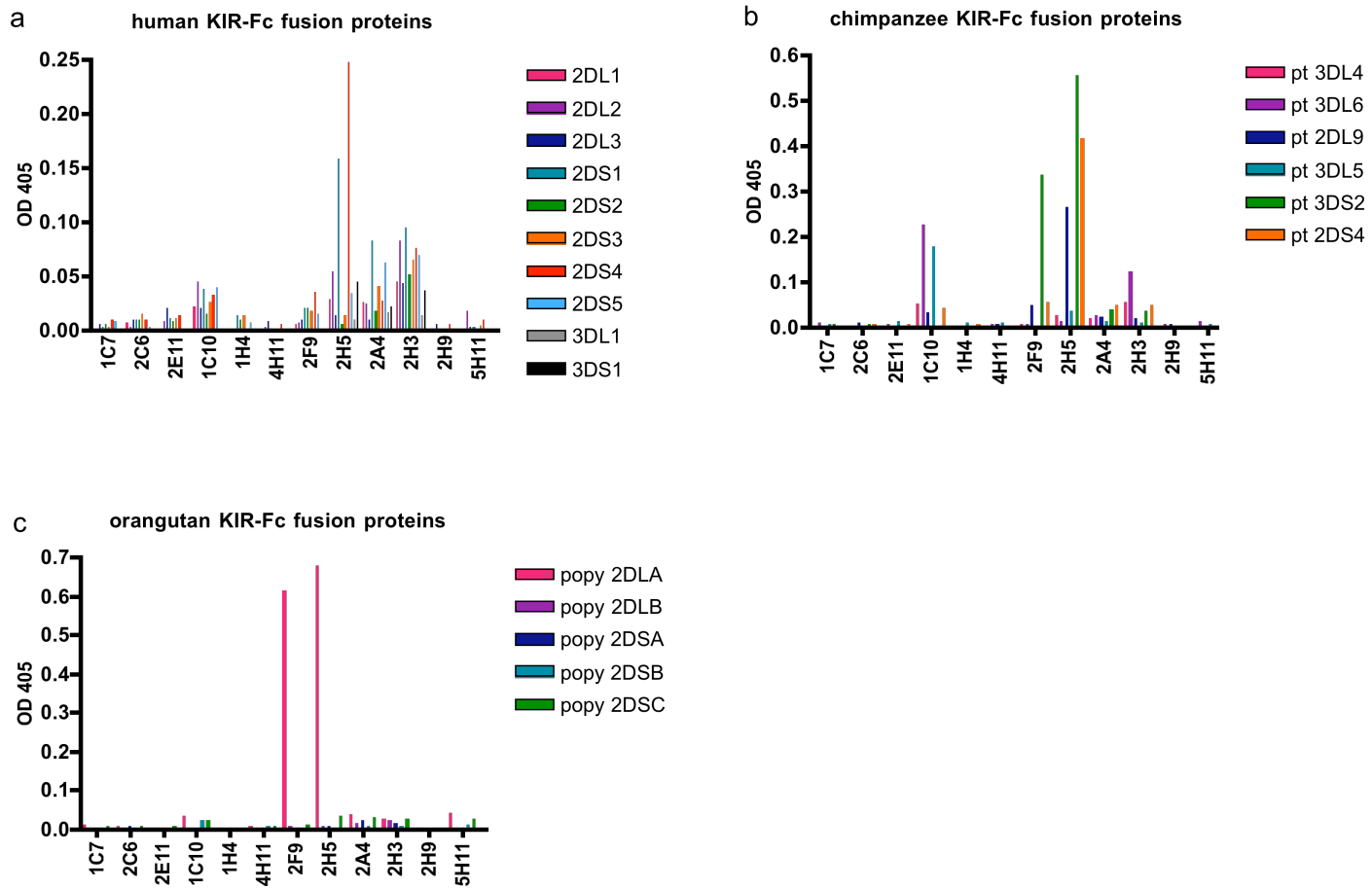

Figure 35. Cross-reactivity of anti-rhesus macaque KIR antibodies with KIR-Fc fusion proteins of other species using ELISA.

All values were corrected for the background. $50 \mu$ of hybridoma supernatant was used for binding the antigen ( $0.5 \mu \mathrm{g}$ per well) coated to the ELISA plate. The OD was measured at $405 \mathrm{~nm}$. a) Human KIR-Fc fusionproteins; b) chimpanzee KIR-Fc fusion proteins; c) orangutan KIR-Fc fusion protein.

Table 6. Peptide spot array sequences of the three rhesus macaque KIR3D proteins.

\begin{tabular}{|c|c|c|c|}
\hline spot & KIR3DLW03*004 & KIR3DSW08*006 & KIR3DL05*007 \\
\hline A 1 & $\mathrm{H}-\mathrm{T}-\mathrm{G}-\mathrm{G}-\mathrm{Q}-\mathrm{D}-\mathrm{K}-\mathrm{N}-\mathrm{F}-\mathrm{L}-\mathrm{S}-\mathrm{A}-\mathrm{W}-\mathrm{P}-\mathrm{S}-\mathrm{P}-\mathrm{V}-\mathrm{V}$ & $H-T-G-G-Q-D-K-T-S-L-S-A-R-P-S-A-V-V$ & $H-T-G-G-Q-D-K-I-F-L-S-A-R-P-S-A-V-V$ \\
\hline A 2 & $\mathrm{G}-\mathrm{Q}-\mathrm{D}-\mathrm{K}-\mathrm{N}-\mathrm{F}-\mathrm{L}-\mathrm{S}-\mathrm{A}-\mathrm{W}-\mathrm{P}-\mathrm{S}-\mathrm{P}-\mathrm{V}-\mathrm{V}-\mathrm{P}-\mathrm{Q}-\mathrm{G}$ & $\mathrm{G}-\mathrm{Q}-\mathrm{D}-\mathrm{K}-\mathrm{T}-\mathrm{S}-\mathrm{L}-\mathrm{S}-\mathrm{A}-\mathrm{R}-\mathrm{P}-\mathrm{S}-\mathrm{A}-\mathrm{V}-\mathrm{V}-\mathrm{P}-\mathrm{Q}-\mathrm{G}$ & $\mathrm{G}-\mathrm{Q}-\mathrm{D}-\mathrm{K}-\mathrm{I}-\mathrm{F}-\mathrm{L}-\mathrm{S}-\mathrm{A}-\mathrm{R}-\mathrm{P}-\mathrm{S}-\mathrm{A}-\mathrm{V}-\mathrm{V}-\mathrm{P}-\mathrm{Q}-\mathrm{G}$ \\
\hline A 3 & $\mathrm{~K}-\mathrm{N}-\mathrm{F}-\mathrm{L}-\mathrm{S}-\mathrm{A}-\mathrm{W}-\mathrm{P}-\mathrm{S}-\mathrm{P}-\mathrm{V}-\mathrm{V}-\mathrm{P}-\mathrm{Q}-\mathrm{G}-\mathrm{G}-\mathrm{H}-\mathrm{V}$ & $\mathrm{K}-\mathrm{T}-\mathrm{S}-\mathrm{L}-\mathrm{S}-\mathrm{A}-\mathrm{R}-\mathrm{P}-\mathrm{S}-\mathrm{A}-\mathrm{V}-\mathrm{V}-\mathrm{P}-\mathrm{Q}-\mathrm{G}-\mathrm{G}-\mathrm{H}-\mathrm{V}$ & K-I-E-L-S-A-R-P-S-A-V-V-P-Q-G-G-H-V \\
\hline A 4 & $\mathrm{~L}-\mathrm{S}-\mathrm{A}-\mathrm{W}-\mathrm{P}-\mathrm{S}-\mathrm{P}-\mathrm{V}-\mathrm{V}-\mathrm{P}-\mathrm{Q}-\mathrm{G}-\mathrm{G}-\mathrm{H}-\mathrm{V}-\mathrm{T}-\mathrm{L}-\mathrm{R}$ & $\mathrm{L}-\mathrm{S}-\mathrm{A}-\mathrm{R}-\mathrm{P}-\mathrm{S}-\mathrm{A}-\mathrm{V}-\mathrm{V}-\mathrm{P}-\mathrm{Q}-\mathrm{G}-\mathrm{G}-\mathrm{H}-\mathrm{V}-\mathrm{T}-\mathrm{L}-\mathrm{R}$ & $\mathrm{L}-\mathrm{S}-\mathrm{A}-\mathrm{R}-\mathrm{P}-\mathrm{S}-\mathrm{A}-\mathrm{V}-\mathrm{V}-\mathrm{P}-\mathrm{Q}-\mathrm{G}-\mathrm{G}-\mathrm{H}-\mathrm{V}-\mathrm{T}-\mathrm{L}-\mathrm{R}$ \\
\hline & $\mathrm{W}-\mathrm{P}-\mathrm{S}-\mathrm{P}-\mathrm{V}-\mathrm{V}-\mathrm{P}-\mathrm{Q}-\mathrm{G}-\mathrm{G}-\mathrm{H}-\mathrm{V}-\mathrm{T}-\mathrm{L}-\mathrm{R}-\mathrm{C}-\mathrm{H}-\mathrm{Y}$ & $\mathrm{R}-\mathrm{P}-\mathrm{S}-\mathrm{A}-\mathrm{V}-\mathrm{V}-\mathrm{P}-\mathrm{Q}-\mathrm{G}-\mathrm{G}-\mathrm{H}-\mathrm{V}-\mathrm{T}-\mathrm{L}-\mathrm{R}-\mathrm{C}-\mathrm{H}-\mathrm{Y}$ & $\mathrm{R}-\mathrm{P}-\mathrm{S}-\mathrm{A}-\mathrm{V}-\mathrm{V}-\mathrm{P}-\mathrm{Q}-\mathrm{G}-\mathrm{G}-\mathrm{H}-\mathrm{V}-\mathrm{T}-\mathrm{L}-\mathrm{R}-\mathrm{C}-\mathrm{Y}-\mathrm{Y}$ \\
\hline A 6 & $\mathrm{P}-\mathrm{V}-\mathrm{V}-\mathrm{P}-\mathrm{Q}-\mathrm{G}-\mathrm{G}-\mathrm{H}-\mathrm{V}-\mathrm{T}-\mathrm{L}-\mathrm{R}-\mathrm{C}-\mathrm{H}-\mathrm{Y}-\mathrm{R}-\mathrm{G}-\mathrm{G}$ & $\mathrm{A}-\mathrm{V}-\mathrm{V}-\mathrm{P}-\mathrm{Q}-\mathrm{G}-\mathrm{G}-\mathrm{H}-\mathrm{V}-\mathrm{T}-\mathrm{L}-\mathrm{R}-\mathrm{C}-\mathrm{H}-\mathrm{Y}-\mathrm{R}-\mathrm{R}-\mathrm{G}$ & $\mathrm{A}-\mathrm{V}-\mathrm{V}-\mathrm{P}-\mathrm{Q}-\mathrm{G}-\mathrm{G}-\mathrm{H}-\mathrm{V}-\mathrm{T}-\mathrm{L}-\mathrm{R}-\mathrm{C}-\mathrm{Y}-\mathrm{Y}-\mathrm{R}-\mathrm{D}-\mathrm{G}$ \\
\hline A 7 & P-Q-G-G-H-V-T-L-R-C-H-Y-R-G-G-F-N-N & $\mathrm{P}-\mathrm{Q}-\mathrm{G}-\mathrm{G}-\mathrm{H}-\mathrm{V}-\mathrm{T}-\mathrm{L}-\mathrm{R}-\mathrm{C}-\mathrm{H}-\mathrm{Y}-\mathrm{R}-\mathrm{R}-\mathrm{G}-\mathrm{L}-\mathrm{N}-\mathrm{N}$ & $\mathrm{P}-\mathrm{Q}-\mathrm{G}-\mathrm{G}-\mathrm{H}-\mathrm{V}-\mathrm{T}-\mathrm{L}-\mathrm{R}-\mathrm{C}-\mathrm{Y}-\mathrm{Y}-\mathrm{R}-\mathrm{D}-\mathrm{G}-\mathrm{L}-\mathrm{N}-\mathrm{N}$ \\
\hline A 8 & $\mathrm{G}-\mathrm{H}-\mathrm{V}-\mathrm{T}-\mathrm{L}-\mathrm{R}-\mathrm{C}-\mathrm{H}-\mathrm{Y}-\mathrm{R}-\mathrm{G}-\mathrm{G}-\mathrm{F}-\mathrm{N}-\mathrm{N}-\mathrm{F}-\mathrm{T}-\mathrm{L}$ & $\mathrm{G}-\mathrm{H}-\mathrm{V}-\mathrm{T}-\mathrm{L}-\mathrm{R}-\mathrm{C}-\mathrm{H}-\mathrm{Y}-\mathrm{R}-\mathrm{R}-\mathrm{G}-\mathrm{L}-\mathrm{N}-\mathrm{N}-\mathrm{F}-\mathrm{T}-\mathrm{N}$ & G-H-V-T-L-R-C-Y-Y-R-D-G-L-N-N-F-T-N \\
\hline A 9 & $\mathrm{~T}-\mathrm{L}-\mathrm{R}-\mathrm{C}-\mathrm{H}-\mathrm{Y}-\mathrm{R}-\mathrm{G}-\mathrm{G}-\mathrm{F}-\mathrm{N}-\mathrm{N}-\mathrm{F}-\mathrm{T}-\mathrm{L}-\mathrm{Y}-\mathrm{K}-\mathrm{D}$ & $\mathrm{T}-\mathrm{L}-\mathrm{R}-\mathrm{C}-\mathrm{H}-\mathrm{Y}-\mathrm{R}-\mathrm{R}-\mathrm{G}-\mathrm{L}-\mathrm{N}-\mathrm{N}-\mathrm{F}-\mathrm{T}-\mathrm{N}-\mathrm{F}-\mathrm{T}-\mathrm{L}$ & $\mathrm{T}-\mathrm{L}-\mathrm{R}-\mathrm{C}-\mathrm{Y}-\mathrm{Y}-\mathrm{R}-\mathrm{D}-\mathrm{G}-\mathrm{L}-\mathrm{N}-\mathrm{N}-\mathrm{F}-\mathrm{T}-\mathrm{N}-\mathrm{F}-\mathrm{T}-\mathrm{I}$ \\
\hline A10 & $\mathrm{C}-\mathrm{H}-\mathrm{Y}-\mathrm{R}-\mathrm{G}-\mathrm{G}-\mathrm{F}-\mathrm{N}-\mathrm{N}-\mathrm{F}-\mathrm{T}-\mathrm{L}-\mathrm{Y}-\mathrm{K}-\mathrm{D}-\mathrm{D}-\mathrm{R}-\mathrm{S}$ & $\mathrm{C}-\mathrm{H}-\mathrm{Y}-\mathrm{R}-\mathrm{R}-\mathrm{G}-\mathrm{L}-\mathrm{N}-\mathrm{N}-\mathrm{F}-\mathrm{T}-\mathrm{N}-\mathrm{F}-\mathrm{T}-\mathrm{L}-\mathrm{Y}-\mathrm{K}-\mathrm{D}$ & $\mathrm{C}-\mathrm{Y}-\mathrm{Y}-\mathrm{R}-\mathrm{D}-\mathrm{G}-\mathrm{L}-\mathrm{N}-\mathrm{N}-\mathrm{F}-\mathrm{T}-\mathrm{N}-\mathrm{F}-\mathrm{T}-\mathrm{L}-\mathrm{Y}-\mathrm{K}-\mathrm{D}$ \\
\hline A11 & $\mathrm{R}-\mathrm{G}-\mathrm{G}-\mathrm{F}-\mathrm{N}-\mathrm{N}-\mathrm{F}-\mathrm{T}-\mathrm{L}-\mathrm{Y}-\mathrm{K}-\mathrm{D}-\mathrm{D}-\mathrm{R}-\mathrm{S}-\mathrm{H}-\mathrm{I}-\mathrm{P}$ & $\mathrm{R}-\mathrm{R}-\mathrm{G}-\mathrm{L}-\mathrm{N}-\mathrm{N}-\mathrm{F}-\mathrm{T}-\mathrm{N}-\mathrm{F}-\mathrm{T}-\mathrm{L}-\mathrm{Y}-\mathrm{K}-\mathrm{D}-\mathrm{D}-\mathrm{R}-\mathrm{S}$ & $\mathrm{R}-\mathrm{D}-\mathrm{G}-\mathrm{L}-\mathrm{N}-\mathrm{N}-\mathrm{F}-\mathrm{T}-\mathrm{N}-\mathrm{F}-\mathrm{T}-\mathrm{L}-\mathrm{Y}-\mathrm{K}-\mathrm{D}-\mathrm{D}-\mathrm{R}-\mathrm{S}$ \\
\hline A12 & $\mathrm{F}-\mathrm{N}-\mathrm{N}-\mathrm{F}-\mathrm{T}-\mathrm{L}-\mathrm{Y}-\mathrm{K}-\mathrm{D}-\mathrm{D}-\mathrm{R}-\mathrm{S}-\mathrm{H}-\mathrm{I}-\mathrm{P}-\mathrm{I}-\mathrm{F}-\mathrm{H}$ & $\mathrm{L}-\mathrm{N}-\mathrm{N}-\mathrm{F}-\mathrm{T}-\mathrm{N}-\mathrm{F}-\mathrm{T}-\mathrm{L}-\mathrm{Y}-\mathrm{K}-\mathrm{D}-\mathrm{D}-\mathrm{R}-\mathrm{S}-\mathrm{H}-\mathrm{V}-\mathrm{P}$ & $\mathrm{L}-\mathrm{N}-\mathrm{N}-\mathrm{F}-\mathrm{T}-\mathrm{N}-\mathrm{F}-\mathrm{T}-\mathrm{L}-\mathrm{Y}-\mathrm{K}-\mathrm{D}-\mathrm{D}-\mathrm{R}-\mathrm{S}-\mathrm{H}-\mathrm{V}-\mathrm{P}$ \\
\hline A13 & $\mathrm{F}-\mathrm{T}-\mathrm{L}-\mathrm{Y}-\mathrm{K}-\mathrm{D}-\mathrm{D}-\mathrm{R}-\mathrm{S}-\mathrm{H}-\mathrm{I}-\mathrm{P}-\mathrm{I}-\mathrm{F}-\mathrm{H}-\mathrm{S}-\mathrm{R}-\mathrm{I}$ & $\mathrm{F}-\mathrm{T}-\mathrm{N}-\mathrm{F}-\mathrm{T}-\mathrm{L}-\mathrm{Y}-\mathrm{K}-\mathrm{D}-\mathrm{D}-\mathrm{R}-\mathrm{S}-\mathrm{H}-\mathrm{V}-\mathrm{P}-\mathrm{V}-\mathrm{F}-\mathrm{H}$ & $\mathrm{F}-\mathrm{T}-\mathrm{N}-\mathrm{F}-\mathrm{T}-\mathrm{L}-\mathrm{Y}-\mathrm{K}-\mathrm{D}-\mathrm{D}-\mathrm{R}-\mathrm{S}-\mathrm{H}-\mathrm{V}-\mathrm{P}-\mathrm{I}-\mathrm{F}-\mathrm{H}$ \\
\hline A14 & Y-K-D-D-R-S-H-I-P-I-F-H-S-R-I-F-Q-E & $\mathrm{F}-\mathrm{T}-\mathrm{L}-\mathrm{Y}-\mathrm{K}-\mathrm{D}-\mathrm{D}-\mathrm{R}-\mathrm{S}-\mathrm{H}-\mathrm{V}-\mathrm{P}-\mathrm{V}-\mathrm{F}-\mathrm{H}-\mathrm{S}-\mathrm{R}-\mathrm{I}$ & $\mathrm{F}-\mathrm{T}-\mathrm{L}-\mathrm{Y}-\mathrm{K}-\mathrm{D}-\mathrm{D}-\mathrm{R}-\mathrm{S}-\mathrm{H}-\mathrm{V}-\mathrm{P}-\mathrm{I}-\mathrm{F}-\mathrm{H}-\mathrm{S}-\mathrm{R}-\mathrm{I}$ \\
\hline A15 & $\mathrm{D}-\mathrm{R}-\mathrm{S}-\mathrm{H}-\mathrm{I}-\mathrm{P}-\mathrm{I}-\mathrm{F}-\mathrm{H}-\mathrm{S}-\mathrm{R}-\mathrm{I}-\mathrm{F}-\mathrm{Q}-\mathrm{E}-\mathrm{S}-\mathrm{F}-\mathrm{L}$ & $\mathrm{Y}-\mathrm{K}-\mathrm{D}-\mathrm{D}-\mathrm{R}-\mathrm{S}-\mathrm{H}-\mathrm{V}-\mathrm{P}-\mathrm{V}-\mathrm{F}-\mathrm{H}-\mathrm{S}-\mathrm{R}-\mathrm{I}-\mathrm{F}-\mathrm{Q}-\mathrm{E}$ & Y-K-D-D-R-S-H-V-P-I-F-H-S-R-I-F-Q-E \\
\hline A16 & $\mathrm{H}-\mathrm{I}-\mathrm{P}-\mathrm{I}-\mathrm{F}-\mathrm{H}-\mathrm{S}-\mathrm{R}-\mathrm{I}-\mathrm{F}-\mathrm{Q}-\mathrm{E}-\mathrm{S}-\mathrm{F}-\mathrm{L}-\mathrm{M}-\mathrm{G}-\mathrm{P}$ & $D-R-S-H-V-P-V-F-H-S-R-I-F-Q-E-S-F-L$ & $\mathrm{D}-\mathrm{R}-\mathrm{S}-\mathrm{H}-\mathrm{V}-\mathrm{P}-\mathrm{I}-\mathrm{F}-\mathrm{H}-\mathrm{S}-\mathrm{R}-\mathrm{I}-\mathrm{F}-\mathrm{Q}-\mathrm{E}-\mathrm{S}-\mathrm{F}-\mathrm{I}$ \\
\hline A17 & $I-F-H-S-R-I-F-Q-E-S-F-L-M-G-P-V-T-P$ & $\mathrm{H}-\mathrm{V}-\mathrm{P}-\mathrm{V}-\mathrm{F}-\mathrm{H}-\mathrm{S}-\mathrm{R}-\mathrm{I}-\mathrm{F}-\mathrm{Q}-\mathrm{E}-\mathrm{S}-\mathrm{F}-\mathrm{L}-\mathrm{M}-\mathrm{G}-\mathrm{P}$ & $\mathrm{H}-\mathrm{V}-\mathrm{P}-\mathrm{I}-\mathrm{F}-\mathrm{H}-\mathrm{S}-\mathrm{R}-\mathrm{I}-\mathrm{F}-\mathrm{Q}-\mathrm{E}-\mathrm{S}-\mathrm{F}-\mathrm{L}-\mathrm{M}-\mathrm{G}-\mathrm{P}$ \\
\hline A18 & $\mathrm{S}-\mathrm{R}-\mathrm{I}-\mathrm{F}-\mathrm{Q}-\mathrm{E}-\mathrm{S}-\mathrm{F}-\mathrm{L}-\mathrm{M}-\mathrm{G}-\mathrm{P}-\mathrm{V}-\mathrm{T}-\mathrm{P}-\mathrm{A}-\mathrm{H}-\mathrm{A}$ & V-F-H-S-R-I-F-Q-E-S-F-L-M-G-P-V-T-Q & $\mathrm{I}-\mathrm{F}-\mathrm{H}-\mathrm{S}-\mathrm{R}-\mathrm{I}-\mathrm{F}-\mathrm{Q}-\mathrm{E}-\mathrm{S}-\mathrm{F}-\mathrm{L}-\mathrm{M}-\mathrm{G}-\mathrm{P}-\mathrm{V}-\mathrm{T}-\mathrm{P}$ \\
\hline A19 & $\mathrm{F}-\mathrm{Q}-\mathrm{E}-\mathrm{S}-\mathrm{F}-\mathrm{L}-\mathrm{M}-\mathrm{G}-\mathrm{P}-\mathrm{V}-\mathrm{T}-\mathrm{P}-\mathrm{A}-\mathrm{H}-\mathrm{A}-\mathrm{G}-\mathrm{T}-\mathrm{Y}$ & $S-R-I-F-Q-E-S-F-L-M-G-P-V-T-Q-A-H-T$ & $S-R-I-F-Q-E-S-F-L-M-G-P-V-T-P-A-H-A$ \\
\hline A20 & $\mathrm{S}-\mathrm{F}-\mathrm{L}-\mathrm{M}-\mathrm{G}-\mathrm{P}-\mathrm{V}-\mathrm{T}-\mathrm{P}-\mathrm{A}-\mathrm{H}-\mathrm{A}-\mathrm{G}-\mathrm{T}-\mathrm{Y}-\mathrm{R}-\mathrm{C}-\mathrm{R}$ & $F-Q-E-S-F-L-M-G-P-V-T-Q-A-H-T-G-T-Y$ & $\mathrm{~F}-\mathrm{Q}-\mathrm{E}-\mathrm{S}-\mathrm{F}-\mathrm{L}-\mathrm{M}-\mathrm{G}-\mathrm{P}-\mathrm{V}-\mathrm{T}-\mathrm{P}-\mathrm{A}-\mathrm{H}-\mathrm{A}-\mathrm{G}-\mathrm{T}-\mathrm{Y}$ \\
\hline A21 & $\mathrm{M}-\mathrm{G}-\mathrm{P}-\mathrm{V}-\mathrm{T}-\mathrm{P}-\mathrm{A}-\mathrm{H}-\mathrm{A}-\mathrm{G}-\mathrm{T}-\mathrm{Y}-\mathrm{R}-\mathrm{C}-\mathrm{R}-\mathrm{G}-\mathrm{S}-\mathrm{Y}$ & S-F-L-M-G-P-V-T-Q-A-H-T-G-T-Y-R-C-R & S-F-L-M-G-P-V-T-P-A-H-A-G-T-Y-R-C-R \\
\hline A22 & $\mathrm{V}-\mathrm{T}-\mathrm{P}-\mathrm{A}-\mathrm{H}-\mathrm{A}-\mathrm{G}-\mathrm{T}-\mathrm{Y}-\mathrm{R}-\mathrm{C}-\mathrm{R}-\mathrm{G}-\mathrm{S}-\mathrm{Y}-\mathrm{P}-\mathrm{H}-\mathrm{S}$ & $M-G-P-V-T-Q-A-H-T-G-T-Y-R-C-R-G-S-Y$ & $M-G-P-V-T-P-A-H-A-G-T-Y-R-C-R-G-S-Y$ \\
\hline A23 & $\mathrm{A}-\mathrm{H}-\mathrm{A}-\mathrm{G}-\mathrm{T}-\mathrm{Y}-\mathrm{R}-\mathrm{C}-\mathrm{R}-\mathrm{G}-\mathrm{S}-\mathrm{Y}-\mathrm{P}-\mathrm{H}-\mathrm{S}-\mathrm{P}-\mathrm{T}-\mathrm{E}$ & V-T-Q-A-H-T-G-T-Y-R-C-R-G-S-Y-P-H-S & $\mathrm{V}-\mathrm{T}-\mathrm{P}-\mathrm{A}-\mathrm{H}-\mathrm{A}-\mathrm{G}-\mathrm{T}-\mathrm{Y}-\mathrm{R}-\mathrm{C}-\mathrm{R}-\mathrm{G}-\mathrm{S}-\mathrm{Y}-\mathrm{P}-\mathrm{H}-\mathrm{S}$ \\
\hline A2 4 & G-T-Y-R-C-R-G-S-Y-P-H-S-P-T-E-W-S-T & $A-H-T-G-T-Y-R-C-R-G-S-Y-P-H-S-P-T-E$ & $\mathrm{~A}-\mathrm{H}-\mathrm{A}-\mathrm{G}-\mathrm{T}-\mathrm{Y}-\mathrm{R}-\mathrm{C}-\mathrm{R}-\mathrm{G}-\mathrm{S}-\mathrm{Y}-\mathrm{P}-\mathrm{H}-\mathrm{S}-\mathrm{P}-\mathrm{T}-\mathrm{E}$ \\
\hline A25 & $\mathrm{R}-\mathrm{C}-\mathrm{R}-\mathrm{G}-\mathrm{S}-\mathrm{Y}-\mathrm{P}-\mathrm{H}-\mathrm{S}-\mathrm{P}-\mathrm{T}-\mathrm{E}-\mathrm{W}-\mathrm{S}-\mathrm{T}-\mathrm{P}-\mathrm{S}-\mathrm{N}$ & G-T-Y-R-C-R-G-S-Y-P-H-S-P-T-E-W-S-A & $G-T-Y-R-C-R-G-S-Y-P-H-S-P-T-E-W-S-A$ \\
\hline A26 & $\mathrm{G}-\mathrm{S}-\mathrm{Y}-\mathrm{P}-\mathrm{H}-\mathrm{S}-\mathrm{P}-\mathrm{T}-\mathrm{E}-\mathrm{W}-\mathrm{S}-\mathrm{T}-\mathrm{P}-\mathrm{S}-\mathrm{N}-\mathrm{P}-\mathrm{L}-\mathrm{A}$ & $\mathrm{R}-\mathrm{C}-\mathrm{R}-\mathrm{G}-\mathrm{S}-\mathrm{Y}-\mathrm{P}-\mathrm{H}-\mathrm{S}-\mathrm{P}-\mathrm{T}-\mathrm{E}-\mathrm{W}-\mathrm{S}-\mathrm{A}-\mathrm{L}-\mathrm{S}-\mathrm{E}$ & $\mathrm{R}-\mathrm{C}-\mathrm{R}-\mathrm{G}-\mathrm{S}-\mathrm{Y}-\mathrm{P}-\mathrm{H}-\mathrm{S}-\mathrm{P}-\mathrm{T}-\mathrm{E}-\mathrm{W}-\mathrm{S}-\mathrm{A}-\mathrm{L}-\mathrm{S}-\mathrm{D}$ \\
\hline A27 & $\mathrm{P}-\mathrm{H}-\mathrm{S}-\mathrm{P}-\mathrm{T}-\mathrm{E}-\mathrm{W}-\mathrm{S}-\mathrm{T}-\mathrm{P}-\mathrm{S}-\mathrm{N}-\mathrm{P}-\mathrm{L}-\mathrm{A}-\mathrm{I}-\mathrm{R}-\mathrm{V}$ & G-S-Y-P-H-S-P-T-E-W-S-A-L-S-E-P-L-A & G-S-Y-P-H-S-P-T-E-W-S-A-L-S-D-P-L-A \\
\hline A28 & $\mathrm{P}-\mathrm{T}-\mathrm{E}-\mathrm{W}-\mathrm{S}-\mathrm{T}-\mathrm{P}-\mathrm{S}-\mathrm{N}-\mathrm{P}-\mathrm{L}-\mathrm{A}-\mathrm{I}-\mathrm{R}-\mathrm{V}-\mathrm{T}-\mathrm{G}-\mathrm{V}$ & $\mathrm{P}-\mathrm{H}-\mathrm{S}-\mathrm{P}-\mathrm{T}-\mathrm{E}-\mathrm{W}-\mathrm{S}-\mathrm{A}-\mathrm{L}-\mathrm{S}-\mathrm{E}-\mathrm{P}-\mathrm{L}-\mathrm{A}-\mathrm{I}-\mathrm{M}-\mathrm{V}$ & $\mathrm{P}-\mathrm{H}-\mathrm{S}-\mathrm{P}-\mathrm{T}-\mathrm{E}-\mathrm{W}-\mathrm{S}-\mathrm{A}-\mathrm{L}-\mathrm{S}-\mathrm{D}-\mathrm{P}-\mathrm{L}-\mathrm{A}-\mathrm{I}-\mathrm{R}-\mathrm{V}$ \\
\hline A2 9 & $\mathrm{~W}-\mathrm{S}-\mathrm{T}-\mathrm{P}-\mathrm{S}-\mathrm{N}-\mathrm{P}-\mathrm{L}-\mathrm{A}-\mathrm{I}-\mathrm{R}-\mathrm{V}-\mathrm{T}-\mathrm{G}-\mathrm{V}-\mathrm{H}-\mathrm{K}-\mathrm{K}$ & $\mathrm{P}-\mathrm{T}-\mathrm{E}-\mathrm{W}-\mathrm{S}-\mathrm{A}-\mathrm{L}-\mathrm{S}-\mathrm{E}-\mathrm{P}-\mathrm{L}-\mathrm{A}-\mathrm{I}-\mathrm{M}-\mathrm{V}-\mathrm{T}-\mathrm{G}-\mathrm{V}$ & P-T-E-W-S-A-L-S-D-P-L-A-I-R-V-T-G-V \\
\hline А 30 & $\mathrm{P}-\mathrm{S}-\mathrm{N}-\mathrm{P}-\mathrm{L}-\mathrm{A}-\mathrm{I}-\mathrm{R}-\mathrm{V}-\mathrm{T}-\mathrm{G}-\mathrm{V}-\mathrm{H}-\mathrm{K}-\mathrm{K}-\mathrm{P}-\mathrm{S}-\mathrm{L}$ & $\mathrm{W}-\mathrm{S}-\mathrm{A}-\mathrm{L}-\mathrm{S}-\mathrm{E}-\mathrm{P}-\mathrm{L}-\mathrm{A}-\mathrm{I}-\mathrm{M}-\mathrm{V}-\mathrm{T}-\mathrm{G}-\mathrm{V}-\mathrm{H}-\mathrm{R}-\mathrm{K}$ & W-S-A-L-S-D-P-L-A-I-R-V-T-G-V-H-R-K \\
\hline A31 & P-L-A-I-R-V-T-G-V-H-K-K-P-S-L-L-A-L & $\mathrm{L}-\mathrm{S}-\mathrm{E}-\mathrm{P}-\mathrm{L}-\mathrm{A}-\mathrm{I}-\mathrm{M}-\mathrm{V}-\mathrm{T}-\mathrm{G}-\mathrm{V}-\mathrm{H}-\mathrm{R}-\mathrm{K}-\mathrm{P}-\mathrm{S}-\mathrm{L}$ & $\mathrm{L}-\mathrm{S}-\mathrm{D}-\mathrm{P}-\mathrm{L}-\mathrm{A}-\mathrm{I}-\mathrm{R}-\mathrm{V}-\mathrm{T}-\mathrm{G}-\mathrm{V}-\mathrm{H}-\mathrm{R}-\mathrm{K}-\mathrm{P}-\mathrm{S}-\mathrm{I}$ \\
\hline A32 & $\mathrm{I}-\mathrm{R}-\mathrm{V}-\mathrm{T}-\mathrm{G}-\mathrm{V}-\mathrm{H}-\mathrm{K}-\mathrm{K}-\mathrm{P}-\mathrm{S}-\mathrm{L}-\mathrm{L}-\mathrm{A}-\mathrm{L}-\mathrm{P}-\mathrm{G}-\mathrm{P}$ & $\mathrm{P}-\mathrm{L}-\mathrm{A}-\mathrm{I}-\mathrm{M}-\mathrm{V}-\mathrm{T}-\mathrm{G}-\mathrm{V}-\mathrm{H}-\mathrm{R}-\mathrm{K}-\mathrm{P}-\mathrm{S}-\mathrm{L}-\mathrm{L}-\mathrm{A}-\mathrm{L}$ & $\mathrm{P}-\mathrm{L}-\mathrm{A}-\mathrm{I}-\mathrm{R}-\mathrm{V}-\mathrm{T}-\mathrm{G}-\mathrm{V}-\mathrm{H}-\mathrm{R}-\mathrm{K}-\mathrm{P}-\mathrm{S}-\mathrm{L}-\mathrm{L}-\mathrm{A}-\mathrm{I}$ \\
\hline A33 & $\mathrm{T}-\mathrm{G}-\mathrm{V}-\mathrm{H}-\mathrm{K}-\mathrm{K}-\mathrm{P}-\mathrm{S}-\mathrm{L}-\mathrm{L}-\mathrm{A}-\mathrm{L}-\mathrm{P}-\mathrm{G}-\mathrm{P}-\mathrm{L}-\mathrm{V}-\mathrm{K}$ & $\mathrm{I}-\mathrm{M}-\mathrm{V}-\mathrm{T}-\mathrm{G}-\mathrm{V}-\mathrm{H}-\mathrm{R}-\mathrm{K}-\mathrm{P}-\mathrm{S}-\mathrm{L}-\mathrm{L}-\mathrm{A}-\mathrm{L}-\mathrm{P}-\mathrm{G}-\mathrm{P}$ & $\mathrm{I}-\mathrm{R}-\mathrm{V}-\mathrm{T}-\mathrm{G}-\mathrm{V}-\mathrm{H}-\mathrm{R}-\mathrm{K}-\mathrm{P}-\mathrm{S}-\mathrm{L}-\mathrm{L}-\mathrm{A}-\mathrm{L}-\mathrm{P}-\mathrm{G}-\mathrm{P}$ \\
\hline
\end{tabular}


T-G-V-H-R-K-P-S-L-L-A-L-P-G-P-L-V-K - R-K-P-S-L-L-A-L-P-G-P-L-V-K-S-G-E P-S-L-L-A-L-P-G-P-L-V-K-S-G-E-T-VL-A-L-P-G-P-L-V-K-S-G-E-T-V-T-L-Q-C T-V-T-S-V-K-S-G-E-T-V-T-L-Q-C-S-S-D $S-G-E-T-V-T-I-Q-C-S-S-D-M-V-F-E-H-E$ T-V-T-I- $-\mathrm{C}-\mathrm{S}-\mathrm{S}-\mathrm{C}-\mathrm{S}-\mathrm{V}-\mathrm{D}-\mathrm{T}-\mathrm{V}-\mathrm{H}-\mathrm{E}-\mathrm{E}-\mathrm{I}-\mathrm{H}$

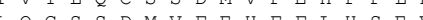

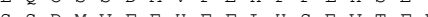
S-V $-\mathrm{D}-\mathrm{E}-\mathrm{H}-\mathrm{F}-\mathrm{F}-\mathrm{I}-\mathrm{H}-\mathrm{S}-\mathrm{E}-\mathrm{V}-\mathrm{T}-\mathrm{E}-\mathrm{E}-\mathrm{E}-\mathrm{I}-\mathrm{I}$ 1)

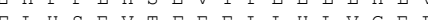
T) TI-P-D-E-L-L-H-L-V-G-E-L-H-G-G-G-S-Q $\mathrm{E}-\mathrm{L}-\mathrm{L}-\mathrm{H}-\mathrm{L}-\mathrm{V}-\mathrm{G}-\mathrm{E}-\mathrm{L}-\mathrm{H}-\mathrm{G}-\mathrm{G}-\mathrm{G}-\mathrm{S}-\mathrm{Q}-\mathrm{A}-\mathrm{N}-\mathrm{Y}$ G- $-V-G-D-I-H-G-G-G-S-Q-A-N-Y-S-I-N$ G-E-T-H-G-G-G-S-Q-A-N-Y-S-I-N-S-MH-G-G-G-S-Q-A-N-Y-S-I-N-S-M-T-S-D-I G-S-Q-A-N-Y-S-I-N-S-M-T-S-D-T-A-GA-N-Y-S-I-N-S-M-T-S-D-L-A-G-T-Y-R-C S-I-N-S-M-T-S-D-L-A-G-T-Y-R-C-Y-G-S S-M-T-S-D-L-A-G-T-Y-R-C-Y-G-S-V-T-H S-D-L-A-G-T-Y-R-C-Y-G-S-V-T-H-S-P-D A-G-T-Y-R-C-Y-G-S-V-T-H-S-P-D-V-L-S Y-R-C-Y-G-S-V-T-H-S-P-D-V-L-S-A-P-S $Y-G-S-V-T-H-S-P-D-V-L-S-A-P-S-D-T-I$ $\mathrm{V}-\mathrm{T}-\mathrm{H}-\mathrm{S}-\mathrm{P}-\mathrm{D}-\mathrm{V}-\mathrm{L}-\mathrm{S}-\mathrm{A}-\mathrm{P}-\mathrm{S}-\mathrm{D}-\mathrm{T}-\mathrm{L}-\mathrm{D}-\mathrm{I}-\mathrm{V}$ $S-P-D-V-L-S-A-P-S-D-T-L-D-I-V-I-T-G$ $V-L-S-A-P-S-D-T-L-D-I-V-I-T-G-L-Y-E$ A-P-S-D-T-I-D-I-V-I-T-G-I-Y-E-K-P-S D-T-L-D-I-V-I-T-G-I-Y-E-K-P-S-I-SD-I-V-I-T-G-L-Y-E-K-P-S-L-S-A-O-P-C I-T-G-I-Y-E-K-P-S-L-S-A-Q-P-G-P-T-V L-Y-E-K-P-S-L-S-A-Q-P-G-P-T-V-Q-A-G $\mathrm{X}-\mathrm{P}-\mathrm{S}-\mathrm{I}-\mathrm{S}-\mathrm{A}-\mathrm{O}-\mathrm{P}-\mathrm{C}-\mathrm{P}-\mathrm{T}-\mathrm{V}-\mathrm{O}-\mathrm{A}-\mathrm{C}-\mathrm{C}-\mathrm{N}-\mathrm{V}$

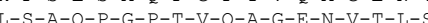
Q $-\mathrm{P}-\mathrm{C}-\mathrm{P}-\mathrm{T}-\mathrm{V}-\mathrm{Q}-\mathrm{A}-\mathrm{C}-\mathrm{E}-\mathrm{N}-\mathrm{T}-\mathrm{T}-\mathrm{T}-\mathrm{S}-\mathrm{C}-\mathrm{S}-\mathrm{S}$ Q $-T-V-Q-T-C-\mathrm{Q}-\mathrm{N}-\mathrm{C}-\mathrm{T}-\mathrm{I}-\mathrm{S}-\mathrm{C}-\mathrm{S}-\mathrm{S}-\mathrm{C}-\mathrm{N}-\mathrm{S}$ Q $-A-C-E-N-V-T-I-S-C-S-S-Q-O-S-E-D-M$ Q $-1-C-T-N-V-T-I-S-C-S-S-Q-N-S-P-D-M$ T) T- $-2-S-C-S-S-Q-N-S-P-D-M-Y-H-L-S-R-E$ Q $-2-S-Q-T-S-T-D-M-Y-H-D-S-R-E-G-E-A$ Q $-N-S-F-D-M-Y-H-I-S-R-E-G-E-A-R-G-I$ P-D-M-Y-H-I-S-R-E-G-E-A-R-G-L-S-L-S Y $S-R-E-G-E-A-R-G-L-S-L-S-A-V-Q-S-V-N$

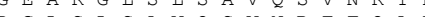
R-G-L-S-L-S-A-V-Q-S-V-N-R-T-F-Q-A-D $S-\mathrm{L}-\mathrm{S}-\mathrm{A}-\mathrm{V}-\mathrm{Q}-\mathrm{S}-\mathrm{V}-\mathrm{N}-\mathrm{R}-\mathrm{T}-\mathrm{F}-\mathrm{Q}-\mathrm{A}-\mathrm{D}-\mathrm{F}-\mathrm{P}-\mathrm{I}$ $A-V-Q-S-V-N-R-T-F-Q-A-D-F-P-L-G-P-A$ S-V-N-R-T-F-Q-A-D-F-P-L-G-P-A-T-HR-T-F-Q-A-D-F-P-L-G-P-A-T-H-G-G-T-Y Q-A-D-F-P-L-G-P-A-T-H-G-G-T-Y-R-CF-P-L-G-P-A-T-H-G-G-T-Y-R-C-F-G-S-E G-P-A-T-H-G-G-T-Y-R-C-F-G-S-F-R-TT-H-G-G-T-Y-R-C-F-G-S-F-R-T-A-P-YG-T-Y-R-C-F-G-S-F-R-T-A-P-Y-Q-W-S-D R-C-F-G-S-F-R-T-A-P-Y-O-W-S-D-P-S-D G-S-F-R-T-A-P-Y-O-W-S-D-P-S-D-P-L-S $R-T-A-P-Y-Q-W-S-D-P-S-D-P-T-S-V-S-V$
T-G-V-H-R-K-P-S-I-I-A-L-P-G-P-I-V-K H-R-K-P-S-L-L-A-L-P-G-P-L-V-K-S-G-E P-S-L-L-A-L-P-G-P-L-V-K-S-G-E-T-V-T $\mathrm{L}-\mathrm{A}-\mathrm{L}-\mathrm{P}-\mathrm{G}-\mathrm{P}-\mathrm{L}-\mathrm{V}-\mathrm{K}-\mathrm{S}-\mathrm{G}-\mathrm{E}-\mathrm{T}-\mathrm{V}-\mathrm{T}-\mathrm{L}-\mathrm{Q}-\mathrm{C}$ P-V $-K-S-G-E-T-V-T-I-Q-C-S-S-D-T-V-F$ S-G-E-T-V-T-I-Q-C-S-S-D-T-V-F-E-H$T-V-T-I-Q-C-S-S-D-T-V-F-E-H-F-F-I-Q$ I- $-T-C-Q-C-S-S-D-T-V-P-E-H-F-F-I-Q$ $S-S-D-T-V-F-E-H-F-F-T-Q-S-E-V-T-F-K$ T- $-\mathrm{D}-\mathrm{T}-\mathrm{V}-\mathrm{E}-\mathrm{E}-\mathrm{H}-\mathrm{E}-\mathrm{E}-\mathrm{I}-\mathrm{Q}-S-\mathrm{E}-\mathrm{V}-\mathrm{T}-\mathrm{E}-\mathrm{K}$

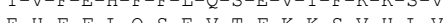

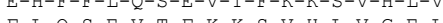
C $-\mathrm{Q}-\mathrm{S}-\mathrm{C}-\mathrm{V}-\mathrm{T}-\mathrm{C}-\mathrm{K}-\mathrm{K}-\mathrm{S}-\mathrm{V}-\mathrm{H}-\mathrm{L}-\mathrm{V}-\mathrm{G}-\mathrm{E}-\mathrm{I}$ $S-V-T-E-K-K-S-V-H-L-V-G-E-I-H-G-G$ T-F-K-K-S-V-H-L-V-G-E- $-\mathrm{H}-\mathrm{G}-\mathrm{G}-\mathrm{G}-\mathrm{S}-\mathrm{Q}$ K-S-V-H-L-V-G-E-L-H-G-G-G-S-Q-A-N-Y H-I-V-G-E-L-H-G-G-G-S-Q-A-N-Y-S-M-G G-E-L-H-G-G-G-S-Q-A-N-Y-S-M-G-P-T-T H-G-G-G-S-Q-A-N-Y-S-M-G-P-T-T-S-A-I G-S-Q-A-N-Y-S-M-G-P-T-I-S-A-L-A-G-T A-N-Y-S-M-G-P-T-T-S-A-L-A-G-T-Y-R-C S-M-G-P-T-T-S-A-L-A-G-T-Y-R-C-Y-G-S P-T-T-S-A-L-A-G-T-Y-R-C-Y-G-S-V-T-H S-A-L-A-G-T-Y-R-C-Y-G-S-V-T-H-S-P-Y A-G-T-Y-R-C-Y-G-S-V-T-H-S-P-Y-V-L-S Y-R-C-Y-G-S-V-T-H-S-P-Y-V-L-S-A-P-S Y-G-S-V-T-H-S-P-Y-V-L-S-A-P-S-D-P-I $\mathrm{V}-\mathrm{T}-\mathrm{H}-\mathrm{S}-\mathrm{P}-\mathrm{Y}-\mathrm{V}-\mathrm{L}-\mathrm{S}-\mathrm{A}-\mathrm{P}-\mathrm{S}-\mathrm{D}-\mathrm{P}-\mathrm{L}-\mathrm{D}-\mathrm{I}-\mathrm{V}$ $S-P-Y-V-L-S-A-P-S-D-P-L-D-I-V-I-T-G$ V-L-S-A-P-S-D-P-L-D-I-V-I-T-G-I-Y-K A-P-S-D-P-L-D-I-V-I-T-G-I-Y-K-K-P-S D-P-L-D-I-V-I-T-G-I-Y-K-K-P-S-I-S-A D-I-V-I-T-G-I-Y-K-K-P-S-I-S-A-O-P-G I-T-G-I-Y-K-K-P-S-L-S-A-Q-P-G-P-T-V I-Y-K-K-P-S-L-S-A-Q-P-G-P-T-V-O-A-G K-P-S-I-S-A-Q-P-G-P-T-V-Q-A-G-E-N-V L-S-A-Q-P-G-P-T-V-O-A-G-E-N-V-T-I-S O-P-G-P-T-V-O-A-G- $-\mathrm{N}-\mathrm{V}-\mathrm{T}-\mathrm{T}-\mathrm{S}-\mathrm{C}-\mathrm{S}-\mathrm{S}$

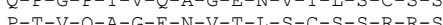

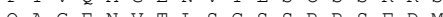

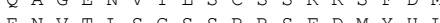
C-N T-I $-S-C-S-R-R-S-E-D-M-Y-H-I-S-R-E$ C-S-S-R-R $S-T-D-M-Y-H-I-S-R-E-G-E-T$ R-R $-S-F-D-M-Y-H-I-S-R-E-G-E-T-H-E-I$ T-D-M-Y $-\mathrm{T}-\mathrm{I}-\mathrm{S}-\mathrm{R}-\mathrm{E}-\mathrm{G}-\mathrm{E}-\mathrm{T}-\mathrm{H}-\mathrm{E}-\mathrm{I}-\mathrm{R}-\mathrm{L}-\mathrm{P}$ Y S-R-E-G-E-T-H-E-L-R-L-P-A-V-P-S-V-N

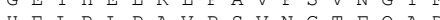
$\mathrm{H}-\mathrm{E}-\mathrm{L}-\mathrm{R}-\mathrm{L}-\mathrm{P}-\mathrm{A}-\mathrm{V}-\mathrm{P}-\mathrm{S}-\mathrm{V}-\mathrm{N}-\mathrm{G}-\mathrm{T}-\mathrm{F}-\mathrm{Q}-\mathrm{A}-\mathrm{D}$ R-L-P-A-V-P-S-V-N-G-T-F-Q-A-D-F-P-I $\mathrm{A}-\mathrm{V}-\mathrm{P}-\mathrm{S}-\mathrm{V}-\mathrm{N}-\mathrm{G}-\mathrm{T}-\mathrm{F}-\mathrm{Q}-\mathrm{A}-\mathrm{D}-\mathrm{P}-\mathrm{P}-\mathrm{L}-\mathrm{G}-\mathrm{P}-\mathrm{V}$ S-V-N-G-T-F-Q-A-D-F-P-L-G-P-V-T-H-G G-T-F-Q-A-D-F-P-L-G-P-V-T-H-G-G-T-Y Q-A-D-F-P-L-G-P-V-T-H-G-G-T-Y-R-C-F F-P-L-G-P-V-T-H-G-G-T-Y-R-C-F-A-S-F G-P-V-T-H-G-G-T-Y-R-C-F-A-S-F-R-T-A T-H-G-G-T-Y-R-C-F-A-S-F-R-T-A-P-Y-E G-T-Y-R-C-F-A-S-F-R-T-A-P-Y-E-W-S-V R-C-F-A-S-F-R-T-A-P-Y-E-W-S-V-P-S-D A-S-F-R-T-A-P-Y-E-W-S-V-P-S-D-P-L-H R-T-A-P-Y-E-W-S-V-P-S-D-P-L-H-V-S-I P-Y-E-W-S-V-P-S-D-P-L-H-V-S-I-T-G-N

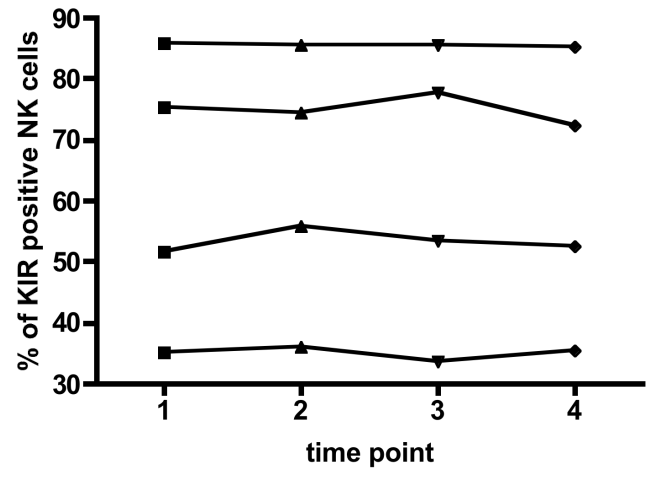

Figure 36. Constant KIR expression over time.

Shown is the percentage of KIR positive NK cells for four representative rhesus macaques and four different time points during one year of sampling. The KIR expression is quite constant in healthy animals. 
Table 7. Anti-human KIR antibodies (adapted from Gardiner, 2007).

\begin{tabular}{ll}
\hline Antibody & KIR \\
\hline EB6 & KIR2DL1/KIR3DS1 \\
GL183 & KIR2DL2/KIR2DL3/KIR2DS2 \\
DX27 & KIR2DL2/KIR2DL3/KIR2DS2 \\
DX9 & KIR3DL1 \\
Z27 & KIR3DL1/KIR3DS1 \\
5.133 & KIR3DL1/KIR3DL2/KIR2DS4 \\
HP-MA4 & KIR2DL1 \\
DX31 & KIR3DL2 \\
mAb 33 & KIR2DL4 \\
UP-R1 & KIR2DL5 \\
CH21 & KIR3DL3
\end{tabular}




\section{Acknowledgement}

First of all I would like to thank Professor Dr. Lutz Walter for supervising my doctoral thesis, for his support, for scientific discussions and for the possibility to attend several international conferences.

I also want to thank Professor Dr. Torben Lübke and Professor Dr. Holger Reichardt for being part of my thesis committee and supporting me during my research at the DPZ. In addition, I would like to thank Professor Dr. Torben Lübke for being the co-reviewer of my thesis.

Special thanks are addressed to Professor Dr. Aftab Ansari. The SIV experiments were only possible due to his generous support and invitation to Atlanta. Thanks for providing the samples of SIV infected rhesus macaques and all consumables! Furthermore, I would like to thank Professor Dr. Francois Villinger who provided the equipment to perform the SIV experiments at Yerkes National Primate Research Center, Atlanta.

Thanks also to Professor Dr. Ralf Dressel and Leslie Elsner for immunising the mice and for helpful tips, concerning the generation of monoclonal antibodies.

I would like to thank PD Dr. Joachim Koch, Dr. Ariane Groth and Sandra Weil for providing me the data of the epitope mapping.

Thanks to Dr. Annette Schrod and Dr. Tamara Becker for providing the blood samples.

A special thanks is addressed to Christina Albrecht for performing the amplicon sequencing. I would like to thank her for all her help, for the scientific and non-scientific discussions, for the support during the doctoral time and all the conference trips we did together.

Thanks to Astrid Backhaus for her help, funny time in the tissue culture and the provided sweets at any time.

I would like to thank all former and current members of the Primate Genetics lab for their general support and a great working atmosphere.

I would like to thank Katrin Wiese und Malte Drobe for their support, reading the manuscript and help with the figures.

Special thanks are addressed to my friends and to my family, in particular to my parents, for help and support. 


\section{Curriculum Vitae}

Name: Meike Hermes

Date and place of birth: 04.07.1983; Hannover, Germany

Nationality: German

\section{Education}

04/2009- 07/2012 PhD Thesis Project at the German Primate Center, Department of Primate Genetics,

Thesis supervisor: Prof. Dr. Lutz Walter

Göttingen Graduate School for Neurosciences, Biophysics, and Molecular Biosciences (GGNB), doctoral program "Molecular Biology of cells"

10/2005- 07/2008 Study of Biology, Leibniz University, Hannover Main subjects: Cell Biology, Biochemistry, Immunology Degree:

Diploma in Biology

Diploma Thesis: Functional analyses of molecular interactions of KIRand MHC-class-I-molecules in rhesus macaques. German Primate Center, Department of Primate Genetics

Thesis supervisor: Prof. Dr. Lutz Walter

10/2003-09/2005 Study of Biology, University of Konstanz

Basic studies of Biology, intermediate examination for the diploma

08/1996-06/2003 Abitur, Gymnasium St. Ursula-Schule, Hannover 